Natalia Pirani Ghilardi

\title{
Utilização do Método dos Povoamentos na Caracterização de Comunidades Bentônicas em Trecho do Infralitoral Consolidado da Enseada das Palmas, Ilha Anchieta, Ubatuba (SP)
}

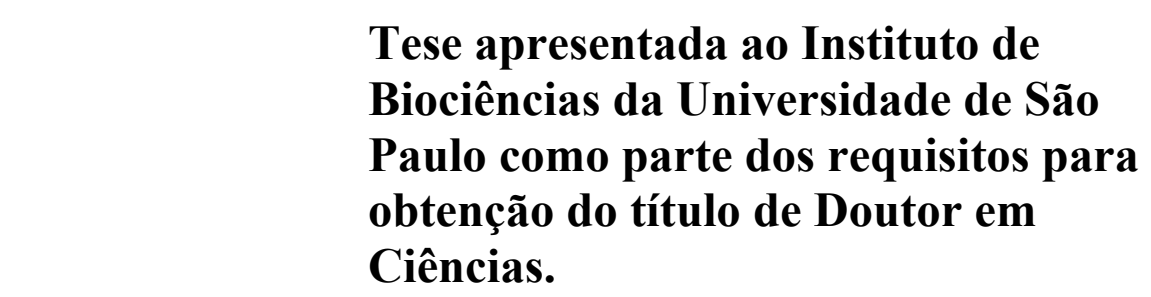

Orientador: Dr. Flávio Augusto de Souza Berchez

São Paulo

2007 

Ficha catalográfica

Ghilardi, Natalia Pirani

Utilização do método dos povoamentos na caracterização de comunidades bentônicas em trecho do infralitoral consolidado da Enseada das Palmas, Ilha Anchieta, Ubatuba (SP). $254 p$.

Tese (Doutorado) - Instituto de Biociências da Universidade de São Paulo. Departamento de Botânica.

1. Povoamentos 2. Ecologia de comunidades 3. Infralitoral 4. "Levantamento Fisionômico" 5. Costão Rochoso

I. Universidade de São Paulo. Instituto de Biociências. Departamento de Botânica. 



\section{Comissão Julgadora:}

Prof(a). Dr(a).

$\operatorname{Prof}(\mathrm{a}) . \operatorname{Dr}(\mathrm{a})$.

$\operatorname{Prof}(a) \cdot \operatorname{Dr}(a)$.

Prof(a). Dr(a).

Prof. Dr. Flávio Augusto de Souza Berchez

Orientador 

A todos aqueles que, assim como eu, são apaixonados pelo mar 



\section{Mar Absoluto}

"Foi desde sempre o mar,

E multidões passadas me empurravam

como o barco esquecido.

Ao mar! - Disciplina humana para a empresa da vida!"

Meu sangue entende-se com essas vozes poderosas.

A solidez da terra, monótona,

parece-mos fraca ilusão.

Queremos a ilusão grande do mar,

multiplicada em suas malhas de perigo.

Queremos a sua solidão robusta,

uma solidão para todos os lados,

uma ausência humana que se opõe ao mesquinho

formigar do mundo,

e faz o tempo inteiriço, livre das lutas de cada dia.

O alento heróico do mar tem seu pólo secreto, que os homens sentem, seduzidos e medrosos.

O mar é só mar, desprovido de apegos,

matando-se e recuperando-se,

correndo como um touro azul por sua própria sombra,

e arremetendo com bravura contra ninguém,

e sendo depois a pura sombra de si mesmo,

por si mesmo vencido. É o seu grande exercício.

Não precisa do destino fixo da terra,

ele que, ao mesmo tempo,

é o dançarino e a sua dança.

Tem um reino de metamorfose, para experiência: seu corpo é o seu próprio jogo,

e sua eternidade lúdica

não apenas gratuita: mas perfeita.

Baralha seus altos contrastes:

cavalo, épico, anêmona suave,

entrega-se todos, despreza ritmo jardins, estrelas, caudas, antenas, olhos, mas é desfolhado,

cego, nu, dono apenas de si,

da sua terminante grandeza despojada.

Não se esquece que é água, ao desdobrar suas visões: água de todas as possibilidades, mas sem fraqueza nenhuma.

E assim como água fala-me.

Atira-me búzios, como lembranças de sua voz, e estrelas eriçadas, como convite ao meu destino.

Não me chama para que siga por cima dele, nem por dentro de si:

mas para que me converta nele mesmo. É o seu máximo dom.

$\cdots$

Aceita-me apenas convertida em sua natureza: plástica, fluida, disponível,

igual a ele, em constante solilóquio, sem exigências de princípio e fim, desprendida de terra e céu.

E recordo minha herança de cordas e âncoras, e encontro tudo sobre-humano.

E este mar visível levanta para mim uma face espantosa.

E retrai-se, ao dizer-me o que preciso.

E é logo uma pequena concha fervilhante,

nódoa líquida e instável,

célula azul sumindo-se

no reino de um outro mar:

ah! do Mar Absoluto. 



\section{Agradecimentos}

Primeiramente agradeço a meus pais, João e Marcia, pelo amor, carinho, ajuda, preocupação, proteção e pelo sacrifício para que eu completasse meus estudos, que sempre foram prioridade. A eles devo tudo que eu sou e serei.

Agradeço ao Peterson, meu marido, pelo amor verdadeiro e eterno, amizade, companheirismo, ajuda em todos os momentos e compreensão nas minhas ausências.

Aos meus irmãos, Renato, Marcelo e Augusto pelas brincadeiras, carinho e amizade durante todos os anos de minha vida. À minha cunhada Renata, que considero uma irmã.

Aos meus sogros, Vera e Antônio, de quem gosto muito e considero como segundos pais.

Ao Flávio Berchez, meu orientador e amigo, a quem devo muito por todos estes 7 anos nos quais eu aprendi e cresci muito. Agradeço por todos os momentos sérios e de descontração também, que fizeram com que eu me sentisse realmente feliz por ter feito a escolha de trabalhar com biologia marinha.

A Sílvia Massironi e Ricardo Mazzaro por sua simpatia e por me emprestarem suas máquinas digitais para meu trabalho de campo, mesmo sabendo dos riscos que corriam.

A Dra. Maria de Jesus Robim e ao Dr. Manoel de Azevedo Fontes, por possibilitarem meu trabalho no Parque Estadual da Ilha Anchieta, oferecendo todo apoio e infra-estrutura.

A Neuzi da Omni Mare, Muñoz da Seachegue e Lalo da Scubapoint, por compreenderem minhas dificuldades em devolver os cilindros de mergulho no tempo previsto (por estar trabalhando na Ilha) e me ajudar facilitando o seu aluguel.

Ao Valentim e ao Vicente, pelo apoio técnico durante meu trabalho e pela amizade desde quando comecei a trabalhar em Ubatuba.

A Dra. Mutuê, pela paciência quando eu ia ao Instituto de Botânica resolver minhas dúvidas e pela identificação das algas mais "complicadas". Ao Dr. Sérgio Rosso, pelos ensinamentos, fornecimento de software e pela paciência. A Dra. Valéria Hadel, por me indicar pessoas para a identificação dos invertebrados.

A Dra. Helena Boscolo, pela identificação das espécies de Carijoa e Palythoa. Ao Dr. Márcio Reis Custódio, pela identificação das espécies de esponja. Ao Gustavo Dias, pela identificação das espécies de ascídia. À Dra. Michelle Klautau, pela identificação das esponjas calcárias. Ao Dr. João Nogueira, pela identificação dos poliquetas.

Ao Dr. Wellington Delitti por permitir a utilização da mufla do Dep. de Ecologia.

Aos meus eternos amigos Aline, San, Bel, Cris, Carol, Wenddi, Clau, Yuki, Sandra Sayuri, Ju, Mel, Mari e Vera por terem feito estes anos mais divertidos e suportáveis nos momentos de dificuldade.

Aos meus companheiros de trabalho Elda, Suzana, Ricardo, Marly, Guilherme F., Mariane, Ana Paula, Guilherme P., Ig, Andréa e Henrique pela ajuda e contribuição.

Aos meus colegas de laboratório Cíntia Coimbra, que me iniciou no mundo das algas e me ensinou muito, Lú, Bia, Vivi, Cíntia Erbert, Rose, Nelso, Dani(s), Lagosta, Cristalina, Alexis, José, Suzana, Amanda, Mônica, Lígia, Ana e Rosário e tantos outros que por lá passaram nesses anos. Um agradecimento especial à Leila, que sofreu estes últimos meses comigo, mas sempre me deu muita força e tornou esta fase muito divertida para mim.

Ao Carlos, Norberto e Cezário, da secretaria da Botânica, e a Socorro e Dalva, da Ecologia, que sempre estavam dispostos a ajudar e resolver alguns probleminhas também.

Aos professores do LAM Dra. Estela M. Plastino, Dra. Mariana C. de Oliveira. Dra. Fungyi Chow Ho, Dr. Eurico Cabral de Oliveira e Dr. Edson José de Paula que contribuíram muito para a minha formação como ficóloga.

Aos estagiários do PEIA que cuidaram da nossa estadia na Ilha e em especial ao Seu Ademir, Walmir, Mário e Carlinhos, barqueiros da Ilha, que tantas vezes me levaram para a Ilha e para o continente sem reclamar do monte de bagagem que lotava os barcos.

À FAPESP (processo 02/ 07412-8) à CAPES e ao CNPq (processo 140787/2004-6) pelo apoio financeiro sem o qual este trabalho não teria sido realizado. 



\section{ÍNDICE}

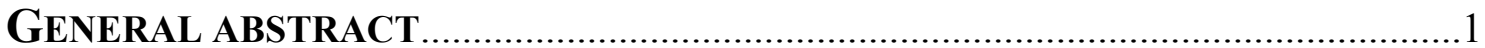

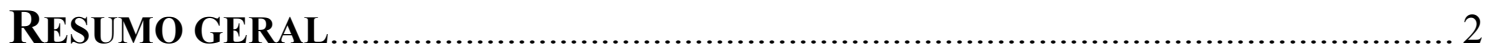

CAPÍTUlo 1 - Caracterização de comunidades marinhas bentônicas de substrato consolidado: abordagem dos povoamentos como alternativa às metodologias tradicionais

ABSTRACT

CAPÍTUlo 2 - Descrição e levantamento da repartição espacial de povoamentos em trecho de infralitoral consolidado da Enseada das Palmas (Parque Estadual de Ilha Anchieta, Ubatuba, SP)

ABSTRACT

CAPítulo 3 - Repartição espacial dos povoamentos em trecho do infralitoral consolidado da Enseada das Palmas (Parque Estadual de Ilha Anchieta, Ubatuba, SP) - análise quantitativa por recobrimento percentual

ABSTRACT.12

CAPÍTUlO 4 - Estrutura e variação espacial dos povoamentos Banco de Sargassum, Tapete de Amphiroa e Jania, Tapete de Ectoprocta e Tapete de Gelidiopsis e Hypnea em trecho do infralitoral consolidado da Enseada das Palmas (Parque Estadual de Ilha Anchieta, Ubatuba, SP)

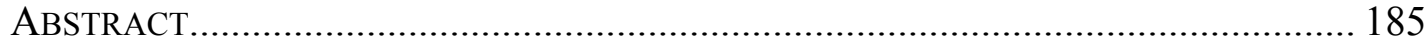

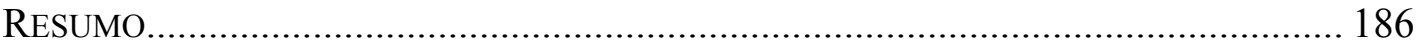

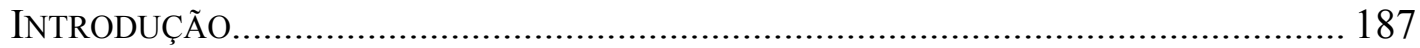

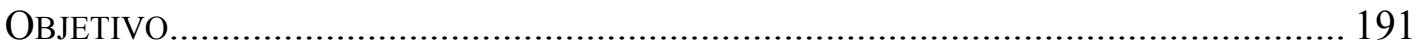

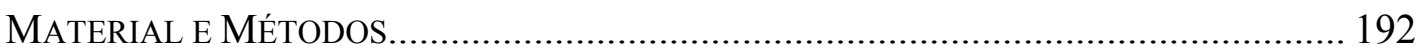

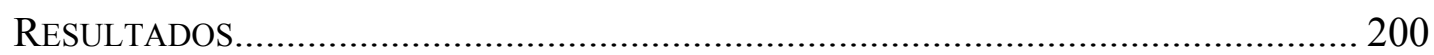

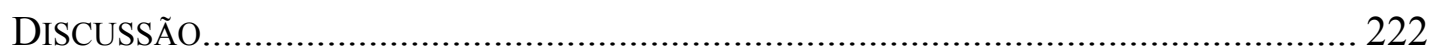

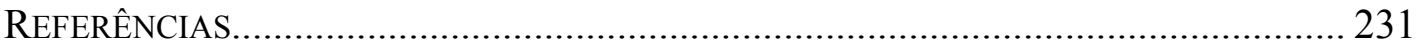

CAPÍtulo 5 - Considerações finais

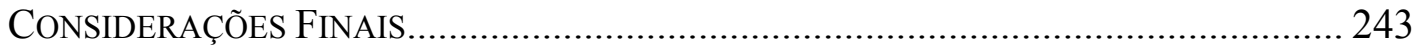

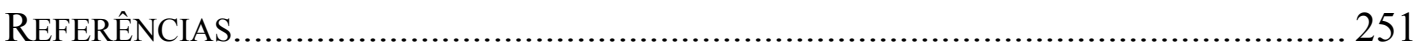





\section{GENERAL ABSTRACT}

The biodiversity characterization of benthic communities in the Brazilian coast is limited to a few works, which studied an area of about $3,400 \mathrm{~m}^{2}$. The objective of this study was to propose a new method, unprecedented in hard bottom marine communities, based in the sampling of landscape heterogeneity units, named physiognomies and settlements, aiming at an increase in sampling speed and covering in this environment. This study was performed in a $260 \mathrm{~m}$ infralittoral stretch of Presidio Beach eastern coast (Palmas Bay, Anchieta Island State Park, Ubatuba, SP) and was divided in four approaches: 1) identification e description of settlements and their dominant species; 2) georeferenced spatial repartition mapping of each settlement and determination of maximum vertical amplitude; 3 ) mean percent cover quantification from digital images; 4) evaluation of specific composition and spatial variation of selected settlements. Thirty settlements, included in 'Bed', 'Colony', 'Crust' and 'Turf' categories, besides a non-biological attribute included in 'Region' category, were identified and described and the information will be available in a database in the internet. Mapping was performed in only 6 dives of 50 to 80 minutes in each season. The major part of the settlements occurred punctually. Settlements number and horizontal repartition practically did not change between summer and winter. Sargassum Bed (SGB) was more frequent in the summer (25.3\%) and Amphiroa and Jania Turf (AJT) in the winter $(21.3 \%)$. In relation to vertical repartition, four main zones were delimited based in relative frequencies: a shallower one defined by SGB, another upper intermediary defined by AJT, another lower intermediary defined by Ectoprocta Turf (ECT) and a last one, deeper, defined by variable settlements according to season. Eighty four sampling units were obtained in summer and 100 in winter, from which 26 and 28 settlements could be recognized, respectively. Cluster analysis in $\mathrm{R}$ and $\mathrm{Q}$ modes and heterogeneity evaluation of the obtained groups were made. SGB showed the highest mean percent cover as much in summer $(26.1 \%)$ as in winter $(32.0 \%)$, followed by ECT (19.7\% in summer and $24.2 \%$ in winter), significantly higher than most of the other settlements $(\mathrm{p}<0.05)$. Phytobenthic settlements were the most representative in the area $(62.2 \%$ of mean cover in summer and $61.8 \%$ in winter). When settlements categories were considered, phytobenthic beds were the most representative $(31.2 \%$ in summer and $37.0 \%$ in winter). With animals and algae altogether, the category 'turf' was the most represented $(46.3 \%$ in summer and $41.4 \%$ in winter), with great contribution of AJT and ECT, indicating a possible sedimentation influence in the area. The cluster analysis in R Mode showed the existence of six groups in summer and five in winter, suggesting settlements with the same ecological exigencies. In Q Mode a highly heterogeneous community could be evidenced, showing a patchy pattern. The settlements SGB, Unconsolidated Substrate Region, AJT, ECT (and some of its variations) and Gelidiopsis and Hypnea Turf (GHT) were the responsible for group formation with the use of Morisita-Horn Similarity Index. Specific composition analysis of SGB, AJT, ECT and GHT showed that these settlements can be considered homogeneous or present themselves as facies in the study area and can be consistently used as operational units. However, studies in other areas are necessary in order to give support to the obtained data, mainly regarding ECT and GHT, which lack ecological studies. Spectral analysis made evident sampling sufficiency for all settlements in relation to Calleja points adopted. Richness spectra were diagonal and diversity spectra were rectangular. For the four settlements, Shannon's Diversity Index was between 1.6 and 2.2 and Simpson's Dominance Index, between 2.6 and 5.7. GHT was the richest and most diverse settlement. The community studied in the present work can be considered typical of Brazilian south eastern region. Settlements method, through approaches 2 and 3, facilitated community structural characterization in a fast way. Micro-heterogeneity evaluation of four settlements showed that they can be used as consistent ecological units. 


\section{RESUMO GERAL}

A caracterização da biodiversidade de comunidades bentônicas resume-se, no litoral brasileiro, a pouco mais de uma dezena de trabalhos estudando, na totalidade, uma área aproximada de apenas $3400 \mathrm{~m}^{2}$. Pretendeu-se aqui propor um novo método, inédito para comunidades marinhas de substrato consolidado, baseado na amostragem de unidades de heterogeneidade da paisagem, denominados povoamentos, visando um aumento na velocidade e abrangência das amostragens neste ambiente. Este estudo foi realizado em um trecho de $260 \mathrm{~m}$ do costão leste da Praia do Presídio (Enseada das Palmas, P. Est. de Ilha Anchieta, Ubatuba, SP) e divididiu-se em quatro abordagens: 1) identificação e descrição dos povoamentos presentes e espécies neles dominantes; 2) mapeamento da repartição horizontal geo-referenciada de cada povoamento e determinação de sua amplitude vertical máxima; 3 ) quantificação de seus recobrimentos percentuais médios a partir de imagens; 4) avaliação da composição específica e da variação espacial de povoamentos selecionados. Trinta povoamentos, incluídos nas categorias 'Banco', 'Colônia', 'Crosta' e 'Tapete', além de um atributo não-biológico incluído na categoria 'Região', foram identificados e descritos e as informações serão disponibilizadas em um banco de dados na internet. $\mathrm{O}$ mapeamento foi realizado em apenas 6 mergulhos, em cada estação, de 50 a 80 minutos. A maior parte dos povoamentos ocorreu pontualmente. $\mathrm{O}$ número de povoamentos e a repartição horizontal dos mesmos praticamente não se alteraram entre verão e inverno. A análise da freqüência relativa dos povoamentos evidenciou que Banco de Sargassum (BSG) apresentou maior valor no verão (25,3\%) e Tapete de Amphiroa e Jania (TAJ), no inverno $(21,3 \%)$. Quanto à distribuição vertical, foram delimitadas quatro principais zonas baseadas na freqüência relativa: uma mais rasa definida por BSG, outra intermediária superior definida por TAJ, outra intermediária inferior definida por Tapete de Ectoprocta (TEC) e uma mais funda definida por povoamentos variáveis com a estação. Foram obtidos 84 elementos amostrais fotográficos no verão e 100 no inverno, os quais evidenciaram 26 e 28 povoamentos, respectivamente. Foram realizadas análises de repartição espacial nos modos $\mathrm{R}$ e Q e avaliação de heterogeneidade dos agrupamentos formados. BSG apresentou maior valor de recobrimento percentual médio tanto no período de verão $(26,1 \%)$ quanto de inverno (32,0\%), seguido de TEC (19,7\% no verão e $24,2 \%$ no inverno), significativamente maior que a maioria dos demais povoamentos $(p<0,05)$. Os povoamentos fitobentônicos foram mais representativos na área $(62,2 \%$ de recobrimento médio no verão e $61,8 \%$ no inverno). Quando consideradas as categorias de povoamentos, os bancos fitobentônicos foram mais representativos ( $31,2 \%$ no verão e $37,0 \%$ no inverno). Se somados animais e algas, a categoria 'tapete' foi a mais representada ( $46,3 \%$ no verão e $41,4 \%$ no inverno), com grande contribuição dos povoamentos TAJ e TEC, indicando uma possível influência da sedimentação na área. A análise de repartição espacial em Modo R evidenciou a existência de seis grupos no verão e cinco no inverno, sugerindo povoamentos com as mesmas exigências ecológicas. Já em Modo Q observou-se que a comunidade da área é bastante heterogênea, apresentando um padrão em manchas, sendo os povoamentos BSG, Região de Substrato Inconsolidado, TAJ, TEC (e algumas de suas variações) e Tapete de Gelidiopsis e Hypnea (TGH) os responsáveis pela formação dos grupos com o Índice de Similaridade de Morisita-Horn. A análise da composição específica dos povoamentos BSG, TAJ, TEC e TGH evidenciou que os mesmos podem ser considerados homogêneos ou apresentam-se na forma de fácies na área de estudo, podendo ser utilizados como unidades operacionais de forma consistente. Entretanto, estudos em outras áreas são necessários para fornecer suporte aos dados obtidos, principalmente em relação aos dois últimos povoamentos, que carecem de estudos ecológicos. A análise espectral evidenciou suficiência amostral para todos os povoamentos em relação aos pontos Calleja adotados. Os espectros de riqueza foram diagonais e os de diversidade foram retangulares. Para os quatro povoamentos, o Índice de Diversidade de Shannon ficou entre 1,6 e 2,2 e o de Diversidade de Simpson, entre 2,6 e 5,7. O povoamento TGH foi o mais rico e o mais diverso. A comunidade estudada no presente estudo pode ser considerada característica da região sudeste do Brasil. O método dos povoamentos, tanto a partir da Abordagem 2 quanto da 3, possibilitou a caracterização estrutural da comunidade de forma rápida. A análise da micro-heterogeneidade de 4 povoamentos evidenciou que podem ser utilizados como unidades ecológicas consistentes. 
CARACTERIZAÇÃO DE COMUNIDADES MARINHAS BENTÔNICAS DE SUBSTRATO CONSOLIDADO: ABORDAGEM DOS POVOAMENTOS COMO ALTERNATIVA ÀS METODOLOGIAS TRADICIONAIS 



\begin{abstract}
The works on community ecology of the Brazilian coast were initiated in the 40's and were basically descriptive. In the 70's and 80's, transects started to be used and in the 90's more sophisticated sampling methods and data analyses were performed. Few works have been published in all this period resulting in insignificant, in terms of area, characterization of our littoral, of about $3,400 \mathrm{~m}^{2}$. This situation put into evidence the need to use techniques which describe more extensive areas and in a faster way, at least as an fundamental initial approach to the characterization of our consolidate substrate benthic communities. This work proposes a new method for this characterization, named "Physiognomic Assessment", which aims at increasing the sampling domain and minimizing the sampling time, through the use of operational unities not based on species, but on heterogeneity units related to visual patterns resulting of ecological patterns. Two levels of heterogeneity are defined: the macroheterogeneity, which can be defined in terms of physiognomies related to physical structuring or architecture of a community and the micro-heterogeneity, defined in terms of settlements, which constitute the faces of the mosaic, characterized by one or few structuring dominant species. This method was used in a stretch of consolidated infralittoral of Anchieta Island State Park and was divided into four approaches: 1) characterization of the settlements present in the area; 2) georeferenced mapping; 3) quantitative evaluation of their spatial repartition; 4) evaluation of the spatial constancy of some selected settlements.
\end{abstract}




\section{RESUMO}

Os trabalhos de ecologia de comunidades do litoral brasileiro tiveram início na década de 40 e eram essencialmente descritivos. Nas décadas de 70 e 80, passaram a utilizar transectos e na década de 90, métodos mais sofisticados de amostragem e análise dos dados. Poucos trabalhos foram publicados em todo este período, resultando em uma caracterização, em termos de área, insignificante de nosso litoral, ao redor de $3400 \mathrm{~m}^{2}$. Esse panorama mostra a necessidade da utilização de técnicas que descrevam áreas mais extensas e de maneira mais rápida, pelo menos como uma abordagem inicial, fundamental para a caracterização de nossas comunidades bentônicas de substrato consolidado. Este trabalho propõe um novo método para esta caracterização, denominado "Levantamento Fisionômico", que visa a ampliação do domínio amostral e a minimização do tempo de amostragem, através da utilização de unidades operacionais não baseadas em espécies, mas em unidades de heterogeneidade relacionadas a padrões visuais resultantes de padrões ecológicos. Dois níveis de heterogeneidade são definidos: a macro-heterogeneidade, que pode ser definida a partir de fisionomias relacionadas com a estruturação física ou arquitetura das comunidades e a microheterogeneidade, definida por povoamentos, que constituem as faces do mosaico, caracterizados por uma ou poucas espécies estruturadoras dominantes. Este método foi empregado em um trecho de infralitoral consolidado do Parque Estadual da Ilha Anchieta e se dividiu em quatro abordagens: 1) caracterização dos povoamentos presentes na área; 2) mapeamento georeferenciado; 3) avaliação quantitativa da repartição espacial; 4) avaliação da constância espacial de povoamentos selecionados. 
Capitulo 1 - Abordagem dos povoamentos como alternativa às metodologias tradicionais

\section{INTRODUÇÃO*}

O estudo da ecologia de comunidades marinhas bentônicas de substrato consolidado é complexo em função da grande quantidade de fatores que determinam a estrutura e funcionamento das mesmas. Dentre estes, podem ser citados como mais influentes: irradiância, hidrodinamismo, temperatura, salinidade, rugosidade do substrato em que a comunidade está instalada, estação do ano, características reprodutivas das espécies componentes, sucesso no recrutamento, herbivoria, predação e competição (Lewis, 1964; Dethier, 1984; Souza, 1984; Connell, 1985; Janke, 1990; Yoneshigue-Valentin \& Valentin, 1992; Siddon \& Witman, 2003).

Possivelmente em função desta complexidade, a maior parte dos estudos realizados mundialmente no ambiente marinho aborda os campos da taxonomia, fisiologia e cultivo, sendo menos numerosos os de ecologia, em especial os que descrevem a repartição espacial das comunidades.

No Brasil esta tendência também pode ser notada, sendo que um grande número de trabalhos enfocando os organismos bentônicos de substrato consolidado foi realizado após a década de 40, resultando no acúmulo de grande quantidade de informações nestes campos. A ecologia de populações intensificou-se, principalmente na costa sul e sudeste do país, a partir do final dos anos 70 e apresentou grande crescimento nos anos 80 (Villaça, 1990).

Como resultado, os processos de interação biológica neste ambiente ainda são pouco conhecidos, principalmente no infralitoral, e são poucos os estudos de biodiversidade com enfoque na estrutura de comunidades, sendo que se extrapolarmos os dados obtidos nos trabalhos para áreas maiores de acordo com a técnica de amostragem utilizada por cada um, apenas uma área insignificante do litoral brasileiro, ao redor de $3500 \mathrm{~m}^{2}$, foi amostrada neste sentido (Tabela 1.1).

\footnotetext{
* Não serão comentados aqui os trabalhos de ecologia experimental e de ecologia de populações, que não são o tema principal deste estudo.
} 
Somam-se a isso algumas regiões nas quais não foi especificada pelos autores a área efetivamente amostrada, onde a abordagem foi basicamente uma descrição visual (Tabela 1.2). Isso é muito pouco se considerarmos que grandes extensões de nosso litoral são cobertas por substrato rochoso (Oliveira Filho, 1977).

Tabela 1.1 - Trabalhos publicados com enfoque em ecologia descritiva de comunidades realizados no Brasil e áreas $\mathrm{em}^{2}$, amostral e extrapolada (de acordo com o método de amostragem utilizado), abrangidas pelos mesmos (modificado de Ghilardi \& Berchez, 2005). A somatória das áreas indica o quanto do nosso litoral já foi amostrado com este enfoque.

\begin{tabular}{|c|c|c|}
\hline Trabalho & Área (amostral - m²) & Área (extrapolada - m²) \\
\hline Amado-Filho et al. (2003) & 1,00 & 20,00 \\
\hline Castro et al. (1995) & 3,50 & 3,50 \\
\hline Corrêa et al. (1998) & 1,08 & 3,60 \\
\hline Costa Jr. et al. (2002) & 21,90 & 62,50 \\
\hline Eston et al. (1986) & $?$ & 150,00 \\
\hline Figueiredo et al. (2004) & 7,20 & 15,00 \\
\hline Gherardi\& Bosence (2001) & 0,84 & 84,20 \\
\hline Guerrazzi (1987) & 0,40 & 0,40 \\
\hline Johnscher-Fornasaro et al. (1990) & 0,95 & 0,95 \\
\hline Kelmo \& Attrill (2001) & 140,00 & 140,00 \\
\hline Maggs et al. (1979) & 40,00 & 40,00 \\
\hline Marins-Rosa et al. (2005) & 1,96 & 28,00 \\
\hline Muñoz \& Pereira (1998) & 1,00 & 1,00 \\
\hline Muricy (1989) & 1030,00 & 1030,00 \\
\hline Oigman-Pszczol et al. (2004) & 600,00 & 1750,00 \\
\hline Oliveira Filho \& Paula (1983) & 3,50 & 3,50 \\
\hline Oliveira Filho\& Mayal (1976) & 3,90 & 3,90 \\
\hline Teixeira et al. (1987) & 5,00 & 5,00 \\
\hline SUDENE (1981) & 207 & 207 \\
\hline Villaça \& Pitombo (1997) & 1,60 & $1,60 \mathrm{~m}^{2}$ \\
\hline Total & 2070,83 & 3550,15 \\
\hline
\end{tabular}

Tabela 1.2 - Trabalhos publicados com enfoque em ecologia de comunidades realizados no Brasil nos quais não foi especificada pelos autores a área amostral.

\begin{tabular}{lc}
\hline \multicolumn{1}{c}{ Trabalho } & Região estudada \\
\hline Coelho \& Ramos-Porto (1980) & $\begin{array}{c}\text { Coroa das Lavadeiras (RN) até Foz do São Francisco (AL/SE) } \\
\text { Ponta do Arpoador, Ponta do Piratininga, Ilha Grande, Urca, } \\
\text { Ilha do Governador (RJ) }\end{array}$ \\
$\begin{array}{l}\text { Edwards \& Lubbock (1983) } \\
\text { Joly (1957) }\end{array}$ & $\begin{array}{c}\text { Penedos de São Pedro e São Paulo (PE) } \\
\text { Muricy \& Moraes (1998) }\end{array}$ \\
Nonato \& Pérès (1961) & $\begin{array}{c}\text { Ponta de Itaipu (Santos) até Ponta das Naus (São Vicente) (SP) } \\
\text { Fernando de Noronha (PE) }\end{array}$ \\
Oliveira (1947) & Ponta Norte da Praia Grande e vizinhanças da Base do Instituto \\
Oliveira (1951) & Oceanográfico (SP) \\
Oliveira Filho \& Berchez (1978) e & Baía da Guanabara (RJ) \\
Berchez \& Oliveira Filho (1992) & Ilha da Trindade (RJ) \\
Rawitscher (1944) & Ponta de Itaipu (Santos) até Ponta das Naus (São Vicente) (SP) \\
Silva \& Fernandes (1990) & Litoral sul do Brasil \\
Yoneshigue-Valentin \& Valentin & Lagoa de Araruama (RJ) \\
(1992) & Cabo Frio (RJ) \\
\hline
\end{tabular}


Os trabalhos pioneiros com enfoque em comunidades (Rawitscher, 1944; Oliveira, 1947, 1951; Nonato \& Pérès, 1961; Costa, 1962) tinham um cunho essencialmente naturalista, com a descrição de grandes áreas na região do mediolitoral. Estes trabalhos não apresentavam um rigor metodológico, mas foram fundamentais para fornecer informações iniciais sobre a estrutura das comunidades desta região, como a organização espacial dos organismos mais conspícuos, que não poderiam ser obtidas com trabalhos apenas taxonômicos.

Posteriormente, os trabalhos de Oliveira Filho \& Mayal, (1976), Maggs et al. (1979), Oliveira Filho \& Paula (1983), Eston et al. (1986), Teixeira et al.(1987), além da tese de Carvalho (1983) e alguns resumos (Mitchell et al., 1986; Van Sluys \& Pedrini, 1986, Rosso, 1987, entre outros) apresentaram uma abordagem qualitativa ou semi-quantitativa baseada em dados pontuais obtidos a partir de transecções, e alguns trabalhos e resumos apresentaram abordagem quantitativa (Johnscher-Fornasaro et al., 1986; Guerrazzi, 1987; Kadekaru et al., 1987; Muricy, 1989; Castro et al., 1995; Kelmo \& Attrill, 2001).

A partir do final da década de 80 , alguns trabalhos, resumos e teses envolveram amostragens e métodos de análise mais sofisticados (Osse \& Rosso, 1989; Rosso, 1990; Johnscher-Fornasaro et al., 1990; Baldresca \& Rosso, 1991; Borges \& Rosso, 1991; Osse \& Rosso, 1991; Rosso, 1991; Yoneshigue-Valentin \& Valentin, 1992; Rosso, 1995; Osse, 1995; Borges, 1996; Correia, 1997; Longo, 1997; Yaobin, 1999; Costa Jr. et al., 2002; Amado-Filho et al., 2003; Figueiredo et al., 2004; Oigman-Pszczol et al., 2004; Marins-Rosa et al., 2005), preocupando-se com o delineamento e a suficiência amostral, a integração dos dados através de análises multivariadas e a precisão dos dados obtidos. Entretanto, todos ainda utilizaram transecções, seguindo uma tendência mundial iniciada com os trabalhos pioneiros de Doty (1946) e Stephenson \& Stephenson (1949).

O método da transecção, embora ainda bastante utilizado em todo o mundo (p.ex. Díez \& Gorostiaga, 2002; Ingólfsson, 2005; Schembri et al., 2005 e muitos outros), não permite a extrapolação dos dados obtidos para o restante da comunidade na área de estudo. Esse 
problema é bastante sério, pois bons métodos de amostragem são criticamente importantes em estudos de ecologia, já que queremos que nossas amostras sejam representativas da população em estudo (Krebs, 1999), mas simultaneamente demandem o menor esforço amostral possível. Para que se atinjam conclusões válidas sobre populações por induções a partir de amostras, os procedimentos estatísticos tipicamente assumem que as mesmas foram obtidas de maneira aleatória. Para amostrar aleatoriamente uma população é necessário que cada membro dessa tenha uma chance igual e independente de ser selecionado (Zar, 1999).

Coimbra (1998) é uma das únicas teses que utilizou elementos amostrais dispostos aleatoriamente na área de estudo, através de um sistema de coordenadas no qual um cabo marcado era estendido ao longo da área e neste cabo eram realizados sorteios de pontos. Nos pontos sorteados se estendia um segundo cabo, perpendicular ao primeiro, no qual um segundo ponto era sorteado e neste ponto era posicionado o elemento amostral. Esta metodologia permitiu, portanto, a extrapolação dos dados para o restante da área de estudo, considerando-se o fato de que houve suficiência amostral. Robles (2003) usou um sistema semelhante para estudar um Banco de Isognomon no litoral sul de São Paulo.

Poucos trabalhos e teses dentre os mencionados enfocaram a região do infralitoral. Dentre eles, grande parte foi realizada na região sudeste do país, podendo ser citados os de Maggs et al. (1979), Teixeira et al. (1987), Yoneshigue-Valentin \& Valentin (1992), Amado Filho et al. (2003), Figueiredo et al. (2004) e Oigman-Pszczol et al. (2004) no estado do Rio de Janeiro e Eston (1987) em São Paulo, e uma pequena parte na região nordeste, como Eston et al. (1986) no arquipélago de Fernando de Noronha, Villaça \& Pitombo (1997), Costa Jr. et al. (2002) e Marins-Rosa et al. (2005), no estado da Bahia.

Nesta região, o conhecimento pode ser adquirido através do mergulho autônomo, técnica que vem sendo utilizada por cientistas desde 1785 (Riedl, 1980). A vantagem da observação direta das comunidades do infralitoral por biólogos mergulhadores é que ela permite a determinação do padrão da comunidade. Não é apenas um método para definir as 
profundidades nas quais as espécies ocorrem, mas é praticamente a única maneira pela qual a ecologia de um fundo rochoso irregular pode ser utilmente estudada (Norton \& Milburn, 1972).

Pelo exposto, pode-se observar que o conhecimento sobre as comunidades de substrato consolidado no Brasil ainda é escasso, sendo necessários maiores esforços de amostragem e metodologias mais rápidas e eficientes.

Esta escassez de conhecimento pode ser em parte também relacionada com o fato de que a grande maioria dos trabalhos sobre comunidades bentônicas de substrato consolidado do litoral brasileiro tem tentado entender sua estrutura através de abordagens baseadas na qualificação e quantificação das espécies presentes como forma de caracterização da diversidade. Inserido neste contexto, o uso de descritores que levam em conta as importâncias relativas das espécies presentes em uma comunidade seriam os melhores, já que o sucesso relativo das espécies nos processos e interações que ocorrem dentro do ecossistema, ou entre ecossistemas, está correlacionado com as abundâncias das mesmas e, portanto, estes descritores são vantajosos na medida em que integram a complexidade da composição específica com a complexidade funcional.

Apesar desta vantagem, as estimativas de abundância e de cobertura de espécies geralmente consomem muito tempo e são exaustivas ou mesmo impossíveis, devido a problemas operacionais (organismos muito pequenos, necessidade de estruturas reprodutivas para identificação, condições de visibilidade da água, tempo de ar do cilindro de mergulho, entre outros) ou a falta de conhecimentos pretéritos ou especialistas em certos grupos. Isso limita severamente o número de amostras que pode ser obtido (Littler \& Littler, 1985, Sabino \& Villaça, 1999).

A solução para este problema seria tratar a diversidade de outra forma, minimizando a influência do paradigma de identificação de espécies. Apenas recentemente alguns trabalhos vêm apresentando enfoques não baseados em espécies como unidades operacionais, como 
Villaça \& Pitombo (1997), Gherardi \& Bosense (2001), Costa Jr. et al. (2002), Figueiredo et al. (2004), que sintetizaram seus dados em amostragens de grupos morfo-funcionais e grandes grupos taxonômicos. Outra estratégia é considerar apenas as espécies dominantes, como foi realizado, por exemplo, por Correia (1997) e Oigman-Pszczol et al. (2004). Estas estratégias são vantajosas na medida em que permitem a ampliação da escala de amostragem sem elevar demasiadamente o esforço amostral, como ocorre no caso da abordagem específica, já que eliminam ao menos em uma primeira abordagem a necessidade de identificação dos organismos pouco abundantes ou raros, que normalmente são os que constituem problemas taxonômicos, e permitem concentrar os esforços na correta identificação dos mais representativos.

Outro enfoque interessante seria basear-se em unidades não taxonômicas. Em termos ecológicos, poder-se-ia falar em unidades de heterogeneidade. Sabe-se que como resultado das interações bióticas e abióticas, as comunidades freqüentemente se apresentam com certo grau de heterogeneidade em uma ou mais escalas de observação. Nas comunidades bentônicas de substrato consolidado, esta heterogeneidade pode ser reconhecida, por exemplo, na forma dos mosaicos (incluem-se aí os "patches" ou manchas) e da zonação (definida apenas na direção vertical ou gradiente batimétrico). Algumas espécies destas comunidades são sistematicamente dominantes, ou por exibirem sucesso incomum na alocação de recursos para si, ou também por estruturarem fisicamente o hábitat (espécies engenheiras), e constituem com muita freqüência associações que tendem a re-ocorrer em ambientes similares, tanto do ponto de vista das interações bióticas como das abióticas que aí se verificam.

Assim, é de se esperar grande similaridade entre comunidades que tenham as mesmas espécies dominantes ou engenheiras. A identificação de muitas associações é possível visualmente mesmo à distância de alguns metros ou então a partir de técnicas tais como a análise de gravações contínuas em vídeo (vídeo-transecção), fotos digitais, entre outras, já que cada uma apresenta uma fisionomia própria. 
Dessa forma, é possível classificar as comunidades de costões rochosos baseando-se nestas unidades de heterogeneidade. Este raciocínio tem como base os estudos de classificação de comunidades de plantas terrestres, que se iniciaram no começo do século XIX, com os trabalhos de Humboldt e Grisebach. As comunidades vegetais são complexas e podem ser classificadas de diferentes formas, dependendo do interesse do estudo e de quais aspectos o pesquisador considera mais importantes para a classificação. Diferentes escolas ecológicas de classificação de comunidades vegetais se desenvolveram e podem ser destacadas 12 diferentes abordagens (Whittaker, 1978): 1) fisionômica ou estrutural, 2) ambiental, 3) multi-fatorial ou da paisagem, 4) de áreas bióticas, 5) de segmentos de gradientes da vegetação, 6) de espécies dominantes, 7) da dinâmica vegetacional, 8) de estratos ou divisões de formas de vida, 9) de combinações de estratos, 10) de tipos subflorestais, 11) de comparações numéricas, 12) de unidades florísticas de Braun-Blanquet.

Baseando-se nestes conceitos e formas de classificação, o desenvolvimento deste trabalho de tese fez parte da criação e propõe um novo método, que já publicamos (Berchez et al., 2005), denominado "Levantamento Fisionômico", o qual tem o objetivo de caracterizar domínios amostrais mais amplos, de maneira rápida e eficiente, o que é fundamental para o conhecimento geral de nossas comunidades bentônicas de substrato consolidado.

Este método baseia-se em aspectos visuais da paisagem dos costões rochosos e é uma abordagem descritiva a qual, em uma escala maior, trata da diversidade de fisionomias colonizando o substrato em certa área (macro-heterogeneidade, sensu Forman \& Godron, 1986).

Poderiam ser citados como exemplos dessas fisionomias os bancos de bivalves e cracas, as crostas de algas calcárias, as colônias de zoantídeos e os tapetes de algas filamentosas.

Dentro da escala de heterogeneidade na qual se encaixam as fisionomias, o método reconhece uma segunda escala, menor, constituída pelas facetas ou faces, que seriam as 
unidades do mosaico, bem delimitadas e que possuiriam um componente biótico nelas representado, chamado povoamentos, caracterizados qualitativamente por uma espécie dominante ou associação de poucas espécies estruturadoras do hábitat (microheterogeneidade). Essas associações são recorrentes e sua identificação envolve uma observação mais detalhada para identificação das principais espécies in loco.

Neste contexto, a abordagem fisionômica ou estrutural apresentada por Whittaker (1978), na qual a fisionomia está relacionada à estrutura da comunidade (divisão em estratos e diferentes formas de vida ou de crescimento), pode ser relacionada com a tentativa de descrição da macro-heterogeneidade proposta por nós e a abordagem de espécies dominantes, com a tentativa de descrição da micro-heterogeneidade.

Além disso, o termo povoamento poderia ser relacionado ao termo "associação" de Braun-Blanquet (na escola de Braun-Blanquet as amostras de vegetação são agrupadas em comunidades-tipos por similaridade de composição, especialmente pela representação de espécies características, que formam associações quando sua distribuição é centrada ou limitada a uma comunidade-tipo), ou à "monocultura" de Paine (1984), aos patches de Machado et al. (1992) e às fácies de Carvalho (1983). O termo fisionomia poderia ser relacionado aos grupos ecológicos de Boudouresque (1971).

É possível notar, a partir de observações empíricas e de informações inferidas a partir de abordagens tradicionais que, de forma geral, poucas espécies são dominantes em cada povoamento, tanto ao se considerar a cobertura como a biomassa (Coimbra \& Berchez, 2000; Borges, 1996; Dethier, 1984). Portanto, a partir de uma amostragem de povoamentos, aspectos importantes da estrutura da comunidade, como ocupação do espaço e relação entre os táxons, podem ser obtidos.

Coimbra \& Berchez (2000) observam, por exemplo, a partir de dados de recobrimento percentual, que há alteração de povoamentos do supralitoral em direção à parte inferior do mediolitoral, relacionada à composição específica e recobrimento percentual dos organismos 
observados. O mesmo pode ser observado nos trabalhos de Carvalho (1983) e Costa Jr. et al. (2002), em estudo realizado no complexo recifal dos Estados da Paraíba e da Bahia, respectivamente, onde houve alterações de povoamentos relacionadas com mudanças das características abióticas do ambiente.

Oliveira Filho \& Berchez (1978) e Berchez \& Oliveira (1992) também observaram, na Baía de Santos, SP, a partir de dados taxonômicos e observações empíricas e baseando-se no trabalho original de Joly (1957) o desaparecimento de espécies chave resultando no desaparecimento completo de alguns povoamentos. A faixa de Sargassum, por exemplo, desapareceu completamente, sendo substituída por outras, como uma faixa bem definida de Ulva. Foi observado ainda o aumento do recobrimento aparente de outros organismos, como por exemplo, do mexilhão, que já ocorre em faixas, formando um povoamento bem definido, mas que, aparentemente, teve sua distribuição consideravelmente ampliada em várias estações. Os autores sugerem que essas mudanças podem estar relacionadas a alterações na qualidade da água do mar, ressaltando a utilidade da amostragem de povoamentos no monitoramento ambiental, muito menos complicado e impreciso do que o monitoramento baseado em espécies, as quais sofrem comumente alterações não sazonais naturalmente e de forma contínua, podendo ser o resultado das mais variadas causas, esporádicas ou cíclicas, como tempestades, secas, correntes, flutuações no sucesso reprodutivo e/ou de recrutamento dos indivíduos jovens e também, os próprios efeitos de poluentes e outras ações antrópicas (Holme \& McIntyre, 1984). Isso se torna bastante claro no infralitoral que, apesar de ser um ambiente estável quanto aos fatores físicos, apresenta interações biológicas intensas que modificam o padrão das comunidades, levando a um problema para o monitoramento efetivo, por exemplo, em relação aos efeitos de poluição (Hawkins \& Hartnoll, 1983).

A utilização de organismos estacionários, como são muitos dos que formam povoamentos, para monitorar ambientes aquáticos tem sido considerada vantajosa em comparação com medidas diretas de poluentes através de métodos de análise química, pois 
estas tendem a ser pontuais e específicas, enquanto que as primeiras são gerais e integradoras, além de muito mais baratas (Levine, 1984).

O presente estudo emprega a abordagem por povoamentos exposta acima em um trecho de infralitoral consolidado do Parque Estadual da Ilha Anchieta com os seguintes propósitos:

1) Caracterização inicial dos povoamentos presentes na área - esta caracterização das comunidades é um passo importante não só para o desenvolvimento das etapas seguintes, mas também pode servir para o estabelecimento de futuras estações de monitoramento na área, que é uma unidade de preservação;

2) Avaliar a repartição espacial dos povoamentos através de mapeamento georeferenciado;

3) Avaliar a repartição espacial dos povoamentos através da quantificação de seus recobrimentos percentuais - as Abordagens 2 e 3 visam avaliar a forma como os povoamentos ocupam o substrato, se ocorrem de forma agregada ou dispersa, se são eqüitativos ou existem alguns que apresentam maior importância relativa;

4) Verificar a constância espacial de alguns povoamentos selecionados - esta abordagem visa verificar se os povoamentos podem ser considerados unidades ecológicas consistentes e detalhar a composição de alguns deles. 


\section{REFERÊNCIAS}

Amado Filho, G.M.; Barreto, M.B.B.B.; Marins, B.V.; Felix, C.; Reis, R.P., 2003. Estrutura das comunidades fitobentônicas do infralitoral da Baía de Sepetiba, RJ, Brasil. Revista Brasil. Bot., São Paulo, v. 26, n. 3, p. 329-342.

BALDRESCA, R.; Rosso, S., 1991. Estudo da estrutura da comunidade de um costão intermareal da Estação Ecológica da Juréia (SP). In: SIMPÓSIO SOBRE OCEANOGRAFIA, 2., 1991, São Paulo. Resumos...São Paulo: IOUSP. p. 297.

BercheZ, F.A.S.; OliveIRA, E.C., 1992. Temporal changes in the benthic marine flora of the Baía de Santos, SP, Brazil, over the last four decades. In: CORDEIRO-MARINO, C.; AZEVEDO, M.T.P.; SANT'ANNA, C.L.; TOMITA, N.Y.; PLASTINO, E.M. (Eds). Algae and environment: a general approach. São Paulo: Sociedade Brasileira de Ficologia. p. 120-131.

Berchez, F.; Rosso, S.; GHILARDI, N.P.; FuJII, M.T.; HAdEL, V., 2005. Characterization of hard bottom marine benthic communities: the physiognomic approach as an alternative to traditional methodologies. In: Sociedade Brasileira de Ficologia (Org.). Formação de Ficólogos: um compromisso com a sustentabilidade dos recursos aquáticos. Rio de Janeiro: Museu Nacional, Série Livros 10, p. 207-220.

Berchez, F.A.S.; Rosso, S.; Tiago, C.G.; Dias, G. Observations on the structure of the benthic communities of a coralline algae bottom, SE Brazilian Continental Shelf. Em revisão.

BORGES, R.P., 1996. Abordagem temporal da repartição espacial, diversidade e dominância em uma comunidade de costão rochoso intermareal da Praia da Tatuíra, São Sebastião (SP). 97 f. Dissertação (Mestrado em Ecologia) - Instituto de Biociências, Universidade de São Paulo, São Paulo.

Borges, R.P.; Rosso, S., 1991. Dimensionamento amostral e avaliação preliminar da estrutura da comunidade de um costão rochoso da Praia da Tatuíra, São Sebastião, São Paulo. In: SIMPÓSIO SOBRE OCEANOGRAFIA, 2., 1991, São Paulo. Resumos...São Paulo: IOUSP. p. 296.

Boudouresque, C., 1971. Méthodes d'étude qualitative et quantitative du benthos (en particulier du phytobenthos). Tethys, v. 3, n. 1, p. 79-104.

CARvalho, F.A.F., 1983. Bionomia bêntica do complexo recifal no litoral do Estado da Paraíba, com ênfase nas macrófitas. 184f. Tese (Doutorado em Ciências) - Instituto Oceanográfico, Universidade de São Paulo, São Paulo. 
Castro, C.B.; Echeverría, C.A.; Pires, D.O.; Mascarenhas, B.J.A.; Freitas, S.G., 1995. Distribuição de Cnidaria e Echinodermata no infralitoral de costões rochosos de Arraial do Cabo, Rio de Janeiro, Brasil. Rev. Bras. Biol., v. 55, p. 471-480.

Coelho, P.A.; Ramos-Porto, M. Bentos litorâneos do nordeste oriental do Brasil. II. Povoamentos de substratos duros. Bolm. Inst. Oceanogr., São Paulo, v. 29, n.2, p. 133134, 1980.

COIMBRA, C.S., 1998. Caracterização ecológica das comunidades bentônicas da região entremarés no costão sul da Praia do Itaguá, Ubatuba, SP. 136f. Dissertação (Mestrado) Instituto de Biociências, Universidade de São Paulo, São Paulo.

CoIMBrA, C.S.; BERCHEZ, F.A.S., 2000. Habitat heterogeneity on tropical rocky shores: a seaweed study in southern Brazil. Journal of Phycology (Suppl.), v. 36, n. 3 , p.14-15.

CONNELL, J.H., 1985. The consequences of variation in initial settlement vs. post settlement mortality in rocky intertidal communities. J. Exp. Mar. Biol. Ecol., v. 93, p. 11-45.

CorrêA, M.S.D.; Ribeiro, R.S.; Brito, L.V.R. De; Carloni, G.G.; Carvalheira, L.V., 1998. Estrutura de comunidades bênticas de mesolitoral de costões rochosos adjacentes ao terminal petrolífero da Baía da Ilha Grande, RJ. In: SEMANA NACIONAL DE OCEANOGRAFIA - Oceanografia e suas interfaces, 11., Rio Grande. Resumos expandidos... Pelotas: UFPel, 1998. p.212-214.

CORREIA, M.D., 1997. Distribuição espacial dos organismos macrobentônicos no recife de coral da Ponta Verde, Maceió, Alagoas - Brasil. 194f. Tese (Doutorado) - Instituto de Biociências, Universidade de São Paulo, São Paulo.

CostA, H.R., 1962. Note preliminaire sur les peuplements intercotidaux de substrat dur du littoral de Rio de Janeiro. Rec. Trav. St. Mar. End., Marseille, bull. 27, fasc. 42, p. 197207.

Costa Jr, O.S.; Attrill, M.J.; Pedrini, A.G.; De-Paula, J.C., 2002. Spatial and seasonal distribution of seaweeds on coral reefs from southern Bahia, Brazil. Botanica mar., Berlin, v. 45, p. 346-355.

DethiER, M.N., 1984. Disturbance and recovery in intertidal pools: maintenance of mosaic paterns. Ecol. Monogr., Tempe, v. 54, n. 1, p. 99-118.

DíEz, I.; SAnTOlaria, A.; Gorostiaga, J.M., 2003. The relationship of environmental factors to the structure and distribution of subtidal seaweed vegetation of the western Basque coast (N Spain). Estuarine, Coastal and Shelf Science, v. 56, p. 1041-1054.

DotY, M.S., 1946. Critical tide factors that are correlated with the vertical distribution of marine algae and other organisms along the Pacific Coast. Ecology, v. 27, n. 4, p. 315328. 
EdwARdS, A.; LubBOcK, R., 1983. The ecology of Saint Paul's Rocks (Equatorial Atlantic). J. Zool., London, v. 200, p. 51-69.

ESTON, V.R. de, 1987. Avaliação experimental da dominância ecológica em uma comunidade de macroalgas do infralitoral rochoso (Ubatuba, São Paulo, Brasil). 129 f. Tese (Doutorado) - Instituto Oceanográfico, Universidade de São Paulo, São Paulo.

Eston, V.R. De; Migotto, A.E.; Oliveira Filho, E.C. de; Rodrigues, S.A.; Freitas, J.C., 1986. Vertical distribution of benthic marine organisms on rocky coasts of the Fernando de Noronha archipelago (Brazil). Bol. Inst. Oceanogr., São Paulo, v. 34, p. 37-54.

Figueiredo, M.A.O.; BARReto, M.B.B.; ReIS, R.P., 2004. Caracterização das macroalgas nas comunidades marinhas da Área de Proteção Ambiental de Cairuçú, Parati, RJ - subsídios para futuros monitoramentos. Revista Brasil. Bot., São Paulo, v. 27, n. 1, p.11-17.

Forman, R.T.T.; GODRON, M., 1986. Landscape ecology. New York: Wiley. 619 p., il.

Gherardi, D.F.M.; Bosence, D.W.J., 2001. Composition and community structure of the coralline algal reefs from Atol das Rocas, South Atlantic, Brazil. Coral reefs, Berlin, v. 19, p. 205-219.

Ghilardi, N.P.; Berchez, F.A.S., 2005. Aleatoriedade em estudos de costões rochosos. Mesa redonda: Novas alternativas no estudo de comunidades de substrato consolidado. In: VII Congresso de Ecologia do Brasil, 20-25 de novembro de 2005, Caxambu. CD de resumos.

GIORDANO, F., 1986. Ouriços do sublitoral rochoso da região de São Sebastião - São Paulo uma abordagem ecológica. 128f. Dissertação (Mestrado em Ecologia) - Instituto de Biologia, Universidade Estadual de Campinas, São Paulo.

GUERRAZZI, M.C., 1987. Estudos preliminares sobre a estrutura de uma comunidade de costão rochoso, em mediolitoral, num gradiente de salinidade. In: SIMPÓSIO DOS ECOSSISTEMAS DA COSTA SUL E SUDESTE BRASILEIRA: SÍNTESE DOS CONHECIMENTOS, 1., p. 221-232. São Paulo: Academia de Ciências do Estado de São Paulo (Publicação ACIESP, 54).

HAWKins, S.J.; HARTNOLL, R.G., 1983. Changes in a rocky shore community: an evaluation of monitoring. Mar. Environ. Res., Barking, v. 9, p. 131-181.

Holme, N.A.; Mcintyre, A.D., 1984. Methods for the study of Marine Benthos. $2^{\text {nd }}$ ed. Oxford: Blackwell. 387p.

INGÓLFSSON, A., 2005. Community structure and zonation patterns of rocky shores at high latitudes: an interocean comparison. Journal of Biogeography (J. Biogeogr.), v.32, p.169-182. 
JANKE, K., 1990. Biological interactions and their role in community structure in the rocky intertidal of Helgoland (German Bight, North Sea). Helgolander Meeresuntersuchungen, v. 44, p. 219-263.

Johnscher-Fornasaro, G.; Quarentei-SouzA, R. de C.; KAdEKARU, N.; RoQuettiHuMAYTÁ, M.H., 1986. Estudos das comunidades bentônicas de substrato consolidado do litoral norte do Estado de São Paulo: praia do Camburi. In: MINI-SIMPÓSIO DE BIOLOGIA MARINHA, 5., 1986, São Sebastião. Resumos... São Sebastião: CEBIMAR - USP. p. 06.

Johnscher-Fornasaro, G.; LoPes, C.F.; Milanelli, J.C. de C., 1990. Similaridade faunística entre comunidades da zona entre-marés de costões rochosos do litoral norte do Estado de São Paulo. . In: SIMPÓSIO DOS ECOSSISTEMAS DA COSTA SUL E SUDESTE BRASILEIRA: ESTRUTUTA, FUNÇÃO E MANEJO, 2., p. 75-88. São Paulo: Academia de Ciências do Estado de São Paulo (Publicação ACIESP, 71).

Joly, A.B., 1957. Contribuição ao conhecimento da flora ficológica marinha da Baía de Santos e arredores. Bol. Fac. Filos. Cienc. Let. Univ. São Paulo Ser Bot., São Paulo, n. 14 , p. $1-220$.

Kadekaru， N.; QuarenteI-Souza， R.C.A.; RoquetTi-HumaytÁ, M.H.; JohnscherFORNASARO, G., 1987. Estudo da fauna das comunidades bentônicas de substrato consolidado do litoral norte do Estado de São Paulo: II - Praia do Estaleiro. In: SIMPÓSIO DOS ECOSSISTEMAS DA COSTA SUL E SUDESTE BRASILEIRA: SÍNTESE DOS CONHECIMENTOS, 1., p. 201-220. São Paulo: Academia de Ciências do Estado de São Paulo (Publicação ACIESP, 54).

Kelmo, F.; AtTrill, M.J., 2001. Cnidarian community structure of coastal reefs from northern Bahia. Bull. Mar. Sci., v. 69, p.547-557.

KREBS, J.C., 1999. Ecological methodoly. $2^{\text {nd }}$ ed. New York: Harper \& Row Publ. 620p.

LEVINE, H.G., 1984. The use of seaweeds for monitoring coastal waters. In: Shubert, L.E. (Ed.). Algae as ecological indicator. Academic Press. p. 189-212.

LEWIS, J.R., 1964. The ecology of rocky shores. London:The English University Press. 300p. LiTTLER, M.M.; LiTTLER, D.S., 1985. Nondestructive sampling. In: Littler, M.M.; Littler, D.S. (Eds). Handbook of phycological methods. Ecological field methods: macroalgae. Cambridge: Cambridge University Press. cap. 8, p. 161-175.

LONGO, L.L., 1997. Repartição espaço-temporal da cnidofauna em arenito de praia em Santa Cruz (Aracruz - ES). 97f. Dissertação (Mestrado em Zoologia) - Instituto de Biociências, Universidade de São Paulo, São Paulo. 
Machado, K.R.S.S.; Chapman, A.R.O.; Coutinho, R., 1992. Patch structure in a tropical rocky shore community in Brazil: a mosaic of successional states? Ophelia, Helsingor, v.35, n.3, p.187-195.

Maggs, C.A.; Milner, A.A.; Watts, W.; Whittle, M.R., 1979. The Oxford diving expedition to Cabo Frio, Brazil. Bull. Oxford Univ. Explor. Club. New. Serv., Oxford, v. 4, p. 13-40.

Marins-Rosa, B.; Amado-Filho, G.; Manso, C.; Yoneshigue-Valentin, Y., 2005. Estrutura do fitobentos do sub-litoral das formações recifais da Baía de Todos os Santos (Bahia, Brasil). In: Sociedade Brasileira de Ficologia (Org.). Formação de Ficólogos: um compromisso com a sustentabilidade dos recursos aquáticos. Rio de Janeiro: Museu Nacional, Série Livros 10, p. 255-274.

MitChell, G.J.P.; SzÉChY, M.T.M.; ShINDO-Mitchell, N., 1986. The algal zonation at Santa Cruz (Espírito Santo State, Brazil). In: INTERNATIONAL SEAWEED SYMPOSIUM, 12., 1986, São Paulo. Resumos... São Paulo: IOUSP. p. 75.

Muñoz, A.O.M.; PereIRA, S.M.B., 1998. Estrutura de comunidades de macroalgas em formações recifais do Estado de Pernambuco, Brasil. In: CONGRESSO LATINOAMERICANO DE FICOLOGIA, 4., 1996, Caxambú. Anais... Caxambú, vol. 2. p. 287297.

MURICY, G., 1989. Sponges as pollution biomonitors at Arraial do Cabo, southeastern Brazil. Rev. Bras. Biol., v. 49, n. 2, p. 347-354.

Muricy, G.; MeIrelles, S., 1988. Análise quantitativa de uma comunidade bentônica de substrato duro em Arraial do Cabo, RJ. Método dos quadrados de freqüência. In: CONGRESSO BRASILEIRO DE ZOOLOGIA, 15., 1988, Curitiba. Resumos... Curitiba: Sociedade Brasileira de Zoologia e Universidade Federal do Paraná, p.603. Muricy, G.; Moraes, F.C., 1998. Marine sponges of Pernambuco State, NE Brazil. Rev. Bras. Oceanogr., v. 46, p. 213-217.

NonATO, E.F.; PÈreZ, J.M., 1961. Observation sur quelques peuplements interdidaux de substrat dur dans la region d'Ubatuba. Cah. Biol. Mar., Paris, v. 2, p. 263- 270.

NorTOn, T.A.; MilbuRn, J.A., 1972. Direct observations on the sublitoral marine algae of Argyll, Scotland. Hydrobiologia, The Hague, v. 40, n. 1, p. 55-68.

Oigman-Pszczol, S.S.; FiqueIREdo,M.A.O.; C REED , J.C., 2004. Distribution of benthic communities on the tropical rocky subtidal of Armação dos Búzios, Southeastern Brazil. Marine Ecology, v. 25, n. 03, p. 173-190.

OliveIRA, L.P.H., 1947. Distribuição geográfica da fauna e flora da Baía da Guanabara. Mem. Inst. Oswaldo Cruz, Rio de Janeiro, v. 45. p. 709-735. 
OliVEIRA, L.P.H., 1951. Nota prévia sobre a fauna e flora marinha bentônica da Ilha da Trindade. Mem. Inst. Oswaldo Cruz, Rio de Janeiro, v. 49. p. 443-456.

Oliveira Filho, E.C. de, 1977. Algas marinhas bentônicas do Brasil. 407 f. Tese (Livre Docência) - Instituto de Biociências, Universidade de São Paulo, São Paulo.

Oliveira Filho, E.C. de; Berchez, F.A.S., 1978. Algas bentônicas da Baía de Santos alterações da flora no período de 1957-1978. Bol. Bot. Univ. São Paulo, São Paulo, v. 6, p. 49-59.

Oliveira Filho, E.C. de; MAyal, E.M., 1976. Seasonal distribution of intertidal organisms at Ubatuba, São Paulo (Brazil). Rev. Bras. Biol., Rio de Janeiro, v. 36, n. 1, p. 305-316.

Oliveira Filho, E.C. de; PAUlA, E.J. de, 1983. Aspectos da distribuição vertical e variação sazonal de comunidades da zona das marés em costões rochosos do litoral norte do Estado de São Paulo. In: ENCONTRO DE MACRÓFITAS MARINHAS, 1., 1983, Arraial do Cabo. Anais... Arraial do Cabo: Instituto de Pesquisas da Marinha. Projeto Cabo Frio (147). p. 44-61.

OsSE, A.C., 1995. Aspectos da estrutura espaço-temporal de uma comunidade intermareal de costão rochoso da Ponta da Fortaleza, Ubatuba, SP. 156 f. Dissertação (Mestrado em Ecologia) - Instituto de Biociências, Universidade de São Paulo, São Paulo.

Osse, A.C.; Rosso, S., 1989. Estudo qualitativo de comunidade da zona entre-marés de um costão rochoso abrigado da Ponta da Fortaleza - Ubatuba - SP. In: MINI-SIMPÓSIO DE BIOLOGIA MARINHA, 8., 1989, São Sebastião. Resumos... São Sebastião: CEBIMAR - USP. p. 27.

Osse, A.C.; Rosso, S., 1991. Estratificação da comunidade intermareal da Ponta da Fortaleza (Ubatuba-SP): avaliação dos resultados obtidos através de diferentes técnicas de “clustering”. In: SIMPÓSIO SOBRE OCEANOGRAFIA, 2., 1991, São Paulo. Resumos...São Paulo: IOUSP. p. 181.

PAINE, R.T., 1984. Ecological determinism in the competition for space. Ecology, v. 65, n. 5, p. $1339-1348$.

RAWITSCHER, F.K., 1944. Algumas noções sobre a vegetação do litoral brasileiro. Boletim da Associação dos Geógrafos Brasileiros, ano 4, n. 5, p. 13-28.

RIEDL, R., 1980. Marine Ecology: a century of changes. P.S.Z.N. 1: Marine Ecology, v. 1, n. 1, p.3-46.

RoBLES, F.R., 2003. O banco de Isognomon bicolour Adams 1845: estrutura da comunidade e processo sucessional inicial. 148f. Tese (Doutorado em Ecologia) - Instituto de Biociências, Universidade de São Paulo, São Paulo. 
Rosso, S., 1987. Comunidade de organismos sésseis e semi-sésseis intermareais de um costão rochoso da Praia das Cigarras, São Sebastião, SP - uma abordagem metodológica. . In: MINI-SIMPÓSIO DE BIOLOGIA MARINHA, 6., 1987, São Sebastião. Resumos... São Sebastião: CEBIMAR - USP. p. 17.

Rosso, S., 1990. Estrutura de comunidades intermareais de substrato consolidado das proximidades da Baía de Santos (SP, Brasil): uma abordagem descritiva enfatizando aspectos metodológicos. 217 f. Tese (Doutorado em Ecologia) - Instituto de Biociências, Universidade de São Paulo, São Paulo.

Rosso, S., 1991. Estratificação e repartição vertical da dominância e diversidade em um domínio intermareal de substrato consolidado da região inferior do estuário de SantosSão Vicente, e considerações sobre a adequação de diversos descritores na discriminação dos sub-sistemas mediolitorais inferior e superior. In: SIMPÓSIO SOBRE OCEANOGRAFIA, 2., 1991, São Paulo. Resumos...São Paulo: IOUSP. p. 141.

Rosso, S., 1995. Dimensionamento amostral em estudos descritivos de comunidades de organismos bênticos sésseis e semi-sésseis. In: SIMPÓSIO SOBRE ESTRUTURA, FUNCIONAMENTO E MANEJO DE ECOSSISTEMAS. OECOLOGIA BRASILIENSIS, 1., 1995, Rio de Janeiro. Anais... Rio de Janeiro: Instituto de Biologia. Universidade Federal do Rio de Janeiro. p. 193-223.

Rosso, S.; Plastino, E.M.; FujiI, Mt.; Braga, M.R.A.; Berchez, F.A.S.; Artaza, O.H., 1986. Distribuição vertical dos organismos no costão rochoso da Praia das Cigarras, São Sebastião, SP. In: MINI-SIMPÓSIO DE BIOLOGIA MARINHA, 5., 1986, São Sebastião. Resumos... São Sabastião: CEBIMAR - USP. p.14.

SABINO, C.M.; VillaçA, R., 1999. Estudo comparativo de métodos de amostragem de comunidades de costão. Rev. Brasil. Biol., v. 59, n. 3, p. 407-419.

SChEMBRI, P.J.; DeIDUN, A.; MalliA, A.; MercieCA, L., 2005. Rocky shore biotic assemblages of the Maltese Islands (Central Mediterranean): A conservation perspective. Journal of Coastal Research, v.21, n.1, p.157-166.

SiDDON, C.E.; WiTMAN, J.D., 2003. Influence of chronic, low-level hydrodynamic forces on subtidal community structure. Mar. Ecol. Prog. Ser., v. 261, p. 99-110.

Silva, E.P. da; FERNANDES, F.C., 1990. O bentos de substrato duro das margens da Lagoa de Araruama. In: SIMPÓSIO DOS ECOSSISTEMAS DA COSTA SUL E SUDESTE BRASILEIRA: ESTRUTUTA, FUNÇÃO E MANEJO, 2., v. 4, p. 231-240, 1990. Águas de Lindóia: Academia de Ciências do Estado de São Paulo (Publicação ACIESP, 71).

SouzA, 1984. The role of disturbance in natural communities. Annual Review of Ecology and Systematics, v. 15, p. 353-391. 
StePhenson, T.A.; StePhEnson, A., 1949. The universal features of zonation between tidemarks on rocky coasts. The Journal of Ecology, v. 37, n. 2, p. 289-305.

SUDENE, 1981. Projeto Algas - Estado do Rio Grande do Norte. Estudos de Pesca, n. 9. $120 \mathrm{p}$.

TeiXeira, V.L.; Pereira, R.C.; Marques Junior, A.N.; Leitão Filho, C.M.; Silva, C.A.R., 1987. Seasonal variations in infralittoral seaweed communities under a pollution gradient in Baía de Guanabara, Rio de Janeiro (Brazil). Ciência e Cultura, São Paulo, v. 39, n. 4, p. $423-428$.

Van Sluys, M.; Pedrini, A.G., 1986. Padrão de distribuição vertical da comunidade bentônica em um costão da praia vermelha, Urca, Rio de Janeiro, RJ. In: CONGRESSO NACIONAL DE BOTÂNICA, 38., São Paulo, 1986. Resumos...São Paulo: Universidade de São Paulo. p. 76.

VILLAÇA, R.C., 1990. Metodologia de amostragem em costões rochosos. Abordagem fitossociológica. In: SIMPÓSIO DOS ECOSSISTEMAS DA COSTA SUL E SUDESTE BRASILEIRA: ESTRUTUTA, FUNÇÃO E MANEJO, 2., p. 1-12. São Paulo: Academia de Ciências do Estado de São Paulo (Publicação ACIESP, 71).

VillaçA, R.C.; Pitombo, F.B., 1997. Benthic communities of shalow-water reefs of Abrolhos, Brazil. Rev. Bras. Oceanogr., v. 45, p. 35-43.

WhitTAKeR, R.H., 1978. Classification of plant communities. The Hague: Dr. W. Junk bv Publishers. 408p.

YAOBIN, Q., 1999. Estudos sobre a variação temporal da composição de macroalgas marinhas em uma baía poluída - o caso de Santos, Litoral de São Paulo, Brasil. 139f. Tese (Doutorado em Ecologia) - Instituto de Biociências da Universidade de São Paulo, São Paulo.

Yoneshigue, Y., 1985. Taxonomie et ecologie des algues marines dans la region de Cabo Frio (Rio de Janeiro, Brésil). 466f. Tese (Doutorado em Ciências) - Faculdade de Ciências de Luminy, Universidade de Aix-Marseille II, Marseille.

Yoneshigue-Valentin, Y.; Valentin, J.L., 1992. Macroalgae of the Cabo Frio. Upwelling region, Brazil: ordination of communities. In: Seeliger, U. (Ed.). Coastal plant communities of Latin America. San Diego: Academic Press. cap. 2, p. 31-50.

ZAR, J.H., 1999. Biostatistical Analysis. $4^{\text {th }}$ ed. New Jersey: Prentice-Hall. 663p. 


\section{CAPÍTULO 2}

DESCRIÇÃO E LEVANTAMENTO DA REPARTIÇÃo ESPACIAL DE POVOAMENTOS EM TRECHO DE INFRALITORAL CONSOLIDADO DA ENSEADA DAS Palmas (Parque estadual de Ilha anchieta, UBATUBA, SP) 



\section{Abstract}

Anchieta Island State Park (Ubatuba, SE Brazil) is a conservation unit exposed to anthropogenic impact (tourism). No study on descriptive community ecology, important to its monitoring, was made in the area. The objective of this study was the identification, description and the georeferenced surveying of settlements spatial repartition on an infralittoral $260 \mathrm{~m}$ stretch between Presídio and Engenho Beaches. The study area was subdivided in 3 sectors. All settlements in each sector were identified and given a descriptive file, which was inserted in a settlement database available in the internet. A GPS was used to mark four key points in the area, between which a rope containing weights and divided meter by meter was extended, along which settlements position was measured. These distance values were afterwards converted to latitude and longitude. Maximum and minimum vertical positions were measured with the aid of a depth meter. Mapping was performed in only 6 dives (in summer and in winter) of 50 to 80 minutes. Based on it, the relative frequencies of each settlement in the total area, by sector and by depth were calculated. Qualitative cluster analyses considering the sectors in both seasons and depth intervals were performed. Thirty settlements and one non-biologic attribute were identified. The category "Turf" was the most represented and the majority of settlements occurred punctually. The number of settlements and their horizontal repartition almost did not change in summer and winter in the three sectors. Some settlements were restricted to one sector, whereas others occurred in more than one, indicating a possible relation to specific ecological requirements. Sargassum Bed was more frequent in the summer (25.3\%) and Amphiroa and Jania Turf in the winter $(21.3 \%)$. In relation to vertical repartition, four main zones were delimited based in relative frequencies: a shallower one defined by Sargassum Bed, another upper intermediary defined by Amphiroa and Jania Turf, another lower intermediary defined by Ectoprocta Turf and a last one, deeper, defined by variable settlements according to season. There was a great qualitative similarity (74.7\%) among sectors in both seasons. All described settlements are characteristic of Brazilian southeast region and of São Paulo State and can be found in other studies on community ecology made in the country. This method allowed the integral mapping of the community in the area and consequently, the understanding of its structure. 


\section{RESUMO}

O Parque Estadual da Ilha Anchieta (Ubatuba, SE do Brasil) é uma unidade de conservação sujeita a impacto antrópico (turismo). Nenhum estudo de ecologia descritiva de comunidades, importante para o seu monitorame nto, foi realizado na área. Objetivou-se neste estudo a identificação, descrição e levantamento da repartição espacial georeferenciada dos povoamentos em trecho de $260 \mathrm{~m}$ do infralitoral entre as Praias do Presídio e do Engenho. A área de estudo foi subdividida em três setores. Foram identificados todos os povoamentos existentes na área e para cada um foi feita uma ficha descritiva, as quais foram inseridas em um banco de dados de povoamentos disponibilizado na Internet. Utilizou-se um GPS para marcação de pontos chave na área, entre os quais foi estendido um cabo lastrado dividido de metro em metro ao longo do qual o posicionamento dos povoamentos foi medido. Os valores de distância foram posteriormente convertidos para valores de latitude e longitude. Os posicionamentos verticais máximo e mínimo foram medidos com auxílio de um profundímetro. O mapeamento foi realizado em apenas 6 mergulhos, no verão e inverno, de 50 a 80 minutos. A partir do mapeamento calculou-se a freqüência relativa de cada povoamento para o total da área, por setor e por profundidade. Foram realizadas análises de agrupamento qualitativo considerando os setores nas duas estações e os intervalos de profundidade. Trinta povoamentos e um atributo não-biológico foram identificados e descritos. A categoria "Tapete" foi a mais representada e a maioria dos povoamentos ocorreu pontualmente. $\mathrm{O}$ número de povoamentos e a repartição horizontal dos mesmos praticamente não se alteraram entre verão e inverno nos três setores. Alguns povoamentos foram restritos a um dos setores, enquanto outros ocorreram em mais de um, indicando uma possível relação com a exigência de condições ambientais específicas. Banco de Sargassum apresentou maior freqüência relativa no verão $(25,3 \%)$ e Tapete de Amphiroa e Jania, no inverno $(21,3 \%)$. Quanto à repartição vertical, foram delimitadas quatro principais zonas baseadas na freqüência relativa: uma mais rasa definida por Banco de Sargassum, outra intermediária superior definida por Tapete de Amphiroa e Jania, outra intermediária inferior definida por Tapete de Ectoprocta e uma mais funda definida por povoamentos variáveis com a estação. Houve alta similaridade qualitativa entre os setores $(74,7 \%)$ em ambas as estações. Todos os povoamentos descritos são característicos da região sudeste do Brasil e do estado de São Paulo, e podem ser encontrados em outros trabalhos sobre ecologia de comunidades realizados no país. Este método permitiu o mapeamento integral da área de estudo e conseqüentemente, o entendimento de sua estrutura. 


\section{INTRODUÇÃO}

A necessidade atual de se obter informações mais detalhadas a respeito das populações e comunidades de substrato consolidado é alta na medida em que aumenta a procura por respostas a problemas concretos como impactos ambientais de diferentes origens, aproveitamento econômico de certos organismos e fatores determinantes da distribuição dessas populações e comunidades. Essas respostas só podem ser dadas a partir de um conhecimento dinâmico dos costões rochosos (Lewis, 1980; Villaça, 1990) e de monitorações periódicas para que se distingam alterações naturais das causadas pelo homem (Oliveira Filho, 1987). Portanto, qualquer assertiva que dependa da definição prévia da estrutura de uma comunidade estará sujeita a longos e detalhados estudos, pois caso contrário será sempre passível de incertezas e alterações (Osse, 1995).

No Brasil, há uma grande falta de dados prévios nos quais os estudos atuais possam se basear (Berchez et al., 2005) e provavelmente alterações significativas na estrutura de muitas comunidades ao longo dos anos não foram sequer relatadas. Esta falta de conhecimento a respeito das comunidades bentônicas de costão rochoso, de suas relações com o meio ambiente e de seu potencial para o homem é um problema grave para o Brasil, já que este ambiente vem sendo altamente impactado ao longo dos anos devido à ação antrópica (Tommasi, 1987), que em excesso pode diminuir a diversidade dos organismos marinhos (Tommasi, 1976) e levar à perda irreversível de informações relevantes para a ciência. A exemplo disso pode-se citar o trabalho taxonômico realizado na Baía de Santos, onde houve alteração substancial nas comunidades devido ao impacto antrópico, com uma redução do número de espécies de algas (Joly, 1957; Oliveira Filho \& Berchez, 1978; Berchez \& Oliveira, 1992). Uma série de medidas foi tomada para reduzir a poluição e provavelmente isto resultou na recuperação, pelo menos parcial, da biodiversidade (Yaobin, 1999).

O método do "Levantamento Fisionômico" (Berchez et al., 2005), que é baseado em duas escalas de heterogeneidade da paisagem dos costões rochosos, denominadas fisionomias 
e povoamentos, é uma alternativa para a descrição inicial rápida e abrangente e para o monitoramento de comunidades marinhas bentônicas de substrato consolidado. O método é dividido em quatro abordagens: Abordagem 1 - caracterização e descrição inicial dos povoamentos presentes na área de estudo e suas espécies dominantes; Abordagem 2 levantamento da distribuição espacial (horizontal e vertical) georeferenciada e temporal dos povoamentos; Abordagem 3 - avaliação quantitativa da distribuição espaço-temporal dos povoamentos; Abordagem 4 - avaliação qualitativa e quantitativa da composição específica de povoamentos selecionados para verificação da constância espaço-temporal dos mesmos, e conseqüentemente, verificação de sua eficácia como unidade não taxonômica a ser utilizada em estudos de comunidades.

A caracterização de comunidades bentônicas a partir de povoamentos é provavelmente inédita, não tendo sido encontradas referências a esse método mesmo na literatura internacional.

O estudo das comunidades marinhas bentônicas de substrato consolidado através de um método rápido e abrangente como o "Levantamento Fisionômico" em áreas como o Parque Estadual da Ilha Anchieta (PEIA) se justifica, já que a Ilha, a qual é um dos três Parques Insulares do país (criado em 1977), juntamente com o Parque Estadual da Ilha do Cardoso (criado em 1962) e o Parque Estadual da Ilha Bela (criado em 1977), é uma área de preservação sujeita a impacto ambiental devido ao grande afluxo de turistas e embarcações especialmente durante o período de verão, e seus costões rochosos, que compreendem cerca de $80 \%$ do litoral da Ilha, ainda não foram estudados. Além disso, está sendo proposta a transformação da área em um parque marinho, uma vez que no entorno da região tem sido referidas novas espécies e ocorrências, a exemplo da rodofícea Botryocladia occidentalis (Berchez \& Oliveira, 1986) e também pelo fato de ser uma importante área de desenvolvimento de juvenis de peixes, que são "exportados” para outras áreas posteriormente, e conseqüentemente, representar um importante fator de interferência nas atividades de pesca 
da região de Ubatuba (Cunnigham et al., 1996; Cunnigham \& Rocha, 1991; Furia \& Cunnigham, 1996).

Nenhum estudo sobre a ecologia das comunidades marinhas bentônicas de substrato consolidado foi realizado na área, porém há uma lista de espécies de algas elaborada por Coutinho (1974) e um estudo relacionando a diversidade da fauna e flora com o gradiente de profundidade na área costeira envolvente da ilha realizado por Nonato (1974), ambos anexados ao Plano de Manejo do Parque (Guillaumon et al., 1989). Outros estudos e teses realizados na área enfocam principalmente a fauna (Forneris, 1969; Amaral, 1977; Absher, 1982; Oliveira, 1983).

Alguns estudos descritivos foram realizados em áreas relativamente próximas à ilha, no Município de Ubatuba, e fornecem um panorama geral da estrutura das comunidades na região (Nonato \& Pérès, 1961; Oliveira Filho \& Mayal, 1976; Oliveira Filho \& Paula,1983), entretanto todos enfocam o mediolitoral.

Considerando-se o infralitoral, a partir das informações dos trabalhos realizados na região sudeste do país, mais especificamente no estado do Rio de Janeiro (Maggs et al.,1979; Teixeira et al., 1987; Amado Filho et al., 2003; Figueiredo et al., 2004 e Oigman-Pszczol et al., 2004) podemos esperar para a Ilha Anchieta, de uma maneira bem generalizada, comunidades bentônicas apresentando zonação marcada, sendo as algas predominantes nas áreas mais rasas e animais nas mais profundas, com poucas espécies dominando as faces do mosaico da paisagem (manchas). Dentre as algas, podemos esperar a presença importante dos gêneros Sargassum e Amphiroa, além de algas calcárias crostosas e dentre os animais, a presença importante de cnidários, como Palythoa e Siderastrea, e de esponjas. Fora estes, também podemos esperar a presença, porém de forma menos importante, de briozoários, equinodermos e de ascídias.

Em função da importância da área e desta necessidade de estudos, iniciou-se em 2002 um trabalho de caracterização das comunidades da Enseada das Palmas (Biota/FAPESP n. 
02/07412-8), a qual foi dividida em 3 sub-áreas, sendo que a Área 1, situada entre a Praia do Presídio e Praia do Engenho, teve o mediolitoral estudado quanto às Abordagens 1 e 2 do método "Levantamento Fisionômico" e o infralitoral quanto às Abordagens 1, 2, 3 e 4. Os resultados referentes à Abordagem 1 do medio e infralitoral foram submetidos à publicação no Journal of Experimental Marine Biology and Ecology (Berchez et al., sendo revisto para ressubmissão), sendo que os resultados do infralitoral são apresentados no presente capítulo juntamente com os resultados da Abordagem 2.

\section{OBJETIVOS}

Este estudo objetiva caracterizar os povoamentos em um trecho de aproximadamente 260m do infralitoral da Enseada das Palmas (Parque Estadual da Ilha Anchieta) e verificar quais espécies são dominantes em cada um deles (Abordagem 1 do método "Levantamento Fisionômico"). Além disso, pretende avaliar a repartição horizontal georeferenciada e a amplitude vertical máxima destes povoamentos (Abordagem 2).

\section{Material e Métodos}

\section{Local}

O estudo foi realizado no costão leste da Praia do Presídio, na Enseada da Palmas (Área 1 - Figura 2.1a), Parque Estadual de Ilha Anchieta (Decreto Estadual 9629 de 29/03/77), litoral norte do Estado de São Paulo (23 32' $18.6^{\prime}$ 'S $45^{\circ} 03^{\prime} 51.0^{\prime \prime} \mathrm{W}$ até $23^{\circ} 32^{\prime}$ 11.5 'S $45^{\circ} 03$ ' 45.5”W).

A Ilha Anchieta é a segunda maior ilha do litoral norte do Estado de São Paulo, possuindo 828 hectares de área (Vieitas, 1995).

Tendo em vista os objetivos propostos e a metodologia utilizada, realizou-se a amostragem de um trecho de substrato consolidado situado entre a Praia do Presídio e a Praia do Engenho, com aproximadamente 260m, ao invés do estabelecimento de estações de coleta. 
O trecho foi subdividido em três setores (Figura 2.1b), de acordo com as características do substrato e profundidade. O Setor 1 é caracterizado por substrato fragmentado, inclinação de aproximadamente $30^{\circ}$, profundidade máxima de $2,0 \mathrm{~m}$ e $50 \mathrm{~m}$ de extensão; o Setor 2 é um paredão com inclinação de $90^{\circ}$ até $2,0 \mathrm{~m}$ de profundidade e inclinação de aproximadamente $110^{\circ}$ de 2,0 a 3,6 m, que é sua profundidade máxima, e possui $150 \mathrm{~m}$ de extensão; finalmente o Setor 3 também é fragmentado, com inclinação de $30^{\circ}$, sombreamento pela manhã, profundidade máxima de 2,0 m e extensão de $60 \mathrm{~m}$.
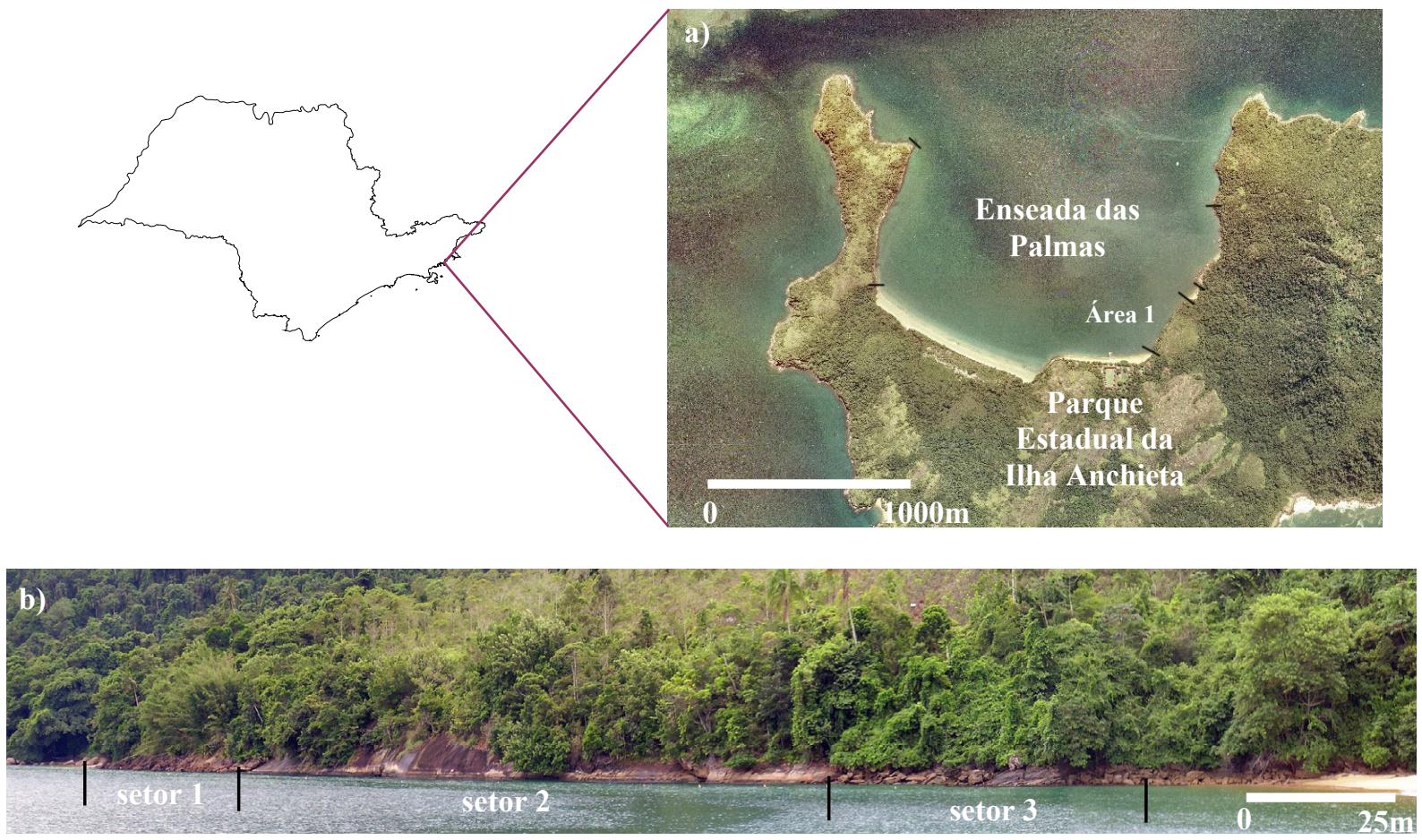

Figura 2.1 - a) Enseada das Palmas (Parque Estadual da Ilha Anchieta, Ubatuba, São Paulo) destacada a partir do mapa do Estado de São Paulo e detalhe da área (Área 1) de estudo (Fonte: UNESP - Faculdade de Engenharia Cartográfica), b) Área 1 e os setores em que foi dividida.

\section{1) Avaliação dos povoamentos existentes no local}

Foram realizados mergulhos de reconhecimento no local, nos quais foram listados todos os povoamentos que puderam ser discriminados visualmente (Dethier et al., 1993). Para cada um, selecionou-se um local dentro da área amostrada em que ele se apresentasse mais característico e posteriormente foi confeccionada uma ficha com sua descrição, contendo uma foto do povoamento, a relação dos organismos dominantes, ou seja, aqueles cuja soma corresponde a $80 \%$ ou mais do recobrimento do povoamento (Foster et al., 1991), nível de 
ocorrência superior e inferior em relação ao 0.0 de maré, posicionamento em relação a outros povoamentos, ambiente e possíveis variações encontradas. Os organismos dominantes foram coletados para a confecção de uma coleção de referência e para identificação quando necessário. Não foram consideradas as espécies epífitas.

Os dados obtidos foram armazenados no "Banco de dados eletrônico de povoamentos" disponível na internet no endereço: http://www.ib.usp.br/fisionomia.

\section{2) Repartição espacial georeferenciada dos povoamentos}

Para cada povoamento encontrado foi determinada a distribuição horizontal em termos de latitude e longitude com o auxílio de um GPS Garmin modelo eTrex, configurado com o datum de Córrego Alegre, sendo determinados quatro pontos principais: um no começo, dois intermediários e um no fim da área. A partir destes, visando reduzir a imprecisão inerente ao posicionamento por GPS, foi utilizado um cabo marcado de metro em metro estendido ao longo do costão para as medidas, posteriormente convertidas para latitude e longitude (Anexo - Tabela A2.1). Foram realizados seis mergulhos na área em cada estação (verão e inverno de 2005). A profundidade de todo o trecho foi medida e a presença dos povoamentos foi analisada de 5 em 5m (Anexo - Figuras A2.1 e A2.2). Neste caso, não foi analisada a presença de atributos não biológicos (Região de Substrato Inconsolidado ou Consolidado). Baseandose nestes dados, construiu-se um mapa esquemático da área, a partir do qual foi possível calcular a freqüência relativa de cada um dos povoamentos em cada setor e para o total da área de estudo, sendo: $\mathrm{FR}=\mathrm{n}_{\mathrm{oc}}$ povoamento/ $\mathrm{n}_{\mathrm{oc}}$ total, onde $\mathrm{FR}=$ freqüência relativa e $\mathrm{n}_{\mathrm{oc}}=$ número de ocorrências.

A partir deste mapa também foi possível calcular a FR dos povoamentos em relação à distribuição vertical, sendo que o costão foi subdividido em 7 intervalos de profundidade $(0,0$ $0,5 \mathrm{~m} ; 0,5-1,0 \mathrm{~m} ; 1,0-1,5 \mathrm{~m} ; 1,5-2,0 \mathrm{~m} ; 2,0-2,5 \mathrm{~m} ; 2,5-3,0 \mathrm{~m}$ e $3,0-3,5 \mathrm{~m})$, a partir dos quais zonas biológicas foram identificadas na área de estudo. 


\section{3) Repartição espacial em modo $R$}

Para a análise em modo $\mathrm{R}$, foram utilizados os dados qualitativos (presença e ausência) dos povoamentos nos diferentes setores (1, 2 e 3 ) nas diferentes estações (verão e inverno) para a verificação da similaridade entre os mesmos. O descritor de heterogeneidade utilizado foi o índice de similaridade de Dice-Sørensen.

$$
\mathrm{S}_{\mathrm{S} \varnothing \mathrm{R}}=\frac{2 c}{a+b+2 c}
$$

Onde: $\mathrm{a}=$ número de elementos exclusivos da amostra a $\mathrm{b}=$ número de elementos exclusivos da amostra $\mathrm{b}$ $\mathrm{c}=$ número de elementos comuns às duas amostras

Foram produzidos dendrogramas pela estratégia da média ponderada - WPGMA- que nivela os pesos dos grupos de diferentes tamanhos nas sucessivas fusões e assegura espaçoconservação (Legendre \& Legendre, 1984).

A definição de grupos com a utilização de setores como unidade (modo R) possibilitou destacar a homogeneidade dos mesmos em termos de composição de povoamentos nas duas estações estudadas. Adotou-se como nível crítico de fusão dos elementos a similaridade de $75 \%$, que fornece um balanceamento entre excesso e escassez de exigência para a formação de grupos homogêneos. 


\section{RESULTADOS}

\section{1) Relação e descrição dos povoamentos existentes no local}

\section{1) Definição das categorias de povoamentos}

Tendo em vista a inexistência de um padrão relativo à categorização de povoamentos, foram propostas neste trabalho, e no correspondente enviado para publicação (Berchez et al., em revisão), as seguintes categorias: Banco, Colônia, Crosta, Tapete e Região.

"Tapete" se refere aos povoamentos constituídos por organismos filamentosos pequenos de uma ou mais espécies, densamente agrupados, freqüentemente emaranhados, cobrindo completamente o substrato.

"Banco" engloba grupos de organismos cujos indivíduos podem ser diferenciados uns dos outros, freqüentemente deixando algum espaço vazio entre eles. Os indivíduos são maiores e menos associados que nos tapetes, correspondendo a algas com talo gelatinoso cilíndrico e animais como os bivalves e cracas.

"Colônia" é atribuído a grupos de indivíduos da mesma espécie vivendo em íntima associação, cada colônia ocupando uma porção significativa do substrato, permitindo sua distinção como um aspecto definido da paisagem. Em casos nos quais o povoamento é resultado de grupos de colônias individuais, um nome de categoria diferente foi atribuído, como para o Tapete de Ectoprocta.

"Crosta" é usado para designar povoamentos dispostos de maneira achatada e próxima ao substrato, às vezes calcificadas e fortemente aderentes.

Finalmente, "Região" é empregado para designar áreas de substrato onde o espaço vazio é o atributo principal, às vezes com espécies características com baixo recobrimento percentual que podem ser usadas para sua distinção dos demais aspectos da paisagem.

\section{2) Descrição dos povoamentos}

Levando em consideração que este é o primeiro trabalho a apresentar resultados relativos ao método "Levantamento Fisionômico", são apresentadas aqui, bem como no 
trabalho correspondente enviado para publicação (Berchez et al., em revisão), as descrições iniciais dos povoamentos. Estas descrições também estão inseridas em um banco de dados de povoamentos, disponível no endereço eletrônico http://www.ib.usp.br/fisionomia.

Povoamento 1 - Banco de Asparagopsis (Figura 2.2)

Espécies/UTOs dominantes: Asparagopsis taxiformis (Delile) Trevisan e substrato inconsolidado.

Descrição: manchas rosadas ou faixas de algas vermelhas, com algum espaço não ocupado entre os indivíduos, freqüentemente recoberto por silte e areia. Rhodophyta dominante apresenta talo de aspecto piramidal, sendo constituído por eixo principal cilíndrico, com abundante ramificação verticilada.

Ambiente: face superior de rochas situadas no infralitoral; irradiância alta e hidrodinamismo intermediário a alto.

Níveis extremos de ocorrência (em relação ao 0.0 de maré): inferior: (-) 1.5 superior: 0.0

Posição: acima do povoamento Tapete de Ectoprocta e abaixo de povoamentos variáveis.

Observações: a fase alternante do ciclo de vida (Falkenbergia hillebrandii) forma outro povoamento (Tapete de Falkenbergia).

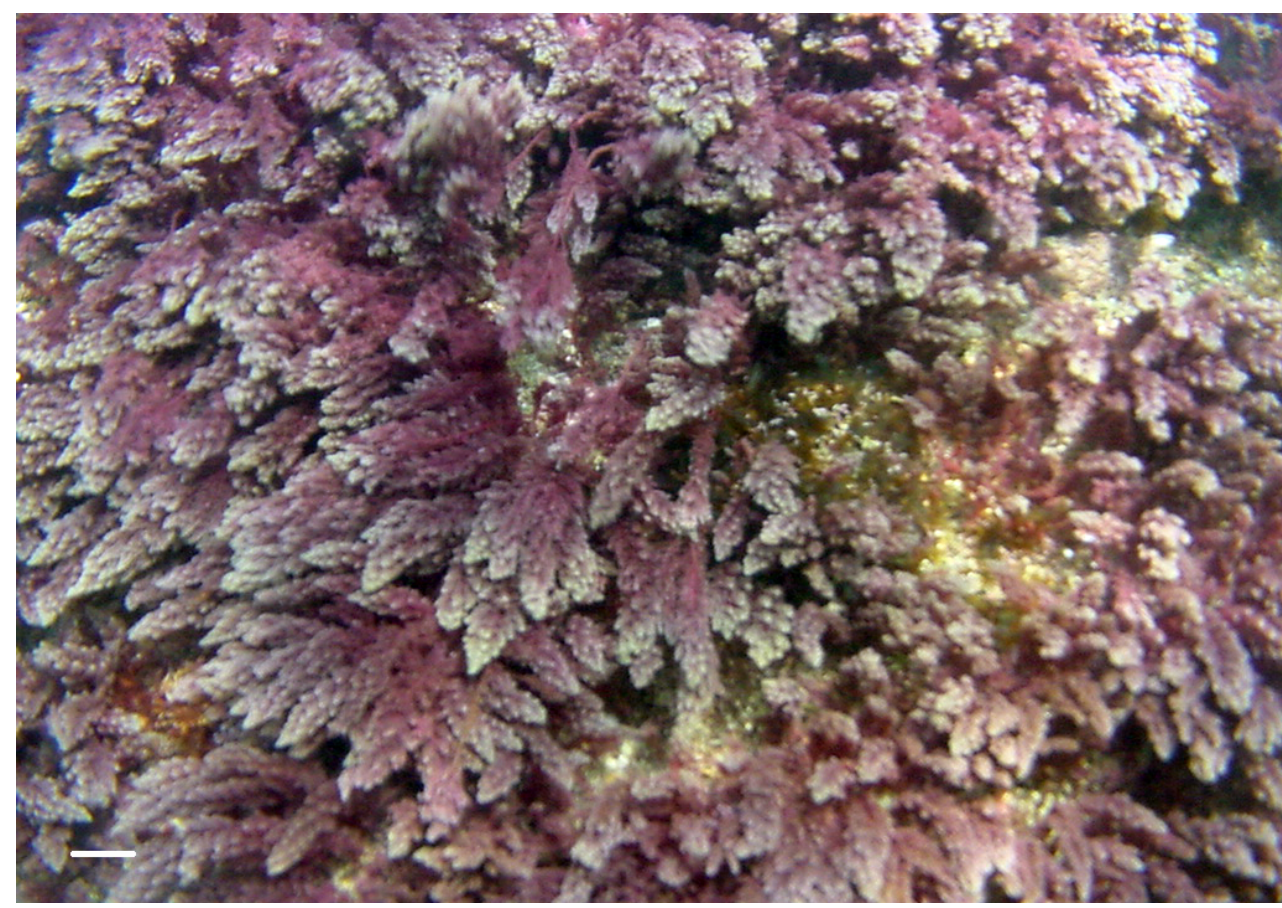

Figura 2.2 - Povoamento Banco de Asparagopsis. Barra horizontal=2 cm. 
Povoamento 2 - Banco de Caulerpa (Figura 2.3)

Espécies/UTOs dominantes: Caulerpa racemosa (Forsskål) J. Agardh var. racemosa

Descrição: manchas isoladas de cor verde claro, com indivíduos deixando pouco espaço entre eles, o qual é coberto por areia ou silte ou ocupado por outros povoamentos. Chlorophyta dominante com eixo principal estolonífero prostrado a partir dos quais se desenvolvem frondes eretas contendo agrupamentos de ramos com aspecto de cachos de uva.

Ambiente: paredes verticais ou em faces de rocha voltadas diretamente para o mar aberto, no limite inferior do mediolitoral ou infralitoral; hidrodinamismo médio a alto e irradiância alta.

Níveis extremos de ocorrência (em relação ao 0.0 de maré): inferior: (-)1.5 superior: (-)0.6

Posição: acima dos povoamentos Tapete de Ectoprocta e Tapete de Amphiroa e Jania e abaixo do povoamento Banco de Sargassum.

Observações: tendo em vista a indefinição da literatura, as variedades dentro da espécie Caulerpa racemosa são incluídas dentro do mesmo povoamento.

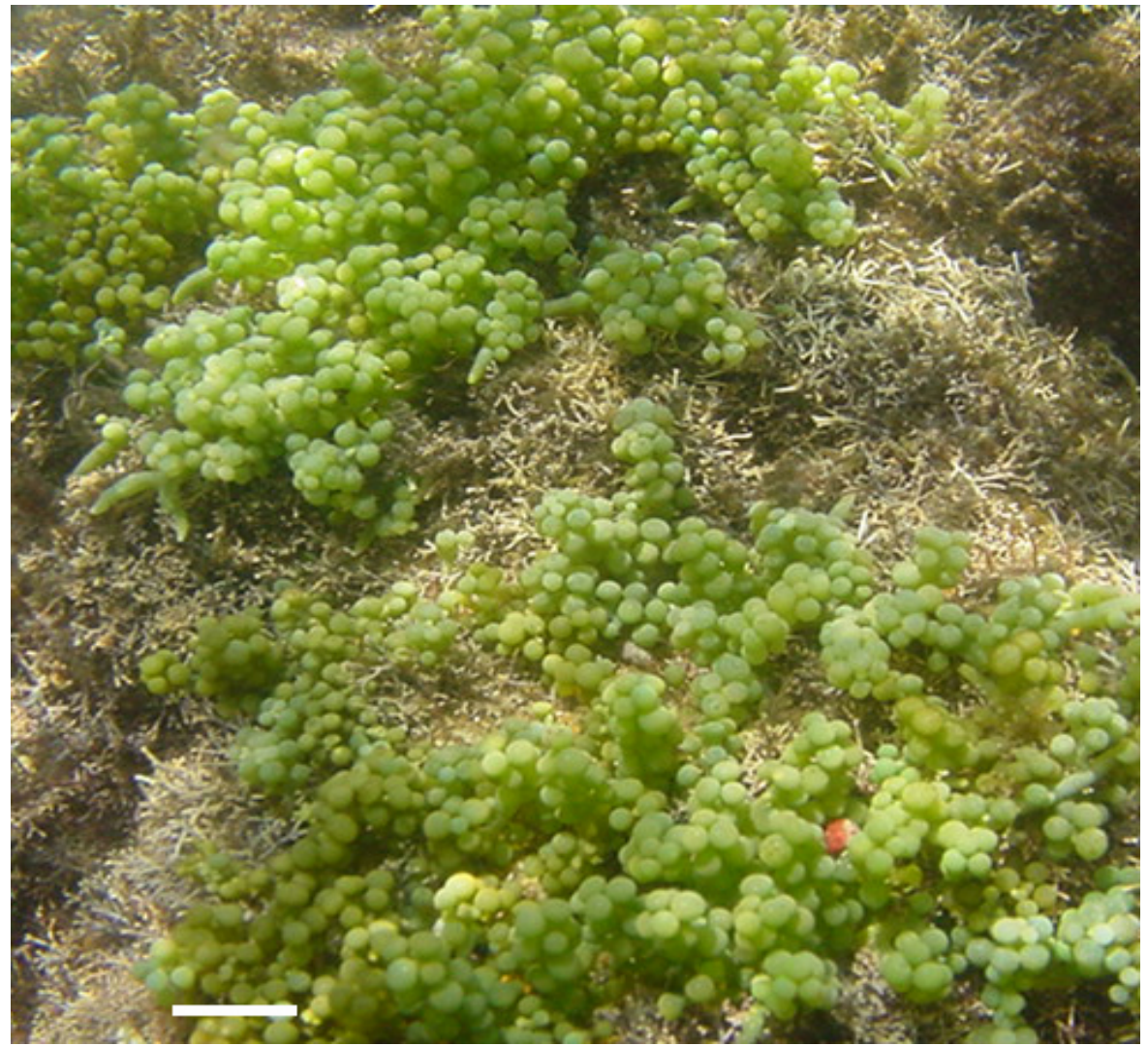

Figura 2.3 - Povoamento Banco de Caulerpa. Barra horizontal=2 cm. 


\section{Povoamento 3 - Banco de Colpomenia (Figura 2.4)}

Espécies/UTOs dominantes: Colpomenia sinuosa (Roth) Derbès \& Solier

Descrição: manchas isoladas de cor parda, formadas por algas com talo globoso, caracteristicamente oco, em forma de vesícula, densamente justapostas, cobrindo completamente o substrato, mas nunca formando zonas definidas. Phaeophyta dominante globosa a irregularmente expandida com diâmetro variando de 2,0-8,0 cm.

Ambiente: porção superior de blocos de rocha do infralitoral; hidrodinamismo intermediário e irradiância baixa a intermediária.

Níveis extremos de ocorrência (em relação ao 0.0 de maré): inferior: (-)2.2 superior: 0.0

Posição: acima dos povoamentos Tapete de Ectoprocta e Crosta de Corallinaceae e abaixo do povoamento Banco de Sargassum.

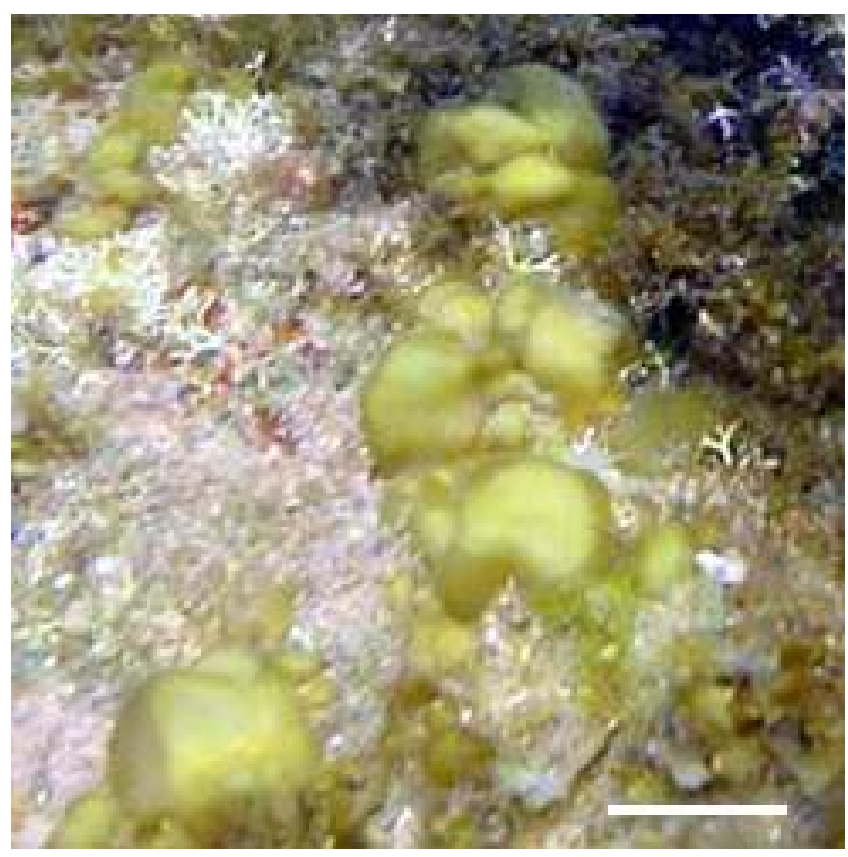

Figura 2.4 - Povoamento Banco de Colpomenia. Barra horizontal=2 cm. 
Povoamento 4 - Banco de Dichotomaria (Figura 2.5)

Espécies/UTOs dominantes: Dichotomaria marginata (Ellis \& Solander) Lamarck

Descrição: manchas de coloração vermelha a rosa claro ou então esbranquiçadas de algas vermelhas formando densos tufos, cobrindo completamente o substrato. Rhodophyta dominante achatada, com até $25,0 \mathrm{~cm}$ de comprimento.

Ambiente: predominantemente na face superior de pedras ou em locais próximos ao fundo arenoso (em alguns casos encontrava-se coberto com lodo); hidrodinamismo baixo a intermediário e irradiância intermediária a alta.

Níveis extremos de ocorrência (em relação ao 0.0 de maré): inferior: (-)2.3 superior: (-)1.4

Posição: acima do povoamento Região de Substrato Inconsolidado e abaixo do povoamento Banco de Sargassum.

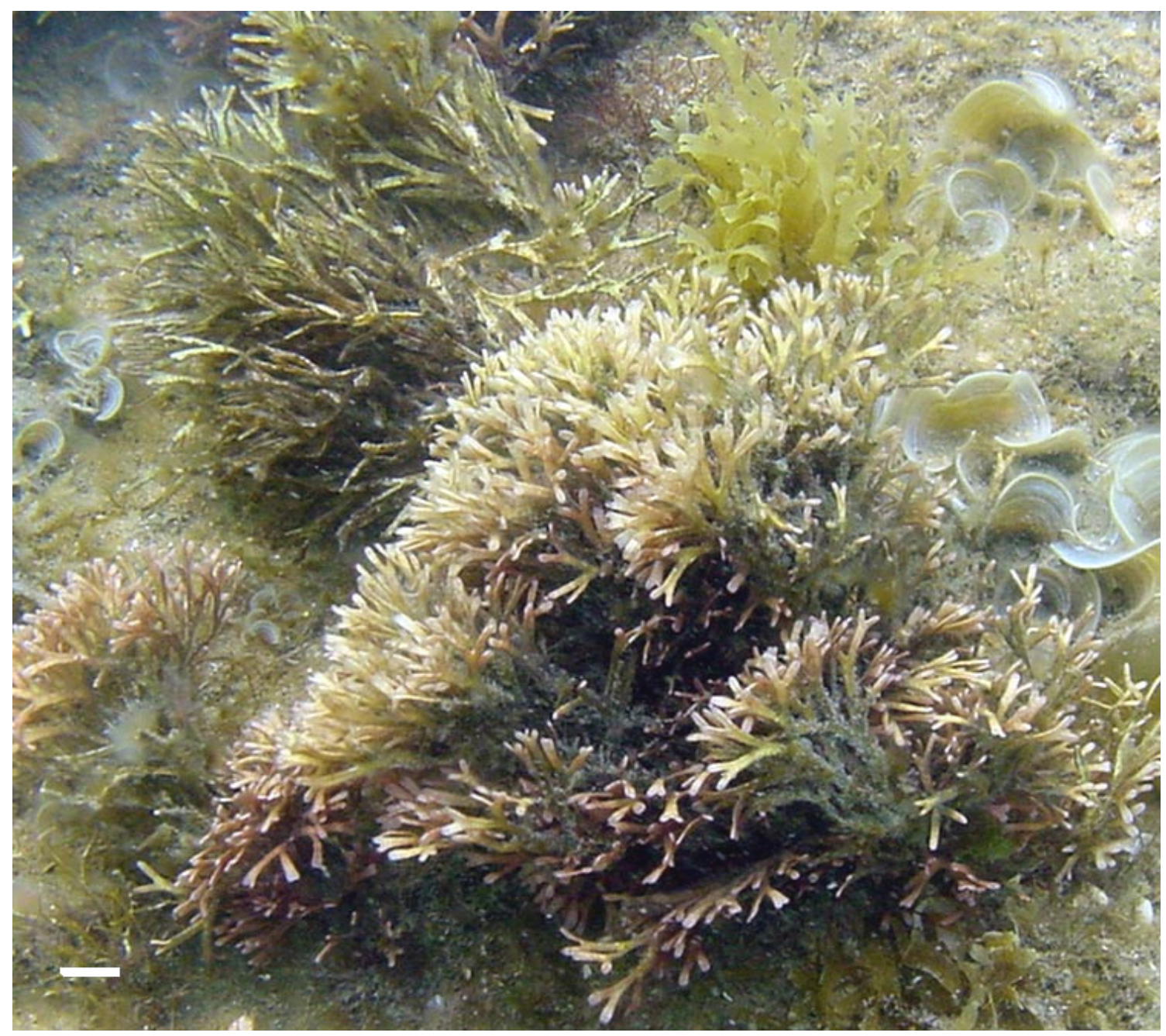

Figura 2.5 - Povoamento Banco de Dichotomaria. Barra horizontal=2 cm. 


\section{Povoamento 5 - Banco de Dictyota (Figura 2.6)}

Espécies/UTOs dominantes: Dictyota menstrualis (Hoyt) Schnetter, Hörning \& WeberPeukert

Descrição: manchas de algas de coloração pardo-amarelada com indivíduos esparsos, às vezes sobre outros povoamentos. Phaeophyta dominante delicada, com forma de fita e ramificação dicotômica evidente, com tamanho variando entre 3,0-15,0 cm.

Ambiente: face protegida das rochas próximas ao fundo arenoso no infralitoral; hidrodinamismo baixo e irradiância baixa a intermediária.

Níveis extremos de ocorrência (em relação ao 0.0 de maré): inferior: (-)2.0 superior: (-)1.5

Posição: acima do povoamento Tapete de Ectoprocta e abaixo do povoamento Banco de Sargassum.

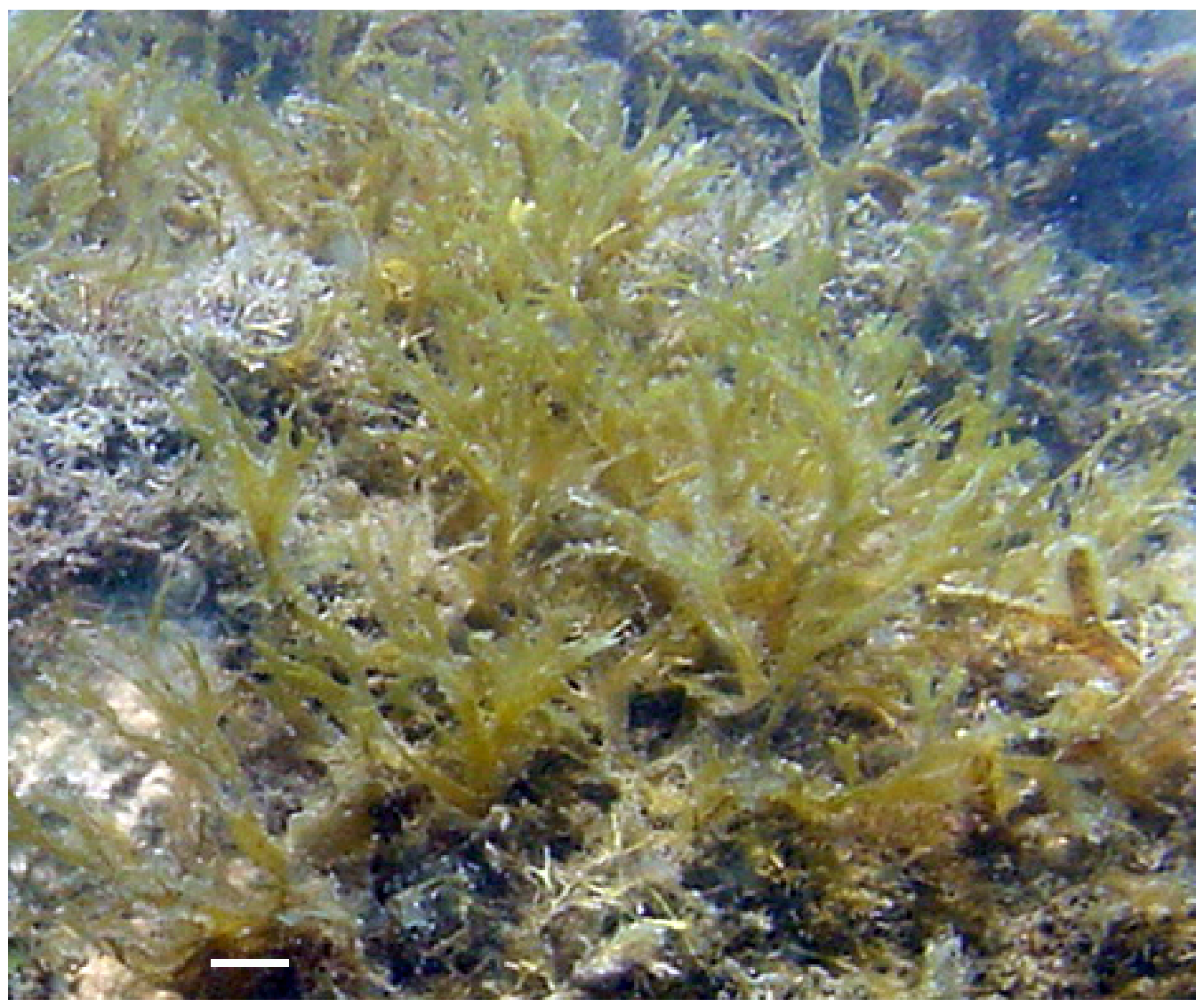

Figura 2.6 - Povoamento Banco de Dictyota. Barra horizontal $=2 \mathrm{~cm}$. 
Povoamento 6 - Banco de Padina (Figura 2.7)

Espécies/UTOs dominantes: Padina gymnospora (Kützing) Sonder

Descrição: manchas pardo amareladas de algas pardas com talo laminar caracteristicamente em forma de ventarola, cobrindo completamente o substrato. Phaeophyta dominante com talo apresentando margem externa enrolada e com evidentes linhas concêntricas, calcificado ou não, com tamanho variando entre 5,0 e $25,0 \mathrm{~cm}$.

Ambiente: geralmente próximo ao fundo arenoso, em locais pouco profundos com certo grau de agitação de partículas no fundo, o que leva ao recobrimento parcial das frondes da alga por areia; hidrodinamismo baixo e irradiância baixa a intermediária.

Níveis extremos de ocorrência (em relação ao 0.0 de maré): inferior: (-)2.4 superior: (-)1.4

Posição: acima do povoamento Região de Substrato Inconsolidado e abaixo dos povoamentos Banco de Sargassum e Banco de Dichotomaria.

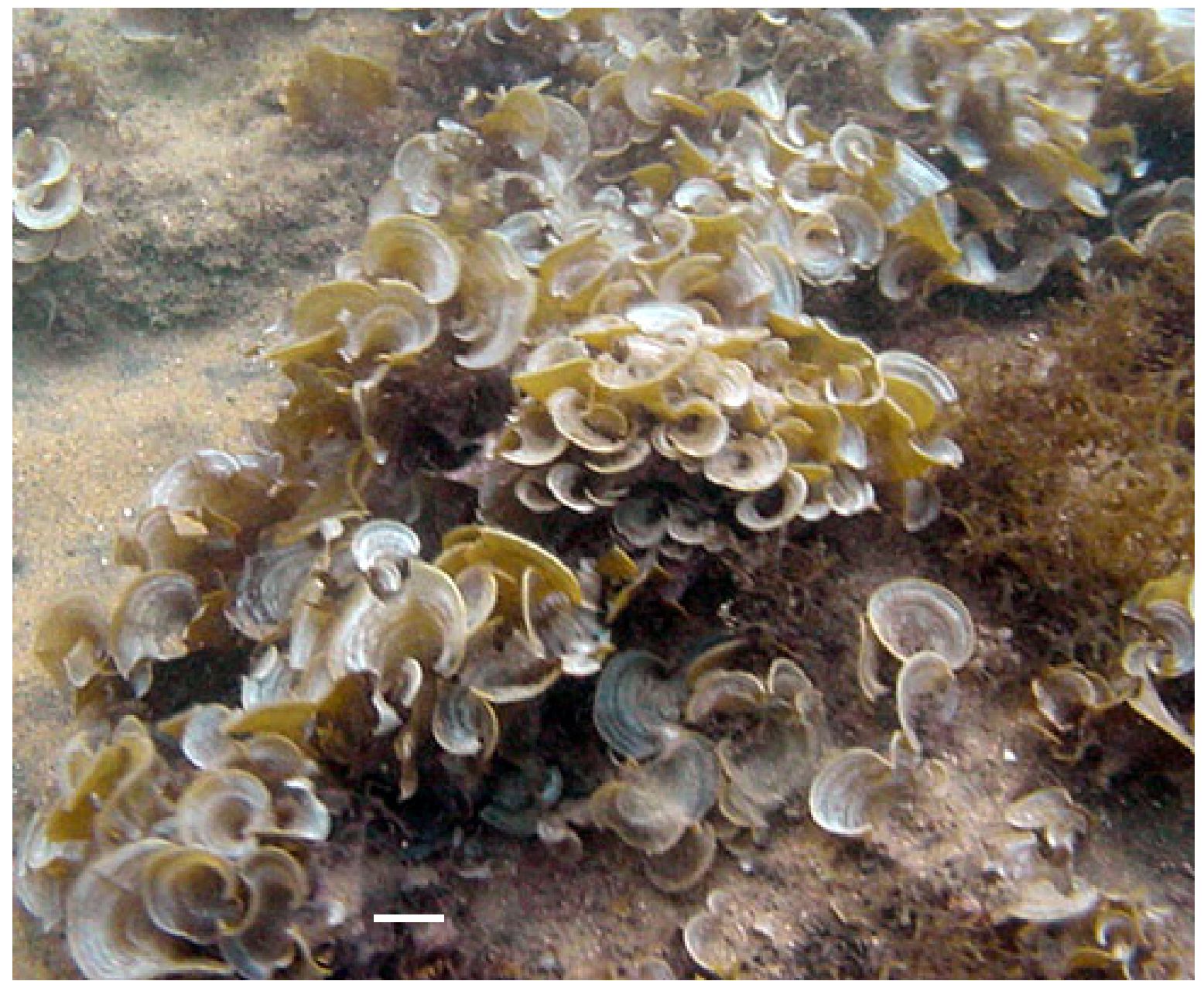

Figura 2.7 - Povoamento Banco de Padina. Barra horizontal $=2 \mathrm{~cm}$. 
Povoamento 7 - Banco de Sargassum (Figura 2.8)

Espécies/UTOs dominantes: Sargassum vulgare C. Agardh var. vulgare e Sargassum filipendula C. Agardh

Espécies associadas características: Tedania ignis (Duchassaing \& Michelotti, 1864), Caulerpa racemosa (Forsskål) J. Agardh, Dictyota cervicornis Kütz., Corallinaceae.

Descrição: bancos de algas pardas formando zonas definidas, com indivíduos deixando espaço vazio entre os talos, o qual pode ser ocupado por outros organismos não dominantes, principalmente coralináceas incrustantes. Phaeophyta dominante com ramos achatados com aspecto de folhas e eventualmente vesículas globosas destinadas à flutuação presas a um eixo central cilíndrico. Os talos chegam a medir até $60,0 \mathrm{~cm}$ de altura. Propiciam sobre o talo espaço ocupado por uma grande variedade de epífitos (briozoários crostosos, Dictyopteris delicatula, Falkenbergia hillebrandii, Hypnea musciformis e Sertularia sp.).

Ambiente: face superior ou lateral das rochas, direta ou lateralmente voltadas para o mar; hidrodinamismo médio a alto e irradiância alta.

Níveis extremos de ocorrência (em relação ao 0.0 de maré): inferior: (-)2.8 superior: 0.0

Posição: acima e abaixo de povoamentos muito variáveis.

Observações: as espécies de Sargassum encontradas apresentavam-se misturadas, demonstrando dividir habitats ecológicos similares e, portanto, não sendo possível a diferenciação em dois povoamentos distintos.

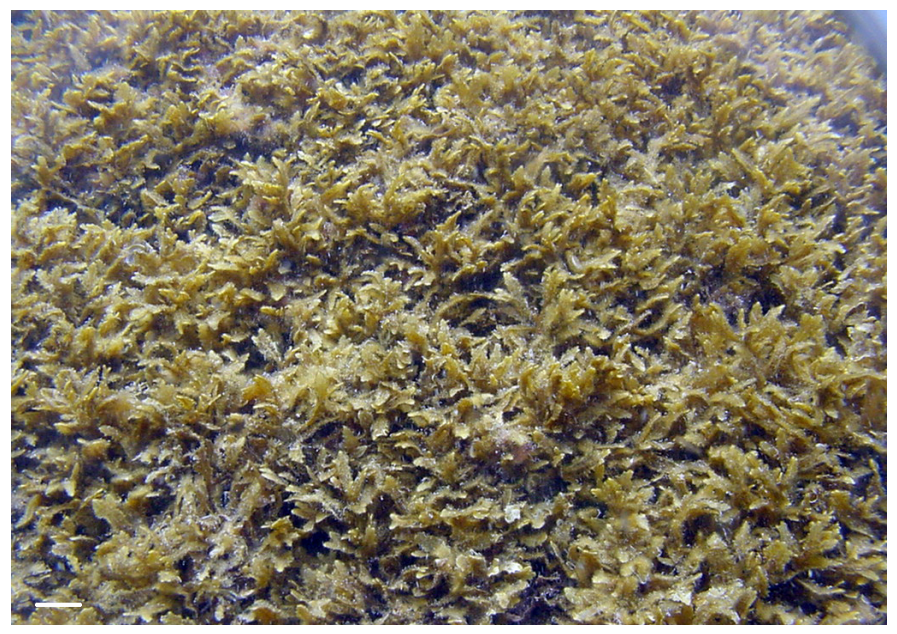

Figura 2.8 - Povoamento Banco de Sargassum. Barra horizontal=2 cm. 


\section{Povoamento 8 - Banco de Tropiometra (Figura 2.9)}

Espécies/UTOs dominantes: Tropiometra carinata carinata (Lamark,1816) A.H. Clark, 1907

Descrição: manchas isoladas formadas por grupos de crinóides de coloração marrom, amarelo escura ou preta, deixando espaço livre entre os indivíduos, que se destacam de outros povoamentos devido aos seus longos braços. Como são vágeis, sua presença pode representar uma característica efêmera da comunidade. Echinodermata dominante apresenta corpo em forma de tubo ao qual braços pinados, radiais e flexíveis são conectados.

Ambiente: sobre blocos de rochas, presente próximo de fundos lodosos, onde a própria rocha se encontra recoberta por uma camada de sedimento, às vezes como única espécie presente. Também freqüente em fendas nas rochas em níveis mais distantes do fundo; hidrodinamismo intermediário e irradiância baixa.

Níveis extremos de ocorrência (em relação ao 0.0 de maré): inferior: (-)3.4 superior: (-)1.7 Posição: acima e abaixo de povoamentos variáveis, geralmente no mesmo nível de Crosta de Amphimedon e Tapete de Ectoprocta.

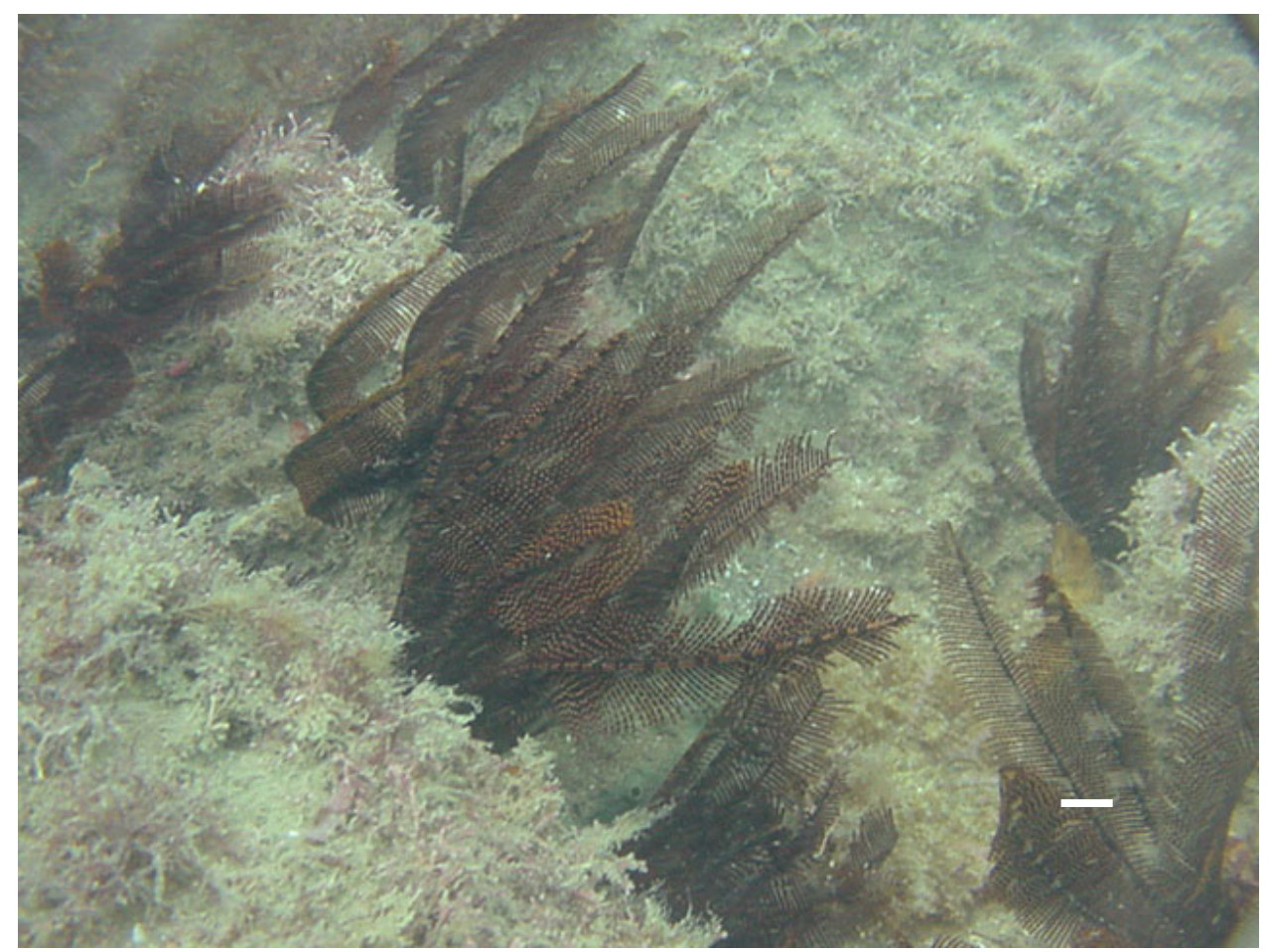

Figura 2.9 - Povoamento Banco de Tropiometra. Barra horizontal=2 cm. 


\section{Povoamento 9 - Colônia de Didemnum (Figura 2.10)}

Espécies/UTOs dominantes: Didemnum speciosum (Herdman, 1886)

Descrição: manchas isoladas de colônias de ascídias de coloração branca, de consistência gelatinosa, completa e homogeneamente cobrindo o substrato. Chordata dominante séssil, colonial, firme ao tato, com zoóides com 1,0-1,5 mm de diâmetro, formando colônias de tamanho variável.

Povoamentos relacionados: Colônia de Symplegma (Figura 2.13).

Ambiente: face lateral das rochas, protegida do embate das ondas, geralmente próximo ao fundo arenoso; irradiância baixa.

Níveis extremos de ocorrência (em relação ao 0.0 de maré): inferior: (-)2.2 superior: (-)0.4

Posição: no mesmo nível do povoamento Banco de Sargassum e Tapete de Ectoprocta.

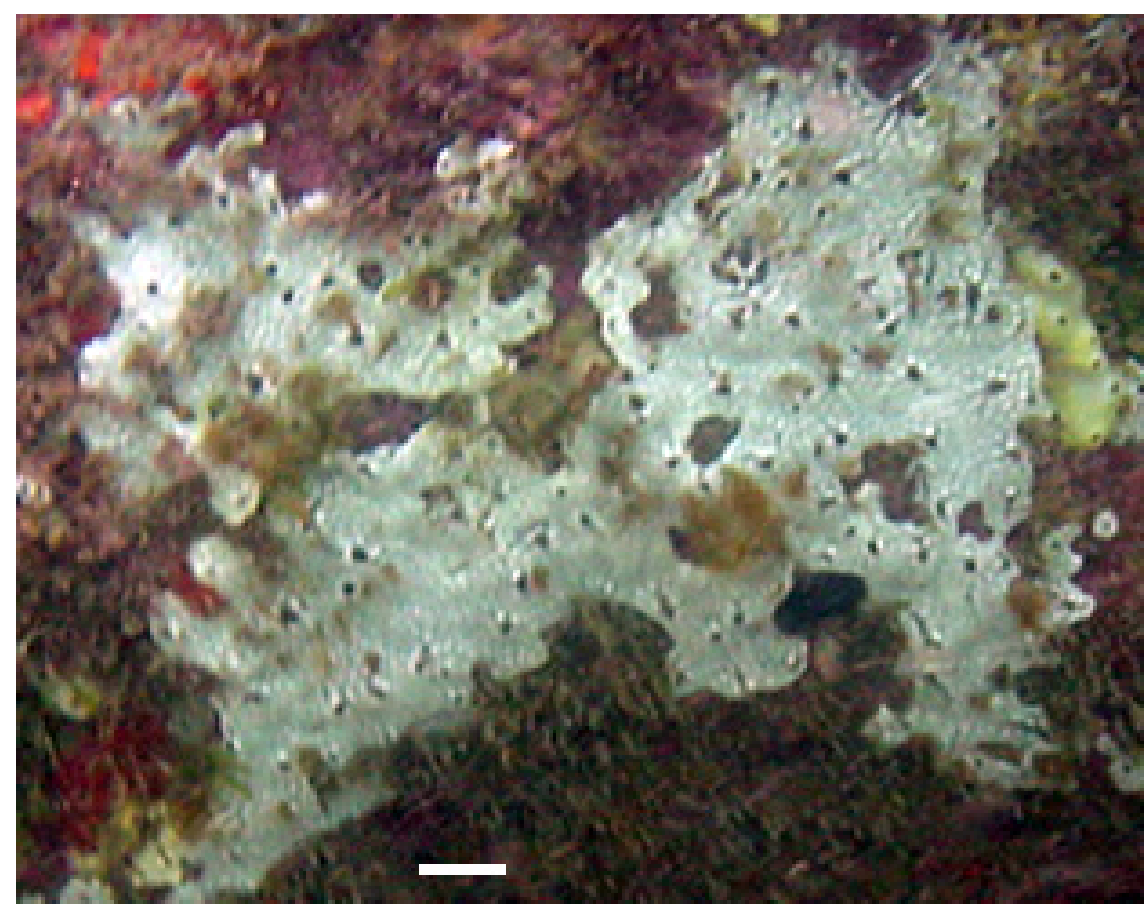

Figura 2.10 - Povoamento Colônia de Didemnum. Barra horizontal=2 cm. 
Povoamento 10 - Colônia de Mussismilia (Figura 2.11)

Espécies/UTOs dominantes: Mussismilia hispida (Verril, 1868)

Descrição: manchas isoladas de coral com formato globoso, com superfície apresentando aspecto sinuoso lembrando um cérebro, de cor verde-amarronzado, cobrindo completamente o substrato. O esqueleto calcário de colônias mortas apresenta coloração cinza clara ou branca. Cnidaria escleractíneo dominante forma colônias globosas maciças, com menos de 0,5 m de diâmetro, geralmente achatadas, com indivíduos circulares apresentando paredes grossas, com 10,0-15,0 mm de diâmetro.

Ambiente: Ocorrem em regiões rasas do infralitoral, onde o fundo de areia é alcançado em profundidades inferiores a $3 \mathrm{~m}$, com hidrodinamismo intermediário a baixo e irradiância intermediária.

Níveis extremos de ocorrência (em relação ao 0.0 de maré): inferior: (-)0.8 superior: (-)0.6

Posição: acima do povoamento Tapete de Gelidiopsis e Hypnea e abaixo dos povoamentos Tapete de Amphiroa e Jania e Tapete de Ectoprocta.

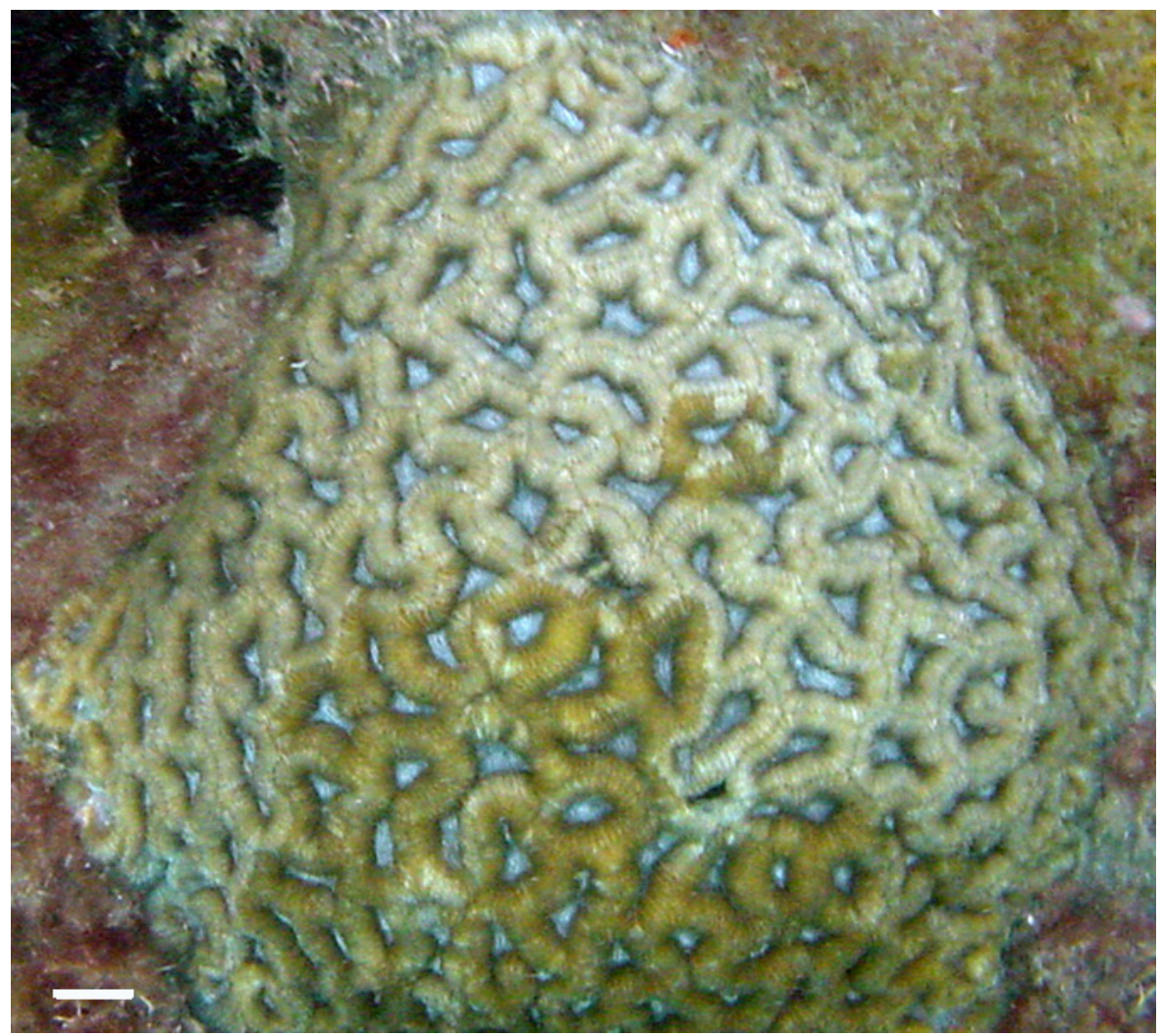

Figura 2.11 - Povoamento Colônia de Mussismilia. Barra horizontal=2 cm. 
Povoamento 11 - Colônia de Palythoa (Figura 2.12)

Espécies/UTOs dominantes: Palythoa caribaeorum (Duchassaing e Michelotti, 1860).

Descrição: colônias de coloração laranja até marrom, formadas por zoantídeos coloniais incrustantes, caracteristicamente recobertas por muco, o que lhe confere o nome popular de "baba-de-boi", recobrindo completa e homogeneamente grandes porções do substrato e formando faixas junto à superfície da água. Cnidaria dominante séssil, com indivíduos densamente agrupados, conectados por um cenênquima.

Ambiente: locais rasos, no limite inferior do mediolitoral e infralitoral; hidrodinamismo médio a baixo e irradiância média a alta.

Níveis extremos de ocorrência (em relação ao 0.0 de maré): inferior: (-)2.0 superior: (-)0.5

Posição: acima do povoamento Tapete de Ectoprocta e abaixo dos povoamentos Tapete de Amphiroa e Jania e Banco de Sargassum.

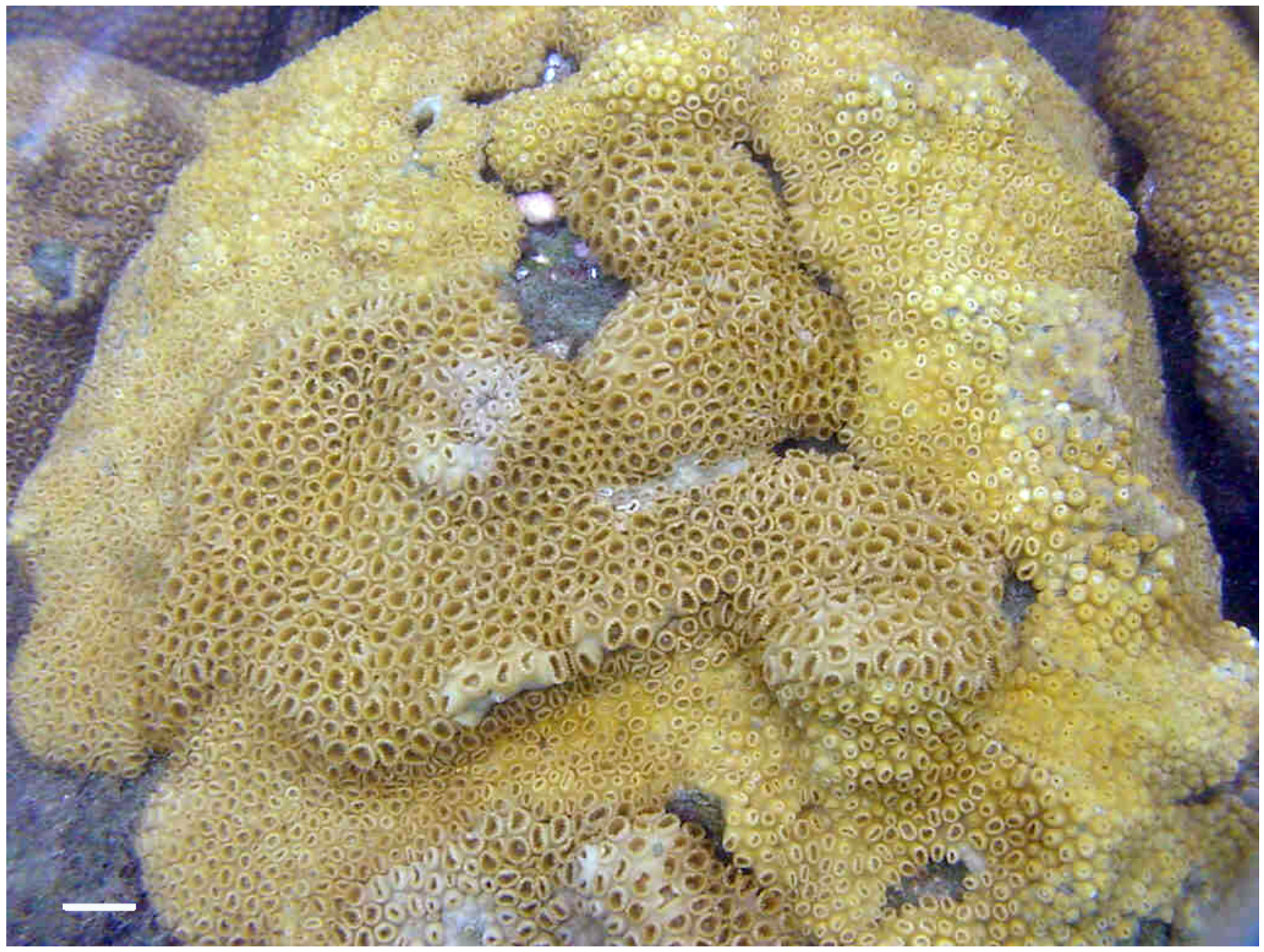

Figura 2.12 - Povoamento Colônia de Palythoa. Barra horizontal=2 cm. 
Povoamento 12- Colônia de Schizoporella (Figura 2.13)

Espécies/UTOs dominantes: Schizoporella unicornis (Johnston, 1847).

Descrição: manchas laranja intenso ou vermelho enegrecido de Ectoprocta coloniais ocorrendo como crostas cobrindo completamente o substrato, às vezes apresentando porções eretas. Colônias do Ectoprocta dominante calcificadas, em forma de disco, incrustantes, com até $10,0 \mathrm{~cm}$ de largura, com porções eretas ausentes nas formas imaturas e presentes nas maduras, com a superfície com muitos poros, que correspondem aos zoóides, os quais são aproximadamente retangulares, apresentando uma abertura circular.

Ambiente: face lateral de rochas situadas no infralitoral e na franja do infralitoral; hidrodinamismo baixo a intermediário e irradiância variável.

Níveis extremos de ocorrência (em relação ao 0.0 de maré): inferior: (-)3.4 superior: (-)1.8

Posição: acima do povoamento Tapete de Ectoprocta e abaixo de diversos povoamentos.

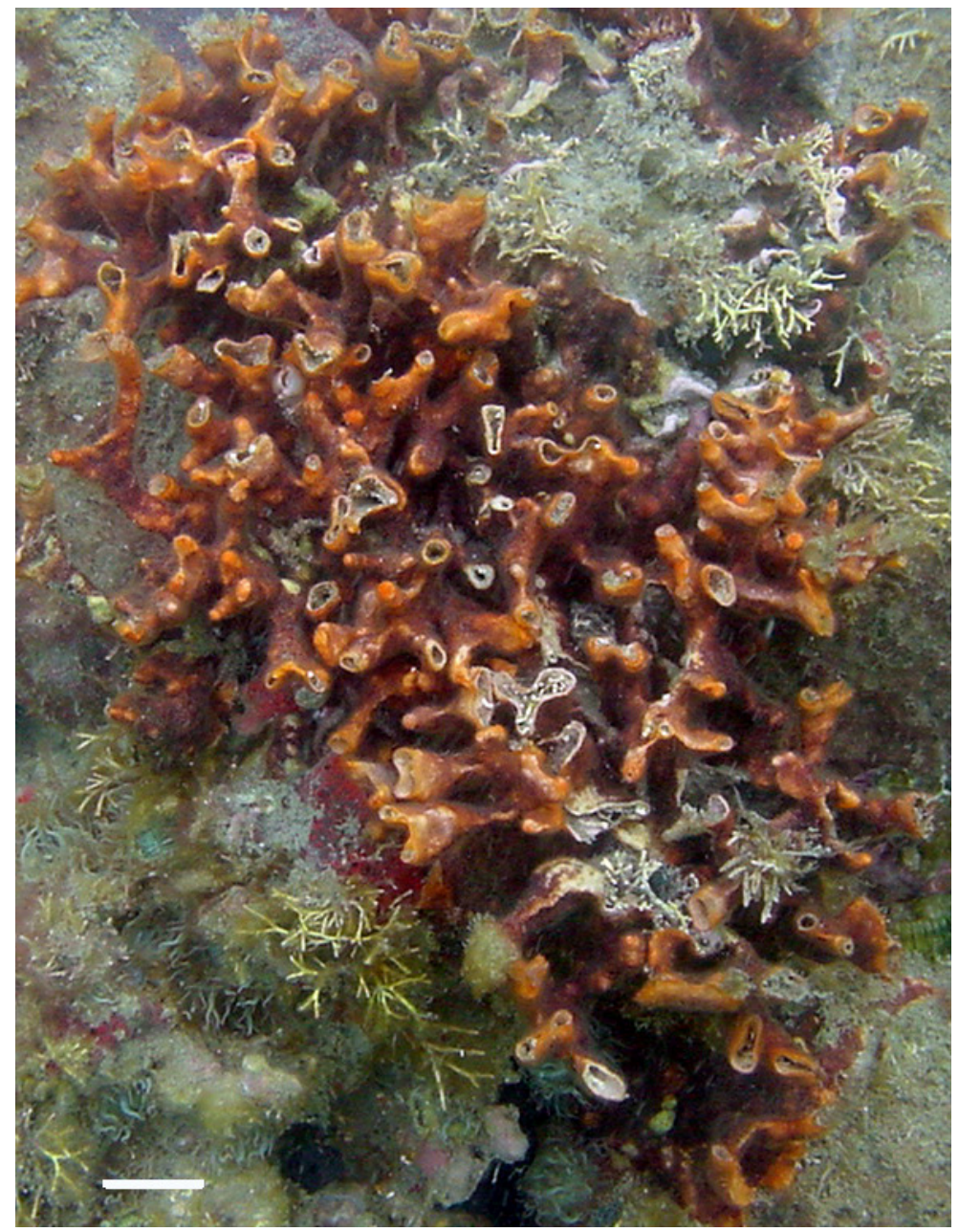

Figura 2.13 - Povoamento Colônia de Schizoporella. Barra horizontal=2 cm. 
Povoamento 13 - Colônia de Symplegma (Figura 2.14)

Espécies/UTOs dominantes: Symplegma rubra Herdman, 1886.

Descrição: manchas de tamanho variável formadas por colônias de coloração vermelho brilhante, de consistência suave e gelatinosa, cobrindo completamente o substrato. Chordata dominante colonial séssil, até $10,0 \mathrm{~cm}$ de largura, firme ao tato, com zoóides distinguíveis a olho nú com 1,0-1,5 cm de comprimento, com um distinto contorno oval e dois sifões tubulares abrindo na superfície.

Povoamentos relacionados: Colônia de Didemnum (Figura 2.10).

Ambiente: face lateral das rochas, protegida do embate das ondas, geralmente próximo ao fundo arenoso; irradiância baixa.

Níveis extremos de ocorrência (em relação ao 0.0 de maré): inferior: (-)2.2 superior: (-)0.4

Posição: no mesmo nível dos povoamentos Banco de Sargassum, Crosta de Amphimedon,

Crosta de Mycale e Tapete de Ectoprocta

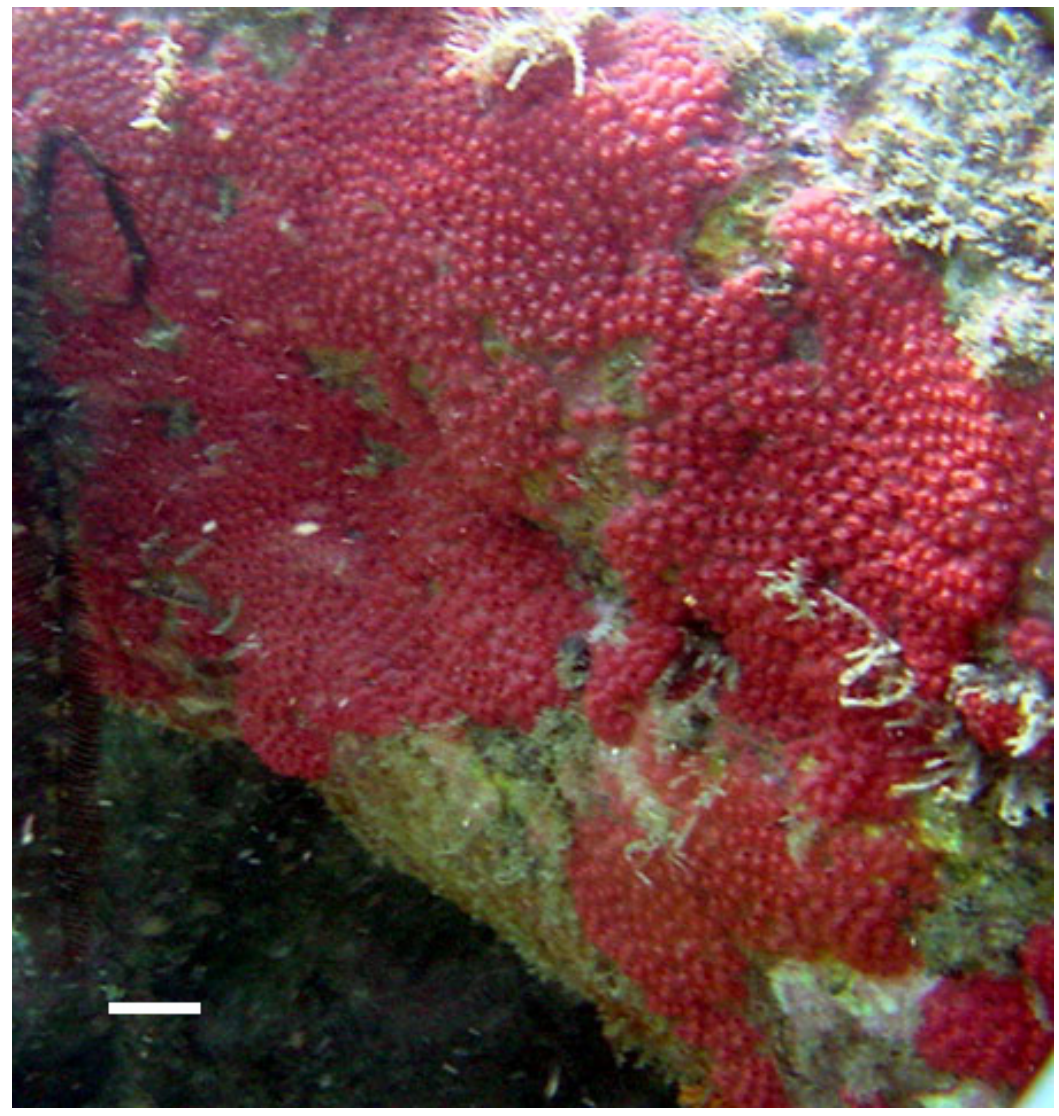

Figura 2.14 - Povoamento Colônia de Symplegma. Barra horizontal=2 cm. 
Povoamento 14 - Crosta de Amphimedon (Figura 2.15)

Espécies/UTOs dominantes: Amphimedon viridis (Duchassaing \& Michelloti, 1864).

Descrição: manchas de crostas de esponjas verde-claro, fortemente aderidas ao substrato, formadas por indivíduos agregados, de consistência suave e compressível, cobrindo completa e homogeneamente o substrato. Porifera dominante formando crostas espessas, com ramificação maciça e rastejante, com 1,0-3,0 cm de diâmetro, em alguns casos com porções tubulares, com ósculos em forma de vulcão evidentes, com 2,0-4,0 mm de diâmetro.

Povoamentos relacionados: Crosta de Mycale (Figura 2.19) e Crosta de Tedania (Figura 2.21).

Ambiente: sobre rochas próximas ao fundo, geralmente em faces protegidas ou em fendas; hidrodinamismo intermediário e irradiância baixa a intermediária.

Níveis extremos de ocorrência (em relação ao 0.0 de maré): inferior: (-)3.4 superior: (-)1.5

Posição: acima dos povoamentos Tapete de Gelidiopsis e Hypnea e Tapete de Ectoprocta; abaixo dos povoamentos Tapete de Ectoprocta e Crosta de Corallinaceae e no mesmo nível do povoamento Colônia de Symplegma.

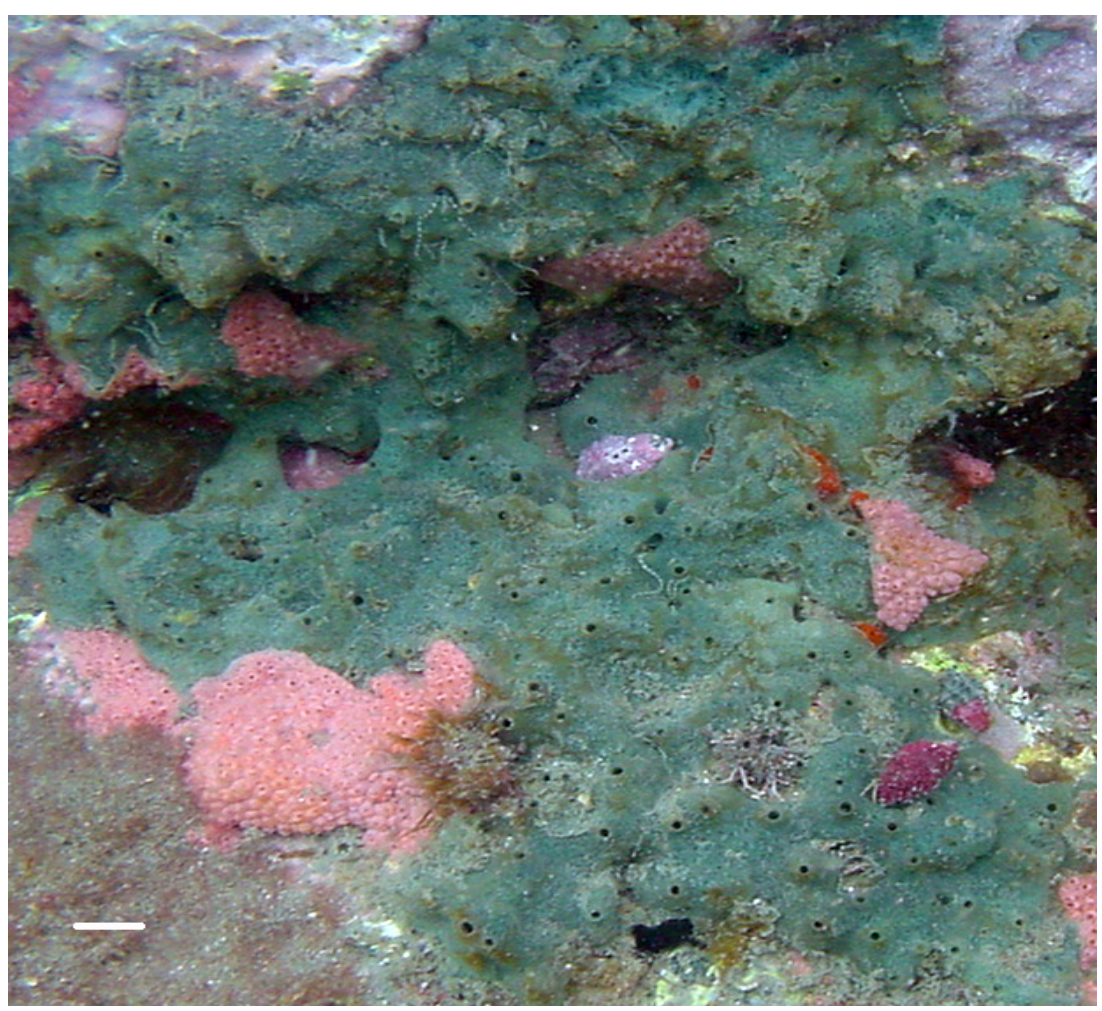

Figura 2.15 - Povoamento Crosta de Amphimedon. Barra horizontal=2 cm. 


\section{Povoamento 15 - Crosta de Corallinaceae (Figura 2.16)}

Espécies/UTOs dominantes: Família Corallinaceae (táxons crostosos).

Descrição: crostas lisas e duras de algas calcárias vermelhas de cor rosa claro, ou brancas quando mortas, fortemente aderidas ao substrato, recobrindo totalmente a rocha na região de ocorrência, encontradas tanto como manchas quanto como faixas. UTO dominante constituída de representantes crostosos calcificados de Corallinaceae, que podem ser distinguidos por sua cor característica. É freqüentemente recoberta por outras espécies de algas ou animais (dominantes) formando nestes casos outros povoamentos. Tendo em vista a dificuldade de identificação mesmo do gênero em laboratório, aliado ao desconhecimento sobre o grupo, é tratada apenas em nível de família.

Povoamentos relacionados: Crosta de Corallinaceae com Echinometra (Figura 2.17) e Crosta de Corallinaceae com Polysiphonia (Figura 2.18).

Ambiente: até o limite inferior do infralitoral, cobrindo a face superior ou lateral de pedras; irradiância e hidrodinamismo variáveis.

Níveis extremos de ocorrência (em relação ao 0.0 de maré): inferior: (-)3.4 superior: 0.0 Posição: acima do povoamento Tapete de Ectoprocta e abaixo do povoamento Banco de Sargassum.

Observações: nas regiões mais profundas pode ser recoberto por outros povoamentos, como lodo ou tapetes recentes junto ao fundo, só sendo percebido quando se retira a cobertura.

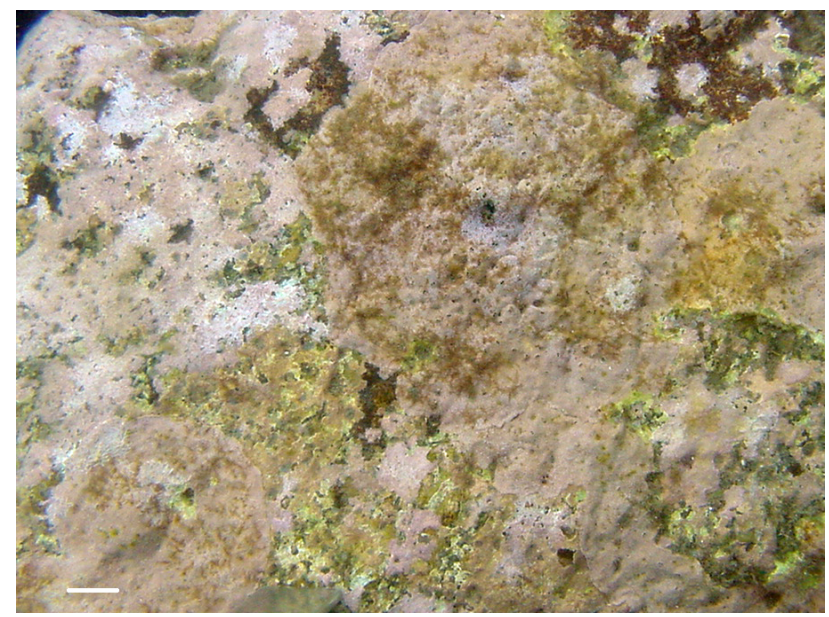

Figura 2.16 - Povoamento Crosta de Corallinaceae. Barra horizontal $=2 \mathrm{~cm}$. 
Povoamento 16 - Crosta de Corallinaceae com Echinometra (Figura 2.17)

Espécies/UTOs dominantes: Família Corallinaceae (táxons crostosos).

Espécies associadas características: Echinometra lucunter Linnaeus, 1758.

Descrição: compartilha as mesmas características da Crosta de Corallinaceae, mas com ouriços pretos sobre ele, ocorrendo tanto isolados como agregados, mas sempre deixando espaço livre entre os indivíduos. Echinodermata dominante apresenta carapaça globosa, às vezes ligeiramente elíptica, atingindo o diâmetro máximo de $17,0 \mathrm{~cm}$; os espinhos são violeta escuro, quase pretos, os primários com 1/4 até 2 vezes o tamanho da carapaça, grossos na base e finos na extremidade.

Povoamentos relacionados: Crosta de Corallinaceae (Figura 2.16) e Crosta de Corallinaceae com Polysiphonia (Figura 2.18).

Ambiente: sobre grandes matacões em diferentes profundidades ou em fissuras no mediolitoral inferior e infralitoral; hidrodinamismo intermediário a alto e irradiância baixa a intermediária.

Níveis extremos de ocorrência (em relação ao 0.0 de maré): inferior: (-)3.4 superior: 0.0

Posição: acima do povoamento Tapete de Ectoprocta e abaixo do povoamento Banco de Sargassum.

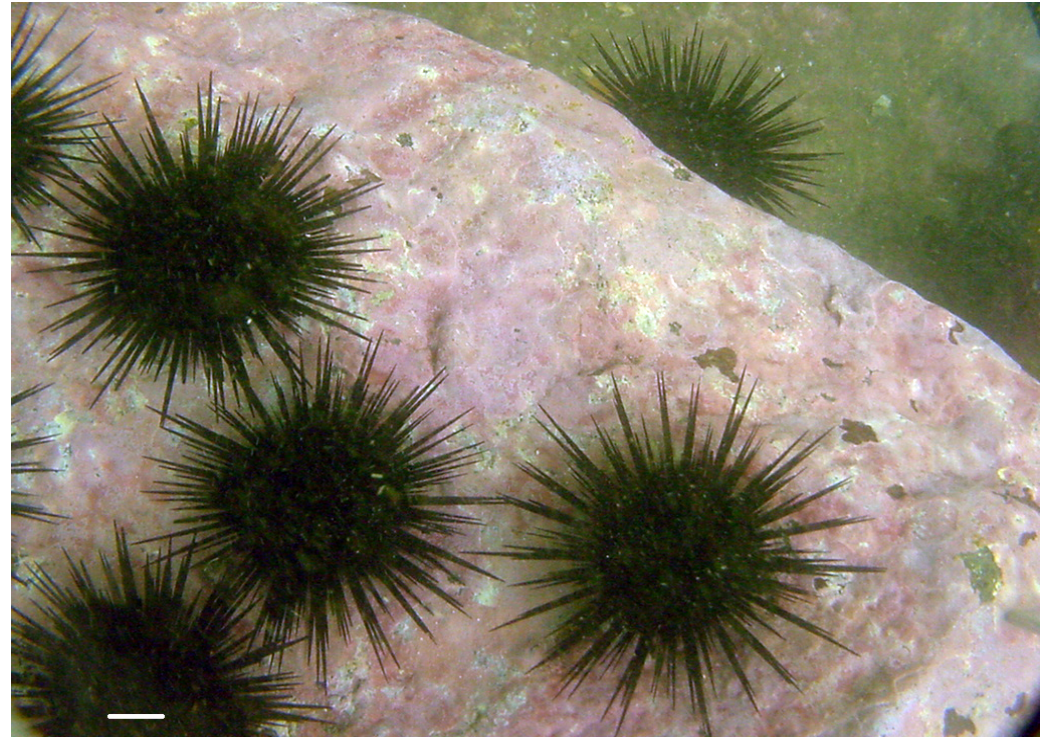

Figura 2.17 - Povoamento Crosta de Corallinaceae com Echinometra. Barra horizontal=2 cm. 
Povoamento 17 - Crosta de Corallinaceae com Polysiphonia (Figura 2.18)

Espécies/UTOs dominantes: Família Corallinaceae (táxons crostosos).

Espécies associadas características: Polysiphonia subtilissima Mont. e $P$. denudata (Dillwyn) Greville.

Descrição: compartilha as mesmas características da Crosta de Corallinaceae, mas com as crostas parcialmente cobertas por tufos de algas filamentosas com textura bastante escorregadia. Ambas Rhodophyta filamentosas dominantes pertencem ao gênero Polysiphonia, constituído de filamentos delicados, abundantemente ramificados em densos agrupamentos.

Povoamentos relacionados: Crosta de Corallinaceae (Figura 2.16) e Crosta de Corallinaceae com Echinometra (Figura 2.17).

Ambiente: sobre grandes matacões em diferentes profundidades ou em fissuras no mediolitoral inferior e infralitoral; hidrodinamismo intermediário a alto e irradiância baixa a intermediária.

Níveis extremos de ocorrência (em relação ao 0.0 de maré): inferior: (-)1.5 superior: (-)0.2

Posição: acima do povoamento Tapete de Ectoprocta e abaixo do povoamento Banco de Sargassum.

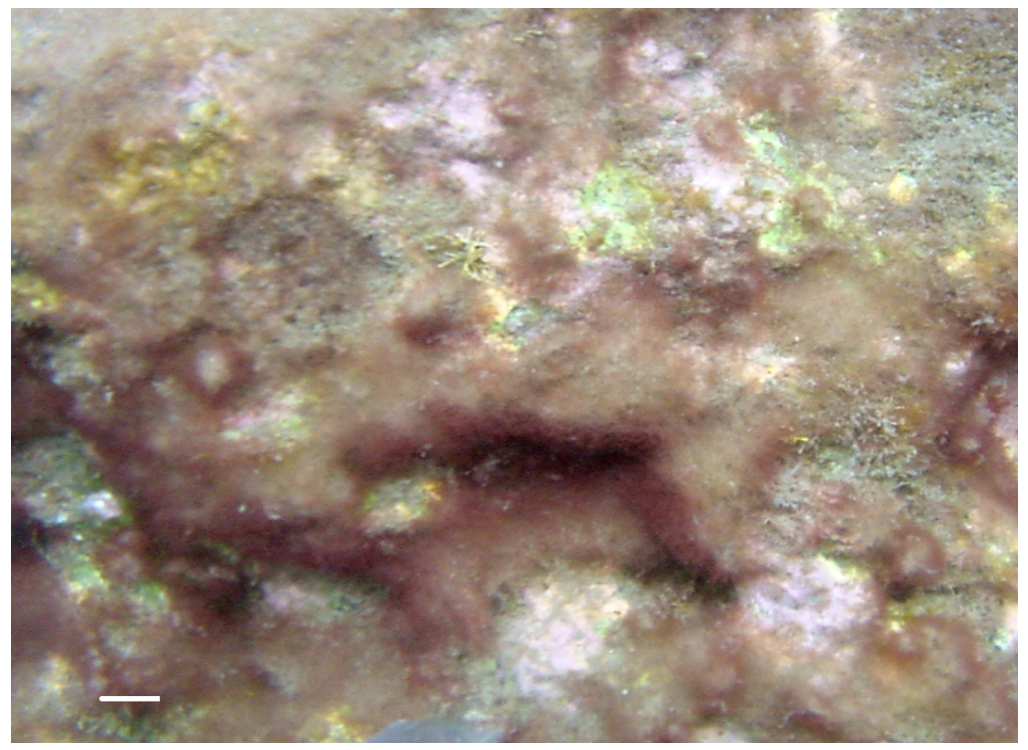

Figura 2.18 - Povoamento Crosta de Corallinaceae com Polysiphonia. Barra horizontal=2 cm. 


\section{Povoamento 18 - Crosta de Mycale (Figura 2.19)}

Espécies/UTOs dominantes: Mycale angulosa (Duchassaing \& Michelloti, 1864).

Descrição: manchas de crostas de esponjas de coloração violeta, de consistência suave e rugosa, de tamanho variável, cobrindo completa e homogeneamente o substrato. Porifera dominante possui ósculos visíveis a olho nu, com 3,0-7,0 mm de diâmetro.

Povoamentos relacionados: Crosta de Amphimedon (Figura 2.15), Crosta de Tedania (Figura 2.21).

Ambiente: face lateral das rochas, protegida do embate das ondas; hidrodinamismo e irradiância intermediários.

Níveis extremos de ocorrência (em relação ao 0.0 de maré): inferior: (-)2.2 superior: (-)0.4

Posição: no mesmo nível dos povoamentos Banco de Sargassum e Tapete de Ectoprocta.

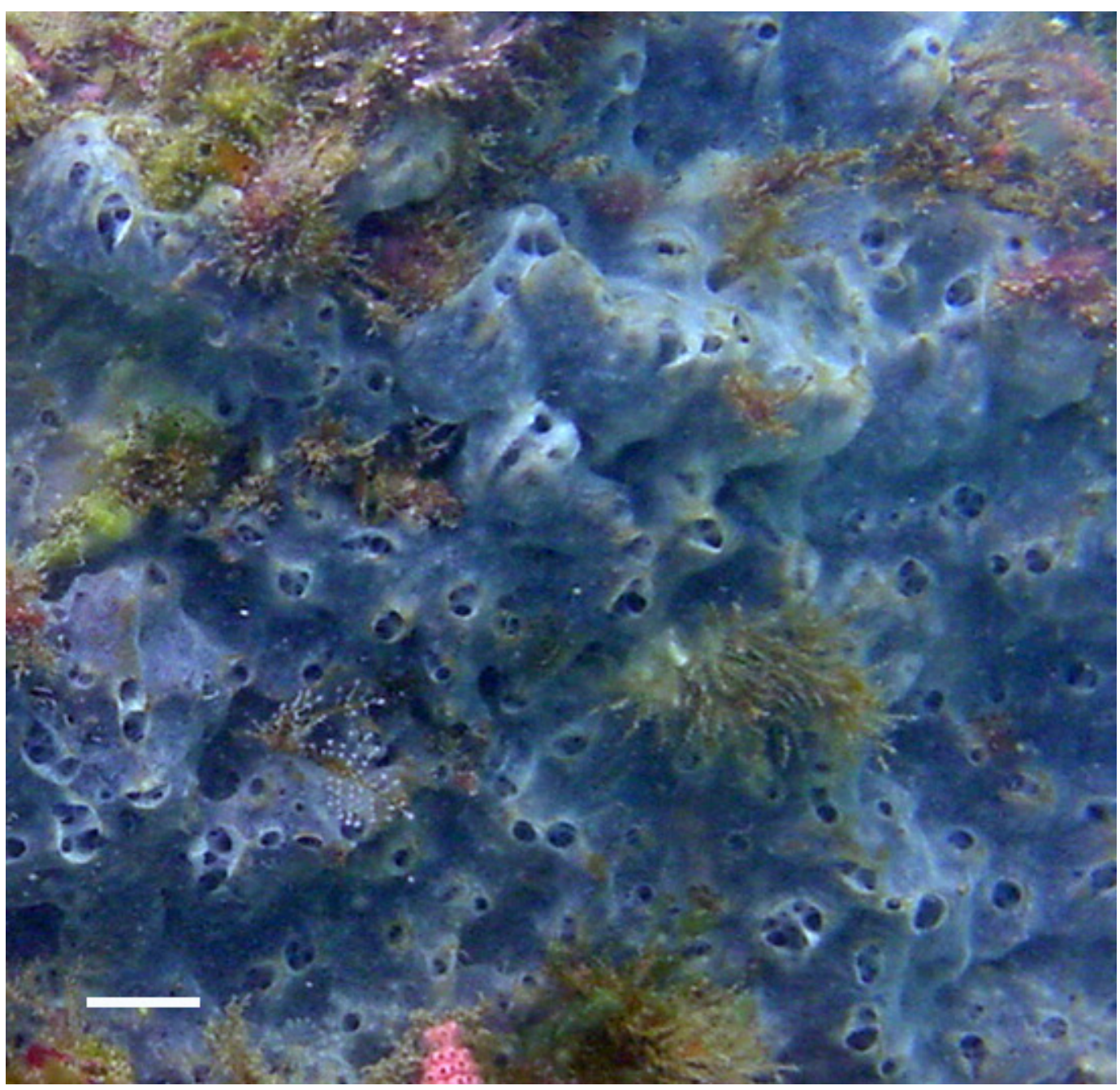

Figura 2.19 - Povoamento Crosta de Mycale. Barra horizontal $=2 \mathrm{~cm}$. 


\section{Povoamento 19 - Crosta de Peyssonnelia (Figura 2.20)}

Espécies/UTOs dominantes: Peyssonnelia simulans Weber Bosse in Børgesen

Descrição: manchas isoladas de crostas duras e lisas, de algas de coloração vermelho escuro, fortemente aderidas ao substrato, cobrindo-o completamente. Rhodophyta dominante consiste de crostas variando de circular à irregular, crescendo da primeira para a segunda forma.

Ambiente: infralitoral, na face lateral das rochas; hidrodinamismo intermediário a alto e irradiância baixa a intermediária.

Níveis extremos de ocorrência (em relação ao 0.0 de maré): inferior: (-)3.5 superior: (-)0.4 Posição: no mesmo nível dos povoamentos Banco de Sargassum, Colônia de Schizoporella e Tapete de Amphiroa e Jania.

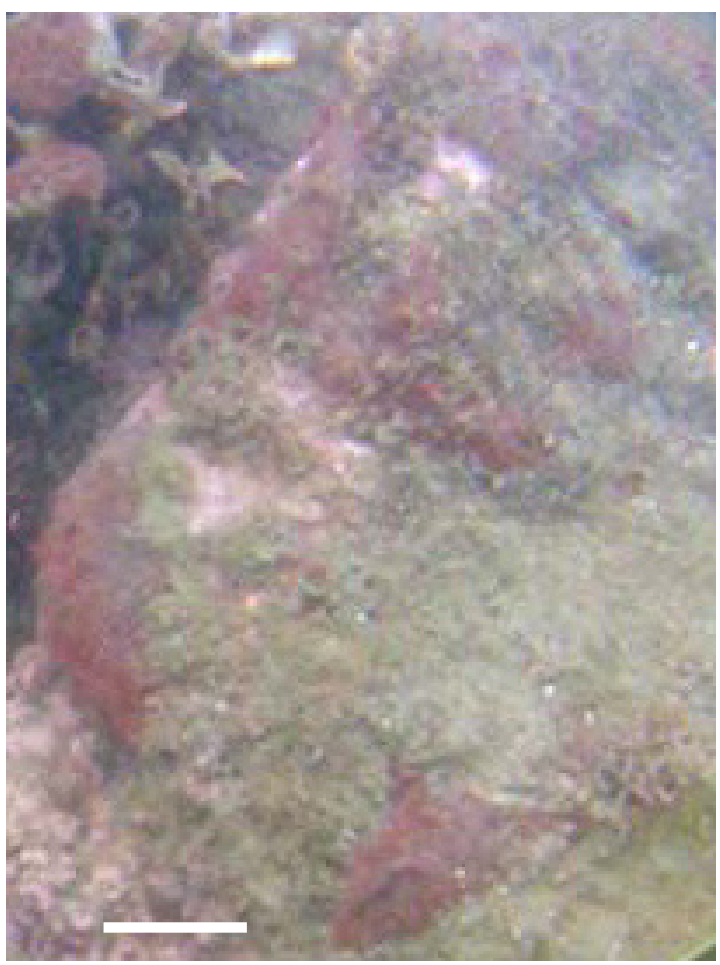

Figura 2.20 - Povoamento Crosta de Peyssonnelia. Barra horizontal=2 cm. 
Povoamento 20 - Crosta de Tedania (Figura 2.21)

Espécies/UTOs dominantes: Tedania ignis (Duchassaing \& Michelotti, 1864)

Descrição: manchas de crostas rugosas e consistentes de esponjas de coloração laranja, suaves, compressíveis e facilmente removidas, cobrindo completa e homogeneamente o substrato. Os Porifera dominantes são de coloração vermelho vivo ou vermelho alaranjado, maciços e amorfos a lobados, com superfície lisa à tuberculada, lobos com 1,0-2,0 $\mathrm{cm}$ de largura com ósculos sobre eles.

Povoamentos relacionados: Crosta de Amphimedon (Figura 2.15) e Crosta de Mycale (Figura 2.19).

Ambiente: Ocorrem muito freqüentemente na face inferior de rochas ou paredes com inclinação negativa, mas também na face lateral ou mesmo superior de rochas em condições de hidrodinamismo intermediário e irradiância baixa a intermediária.

Níveis extremos de ocorrência (em relação ao 0.0 de maré): inferior: (-)2.4 superior: 0.0

Posição: no mesmo nível do povoamento Tapete de Ectoprocta e abaixo do povoamento Banco de Sargassum

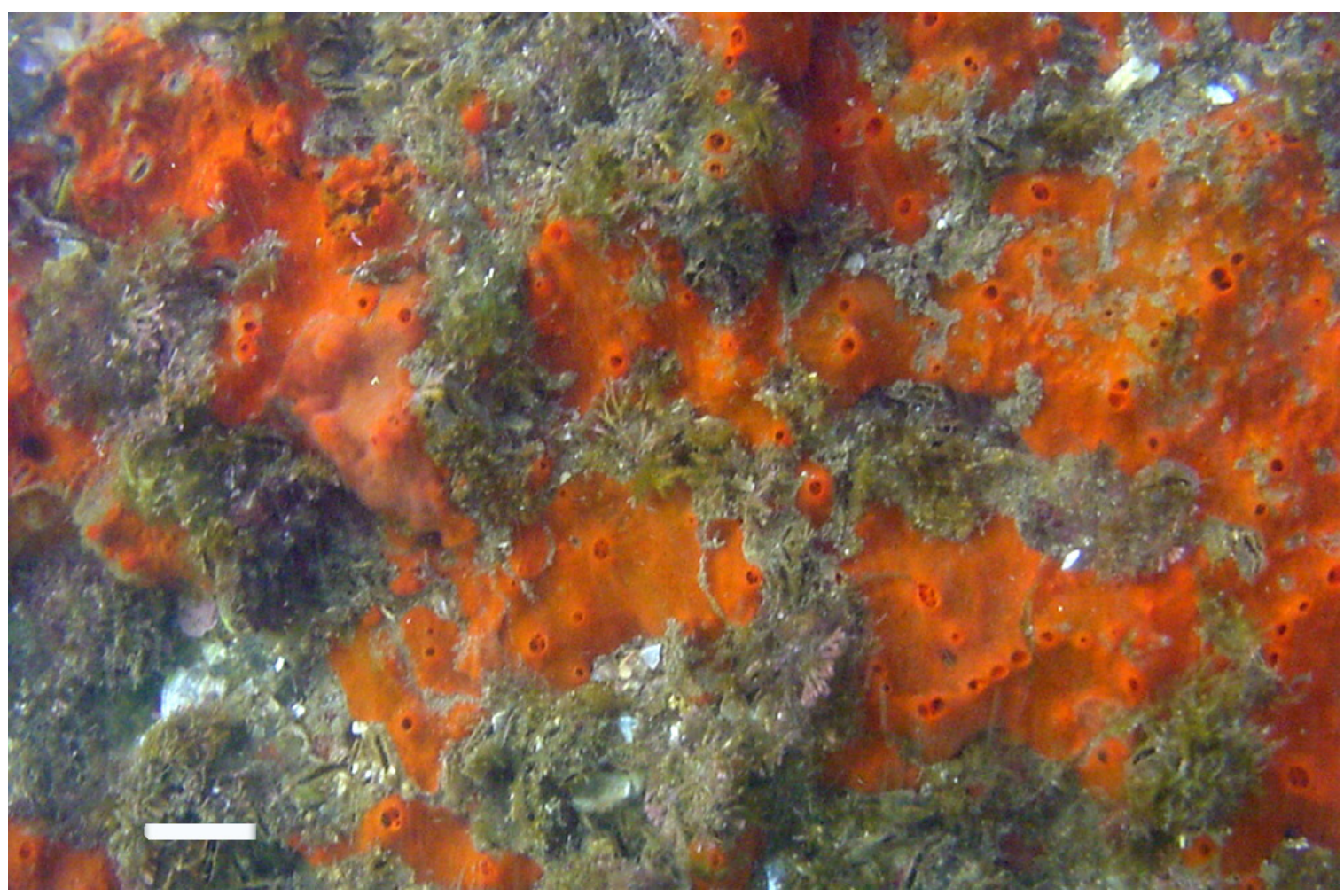

Figura 2.21 - Povoamento Crosta de Tedania. Barra horizontal $=2 \mathrm{~cm}$. 
Povoamento 21 - Região de Substrato Inconsolidado (Figura 2.22)

Atributos: areia ou silte

Descrição: áreas de rocha coberta por substrato inconsolidado com granulação caracterizada empiricamente como areia ou silte, geralmente recobrindo crostas de Corallinaceae ou outros organismos crostosos. Atributo discriminado apenas ao ocorrer entremeado com o substrato consolidado.

Atributos relacionados: Areia fina e lodo, areia recoberta por lodo, areia média a grossa, areia com fragmentos de conchas. As variações estão sendo anotadas empiricamente no relato da ocorrência, porém analisadas como fisionomia única devido à difículdade de caracterização e à grande variação.

Ambiente: presente no limite de ocorrência do costão rochoso.

Níveis extremos de ocorrência (em relação ao 0.0 de maré): inferior: (-)4.0 superior: 0.0

Posição: abaixo dos povoamentos Tapete de Ectoprocta, Tapete de Gelidiopsis e Hypnea, Banco de Dichotomaria, Banco de Padina e Banco de Sargassum.

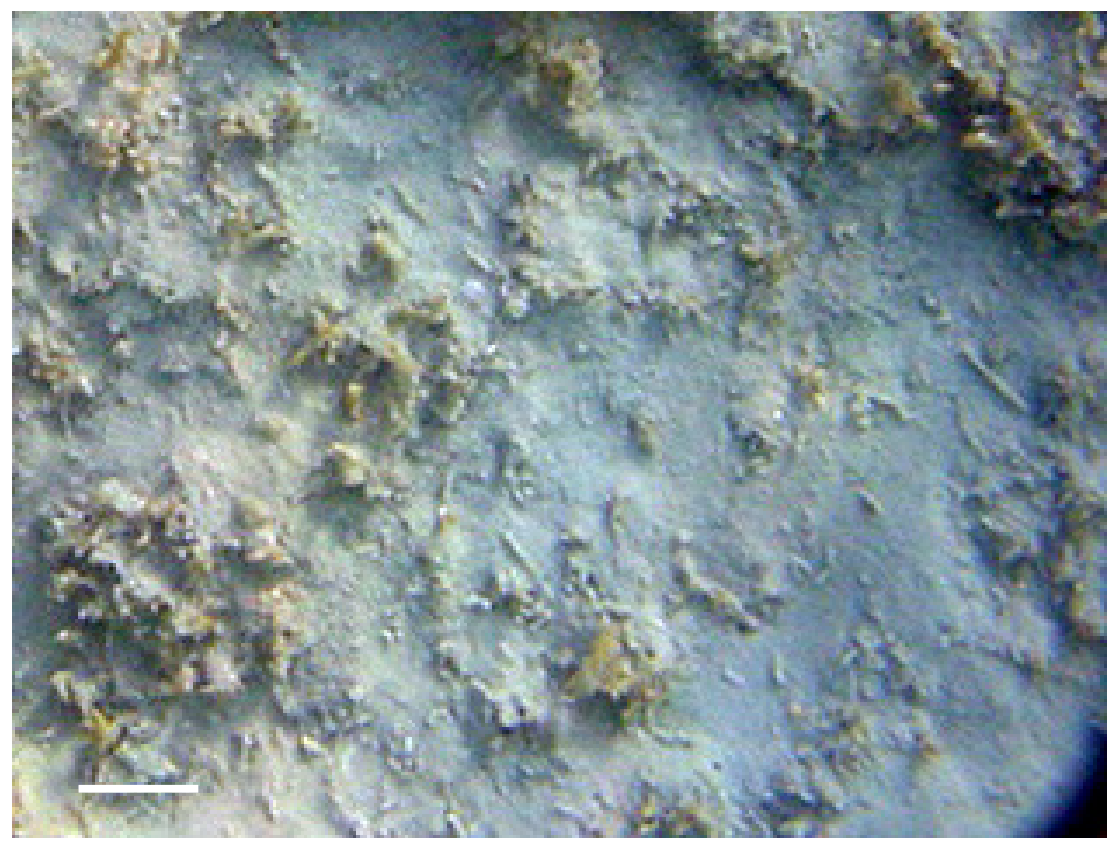

Figura 2.22 - Povoamento Região de Substrato Inconsolidado. Barra horizontal=2 cm. 
Povoamento 22 - Tapete de Amphiroa e Jania (Figura 2.23)

Espécies/UTOs dominantes: Jania adhaerens J.V. Lamour. e Amphiroa beauvoisii J.V. Lamour.

Descrição: faixas de coloração branca ou branco-rosadas, ásperos, rígidos e formados por algas vermelhas calcificadas quebradiças ao tato, que recobrem completamente grandes porções do substrato, onde as espécies dominantes ocorrem associadas em diferentes proporções. Os indivíduos da Rhodophyta $J$. adhaerens são cilíndricos, regularmente bifurcados, enquanto a Rhodophyta $A$. beauvoisii possui segmentos cilíndricos a comprimidos, com ramificação dicotômica à irregular. Ambas são facilmente quebráveis devido às porções não calcificadas do talo.

Povoamentos relacionados: Tapete de Amphiroa e Jania com Echinometra (Figura 2.23).

Ambiente: face superior ou lateral de rochas expostas, em diferentes níveis do costão; hidrodinamismo médio a alto e irradiância média à alta.

Níveis extremos de ocorrência (em relação ao 0.0 de maré): inferior: (-)3.4 superior: 0.0 Posição: acima do povoamento Tapete de Ectoprocta e abaixo do povoamento Crosta de Corallinaceae.

Observações: As UTOs dominantes podem ocorrer de forma isolada, sendo então incluídas em outros povoamentos.

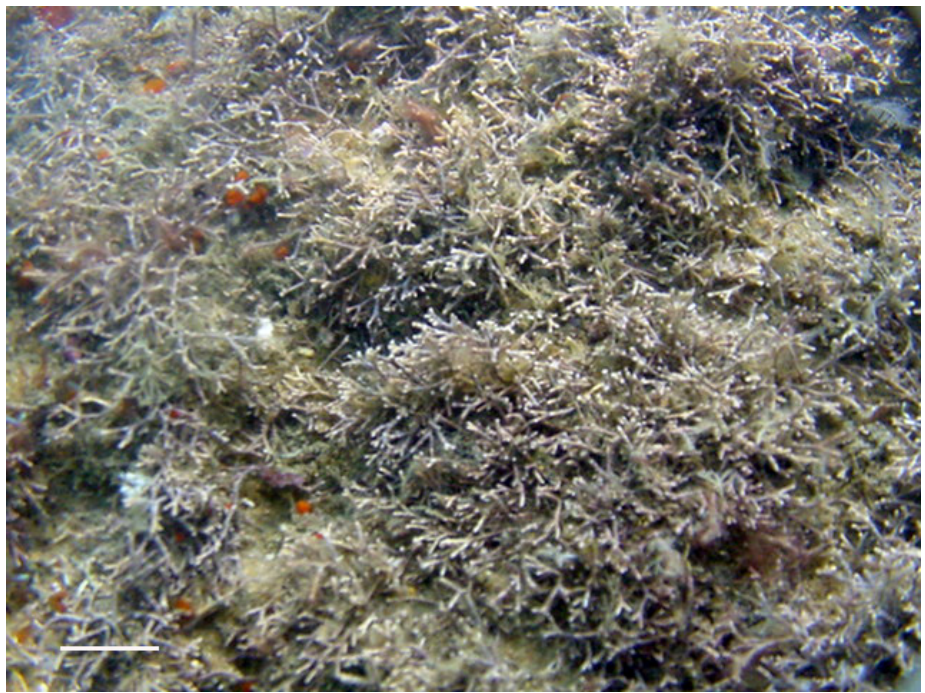

Figura 2.23 - Povoamento Tapete de Amphiroa e Jania. Barra horizontal=2 cm. 
Povoamento 23 - Tapete de Amphiroa e Jania com Echinometra (Figura 2.24)

Espécies/UTOs dominantes: Jania adhaerens J.V. Lamour. e Amphiroa beauvoisii J.V. Lamour.

Espécies associadas características: Echinometra lucunter Linnaeus, 1758

Descrição: compartilha as mesmas características que o Tapete de Amphiroa e Jania, porém com pequenas quantidades de indivíduos de ouriço, não dominantes, associados.

Povoamentos relacionadas: Tapete de Amphiroa e Jania (Figura 2.23)

Ambiente: hidrodinamismo médio a alto

Níveis extremos de ocorrência (em relação ao 0.0 de maré): inferior: (-)3.4 superior: 0.0

Posição: acima do povoamento Tapete de Ectoprocta e abaixo de povoamentos variáveis

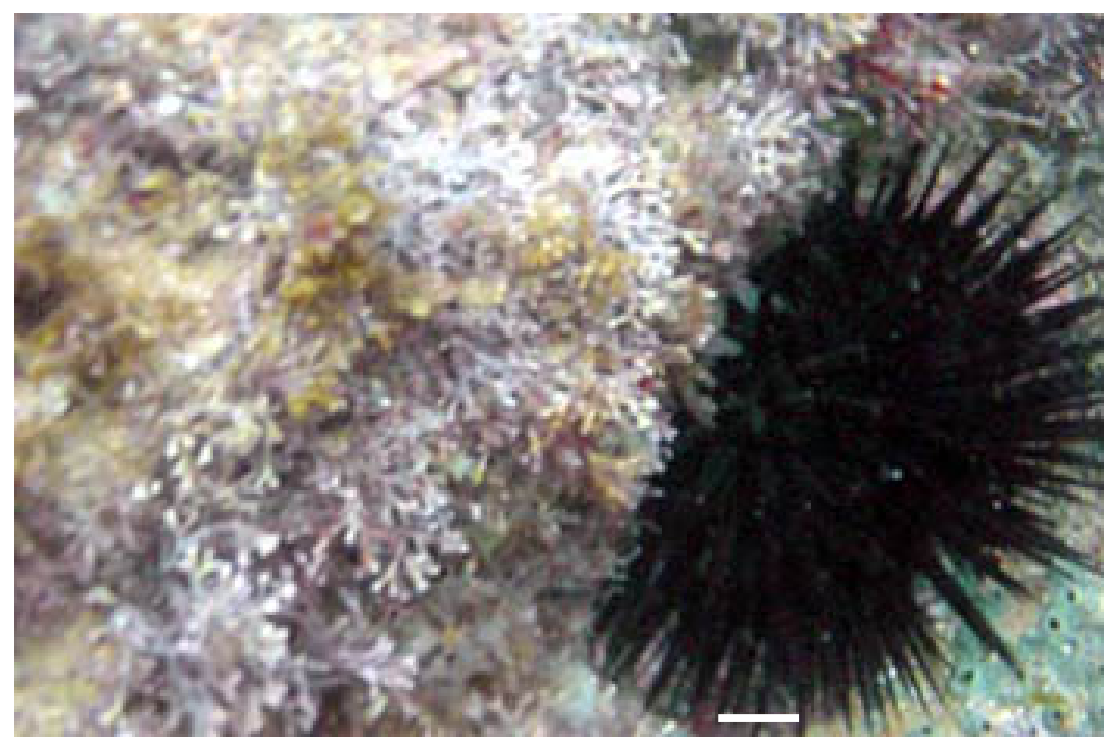

Figura 2.24 - Povoamento Tapete de Amphiroa e Jania com Echinometra.

Barra horizontal $=2 \mathrm{~cm}$. 
Povoamento 24 - Tapete de Ectoprocta (Figura 2.25)

Espécies/UTOs dominantes: Scrupocellaria van Beneden, 1845

Espécies associadas características: Catenicella de Blainville, 1830; Amathia Lamouroux, 1812; e Savignyella lafontii (Audouin), 1826.

Descrição: faixas de colônias de coloração marrom amarelado, bastante emaranhadas, cobrindo completamente o substrato, freqüentemente associadas com uma grande quantidade de sedimentos. Colônias de Ectoprocta são ramificadas dicotomicamente, com eixo principal e ramos bi-seriais a multi-seriais. O Ectoprocta dominante apresenta colônias livres e ramificadas, mas geralmente rastejantes ao invés de eretas, com os ramos ancorados em intervalos regulares ao substrato por rizóides. Ramos dividindo-se regularmente, constituídos de zoóides alternando-se em duas séries. Zoóides rômbicos, com uma membrana frontal oval. Povoamentos relacionados: Tapete de Ectoprocta com Carijoa (Figura 2.26), Tapete de Ectoprocta com Phallusia (Figura 2.27), Tapete de Ectoprocta com Polysiphonia (Figura 2.28), Tapete de Ectoprocta com Wrangelia (Figura 2.29).

Ambiente: face lateral de rochas voltadas para o mar, em níveis variáveis; hidrodinamismo intermediário a alto e irradiância variável.

Níveis extremos de ocorrência (em relação ao 0.0 de maré): inferior: (-)3.5 superior: 0.0

Posição: acima e abaixo de povoamentos muito variáveis

Observações: os diversos táxons de Ectoprocta são pouco estudados no Brasil e sua melhor definição depende de estudos futuros.

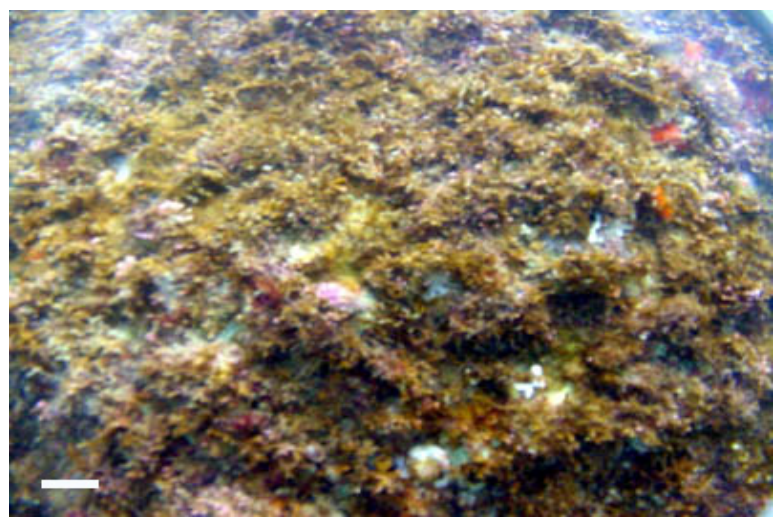

Figura 2.25 - Povoamento Tapete de Ectoprocta. Barra horizontal $=2 \mathrm{~cm}$. 
Povoamento 25 - Tapete de Ectoprocta com Carijoa (Figura 2.26)

Espécies/UTOs dominantes: Scrupocellaria van Beneden, 1845 e Carijoa riisei

(Duchassaing \& Michelotti, 1860)

Descrição: manchas de organismos como o descrito para o povoamento Tapete de Ectoprocta misturadas com indivíduos de Carijoa riisei, e associadas com uma grande quantidade de sedimentos. Cnidaria dominante forma colônias eretas, ramificadas, com eixos e ramos flexíveis, de coloração marrom, geralmente recobertos por uma esponja alaranjada delicada. Pólipos laterais brancos apresentando 8 tentáculos pinados.

Povoamentos relacionados: Tapete de Ectoprocta (Figura 2.25), Tapete de Ectoprocta com Phallusia (Figura 2.27), Tapete de Ectoprocta com Polysiphonia (Figura 2.28), Tapete de Ectoprocta com Wrangelia (Figura 2.29).

Ambiente: paredão; hidrodinamismo e irradiância intermediários.

Níveis extremos de ocorrência (em relação ao 0.0 de maré): inferior: (-)3.0 superior: (-)0.2 Posição: acima dos povoamentos Crosta de Mycale, Região de Substrato Inconsolidado, Crosta de Amphimedon, Banco de Dichotomaria e Tapete de Gelidiopsis e Hypnea e abaixo de povoamentos variáveis

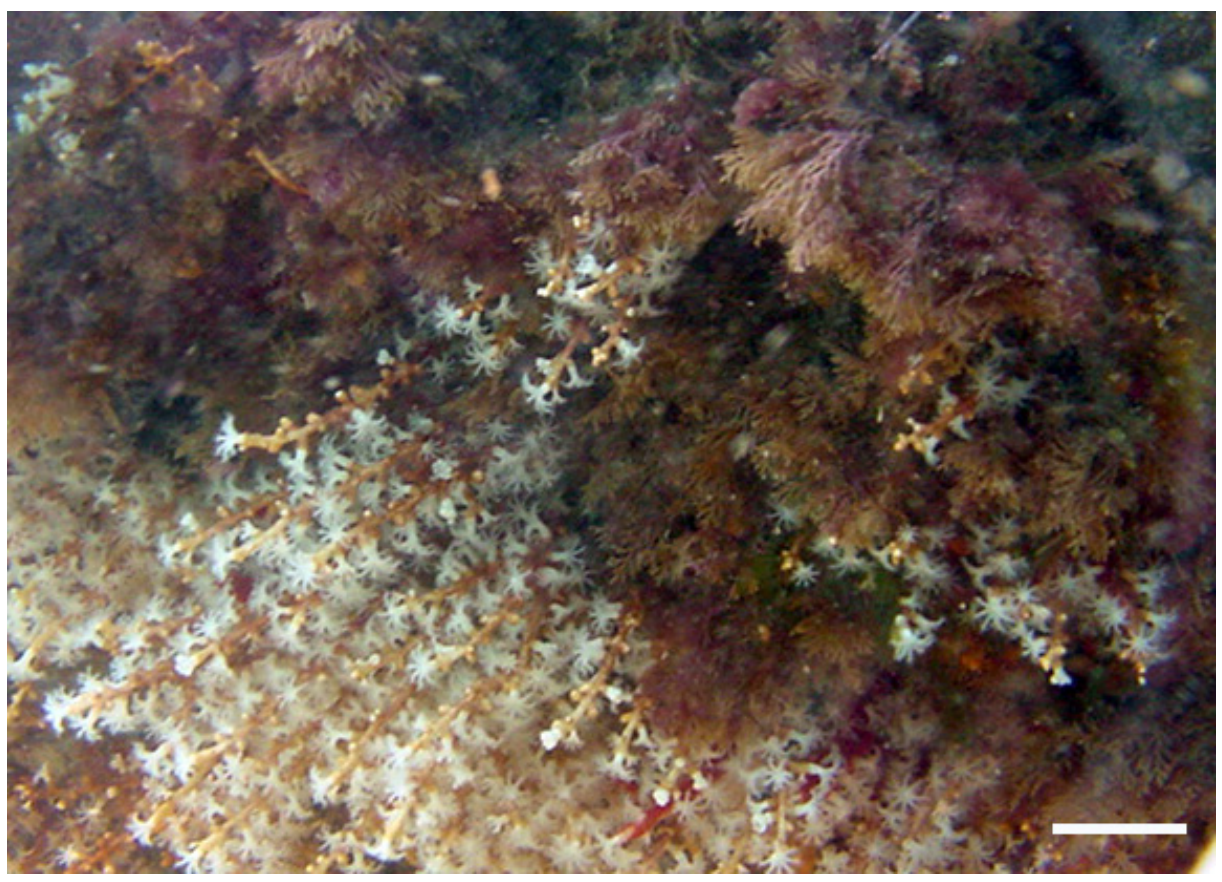

Figura 2.26 - Povoamento Tapete de Ectoprocta com Carijoa. Barra horizontal $=2 \mathrm{~cm}$. 
Povoamento 26 - Tapete de Ectoprocta com Phallusia (Figura 2.27)

Espécies/UTOs dominantes: Scrupocellaria van Beneden, 1845.

Espécies associadas características: Phallusia nigra Savigny, 1816.

Descrição: manchas de organismos como o descrito para o povoamento Tapete de Ectoprocta misturadas com indivíduos não dominantes, isolados ou pouco agregados, de P. nigra. A associação parece ser característica de apenas alguns pontos definidos do costão, permitindo a distinção com o Tapete de Ectoprocta. Os Chordata não dominantes são sésseis, com 8,0-9,0 cm de tamanho, solitários, preto aveludados ou marrom escuro, sendo que espécimes menores podem ser cinza translúcido com manchas esparsas de pigmento; os sifões são separados na terça parte ou na metade do comprimento do corpo.

Povoamentos relacionados: Tapete de Ectoprocta (Figura 2.25), Tapete de Ectoprocta com Carijoa (Figura 2.26), Tapete de Ectoprocta com Polysiphonia (Figura 2.28), Tapete de Ectoprocta com Wrangelia (Figura 2.29).

Ambiente: infralitoral intermediário, em níveis variáveis, na face lateral de rochas voltadas para o mar; hidrodinamismo intermediário a alto e irradiância baixa à intermediária.

Níveis extremos de ocorrência (em relação ao 0.0 de maré): inferior: (-)3.5 superior: 0.0 Posição: acima dos povoamentos Região de Substrato Inconsolidado, Banco de Padina, Banco de Dichotomaria e Tapete de Gelidiopsis e Hypnea e abaixo de povoamentos muito variáveis

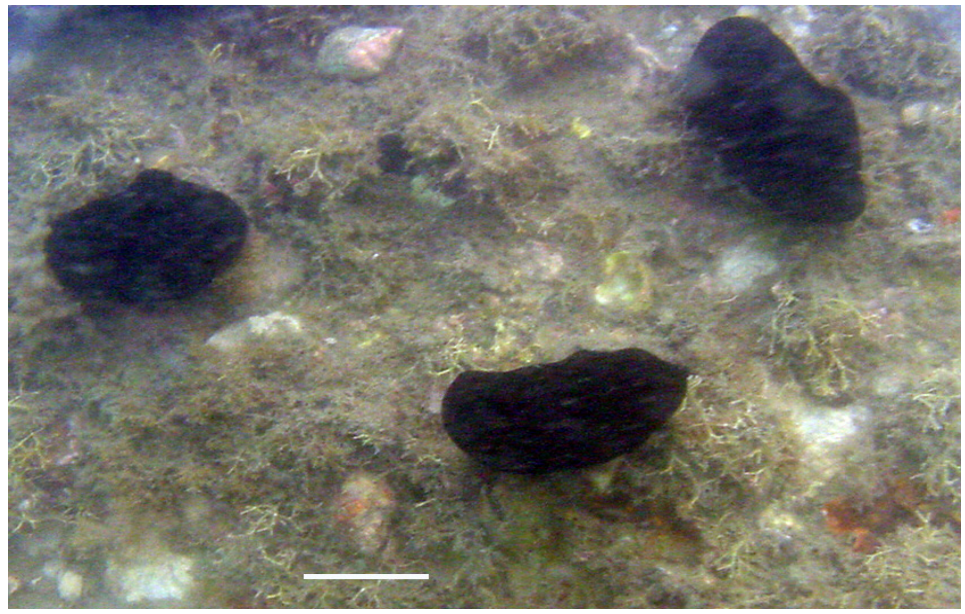

Figura 2.27 - Povoamento Tapete de Ectoprocta com Phallusia. Barra horizontal=2 cm. 
Povoamento 27 - Tapete de Ectoprocta com Polysiphonia (Figura 2.28)

Espécies/UTOs dominantes: Scrupocellaria van Beneden, 1845.

Espécies associadas características: Polysiphonia denudata (Dillwyn) Greville

Descrição: faixas de associações de coloração avermelhada entre Ectoprocta coloniais e algas vermelhas filamentosas epizóicas, cobrindo completamente o substrato. Colônias de Ectoprocta como as descritas anteriormente. A Rhodophyta dominante $P$. denudata é formada por filamentos delicados, abundantemente ramificados, em densos agrupamentos.

Povoamentos relacionados: Tapete de Ectoprocta (Figura 2.25), Tapete de Ectoprocta com Carijoa (Figura 2.26), Tapete de Ectoprocta com Phallusia (Figura 2.27), Tapete de Ectoprocta com Wrangelia (Figura 2.29).

Ambiente: face lateral de rochas voltadas para o mar; hidrodinamismo e irradiância intermediários.

Níveis extremos de ocorrência (em relação ao 0.0 de maré): inferior: (-)2.4 superior: (-)0.2 Posição: acima dos povoamentos Banco de Tropiometra, Colônia de Didemnum, colônia de Schizoporella, Crosta de Mycale, Tapete de Ectoprocta, Tapete de Amphiroa e Jania e Tapete de Gelidiopsis e Hypnea e abaixo de povoamentos variáveis

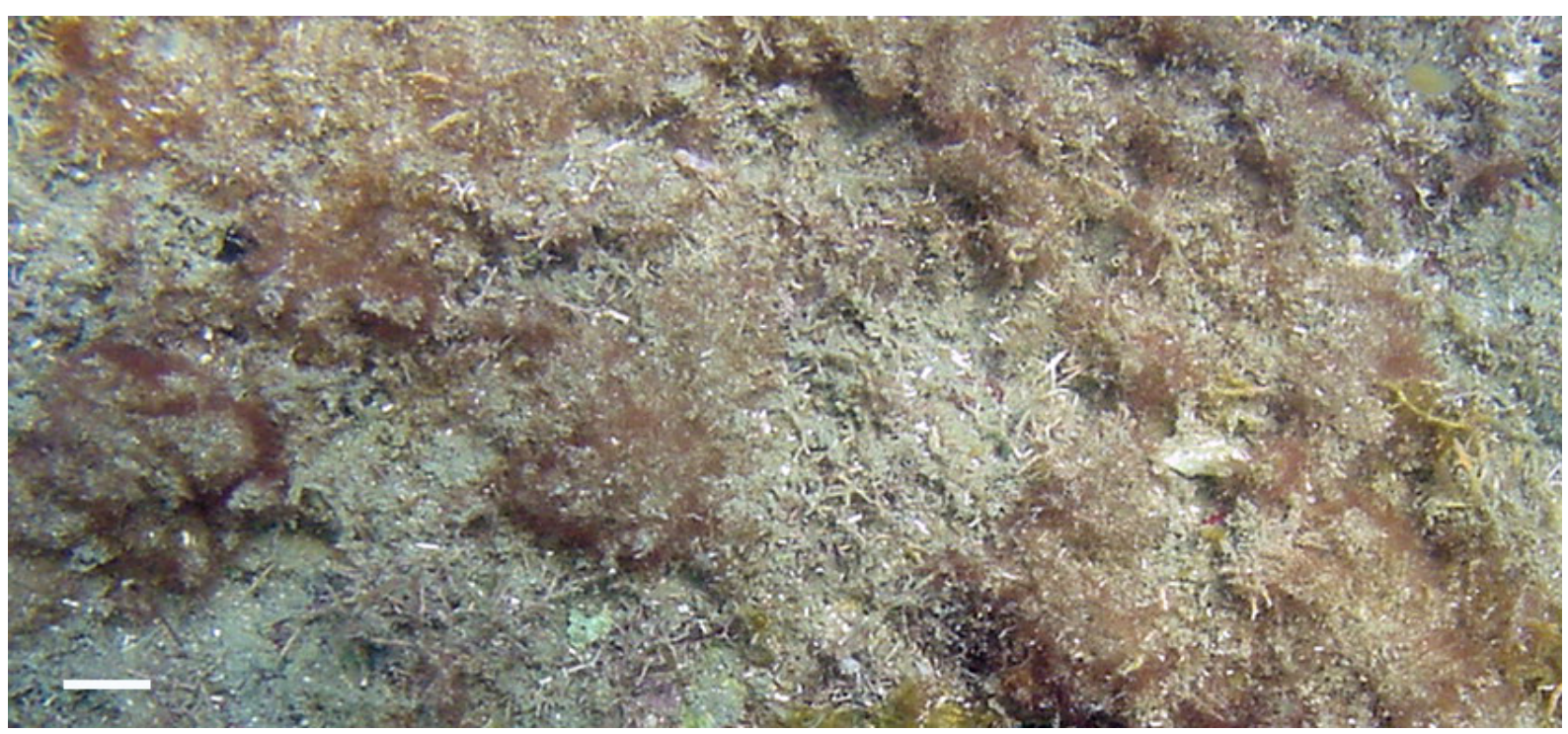

Figura 2.28 - Povoamento Tapete de Ectoprocta com Polysiphonia. Barra horizontal=2 cm. 
Povoamento 28 - Tapete de Ectoprocta com Wrangelia (Figura 2.29)

Espécies/UTOs dominantes: Scrupocellaria van Beneden, 1845.

Espécies associadas características: Wrangelia argus (Mont.) Mont.

Descrição: manchas de organismos como o descrito para o povoamento Tapete de Ectoprocta misturadas a tufos esparsos de algas vermelhas filamentosas não dominantes, cobrindo completamente o substrato. $W$. argus é vermelha, com talo filamentoso delicado com eixos principais eretos disticamente ramificados, com tufos bastante esparsos.

Povoamentos relacionados: Tapete de Ectoprocta (Figura 2.25), Tapete de Ectoprocta com Carijoa (Figura 2.26), Tapete de Ectoprocta com Phallusia (Figura 2.27), Tapete de Ectoprocta com Polysiphonia (Figura 2.28).

Ambiente: face lateral de rochas voltadas para o mar; hidrodinamismo baixo a intermediário e irradiância intermediária.

Níveis extremos de ocorrência (em relação ao 0.0 de maré): inferior: (-)0.8 superior: (-)0.5

Posição: acima dos povoamentos Região de Substrato Inconsolidado e Tapete de Gelidiopsis e Hypnea e abaixo de povoamentos variáveis

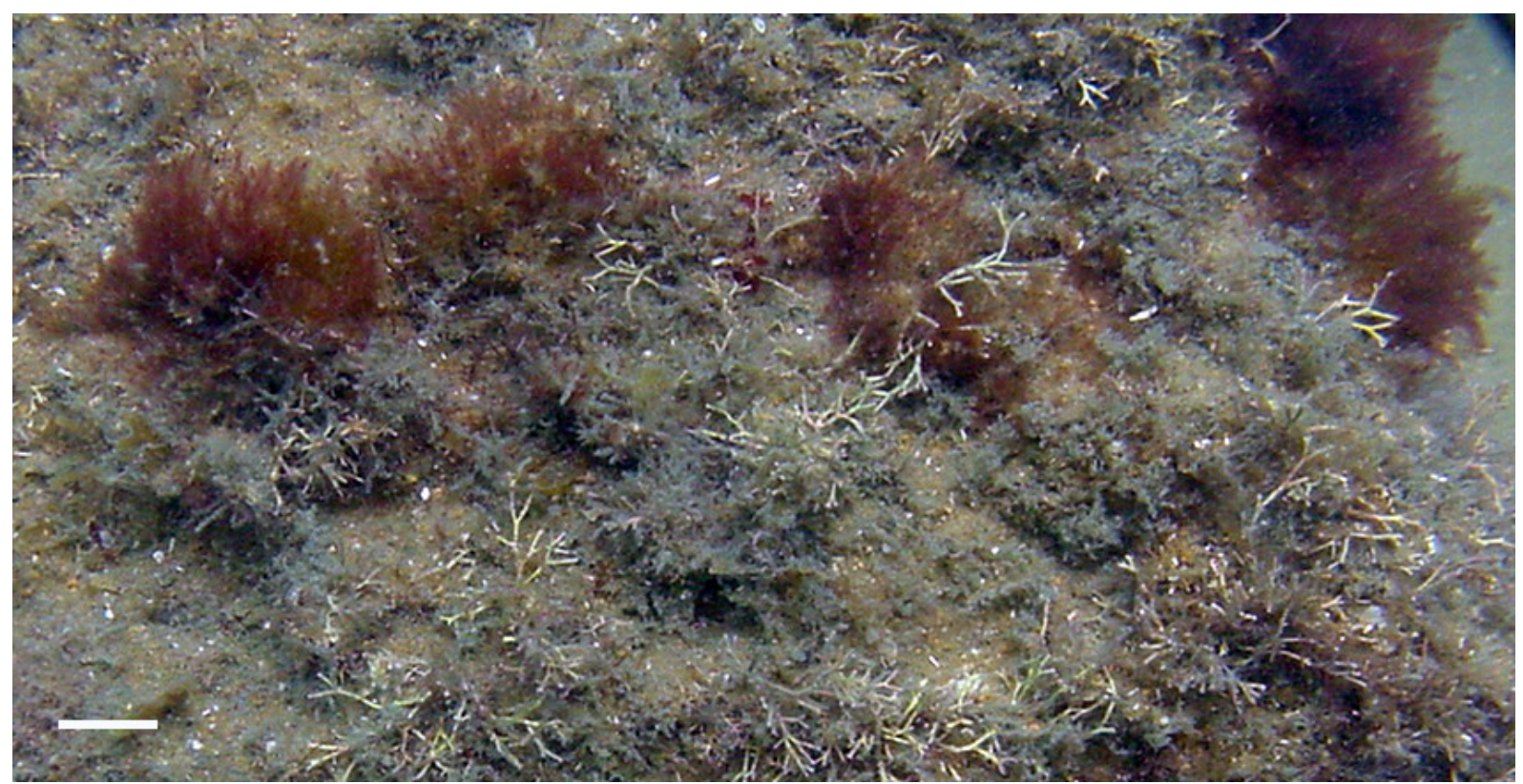

Figura 2.29 - Povoamento Tapete de Ectoprocta com Wrangelia. Barra horizontal=2 cm. 
Povoamento 29 - Tapete de Falkenbergia (Figura 2.30)

Espécies/UTOs dominantes: Asparagopsis taxiformis (Delile) Trevisan.

Descrição: tufos delicados de forma arredondada, de cor vermelha a rósea, recobrindo todo o substrato na forma de manchas isoladas. O povoamento é formado por uma das fases alternantes do ciclo de vida de Asparagopsis taxiformis, descrita anteriormente como Falkenbergia hillebrandii, considerada como povoamento independente devido às características ecológicas distintas. Rhodophyta dominante com talo filamentoso, abundantemente ramificado, constituído de três células pericentrais.

Ambiente: mediolitoral inferior e infralitoral, em faces laterais e superiores de rochas; hidrodinamismo variável e irradiância baixa a intermediária.

Níveis extremos de ocorrência (em relação ao 0.0 de maré): inferior: (-) 1.5 superior: (-) 0.5

Posição: acima dos povoamentos Tapete de Ectoprocta e Região de Substrato Inconsolidado e abaixo do povoamento Banco de Sargassum.

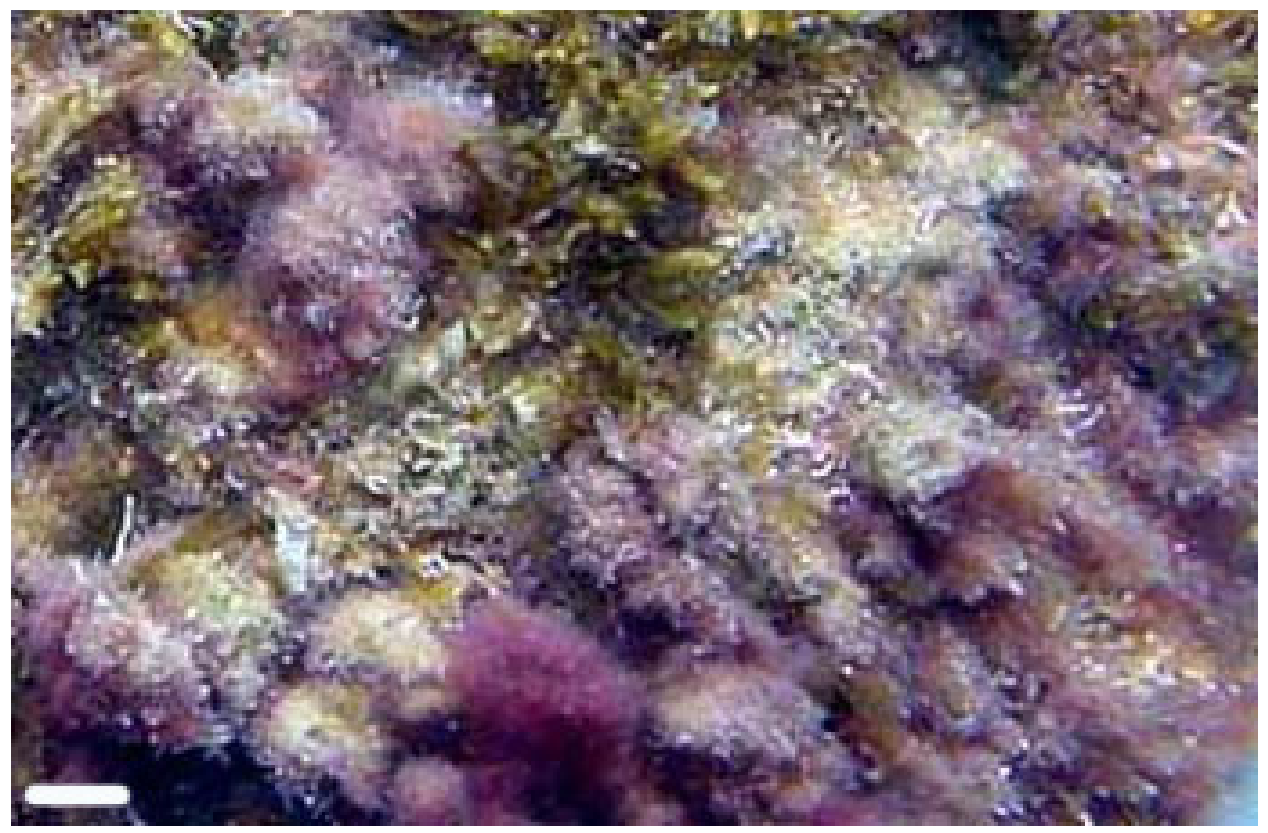

Figura 2.30 - Povoamento Tapete de Falkenbergia. Barra horizontal=2 cm. 
Povoamento 30 - Tapete de Gelidiopsis e Hypnea (Figura 2.31)

Espécies/UTOs dominantes: Hypnea spinella (C. Agardh) Kützing e Gelidiopsis variabilis (J. Agardh) Schmitz.

Descrição: grandes manchas ou faixas com coloração vermelho-escuro a esverdeado, formadas por algas de talo pequeno (menos de 5,0 cm), formando densos tapetes cobrindo completamente o substrato, com eventual espaço vazio entre os talos, que é recoberto por sedimento. $H$. spinella tem eixo cilíndrico com pequenas ramificações em forma de espinho ou espora ao longo de todo o talo. G. variabilis apresenta talo cilíndrico de consistência rígida, lembrando arame.

Ambiente: sobre rochas próximas ao fundo; hidrodinamismo baixo e irradiância baixa.

Níveis extremos de ocorrência (em relação ao 0.0 de maré): inferior: (-)3.4 superior: (-)0.3 Posição: acima do povoamento Região de Substrato Inconsolidado e abaixo de povoamentos muito variáveis.

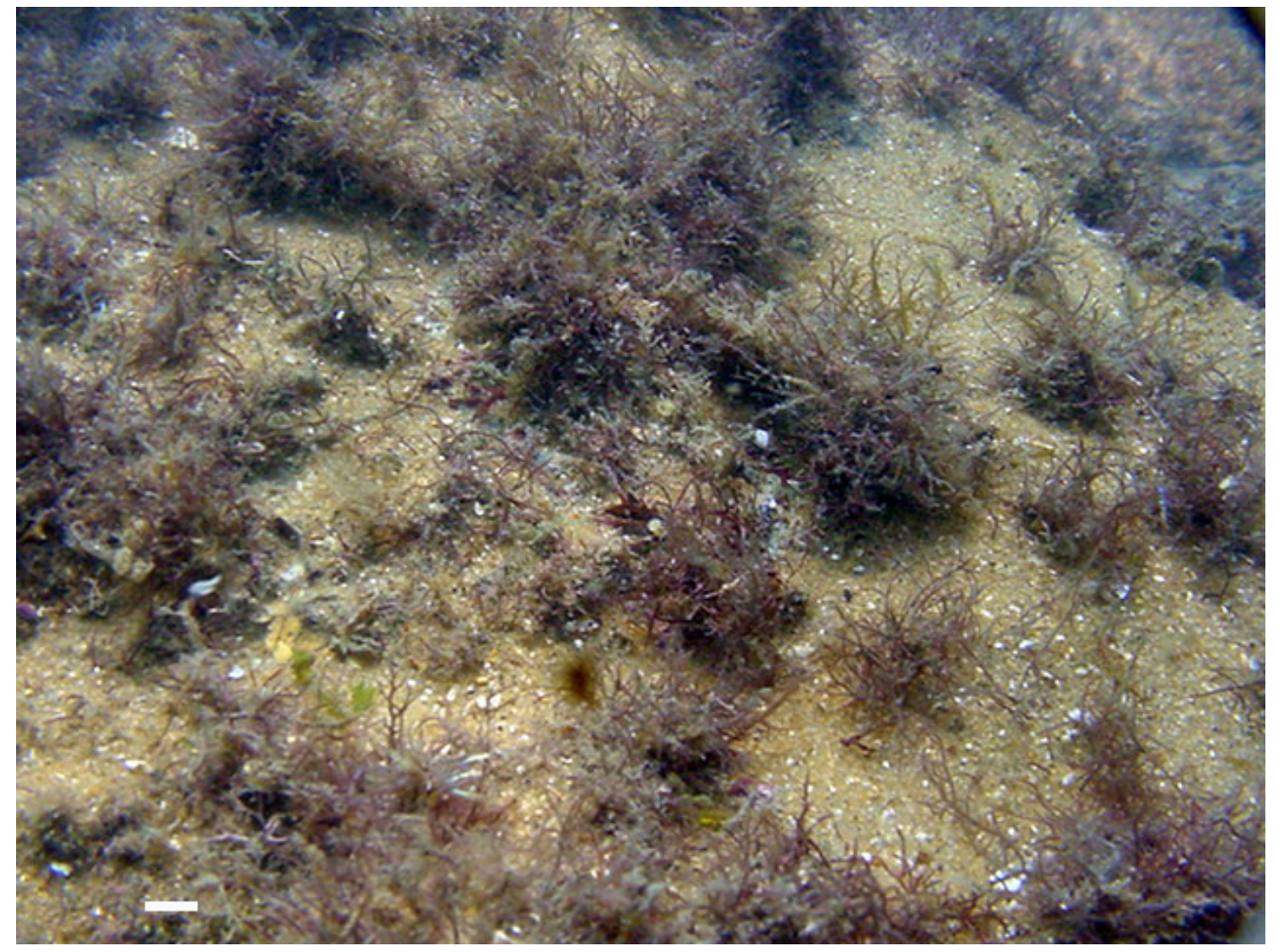

Figura 2.31 - Povoamento Tapete de Gelidiopsis e Hypnea. Barra horizontal=2 cm. 


\section{Povoamento 31 - Tapete de Wrangelia (Figura 2.32)}

Espécies/UTO's dominantes: Wrangelia argus (Mont.) Mont.

Descrição: manchas de tufos densos de cor vermelho intenso, escorregadios ao tato, de algas epibióticas de coloração vermelho escuro, ocorrendo de forma esparsa sobre outros povoamentos, mascarando completamente as espécies hospedeiras, que são variáveis. A Rhodophyta dominante possui talo ereto, eixos abundantemente e alternadamente ramificados, com ramos determinados geralmente subdicotomicamente ramificados.

Ambiente: face superior de rochas; hidrodinamismo intermediário e irradiância baixa a intermediária.

Níveis extremos de ocorrência (em relação ao 0.0 de maré): inferior: (-)2.2 superior: 0.0

Posição: acima dos povoamentos Crosta de Corallinaceae e Tapete de Ectoprocta e abaixo do povoamento Tapete de Ectoprocta (com o qual pode formar uma associação)

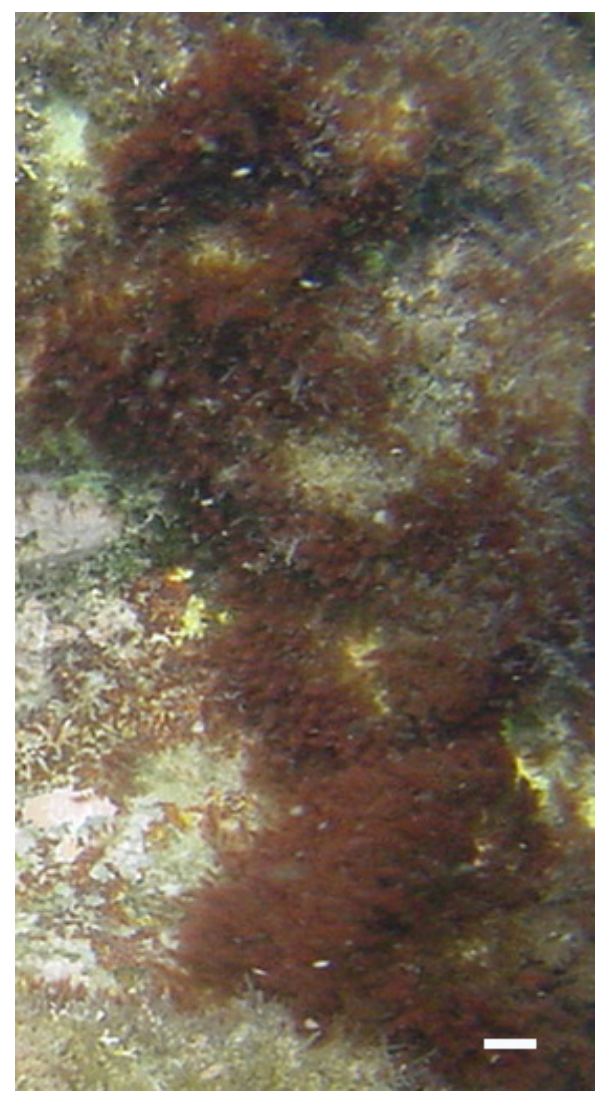

Figura 2.32 - Povoamento Tapete de Wrangelia. Barra horizontal $=2 \mathrm{~cm}$. 


\section{3) Avaliação dos povoamentos encontrados}

Foram encontrados trinta povoamentos e um atributo não biológico (Tabela 2.1). A maior parte dos povoamentos (12 - 38,7\%) apresentou espécies da Divisão Rhodophyta como dominantes, seguida, dentre as algas, de Phaeophyta $(4-12,9 \%)$ e Chlorophyta $(1-3,2 \%)$. Dentre os animais, a distribuição entre os grupos foi mais homogênea, sendo o Filo Ectoprocta o mais representado $(6-19,3 \%)$.

A categoria "Tapete" foi a mais representada, com dez povoamentos (32,2\% do total), seguida de "Banco", com oito, "Crosta", com sete, "Colônia", com cinco e "Região", com um. A maioria dos povoamentos $(22-70,9 \%)$ apresentou apenas uma espécie dominante, sete $(22,3 \%)$ apresentaram duas, e um povoamento apresentou três espécies dominantes.

A grande maioria dos bancos apresentou espécies de alga como dominantes (sete dos oito descritos, ou 87,5\%). O mesmo aconteceu para metade dos tapetes, sendo que a outra metade apresentou Ectoprocta como dominante. Todas as colônias foram relacionadas com animais. As crostas apresentaram como espécie(s) dominante(s) algas (3 - 50\%), animais (2 $33 \%)$ ou ambos $(1-17 \%)$.

Os povoamentos Tapete de Ectoprocta e Crosta de Corallinaceae foram diferenciados em mais de um povoamento pela ocorrência consistente de espécies acompanhantes não dominantes (Carijoa riisei, Phallusia nigra, Polyiphonia spp., Wrangelia argus e Echinometra lucunter).

Os componentes principais de bancos e tapetes foram basicamente associações de espécies que ocorrem aderidas ao substrato. Crostas e colônias apresentam componentes basais responsáveis pela fixação, enquanto espécies associadas, se presentes, ocorriam sobre elas. Colônias foram exclusivamente relacionadas com uma espécie de invertebrado diretamente fixado ao substrato. 
Tabela 2.1 - Listagem dos povoamentos encontrados e Filo/Divisão a que pertence a espécie dominante. O Filo ou Divisão das espécies não dominantes, mas que caracterizam o povoamento, está entre parêntesis.

\begin{tabular}{ll}
\hline \multicolumn{1}{c}{ Povoamento } & Filo/divisão da espécie dominante \\
\hline Banco de Asparagopsis & Rhodophyta \\
Banco de Caulerpa & Chlorophyta \\
Banco de Colpomenia & Phaeophyta \\
Banco de Dichotomaria & Rhodophyta \\
Banco de Dictyota & Phaeophyta \\
Banco de Padina & Phaeophyta \\
Banco de Sargassum & Phaeophyta \\
Banco de Tropiometra & Echinodermata \\
Colônia de Didemnum & Chordata \\
Colônia de Mussismilia & Cnidaria \\
Colônia de Palythoa & Cnidaria \\
Colônia de Schizoporella & Ectoprocta \\
Colônia de Symplegma & Chordata \\
Crosta de Amphimedon & Porifera \\
Crosta de Corallinaceae & Rhodophyta \\
Crosta de Corallinaceae com Echinometra & Rhodophyta e Echinodermata \\
Crosta de Corallinaceae com Polysiphonia & Rhodophyta \\
Crosta de Mycale & Porifera \\
Crosta de Peyssonnelia & Rhodophyta \\
Crosta de Tedania & Porifera \\
Região de Substrato Inconsolidado & Atributo não-biológico \\
Tapete de Amphiroa e Jania & Rhodophyta \\
Tapete de Amphiroa e Jania com Echinometra & Rhodophyta (Echinodermata) \\
Tapete de Ectoprocta & Ectoprocta \\
Tapete de Ectoprocta com Carijoa & Ectoprocta e Cnidaria \\
Tapete de Ectoprocta com Phallusia & Ectoprocta (Chordata) \\
Tapete de Ectoprocta com Polysiphonia & Ectoprocta e Rhodophyta \\
Tapete de Ectoprocta com Wrangelia & Ectoprocta (Rhodophyta) \\
Tapete de Falkenbergia & Rhodophyta \\
Tapete de Gelidiopsis e Hypnea & Rhodophyta \\
Tapete de Wrangelia & Rhodophyta \\
\hline
\end{tabular}

\section{2) Repartição espacial horizontal e vertical georeferencicada dos povoamentos}

\section{1) Repartição horizontal}

$\mathrm{Na}$ Tabela 2.2 é possível notar que apesar de ter havido pequenas alterações nos povoamentos presentes em cada estação nos diferentes setores, o número total de povoamentos ficou praticamente constante. As Figuras 2.33 a 2.35 mostram mais detalhadamente a repartição espacial horizontal dos povoamentos em termos de amplitude e forma de ocupação do espaço nos setores em que foi subdividida a área de estudo. 
Tabela 2.2 - Relação dos povoamentos encontrados na área de estudo e seus respectivos setores de ocorrência.

\begin{tabular}{|c|c|c|c|c|c|c|}
\hline \multirow[t]{2}{*}{ Povoamento } & \multicolumn{2}{|c|}{ Setor 1} & \multicolumn{2}{|c|}{ Setor 2} & \multicolumn{2}{|c|}{ Setor 3} \\
\hline & $\mathbf{V}$ & I & $\mathbf{V}$ & I & $\mathbf{V}$ & I \\
\hline Banco de Asparagopsis & $\mathrm{X}$ & $\mathrm{X}$ & $\mathrm{X}$ & $\mathrm{X}$ & $\mathrm{X}$ & $\mathrm{X}$ \\
\hline Banco de Caulerpa & $\mathrm{X}$ & & & & $\mathrm{X}$ & $\mathrm{X}$ \\
\hline Banco de Colpomenia & & $\mathrm{X}$ & & $\mathrm{X}$ & & $\mathrm{X}$ \\
\hline Banco de Dichotomaria & $\mathrm{X}$ & & $\mathrm{X}$ & $\mathrm{X}$ & $\mathrm{X}$ & $\mathrm{X}$ \\
\hline Banco de Dictyota & $\mathrm{X}$ & $\mathrm{X}$ & $\mathrm{X}$ & & $\mathrm{X}$ & $\mathrm{X}$ \\
\hline Banco de Padina & $\mathrm{X}$ & $\mathrm{X}$ & $\mathrm{X}$ & $\mathrm{X}$ & $\mathrm{X}$ & $\mathrm{X}$ \\
\hline Banco de Sargassum & $\mathrm{X}$ & $\mathrm{X}$ & $\mathrm{X}$ & $\mathrm{X}$ & $\mathrm{X}$ & $\mathrm{X}$ \\
\hline Banco de Tropiometra & & $\mathrm{X}$ & $\mathrm{X}$ & $\mathrm{X}$ & & \\
\hline Colônia de Didemnum & $\mathrm{X}$ & $\mathrm{X}$ & $\mathrm{X}$ & $\mathrm{X}$ & $\mathrm{X}$ & $\mathrm{X}$ \\
\hline Colônia de Mussismilia & $\mathrm{X}$ & $\mathrm{X}$ & $\mathrm{X}$ & $\mathrm{X}$ & & \\
\hline Colônia de Palythoa & $\mathrm{X}$ & $\mathrm{X}$ & & & $\mathrm{X}$ & $\mathrm{X}$ \\
\hline Colônia de Schizoporella & & $\mathrm{X}$ & $\mathrm{X}$ & $\mathrm{X}$ & $\mathrm{X}$ & $\mathrm{X}$ \\
\hline Colônia de Symplegma & & $\mathrm{X}$ & $\mathrm{X}$ & $\mathrm{X}$ & & \\
\hline Crosta de Amphimedon & $\mathrm{X}$ & $\mathrm{X}$ & $\mathrm{X}$ & $\mathrm{X}$ & & \\
\hline Crosta de Corallinaceae & & & & & $\mathrm{X}$ & \\
\hline Crosta de Corallinaceae com Echinometra & $\mathrm{X}$ & $\mathrm{X}$ & $\mathrm{X}$ & $\mathrm{X}$ & $\mathrm{X}$ & $\mathrm{X}$ \\
\hline Crosta de Corallinaceae com Polysiphonia & $\mathrm{X}$ & $\mathrm{X}$ & & & $\mathrm{X}$ & \\
\hline Crosta de Mycale & $\mathrm{X}$ & $\mathrm{X}$ & $\mathrm{X}$ & $\mathrm{X}$ & & \\
\hline Crosta de Peyssonnelia & & & $\mathrm{X}$ & $\mathrm{X}$ & $\mathrm{X}$ & $\mathrm{X}$ \\
\hline Crosta de Tedania & $\mathrm{X}$ & $\mathrm{X}$ & $\mathrm{X}$ & $\mathrm{X}$ & $\mathrm{X}$ & $\mathrm{X}$ \\
\hline Região de Substrato Inconsolidado & $\mathrm{X}$ & $\mathrm{X}$ & $\mathrm{X}$ & $\mathrm{X}$ & $\mathrm{X}$ & $\mathrm{X}$ \\
\hline Tapete de Amphiroa e Jania & $\mathrm{X}$ & $\mathrm{X}$ & $\mathrm{X}$ & $\mathrm{X}$ & $\mathrm{X}$ & $\mathrm{X}$ \\
\hline Tapete de Amphiroa e Jania com Echinometra & & & $\mathrm{X}$ & & & $\mathrm{X}$ \\
\hline Tapete de Ectoprocta & $\mathrm{X}$ & $\mathrm{X}$ & $\mathrm{X}$ & $\mathrm{X}$ & $\mathrm{X}$ & $\mathrm{X}$ \\
\hline Tapete de Ectoprocta com Carijoa & $\mathrm{X}$ & & $\mathrm{X}$ & $\mathrm{X}$ & & \\
\hline Tapete de Ectoprocta com Phallusia & $\mathrm{X}$ & $\mathrm{X}$ & $\mathrm{X}$ & $\mathrm{X}$ & $\mathrm{X}$ & \\
\hline $\begin{array}{l}\text { Tapete de Ectoprocta com Polysiphonia } \\
\text { Tapete de Ectoprocta com Wrangelia }\end{array}$ & $\mathrm{X}$ & $X$ & $\mathrm{X}$ & $\mathrm{X}$ & $\begin{array}{l}X \\
X\end{array}$ & $\mathrm{X}$ \\
\hline Tapete de Falkenbergia & & & $\mathrm{X}$ & $\mathrm{X}$ & & \\
\hline Tapete de Gelidiopsis e Hypnea & $\mathrm{X}$ & $\mathrm{X}$ & $\mathrm{X}$ & $\mathrm{X}$ & $\mathrm{X}$ & $\mathrm{X}$ \\
\hline Tapete de Wrangelia & $\mathrm{X}$ & & & & & $\mathrm{X}$ \\
\hline Total & 22 & 22 & 24 & 23 & 21 & 20 \\
\hline
\end{tabular}




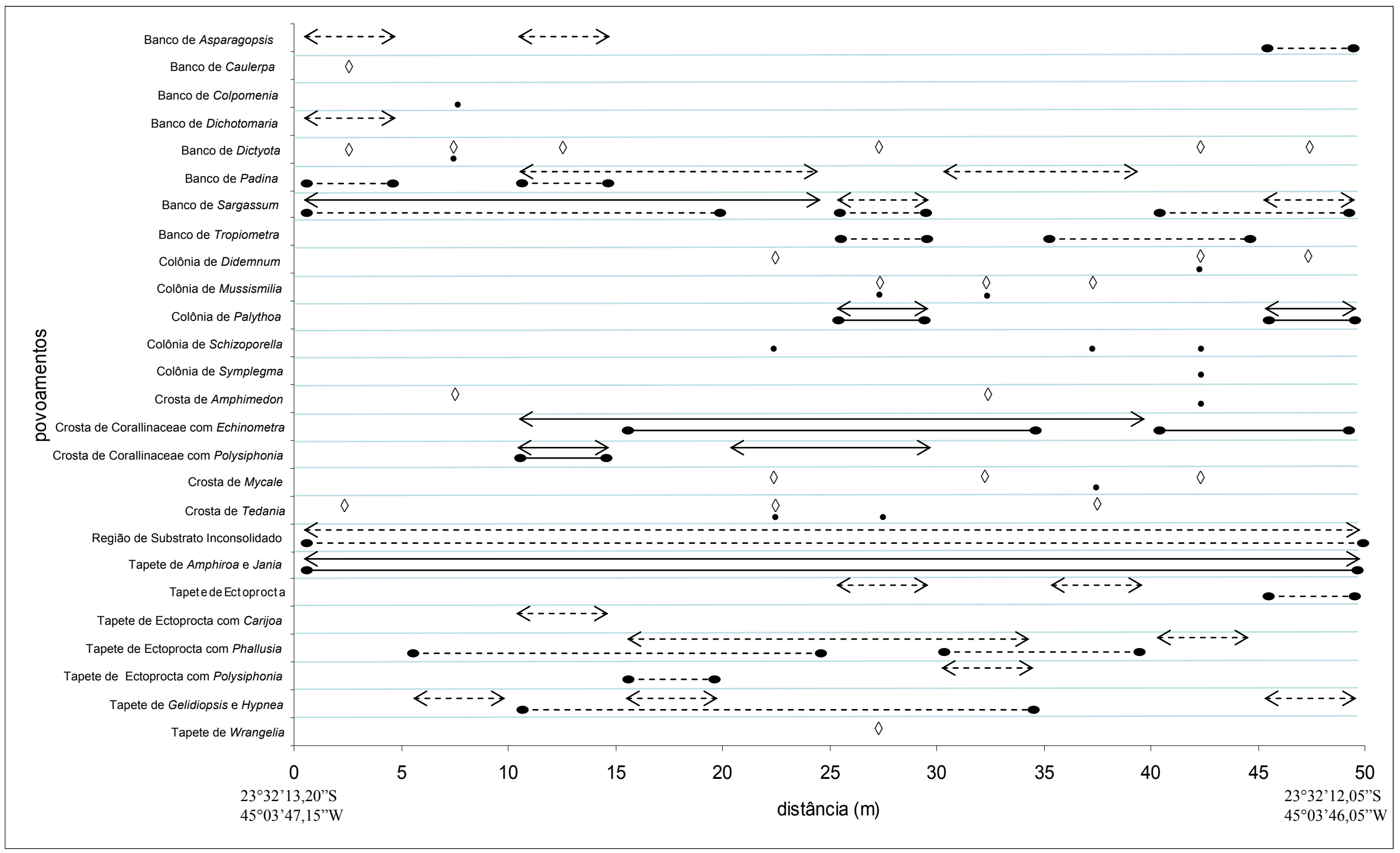

Figura 2.33 - Repartição horizontal dos povoa mentos no Setor 1 no verão e no inverno. Linhas contínuas indicam distribuição contínua; linhas tracejadas indicam distribuição em manchas; losangos indicam distribuição pontual no verão; pontos indicam distribuição pontual no inverno; linhas terminadas em setas são representativas do verão e linhas terminadas em elipses são representativas do inverno. 


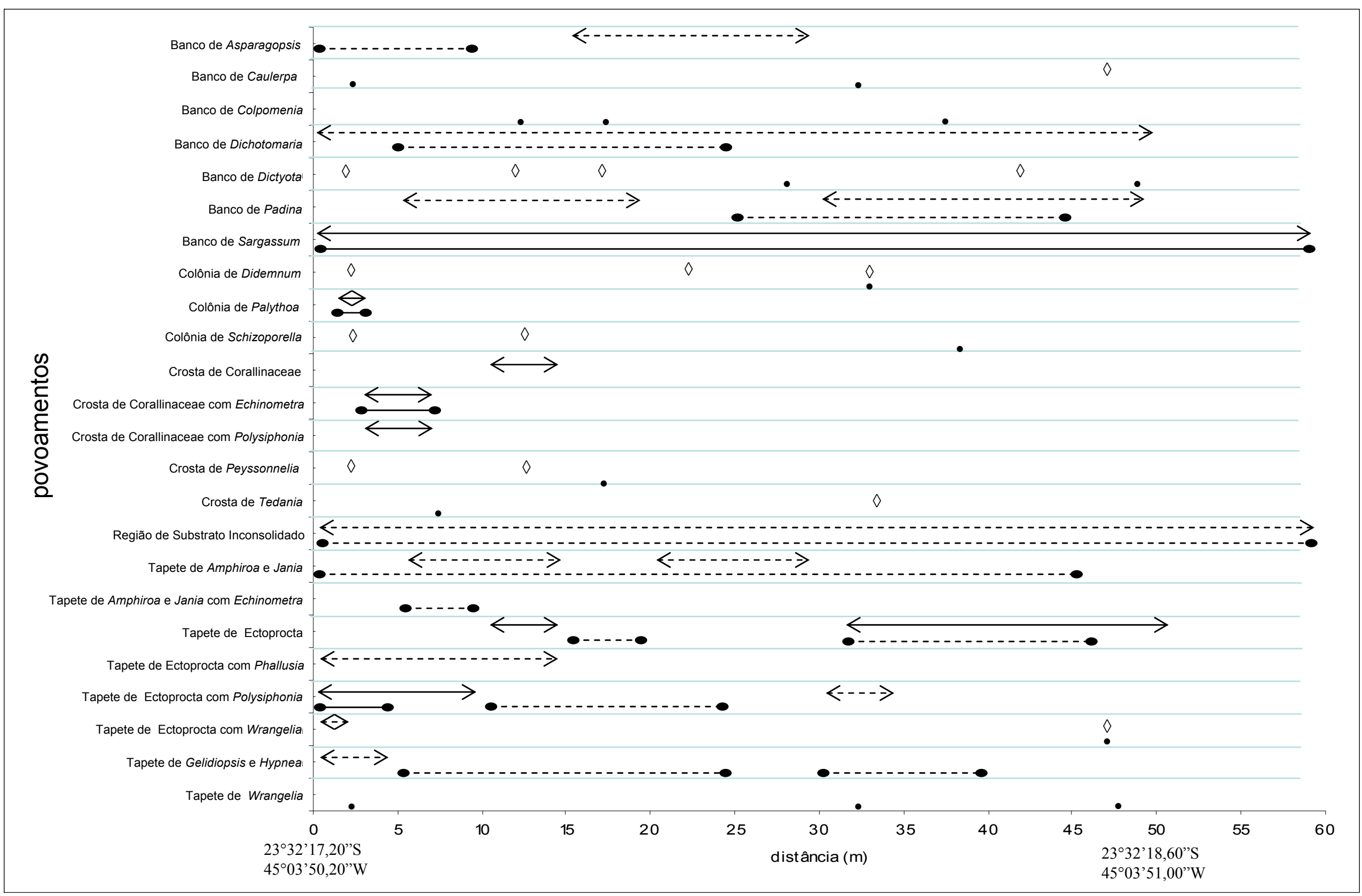

Figura 2.35 - Repartição horizontal dos povoamentos no Setor 3 no verão e no inverno. Linhas contínuas indicam distribuição contínua; 
A maioria dos povoamentos (16 ou 51,6\%) ocorreu nos três setores, seis $(19,3 \%)$ ocorreram nos Setores 1 e 2, quatro (12,9\%) ocorreram nos Setores 1 e 3, dois $(0,06 \%)$ ocorreram nos Setores 2 e 3, dois (Crosta de Corallinaceae e Tapete de Ectoprocta com Wrangelia) foram restritos ao Setor 3 e um (Tapete de Falkenbergia) foi restrito ao Setor 2.

Em relação ao modo de ocorrência, a maior parte dos povoamentos (11 ou 35,5\%) ocorreu apenas pontualmente. Oito povoamentos $(25,8 \%)$ ocorreram apenas na forma de manchas. Três $(0,1 \%)$ ocorreram ora na forma de manchas ora pontualmente, sendo que um deles (Banco de Padina) ocorreu principalmente na forma de manchas. Três $(0,1 \%)$ ocorreram apenas de forma contínua. Seis $(19,3 \%)$ ocorreram ora na forma de manchas e ora de forma contínua, sendo que dois deles (Banco de Dichotomaria e Tapete de Ectoprocta com Polysiphonia) ocorreram principalmente na forma de manchas e um (Banco de Sargassum), principalmente de forma contínua.

Destaca-se no Setor 1 (Figura 2.33) a presença contínua de Tapete de Amphiroa e Jania e a presença de Região de Substrato Inconsolidado ao longo de toda a área, este último na forma de manchas. Outros povoamentos que se destacaram neste setor foram Banco de Sargassum, Crosta de Corallinaceae com Echinometra, Tapete de Ectoprocta com Phallusia e Tapete de Gelidiopsis e Hypnea.

No Setor 2 (Figura 2.34), os povoamentos encontrados ao longo de toda a área foram Banco de Sargassum, ocorrendo principalmente de forma contínua, Banco de Dichotomaria e Região de Substrato Inconsolidado, ocorrendo principalmente na forma de manchas, e Tapete de Amphiroa e Jania e Tapete de Ectoprocta, ocorrendo ora na forma de manchas e ora de maneira contínua. Outros povoamentos que se destacaram neste setor foram Colônia de Schizoporella, Crosta de Amphimedon, Tapete de Ectoprocta com Phallusia e Tapete de Gelidiopsis e Hypnea.

Finalmente, no Setor 3 (Figura 2.35) destaca-se a presença contínua de Banco de Sargassum e de Região de Substrato Inconsolidado ao longo de toda a área, o primeiro de 
forma contínua e o segundo na forma de manchas. Outros povoamentos que se destacaram neste setor foram Banco de Dichotomaria, Banco de Padina e Tapete de Amphiroa e Jania, todos ocorrendo na forma de manchas.

No inverno, notam-se algumas diferenças na repartição espacial de alguns povoamentos. Banco de Caulerpa, Banco de Dichotomaria, Tapete de Ectoprocta com Carijoa e Tapete de Wrangelia desapareceram do Setor 1, Banco de Dictyota e Tapete de Amphiroa e Jania com Echinometra desapareceram do Setor 2, Banco de Colpomenia apareceu em todos os setores, Banco de Tropiometra, Colônia de Schizoporella e Colônia de Symplegma ampliaram suas distribuições para o Setor 1, Crosta de Corallinaceae, Crosta de Corallinaceae com Polysiphonia, Tapete de Ectoprocta com Phallusia e Tapete de Ectoprocta com Wrangelia desapareceram do Setor 3, enquanto Tapete de Amphiroa e Jania com Echinometra e Tapete de Wrangelia apareceram neste setor.

Observou-se ainda nesta estação (Tabela 2.2 e Figuras 2.33 a 2.35) que os indivíduos formadores de Banco de Dictyota estavam bem mais esparsos ou ausentes em diversos pontos onde haviam sido encontrados no verão. Além disso, Banco de Sargassum apresentou-se mais descontínuo no Setor 1 e em parte do Setor 2. Colônia de Didemnum, Crosta de Corallinaceae com Echinometra, Crosta de Tedania, Crosta de Mycale e Crosta de Amphimedon ampliaram suas repartições horizontais no Setor 2. Crosta de Corallinaceae foi encontrada no Setor 3 associada com ouriços do gênero Echinometra. Crosta de Corallinaceae com Polysiphonia apresentou menor repartição no Setor 1. Tapete de Gelidiopsis e Hypnea e Tapete de Amphiroa e Jania tiveram suas repartições aumentadas em todos os setores.

A Figura 2.36 mostra que se o total da área de estudo for considerado, Banco de Sargassum apresentou a maior freqüência relativa no verão $(25,3 \%)$ e Tapete de Amphiroa e Jania apresentou a maior freqüência relativa no inverno (21,3\%). Tapete de Ectoprocta apresentou o terceiro maior valor tanto no verão $(10,6 \%)$ quanto no inverno $(10,3 \%)$. 
Se os setores forem considerados separadamente, o povoamento com maior freqüência relativa no Setor 1 foi Tapete de Amphiroa e Jania, com 24,3\% e 28,6\%, para o verão e inverno, respectivamente, seguido de Banco de Sargassum, com 18,7\% e 17,9\%, para o verão e inverno, respectivamente. Os demais povoamentos não apresentaram valores acima de $15 \%$ e somaram $57,0 \%$ de freqüência relativa no verão e $53,5 \%$ no inverno.

O povoamento com maior freqüência relativa no Setor 2 foi Banco de Sargassum no verão (26,9\%), seguido de Tapete de Ectoprocta (13,0\%) e Tapete de Amphiroa e Jania (10,4\%). No inverno Tapete de Amphiroa e Jania apresentou maior valor (19,2\%), seguido de Banco de Sargassum $(15,1 \%)$ e Tapete de Ectoprocta $(13,4 \%)$. Os demais povoamentos não apresentaram valores acima de $15 \%$ e somaram $49,7 \%$ de freqüência relativa no verão e $52,3 \%$ no inverno.

O povoamento com maior freqüência relativa no Setor 3 foi Banco de Sargassum, com $25,5 \%$ e $33,0 \%$, para o verão e inverno respectivamente, seguido de Banco de Dichotomaria no verão (13,8\%) e de Tapete de Amphiroa e Jania no inverno (23,1\%). Os demais povoamentos não apresentaram valores acima de $15 \%$ e somaram $61,2 \%$ de freqüência relativa no verão e $43,9 \%$ no inverno.

Em síntese, todos os setores são principalmente caracterizados, em termos de freqüência relativa, por povoamentos com algas como espécies dominantes. No Setor 2, os povoamentos que apresentam organismos animais como espécies dominantes foram mais freqüentes que nos demais setores, chegando quase a se igualar à freqüência dos povoamentos de algas (37,7\% e 49,3\% de freqüência relativa no verão e inverno, respectivamente). 

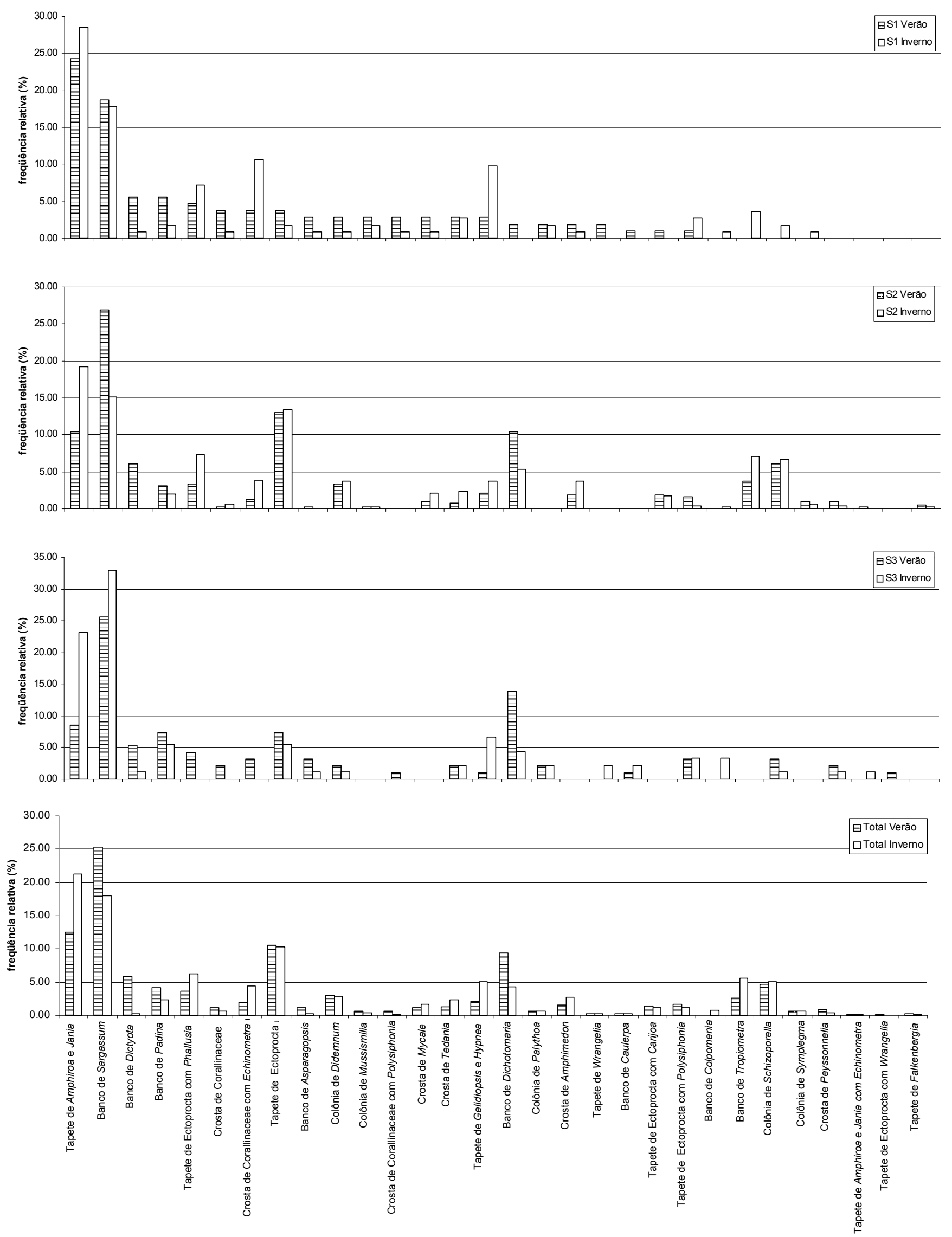

povoamento

Figura 2.36 - Freqüência relativa dos povoamentos separados por setor e para o total da área de estudo. $\mathrm{S} 1=$ Setor $1, \mathrm{~S} 2=$ Setor $2, \mathrm{~S} 3=$ Setor 3 . 


\section{2) Repartição vertical}

Entre $0,0-0,5 \mathrm{~m}$ de profundidade, foram encontrados 12 povoamentos no verão e 21 no inverno (Figura 2.37). Banco de Sargassum apresentou maior freqüência relativa tanto no verão quanto no inverno (62,2\% e 35,1\%, respectivamente). Considerando-se apenas o Setor 2, Banco de Sargassum apresentou $85,7 \%$ de freqüência relativa no verão. Destaca-se o aumento da freqüência relativa de Tapete de Amphiroa e Jania de 5,41\% no verão para 18,9\% no inverno. Os demais povoamentos somaram $32,4 \%$ no verão e $45,95 \%$ no inverno.

Entre $0,5-1,0 \mathrm{~m}$ de profundidade, foram encontrados 22 povoamentos em ambas as estações (Figura 2.38), com Banco de Sargassum apresentando novamente maior freqüência relativa tanto no verão quanto no inverno $(45,4 \%$ e $27,7 \%$, respectivamente), seguido de Tapete de Amphiroa e Jania (11,3\% e 23,2\%, respectivamente para o verão e inverno). Se considerarmos apenas o Setor 1, Tapete de Amphiroa e Jania apresentou maior freqüência relativa tanto no verão quanto no inverno (30,8\% e $29,6 \%$, respectivamente). Ainda quanto a este povoamento, nota-se que no inverno nos Setores 2 e 3 houve um aumento de sua freqüência relativa, fazendo com que nesta estação seu valor se aproximasse do de Banco de Sargassum. Os demais povoamentos somaram $43,3 \%$ no verão e $49,1 \%$ no inverno. 

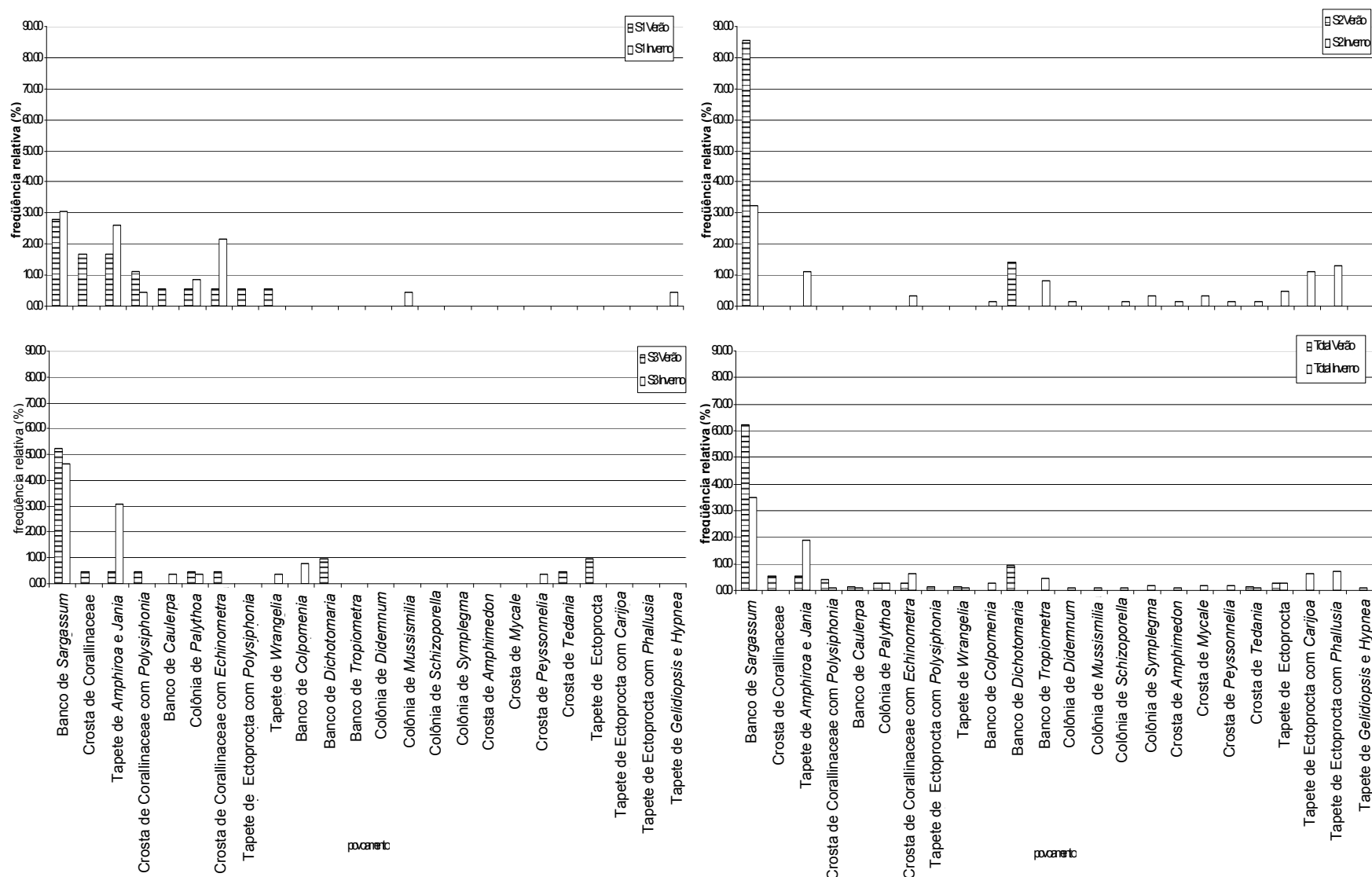

Figura 2.37 - Freqüência relativa dos povoamentos entre $0,0-0,5 \mathrm{~m}$ de profundidade separados por setor e para o total da área de estudo. $\mathrm{S} 1=$ Setor $1, \mathrm{~S} 2=$ Setor 2, $\mathrm{S} 3=$ Setor 3.
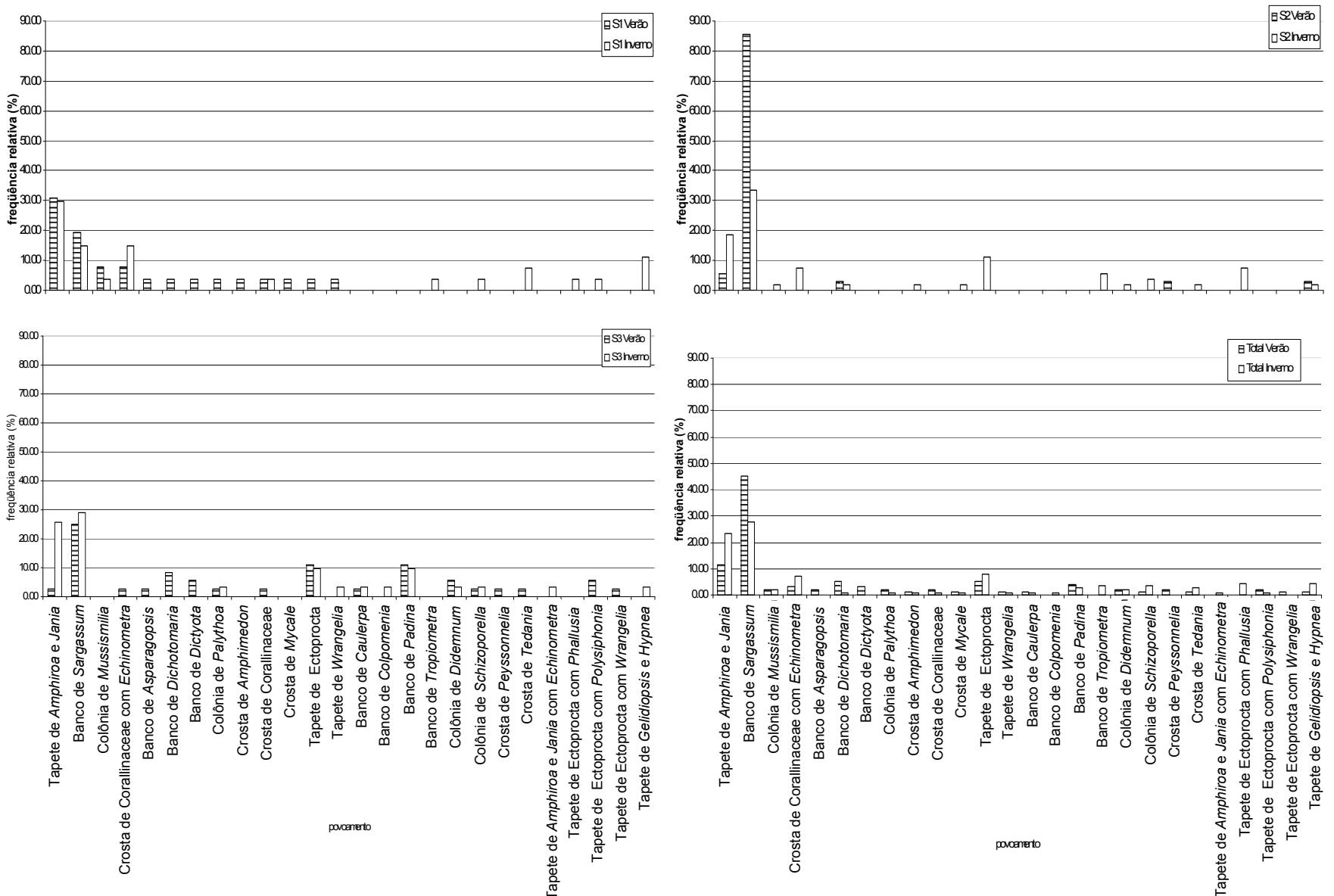

Figura 2.38 - Freqüência relativa dos povoamentos entre $0,5-1,0 \mathrm{~m}$ de profundidade separados por setor e para o total da área de estudo. $\mathrm{S} 1=$ Setor $1, \mathrm{~S} 2=$ Setor $2, \mathrm{~S} 3=\mathrm{Setor} 3$. 
Entre 1,0-1,5 m de profundidade, foram encontrados 19 povoamentos no verão e 15 no inverno (Figura 2.39). Banco de Sargassum apresentou maior freqüência relativa no verão e segunda maior no inverno (31,5\% e $18,3 \%$, respectivamente) e Tapete de Amphiroa e Jania apresentou segunda maior freqüência relativa no verão e maior freqüencia relativa no inverno (18,0\% e 29,2\%, respectivamente). Essa inversão de posições ocorreu pelo aumento da freqüência relativa de Tapete de Amphiroa e Jania no Setor 2 e diminuição da freqüência relativa de Banco de Sargassum neste mesmo setor. Os demais povoamentos somaram 50,5\% no verão e $52,5 \%$ no inverno.

Entre 1,5-2,0 m de profundidade, foram encontrados 19 povoamentos no verão e 21 no inverno (Figura 2.40). No verão, Banco de Sargassum apresentou maior freqüência relativa (15,0\%), seguido de Tapete de Amphiroa e Jania (14,3\%) e Tapete de Ectoprocta (12,1\%). No inverno, Tapete de Amphiroa e Jania apresentou maior freqüência relativa (24,1\%), seguido de Tapete de Ectoprocta (13,5\%) e Banco de Sargassum (9,8\%). Essa mudança de posições ocorreu pelo aumento da freqüência relativa de Tapete de Amphiroa e Jania nos Setores 1 e 2 e diminuição da freqüência relativa de Banco de Sargassum nestes mesmos setores. Os demais povoamentos somaram $58,6 \%$ no verão e $52,6 \%$ no inverno. 
Capitulo 2 - Descrição e levantamento da repartição espacial de povoamentos do P.Est.Ilha Anchieta
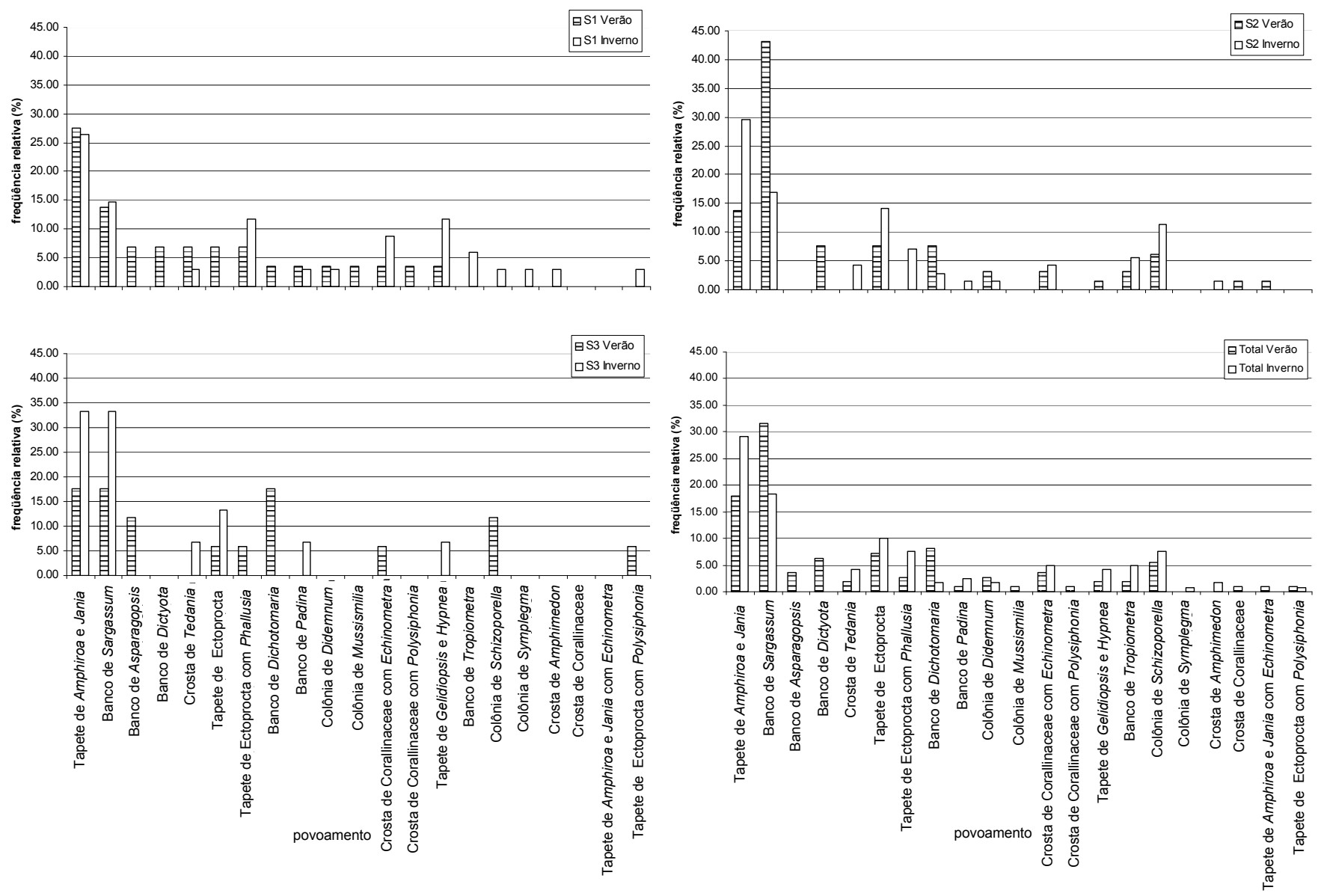

Figura 2.39 - Freqüência relativa dos povoamentos entre 1,0-1,5 $\mathrm{m}$ de profundidade separados por setor e para o total da área de estudo. $\mathrm{S} 1=$ Setor $1, \mathrm{~S} 2=$ Setor $2, \mathrm{~S} 3=$ Setor 3.
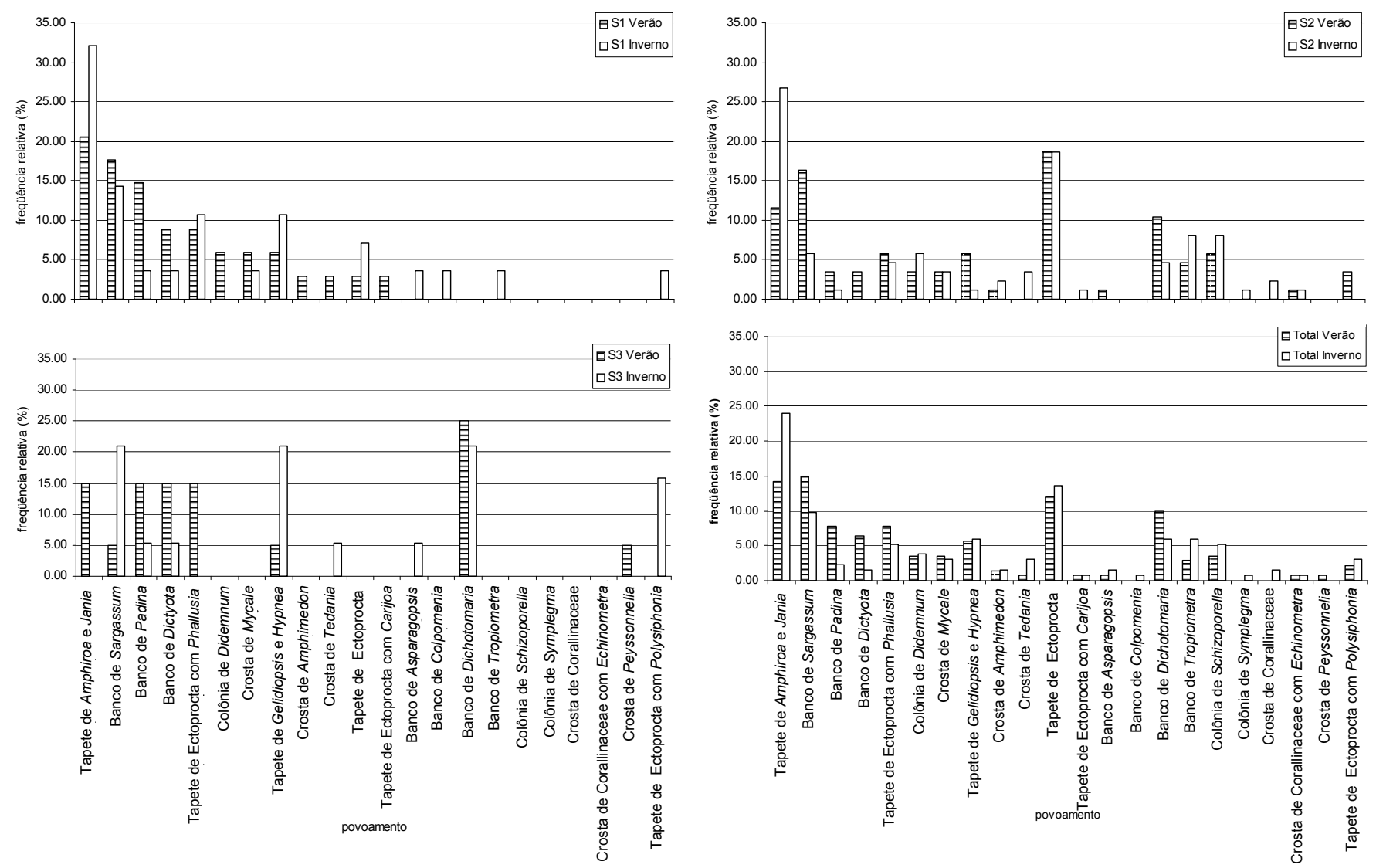

Figura 2.40 - Freqüência relativa dos povoamentos entre 1,5-2,0 m de profundidade separados por setor e para o total da área de estudo. S1 = Setor $1, \mathrm{~S} 2=$ Setor 2, S3 = Setor 3. 
Entre 2,0-2,5 $\mathrm{m}$ de profundidade, foram encontrados 16 povoamentos no verão e 17 no inverno (Figura 2.41a). No verão, Tapete de Amphiroa e Jania apresentou maior freqüência relativa (14,1\%), seguido de Tapete de Ectoprocta (13,0\%) e Colônia de Schizoporella (13,0\%). No inverno, Tapete de Ectoprocta apresentou maior freqüência relativa (17,2\%), seguido de Tapete de Amphiroa e Jania (14,9\%) e Banco de Tropiometra (9,2\%). Nesta estação, Colônia de Schizoporella caiu para a quarta posição junto com Crosta de Amphimedon (ambos com 8,1\%). Os demais povoamentos somaram 59,8\% no verão e 42,5\% no inverno.

Entre 2,5-3,0 $\mathrm{m}$ de profundidade, foram encontrados 19 povoamentos no verão e 16 no inverno (Figura 2.41b). No verão, Tapete de Ectoprocta apresentou maior freqüência relativa (19,6\%), seguido de Banco de Dichotomaria (13,0\%) e Banco de Dictyota $(9,8 \%)$. No inverno, Tapete de Ectoprocta, Tapete de Amphiroa e Jania e Banco de Dichotomaria apresentaram maior freqüência relativa (12,5\%). Banco de Dictyota desapareceu deste nível nesta estação. Os demais povoamentos somaram $57,6 \%$ no verão e $62,5 \%$ no inverno.

Entre 3,0-3,5 m de profundidade, foram encontrados 7 povoamentos no verão e 12 no inverno (Figura 2.41c). No verão, Tapete de Ectoprocta e Banco de Dichotomaria apresentaram maior freqüência relativa (ambos com 21,1\%), seguidos de Banco de Dictyota, Banco de Padina e Tapete de Ampiroa e Jania (os três com 15,8\%). No inverno, Banco de Sargassum e Tapete de Amphiroa e Jania apresentaram maior freqüência relativa (ambos com 18,8\%), seguidos de Tapete de Gelidiopsis e Hypnea (15,6\%). Os demais povoamentos somaram $10,5 \%$ no verão e $46,9 \%$ no inverno. 


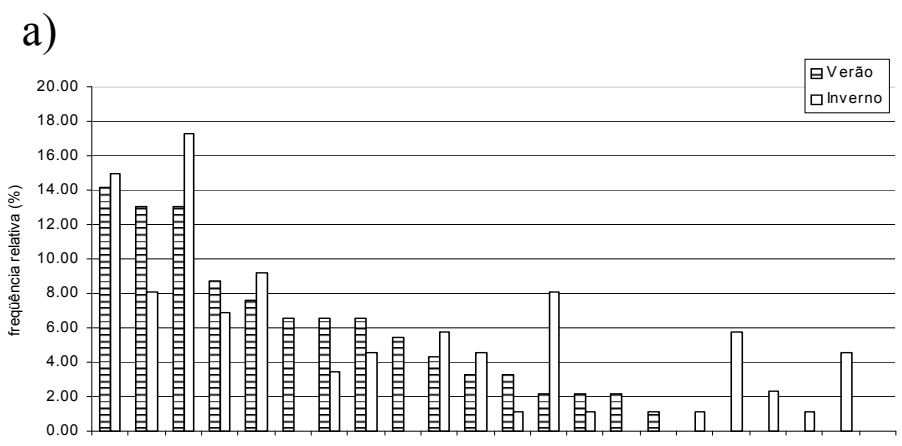

b)

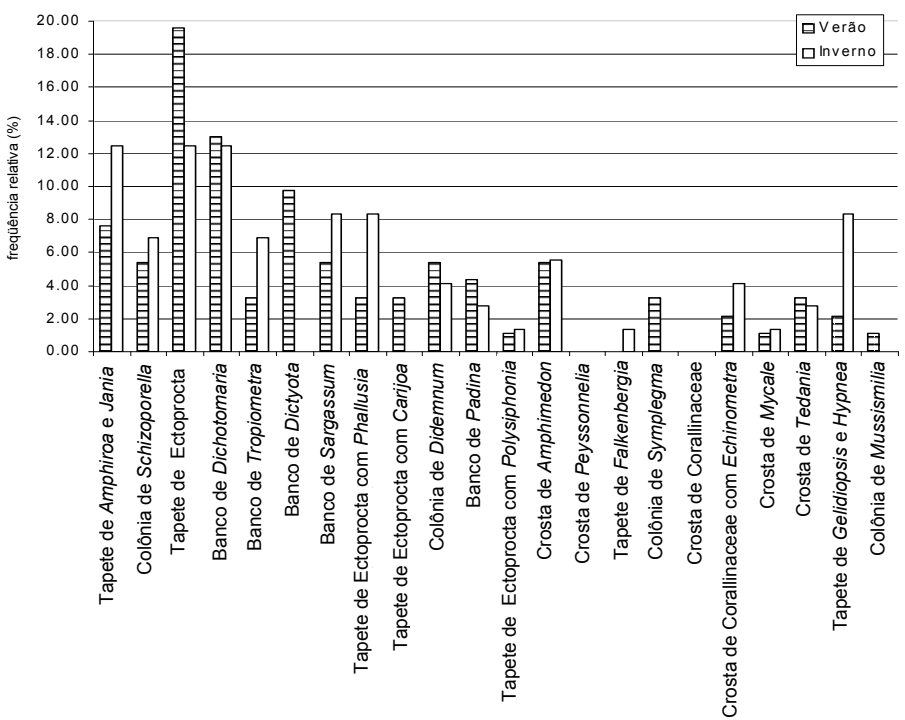

c)

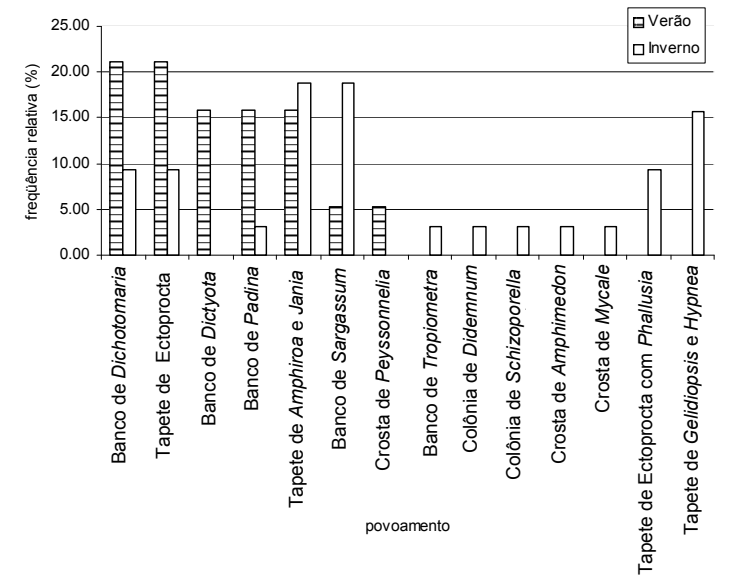

Figura 2.41 - Freqüência relativa dos povoamentos entre a) 2,0-2,5 m, b) 2,5-3,0 m e c) 3,0-3,5 $\mathrm{m}$ de profundidade (presentes apenas no Setor 2). 


\section{3) Repartição espacial em modo $R$}

As Figuras 2.42 e 2.43 mostram os dendrogramas referentes à repartição espacial em modo R dos povoamentos em função dos setores e profundidades.

Quando se considerou a presença dos povoamentos na totalidade dos setores (Figura 2.42) houve a formação de dois agrupamentos significativos: 1) do Setor 1 (verão e inverno) com o Setor 2 (verão e inverno) com $79,4 \%$ de similaridade e 2) do Setor 3 (verão e inverno) com $82,3 \%$ de similaridade.

O Setor 2 apresentou alta similaridade entre as duas estações $(93,6 \%)$.

A similaridade entre os três setores em conjunto, apesar de não ser significativa para o nível crítico adotado, é bastante alta (74,7\%). Isso indica que existiu grande semelhança na composição total dos povoamentos dos três setores.

Quando foi levada em conta a presença dos povoamentos nos diferentes níveis de profundidade (Figura 2.43), houve a formação de dois agrupamentos significativos, entretanto nenhum dos dois foi relacionado com este parâmetro, já que os grupos formados apresentaram elementos de níveis diferentes, sendo um formado principalmente por elementos do Setor 2 e o outro com um elemento do Setor 2 e outro do Setor 3. Observa-se, além disso, que houve a formação de um agrupamento, apesar de não significativo, relacionado com o nível de profundidade entre 0,0-0,5 $\mathrm{m}$ dos Setores 1 e 3, provavelmente pela presença importante de Banco de Sargassum e Tapete de Amphiroa e Jania neste nível em ambos os setores. 


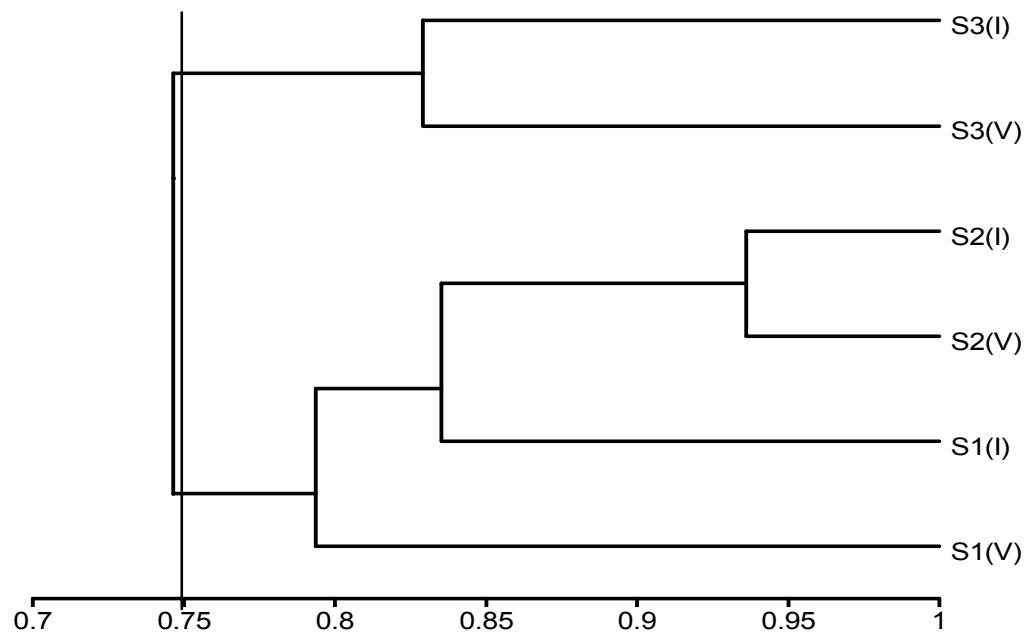

Figura 2.42 - Dendrograma qualitativo baseado na presença/ausência dos povoamentos nos diferentes setores no verão e inverno. Índice de similaridade qualitativo de Sørensen. A linha vertical indica o nível crítico de fusão dos grupos (75\%).

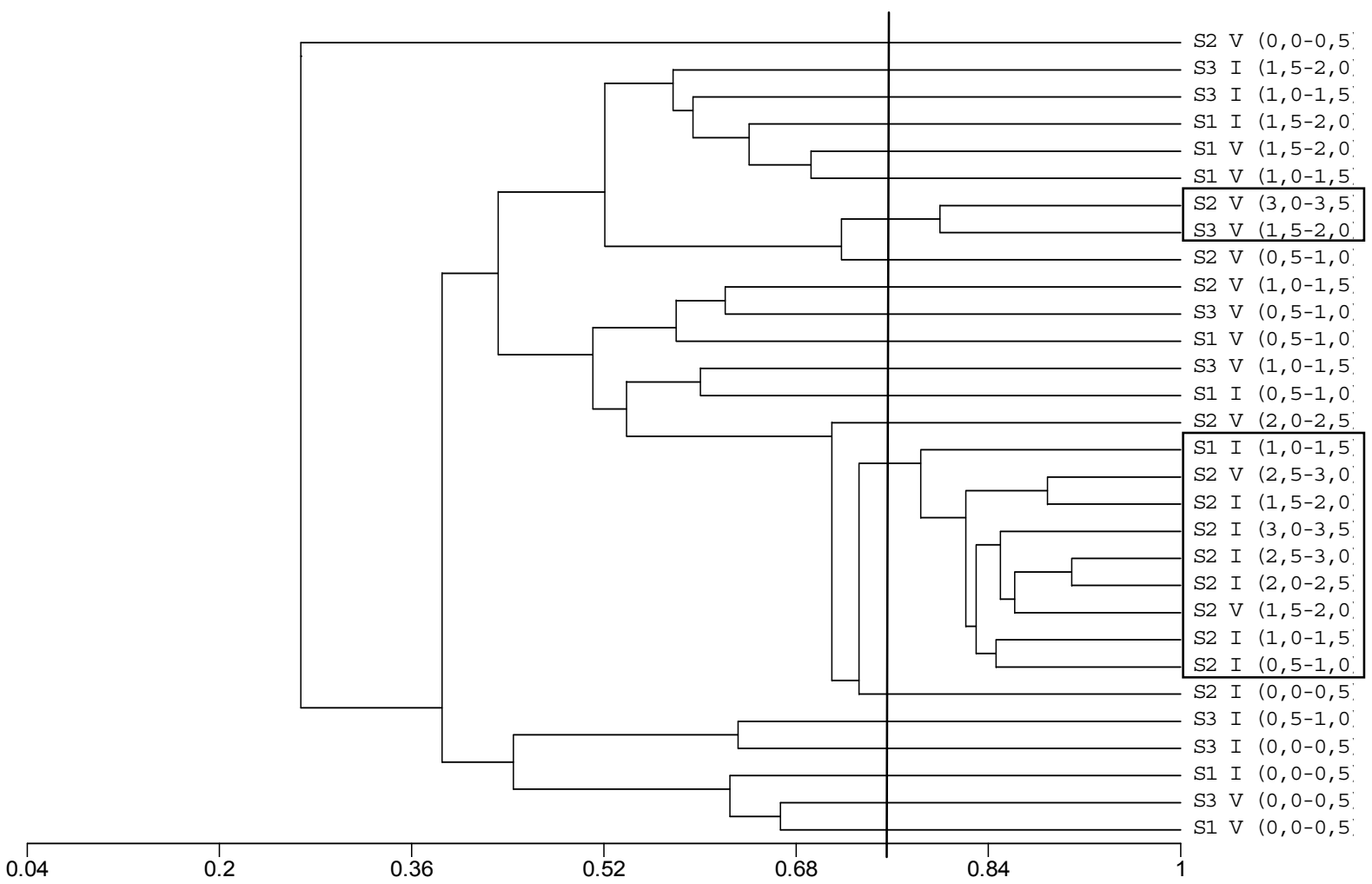

Figura 2.43 - Dendrograma qualitativo baseado na presença/ausência dos povoamentos nos diferentes níveis de profundidade no verão e inverno. Índice de similaridade qualitativo de Sørensen. A linha vertical indica o nível crítico de fusão dos grupos (75\%). 


\section{DISCUSSÃo}

Os resultados obtidos mostram um panorama da paisagem dos costões rochosos da Ilha Anchieta, descrevendo os povoamentos ali presentes, assim como sua repartição espacial.

Um total de 30 povoamentos mais 1 atributo não biológico puderam ser distinguidos no trecho de 260 metros estudado.

A hipótese de que poucas espécies dominam as faces do mosaico da paisagem foi corroborada, sendo que a maior parte dos povoamentos $(70,9 \%)$ apresentou apenas uma espécie recobrindo $80 \%$ ou mais do substrato.

As 29 espécies dominantes (17 de algas e 12 de invertebrados) relacionadas com os 30 povoamentos encontrados provavelmente representam uma proporção significativa do total de táxons esperados para a área, apesar de não haver publicações descrevendo o infralitoral desta região do litoral de São Paulo (Berchez et al., 2005). Fora isso, nos poucos trabalhos que produziram listas incluindo tanto animais quanto algas nos costões rochosos do litoral sudeste do Brasil, o número total de táxons variou de $32 \mathrm{em}$ dois transectos verticais de $50 \mathrm{~cm}$ de largura (Oliveira Filho \& Paula, 1983), a 70 ao longo de uma estação mais longa de aproximadamente $5 \mathrm{~km}$ (Joly, 1957). Outros autores (Oliveira, 1947; Oliveira Filho \& Mayal, 1976; Maggs et al., 1979) encontraram números intermediários. Oigman-Pszczol et al. (2004), que também amostraram as espécies em transectos de 14-56 m posicionados até aproximadamente $2 \mathrm{~m}$ de profundidade, encontraram 14 espécies de invertebrados e 8 de algas dominantes, um número total bastante próximo ao encontrado neste estudo.

Estas espécies dominantes parecem estar representadas na costa do Brasil e a partir dos dados de outros estudos sobre comunidades bentônicas realizados no país, pode-se inferir, mesmo sabendo-se que estes estudos utilizaram abordagens diferentes das daqui empregadas, quais dos aqui denominados povoamentos estavam presentes nos locais estudados (Tabela 2.3). 
Tabela 2.3 - Alguns estudos sobre comunidades marinhas bentônicas de substrato consolidado realizados no Brasil e povoamentos encontrados nos mesmos a partir de inferência sobre os dados.

\begin{tabular}{|c|c|c|c|c|c|c|c|c|c|c|c|c|c|c|c|c|c|c|c|c|c|}
\hline & 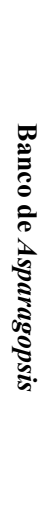 & 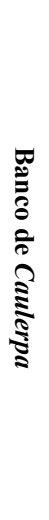 & 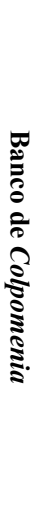 & 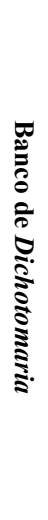 & 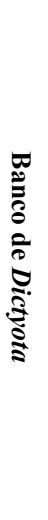 & 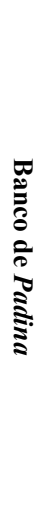 & 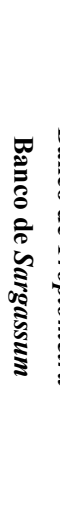 & 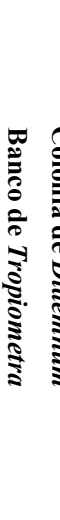 & 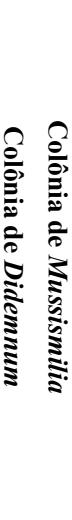 & 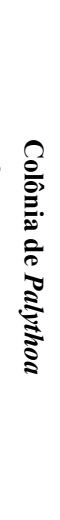 & 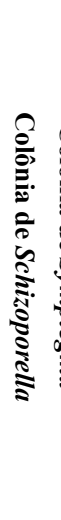 & 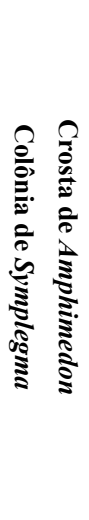 & 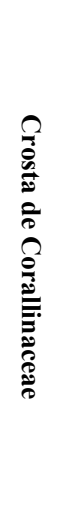 & 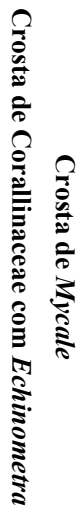 & 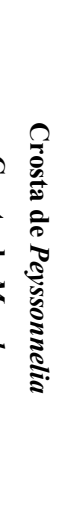 & 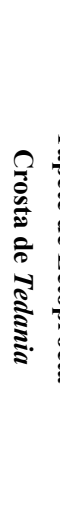 & 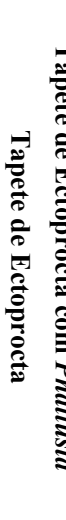 & 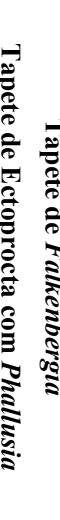 & 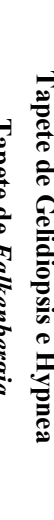 & 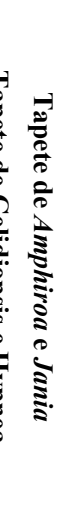 & 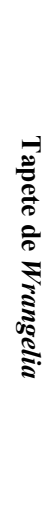 \\
\hline Amado Filho et al. (2003) & & & & & & $\mathrm{X}$ & $\mathrm{X}$ & & & & & & & & & & & & $\mathrm{x}$ & & \\
\hline Carvalho (1983) & & $\mathrm{X}$ & & & $\mathrm{X}$ & & $\mathrm{X}$ & & & & & & & & & & & & & $\mathrm{X}$ & \\
\hline Coelho \& Ramos-Porto (1980) & & $\mathrm{X}$ & & $\mathrm{X}$ & $\mathrm{X}$ & & $\mathrm{X}$ & & $\mathrm{X}$ & ? & & & & $\mathrm{X}$ & & & & & $\mathrm{X}$ & & \\
\hline Coimbra (1998) & & & $\mathrm{X}$ & $\mathrm{X}$ & $\mathrm{X}$ & $\mathrm{X}$ & $\mathrm{X}$ & & $\mathrm{X}$ & & & & $\mathrm{X}$ & & & $\mathrm{X}$ & & & & $\mathrm{X}$ & \\
\hline Correia (1997) & & $\mathrm{X}$ & & & & $\mathrm{X}$ & $\mathrm{X}$ & & & $\mathrm{X}$ & & & & & & & & & & & \\
\hline Costa (1962) & & $\mathrm{X}$ & $\mathrm{X}$ & & & & & & & & $\mathrm{X}$ & & $\mathrm{X}$ & & & $\mathrm{X}$ & $\mathrm{X}$ & & & & \\
\hline Costa Jr. et al. (2002) & & $\mathrm{X}$ & $\mathrm{X}$ & $\mathrm{X}$ & $\mathrm{X}$ & $\mathrm{X}$ & $\mathrm{X}$ & & & & & & & & & & & & & & \\
\hline Edwards \& Lubbock (1983) & & $\mathrm{X}$ & & & $\mathrm{X}$ & & & & & $\mathrm{X}$ & & & $\mathrm{X}$ & & & & & & & & \\
\hline Eston \& Bussab (1990) & & & & & & & $\mathrm{X}$ & & & & & & & & & & & & & & \\
\hline Eston et al. (1986) & & & & & $\mathrm{X}$ & & $\mathrm{X}$ & & $X \quad X$ & $x$ & & & $\mathrm{X}$ & & $\mathrm{X}$ & & & & & & \\
\hline Figueiredo et al. (2004) & & & & $\mathrm{X}$ & & & $\mathrm{X}$ & & & $\mathrm{X}$ & & & $\mathrm{X}$ & & & & & & & $\mathrm{X}$ & \\
\hline Giordano (1986) & & & $\mathrm{X}$ & & $\mathrm{X}$ & $\mathrm{X}$ & $\mathrm{X}$ & & $X \quad X$ & $x$ & $\mathrm{X}$ & $\mathrm{X}$ & $\mathrm{X}$ & $\mathrm{X}$ & & $\mathrm{X}$ & $\mathrm{X}$ & & & $\mathrm{X}$ & \\
\hline Guerrazzi (1987) & & & & & & & & & & & & & $\mathrm{X}$ & & & & & & & $\mathrm{X}$ & \\
\hline Joly (1957) & & $\mathrm{X}$ & $\mathrm{X}$ & & & $\mathrm{X}$ & $\mathrm{X}$ & & & & & & $\mathrm{X}$ & & & & & $x$ & $\mathrm{X}$ & $\mathrm{X}$ & \\
\hline Maggs (1979) & & & & & $\mathrm{X}$ & & $\mathrm{X}$ & $\mathrm{X}$ & $?$ & & $\mathrm{X}$ & $?$ & $\mathrm{X}$ & ? & $\mathrm{X}$ & $\mathrm{X}$ & $\mathrm{X}$ & & & & \\
\hline $\begin{array}{l}\text { Marins-Rosa et al. (2004) } \\
\quad \text { Mitchell et al. (1986) }\end{array}$ & $\mathrm{X}$ & $\mathrm{X}$ & & $\mathrm{X}$ & $\mathrm{X}$ & $\mathrm{X}$ & $\begin{array}{l}X \\
X\end{array}$ & & & & & & & & & & & & $?$ & $\mathrm{X}$ & $\mathrm{X}$ \\
\hline Muñoz \& Pereira (1998) & & $\mathrm{X}$ & $\mathrm{X}$ & $\mathrm{X}$ & $\mathrm{X}$ & & & & & & & & & & & & & & & $\mathrm{X}$ & \\
\hline Muricy \& Meireles (1988) & & & & & & & & & & $\mathrm{X}$ & & $\mathrm{X}$ & $\mathrm{X}$ & & & $\mathrm{X}$ & & & & $\mathrm{X}$ & \\
\hline Nonato \& Pérès (1961) & & $\mathrm{X}$ & & & & & $\mathrm{X}$ & & $\mathrm{X}$ & & $\mathrm{X}$ & $\mathrm{X}$ & $\mathrm{X}$ & & & & $\mathrm{X}$ & & & $\mathrm{X}$ & \\
\hline $\begin{array}{c}\text { Oigman-Pszczol et al. (2004) } \\
\text { Oliveira (1947) }\end{array}$ & & $\mathrm{X}$ & $\mathrm{X}$ & & $\mathrm{X}$ & $\mathrm{X}$ & $\mathrm{X}$ & & $\mathrm{X} \quad \mathrm{X}$ & $\mathrm{X}$ & & $\mathrm{X}$ & & $\mathrm{X}$ & & $\mathrm{X}$ & & $\mathrm{X}$ & & & \\
\hline Oliveira (1951) & & & & & & & & & & & $\mathrm{X}$ & & $\mathrm{X}$ & & & & & & & & \\
\hline Oliveira Filho \& Berchez (1978) & & $\mathrm{X}$ & $\mathrm{X}$ & & $\mathrm{X}$ & $\mathrm{X}$ & & & & & & & & & & & & & & $\mathrm{X}$ & \\
\hline Oliveira Filho \& Mayal (1976) & & & $\mathrm{X}$ & $\mathrm{X}$ & & $\mathrm{X}$ & $\mathrm{X}$ & & & & & & & & & & & & & $\mathrm{X}$ & $\mathrm{X}$ \\
\hline Oliveira Filho \& Paula (1983) & & & & & $\mathrm{X}$ & & $\mathrm{X}$ & & & & & & & & & & & & & $\mathrm{X}$ & \\
\hline Osse \& Rosso (1989) & & & & & & & $\mathrm{X}$ & & & & & & & & & & & & & & \\
\hline Rawitscher (1944) & & $\mathrm{X}$ & $\mathrm{X}$ & & & $\mathrm{X}$ & $\mathrm{X}$ & & & & & & & & & & & & & & \\
\hline Rosso et al. (1986) & & & & & & & $\mathrm{X}$ & $\mathrm{X}$ & & & & & & & & & & & & & \\
\hline Silva \& Fernandes (1990) & & & $\mathrm{X}$ & & $\mathrm{X}$ & & $\mathrm{X}$ & & & & & & $\mathrm{X}$ & & & & $\mathrm{X}$ & & $\mathrm{X}$ & $\mathrm{X} \quad \mathrm{X}$ & \\
\hline Villaça \& Pitombo (1997) & & & & & $\mathrm{X}$ & $\mathrm{X}$ & $\mathrm{X}$ & & $\mathrm{X}$ & $\mathrm{X}$ & & & $\mathrm{X}$ & & & & & & & $\mathrm{X}$ & \\
\hline Yoneshigue (1985) & $\mathrm{X}$ & $\mathrm{X}$ & $\mathrm{X}$ & $\mathrm{X}$ & $\mathrm{X}$ & $\mathrm{X}$ & $\mathrm{X}$ & & & & & & & & $\mathrm{X}$ & & & $x$ & $\mathrm{X}$ & $\mathrm{X}$ & $\mathrm{X}$ \\
\hline Yoneshigue-Valentin \& Valentin (1992) & $\mathrm{X}$ & & $\mathrm{X}$ & & & $\mathrm{X}$ & $\mathrm{X}$ & & & & & & & & & & & & & $\mathrm{X} \quad \mathrm{X}$ & \\
\hline
\end{tabular}

Além disso, a partir de informações na literatura sobre as espécies dominantes destes povoamentos, pode-se ter uma idéia de sua representatividade em termos de distribuição e abundância na região sudeste do país.

O trabalho de Oliveira Filho (1977) sintetiza estas informações para as algas. Em relação às algas da Divisão Chlorophyta, a única espécie encontrada neste estudo como dominante, Caulerpa racemosa, é muito comum em SP, RJ e ES. Em relação as da divisão Phaeophyta, o autor menciona que Colpomenia sinuosa é muito comum em SP, RJ e ES; 
Dictyota menstrualis é abundante e comum em locais protegidos de SP, RJ e ES; Padina gymnospora é muito comum em SP, RJ e sul do ES; Sargassum filipendula é característico do infralitoral no norte de SP, no RJ e no sul do ES e Sargassum vulgare abundante em SP, RJ e ES. Em relação às algas da divisão Rhodophyta, nota-se que Asparagopsis taxiformis é encontrada nos estados de São Paulo (SP), Rio de Janeiro (RJ) e parte do Espírito Santo (ES), Gelidiopsis variabilis em SP e no RJ, Hypnea spinella é freqüente no infralitoral de SP, RJ e ES, Amphiroa beauvoisii é encontrada em SP, RJ e ES, Jania adhaerens é abundante em certas áreas de SP, RJ e ES, Peyssonnelia sp.é pouco comum em SP e RJ; Falkenberia hillebrandii é bastante comum em SP e RJ, Dichotomaria marginata é encontrada no norte de SP, no RJ e ES e Wrangelia argus forma densas populações em costões moderadamente batidos de SP e ES.

Em relação aos animais, a espécie de ascídia colonial Didemnum speciosum tem distribuição restrita à costa brasileira (Rocha \& Moniot, 1995) e foi relatada como freqüente na região de São Sebastião e Cananéia, no Estado de São Paulo (Rocha, 1988; Rodrigues, 1962). Em um dos únicos trabalhos que tratam da distribuição das espécies de ascídias no litoral da região sudeste (Lotufo, 2002), Didemnum speciosum foi relatada como pouco freqüente para SP, RJ e ES e Symplegma rubra como freqüente para o RJ e pouco freqüente para o ES.

Em relação ao Filo Cnidaria, sabe-se que Palythoa caribaeorum é endêmica do Brasil (Castro, 1994), sendo descrita para locais com diferentes graus de hidrodinamismo e ocupando grandes extensões de substrato (Giordano, 1986; Figueiredo et al., 2004 e OigmanPszczol et al., 2004), entre $2 \mathrm{~m}$ e $7 \mathrm{~m}$ de profundidade (Castro et al., 1995). Pereira \& SoaresGomes (2002) citam a ocupação freqüente do infralitoral por antozoários dos gêneros Palythoa e Zoanthus.

Mussismilia hispida também é endêmica do Brasil, e é comum nos recifes de corais atuais, apresentando extensa distribuição na costa, ocorrendo desde a latitude de $3^{\circ} \mathrm{S}$ até a 
latitude de $30^{\circ} \mathrm{S}$ (Castro, 1994; Leão, 1999; Nogueira, 2003), ocorrendo em locais batidos (Castro et al., 1995).

Já Carijoa riisei, que apareceu associada ao povoamento Tapete de Ectoprocta, é de distribuição circumtropical segundo Castro $(1990,1994)$ e na costa sudeste foi citada para São Paulo (Silveira, 1986; Castro, 1990; Boscolo, 2004) e Rio de Janeiro (Maia et al., 1998; Castro et al., 1999).

Em relação ao Filo Echinodermata, Tropiometra carinata parece ter ampla distribuição mundial (Clark, 1947) e é o Crinoidea mais freqüente a abundante na costa do Brasil (BDT, 2005). No litoral norte do Estado de São Paulo e em costões rochosos da Ilha de Santo Amaro/SP, nas décadas de 50 e 60, era possível encontrar densas populações desta espécie, hoje praticamente eliminadas (Hadel et al., 1999), devido ao impacto antrópico.

Por sua vez, Echinometra lucunter, espécie associada formadora do povoamento Crosta de Corallinaceae com Echinometra, é uma espécie de distribuição geográfica ampla (Tommasi, 1966), bastante comum no infralitoral, de norte a sul do Brasil, podendo alcançar profundidades de 45m (Mortesen, 1943) e sua associação com algas calcárias incrustantes é bem conhecida para várias comunidades marinhas do mundo (Lawson \& John, 1975; Lawrence, 1975). O primeiro estudo que cita a importância dos ouriços dentro da comunidade de costão rochosos é o de Rathbun (1879), sendo que o autor enfatiza a presença de $E$. lucunter desde Recife até Santa Catarina. Pereira \& Soares-Gomes (2002) citam a importância dos ouriços na estruturação das comunidades, entre eles os do gênero Echinometra.

Em relação ao Filo Ectoprocta, é conhecido que seus representantes são bastante comuns no ambiente marinho, desde a região entre-marés até grandes profundidades, em todas as latitudes (Rocha \& D’Hondt, 1999).

Atualmente, o Estado de São Paulo é o que apresenta sua fauna de Ectoprocta mais conhecida, graças ao extenso trabalho realizado pelo Dr. Ernst Marcus, que estudou principalmente a fauna da região de Santos e São Sebastião (Rocha \& D’Hondt, 1999). O 
gênero Scrupocellaria foi citado pelo autor para a região da Baía de Santos e para o Rio de Janeiro, em áreas de mar raso. Schizoporella unicornis também foi citada para a Baía de Santos, entre 0 e $20 \mathrm{~m}$ de profundidade (Marcus, 1937).

Em relação aos representantes do Filo Porifera, Amphimedon viridis é citado para diversas localidades da costa brasileira, e na região sudeste é encontrado no Rio de Janeiro (Muricy \& Meireles, 1988; Muricy, 1989; Vieiralves et al., 2004) e é considerado, juntamente com Tedania ignis e Mycale ssp., muito comum para São Sebastião/SP (Hadju et al., 1999).

Tedania ignis é abundante entre $0 \mathrm{~m}$ e $18 \mathrm{~m}$, podendo ocorrer até 63m (Hadju, 1990), ocorrendo desde a latitude de $02^{\circ} \mathrm{S}$ até $27^{\circ} \mathrm{S}$, tendo sido citada para São Paulo (Laubenfels, 1956; Hadju, 1990), Rio de Janeiro (Muricy \& Meireles, 1988; Hadju, 1990; Lerner, 2001) e Espírito Santo (Hadju , 1990).

Em síntese, observa-se que as espécies encontradas são condizentes com o que é descrito para a região sudeste do país. A única informação sobre os organismos presentes no Parque Estadual da Ilha Anchieta é a lista de espécies de algas feita por Coutinho (1974), que apesar de ter enfocado o supralitoral e o mediolitoral, compartilha 7 espécies (das 30 mencionadas pelo autor) com as encontradas no presente estudo e o autor cita a presença dos gêneros Amphiroa e Jania, embora com espécies diferentes das aqui encontradas.

Aspectos importantes da estrutura da comunidade da área de estudo puderam ser visualizados a partir dos dados obtidos.

Em relação à repartição horizontal, a maioria dos povoamentos ocorreu de forma pontual ou em manchas ao longo dos setores, demonstrando que a comunidade é bastante faceteada, sem faixas horizontais muito definidas.

Grande parte dos povoamentos foi encontrada nos três setores, o que resultou em alta similaridade qualitativa $(74,7 \%)$ entre eles. Destacam-se, entretanto, os povoamentos Banco de Sargassum e Tapete de Amphiroa e Jania, que apresentaram maior freqüência relativa, o que confirma a importância dos gêneros Sargassum e Amphiroa encontrada em outros estudos 
de infralitoral na região sudeste do país (Maggs et al.,1979; Teixeira et al., 1987; Amado Filho et al., 2003; Figueiredo et al., 2004 e Oigman-Pszczol et al., 2004).

Temporalmente, houve desaparecimento, diminuição ou substituição de alguns povoamentos de determinados setores e aparecimento ou aumento em outros. Mesmo assim, tanto o Setor 2 quanto o Setor 3 formaram grupos com alta similaridade entre o verão e inverno (93,6\% e 82,9\%, respectivamente). Já o Setor 1 no inverno foi mais semelhante ao Setor 2 do que ao Setor 1 no verão, provavelmente pelo desaparecimento de alguns povoamentos (Banco de Caulerpa e Tapete de Wrangelia) e surgimento de outros (Banco de Tropiometra, Colônia de Schizoporella e Colônia de Symplegma), estes últimos tendo sido encontrados da metade para o final do setor, indicando uma possível influência da presença destes povoamentos no Setor 2 na ocupação da área.

Também houve alteração na repartição horizontal e no aspecto de alguns povoamentos dentro dos setores em que já ocorriam.

Como exemplo, tem-se Colônia de Didemnum, que aumentou a repartição horizontal para áreas adjacentes no inverno no Setor 2. Isso não corrobora a informação de que as ascídias são boas colonizadoras principalmente no verão (Rocha, 1988) e que apresentam menores densidades no inverno (Lotufo, 1997). Entretanto, Colônia de Symplegma parece corroborar esta informação, sendo que apresentou diminuição da repartição horizontal em todos os setores no inverno.

Outro exemplo seria o aumento verificado da freqüência relativa do povoamento Crosta de Corallinaceae com Echinometra no inverno nos Setores 1 e 2. Segundo Airoldi \& Cinelli (1997), as coralináceas incrustantes geralmente são as primeiras colonizadoras em espaços primários disponíveis, sugerindo que a área de estudo pode ter sofrido algum distúrbio que disponibilizou espaço para ser colonizado. Após o estabelecimento destas algas, há o posterior recobrimento por algas formadoras de tapetes (Airoldi, 2000, 2003). Esse processo pode ter levado a um aumento da disponibilidade de alimentos (algas filamentosas) 
para os ouriços, que então aumentaram em número nestes setores também (Leighton et al., 1966) ou ainda pode ter havido uma diminuição da abundância de seus predadores (McLean, 1962; Breen \& Mann, 1976).

Já Banco de Dictyota e Banco de Sargassum apresentaram-se mais descontínuos no inverno. Além disso, Banco de Sargassum mostrou-se bastante epifitado nesta estação (principalmente no Setor 1) por outros organismos, como algas filamentosas (principalmente Falkenbergia hillebrandii), hidrozoários e briozoários, enquanto que o mesmo não foi observado para o verão, onde a alga apresentou-se também com menor porte.

Em relação à distribuição vertical, percebeu-se que a zonação no infralitoral é pouco definida na região, com a maioria dos povoamentos ocorrendo em várias profundidades dependendo do posicionamento ao longo da área estudada, resultando em um posicionamento relativo vertical empírico pouco preciso. Este fato foi confirmado pela análise de agrupamento realizada considerando-se as profundidades, sendo que diferentes níveis agruparam-se.

Entretanto, baseando-se nas análises de freqüência relativa é possível verificar uma diferenciação da comunidade relacionada com a profundidade, sendo que podemos notar quatro principais zonas: uma mais rasa com Banco de Sargassum, outra intermediária superior com Tapete de Amphiroa e Jania, outra intermediária inferior com Tapete de Ectoprocta e, finalmente, uma mais profunda com composição variável dependendo da estação. Este padrão é condizente com o que é descrito em outros estudos realizados no infralitoral da região sudeste, com as algas sendo predominantes em áreas mais rasas e animais nas mais profundas. A diferença no caso foi o fato dos Ectoprocta, e não esponjas ou cnidários como relatado por Maggs et al. (1979) e Oigman-Pszczol et al. (2004), serem os mais freqüentes nas porções mais fundas. Esta diferença poderia ser associada, por exemplo, com o alto grau de sedimentação verificado na área, apesar da freqüência relativa do atributo Região de Substrato Inconsolidado não ter sido medida, que pode favorecer a presença dos Ectoprocta (Boyer et al., 1986; Nicoletti \& Chimenz Gusso, 1995). O alto grau de sedimentação também fica 
evidente pela ausência na área do atributo Região de Substrato Consolidado (substrato primário livre), que é verificado em diversas porções do mediolitoral na mesma área.

Para as algas, é possível observar um padrão de zoneamento semelhante na tese de Yoneshigue (1985), realizada em Cabo Frio (RJ), sendo que as espécies de Sargassum foram encontradas em áreas de infralitoral superior até $2 \mathrm{~m}$ de profundidade e Amphiroa beauvoisii associada com Jania adhaerens, no infralitoral inferior.

Nos Setores 1 e 3, as algas foram encontradas em abundância até o fundo (máximo de $2 \mathrm{~m}$ de profundidade), o que não ocorreu no Setor 2, provavelmente pelo fato de ser menos inclinado e também mais fundo, o que desfavorece o desenvolvimento de muitas espécies de algas pela diminuição na quantidade de luz incidente (Hartnoll, 1983). Além disso, neste setor observou-se uma maior presença de sedimentos finos, tornando a água mais turva do que nos outros setores na maior parte do tempo. O limite inferior das algas é determinado também pela competição e herbivoria (Lubchenco, 1978, 1980), embora nenhuma observação neste sentido tenha sido efetuada no presente estudo.

Os cnidários não foram positivamente relacionados com a profundidade como relatado por Oigman-Pszczol et al. (2004), sendo que Colônia de Mussismilia foi encontrada em áreas rasas, padrão semelhante ao relatado para Siderastrea stellata (Castro, 1994; Echeverría et al., 1997; Leão et al., 1997; Kelmo \& Attrill, 2001) e Millepora (Castro et al., 1995). Sabe-se que Mussismilia hispida tem preferência por áreas com alta irradiância, sendo comum em locais muito rasos (Castro, 1994). Além disso, exibe adaptações morfológicas para condições normalmente turvas, o que ocorre na área estudada, já que tem grandes pólipos $(3 \mathrm{~cm}$ de diâmetro) capazes de suportar uma quantidade maior de sedimentos do que espécies com pólipos menores (Kelmo \& Attrill, 2001). Colônia de Palythoa também foi encontrada em profundidades rasas a intermediárias, assim como relatado por Villaça \& Pitombo (1997), e com hidrodinamismo intermediário, como relatado por Edwards \& Lubbock (1983). 
Já as esponjas, em geral, não são organismos dominantes em áreas muito rasas (Leão, 1999) enquanto que em ambientes mais fundos, em geral mais estáveis, muitas vezes apresentam alta cobertura, como evidenciado pelo padrão descrito por Oigman-Pszczol et al. (2004) para Armação dos Búzios, no qual as esponjas apresentaram uma correlação positiva com a profundidade.

No presente estudo, Crosta de Amphimedon ocorreu com maior freqüência relativa em áreas mais profundas, entretanto Crosta de Tedania e Crosta de Mycale ocorreram com maior freqüência em profundidades intermediárias. A distribuição das esponjas está relacionada principalmente com o tipo de substrato, aporte de sedimentos, temperatura e hidrodinamismo (Sará \& Vacelet, 1973; Rutzler, 1980). Muricy \& Moraes (1998) observaram que a sedimentação e hidrodinamismo pareciam reduzir a riqueza de espécies de esponjas em Pernambuco, sendo o número de espécies maior em águas mais profundas e sem sedimentação. Entretanto, todos os povoamentos formados por esponjas presentes no Parque Estadual da Ilha Anchieta foram citados por estes autores apenas para áreas com alto grau de sedimentação, o que parece sugerir a tolerância dos mesmos a este fator ambiental. Essa tolerância também foi reportada por Carballo et al. (1996) e Muricy et al. (1991).

Crosta de Corallinaceae com Echinometra ocorreu com maior freqüência relativa nas profundidades mais rasas (até 1,5 $\mathrm{m}$ de profundidade). Este tipo de distribuição foi relatado por Giordano (1986) para áreas com alto grau de hidrodinamismo.

Os povoamentos Banco de Dichotomaria e Banco de Padina ocorreram principalmente junto ao fundo, sendo que o primeiro também ocorreu em níveis superiores do paredão, abaixo do povoamento Banco de Sargassum. Isso indica bastante exigência das algas formadoras destes povoamentos, provavelmente em relação ao hidrodinamismo, já que junto ao fundo o arrasto normalmente é menor do que em profundidades menores, ou uma maior tolerância destas ao soterramento por areia, o que permite que obtenham uma vantagem competitiva em relação a outras algas. Yoneshigue (1985), também relata a presença de 
Dichotomaria marginata junto ao sedimento de fundo em Cabo Frio (RJ), mas Padina gymnospora é relatada pela autora para regiões do infralitoral superior.

Tapete de Ectoprocta com Carijoa apresentou maior freqüência relativa em áreas mais rasas, o que não corrobora a informação de Castro (1994) de que Carijoa riisei é uma espécie que ocupa grandes áreas principalmente a partir dos $8 \mathrm{~m}$ de profundidade. Entretanto, este povoamento tem sido observado em área profundas, até próximas ao fundo arenoso, em outras localidades da costa do Estado de São Paulo (Berchez et al., em andamento).

Em síntese, este trabalho, que representa o primeiro efetuado utilizando-se o método "Levantamento Fisionômico", permitiu, de forma pioneira, o mapeamento integral de uma área relativamente extensa de costão rochoso e a conseqüente compreensão de sua estrutura, indicando que a comunidade estudada pode ser inserida dentro do padrão esperado para a região sudeste do país. 



\section{REFERÊNCIAS}

ABSHER, T.M., 1982. Aspectos oceanográficos e malacofauna bêntica da Enseada das Palmas - Ilha Anchieta (São Paulo). 110f. Dissertação (Mestrado) - Instituto Oceanográfico, Universidade de São Paulo, São Paulo.

AIROLDI, L., 2000. Responses of algae with different life histories to temporal and spatial variability of disturbance in subtidal reefs. Mar. Ecol. Prog. Ser.195: 81-92

AIROLDI, L., 2003. The effects of sedimentation on rocky coast assemblages. Oceanography and Marine Biology, v. 41, p.161-236.

AIROLDI, L.; CinELli, F., 1997. Effects of sedimentation on subtidal macroalgal assemblages: an experimental study from a Mediterranean rocky shore. J. Exp. Mar. Biol. Ecol., v. 215, p. 269-288.

Amado Filho, G.M.; Barreto, M.B.B.B.; Marins, B.V.; FeliX, C.; Reis, R.P., 2003. Estrutura das comunidades fitobentônicas do infralitoral da Baía de Sepetiba, RJ, Brasil. Revista Brasil. Bot., v. 26, n. 3, p. 329-342.

AmARAL, A.C.Z., 1977. Anelídeos poliquetos do infralitoral em duas enseadas da região de Ubatuba - aspectos ecológicos. 137f. Tese (Doutorado) - Instituto Oceanográfico, Universidade de São Paulo, São Paulo.

BDT, 2005. Invertebrados marinhos registrados no litoral brasileiro - Echinodermata recentes e fósseis do Brasil. 9. Classe Crinoidea Müller, 1821. Disponível em: $<$ http://www.bdt.fat.org.br/zoologia/echinodermata/echnocrinoidea $>$. Acesso em 10 nov. 2005.

Berchez, F.; Rosso, S.; Ghilardi, N.P.; FuJII, M.T.; HAdel, V., 2005. Characterization of hard bottom marine benthic communities: the physiognomic approach as an alternative to traditional methodologies. In: Sociedade Brasileira de Ficologia (Org.). Formação de Ficólogos: um compromisso com a sustentabilidade dos recursos aquáticos. Rio de Janeiro: Museu Nacional, Série Livros 10, p. 207-220.

Berchez, F.; Ghilardi, N.P.; FujII, M.T.; Hadel, V.; Rosso, S. Physiognomic surveying of the hard bottom benthic communities of Palmas Bay (Anchieta Island Natural Park, São Paulo, Brazil). J. Exp. Mar. Biol. Ecol. (em revisão).

Berchez, F.A.S.; OliveirA, E.C., 1986. Uma espécie de Botryocladia no Litoral do Estado de São Paulo. Bol. Soc. Bras. Ficol., São Paulo, v. 6, n. 1, p. 4-5.

Berchez, F.A.S.; OliveIRA, E.C., 1992. Temporal changes in the benthic marine flora of the Baía de Santos, SP, Brazil, over the last four decades. In: CORDEIRO-MARINO, C.; AZEVEDO, M.T.P.; SANT’ANNA, C.L.; TOMITA, N.Y.; PLASTINO, E.M. (Eds). 
Algae and environment: a general approach. São Paulo: Sociedade Brasileira de Ficologia. p. 120-131.

Boscolo, H.K., 2004. Aspectos da biologia de Carijoa riisei (Duchaissaing \& Michelotti, 1860) (Cnidaria, Anthozoa, Octocorallia) do canal de São Sebastião, SP, com ênfase no crescimento e na reprodução assexuada. 212f. Tese (Doutorado em Zoologia) - Instituto de Biociências, Universidade de São Paulo, São Paulo.

Boyer, M.; Matricardi, G.; Pisano, E., 1986. Variazioni dello spettro zoariale in uma comunità infralitorale di briozoi. Boll. Mus. Ist. Biol. Univ. Genova, v. 52 (suppl.), p. 301-316.

BReEN, P.A.; MANN, K.H., 1976. Destructive grazing of kelp by sea urchins in eastern Canada. J. Fish. Res. Bd. Can., v. 33, n. 6, p. 1278-1283.

Carballo, J.L.; NARANJO, S.A.; GarCíA-Gómez, J.C., 1996. Use of marine sponges as stress indicators in marine ecosystems at Algeciras Bay (southern Iberian Peninsula). Mar. Ecol. Prog. Ser., v. 135, p. 109-122.

Carvalho, F.A.F., 1983. Bionomia bêntica do complexo recifal no litoral do Estado da Paraíba, com ênfase nas macrófitas. 184f. Tese (Doutorado em Ciências) - Instituto Oceanográfico, Universidade de São Paulo, São Paulo.

CASTRO, C.B., 1990. Revisão taxonômica dos Octocorallia (Cnidaria, Anthozoa) do litoral sulamericano: da foz do rio Amazonas à foz do rio Prata. 343f. Tese (Doutorado em Zoologia) - Instituto de Biociências, Universidade de São Paulo, São Paulo.

Castro, C.B., 1994. Corais do sul da Bahia. In: Hetzel, B.; Castro, C.B. (Eds). Corais do sul da Bahia. Rio de Janeiro: Nova Fronteira, p. 161-176.

Castro, C.B.; Echeverría, C.A.; Pires, D.O.; FonseCA, C.G., 1999. Distribuição do bentos (Cnidaria \& Echinodermata) em costões rochosos da Baía da Ilha Grande, Rio de Janeiro, Brasil. In: Silva, S.H.G.; Lavrado, H.P. (eds). Ecologia dos ambientes costeiros do Estado do Rio de Janeiro. Série Oecologia Brasiliensis, v. 7. Rio de Janeiro: PPGEUFRJ, p. 179-193.

Castro, C.B.; Echeverría, C.A.; Pires, D.O.; Mascarenhas, B.J.A.; Freitas, S.G., 1995. Distribuição de Cnidaria e Echinodermata no infralitoral de costões rochosos de Arraial do Cabo, Rio de Janeiro, Brasil. Rev. Bras. Biol., v. 55, p. 471-480.

Clark, A.H., 1947. Monograph of the existing crinoids. VI. The cromatulids. Part 4b. Superfamily Marimatrida and Superfamily Tropiometrida. Washington: Government Printing Office (Smithsonian Institution, United States National Museum, Bulletin 82). $473 p$. 
Coelho, P.A.; Ramos-Porto, M., 1980. Bentos litorâneos do nordeste oriental do Brasil. II. Povoamentos de substratos duros. Bolm. Inst. Oceanogr., São Paulo, v. 29, n. 2, p. 133 134.

COIMBRA, C.S., 1998. Caracterização ecológica das comunidades bentônicas da região entremarés no costão sul da Praia do Itaguá, Ubatuba, SP. 136f. Dissertação (Mestrado) Instituto de Biociências, Universidade de São Paulo, São Paulo.

CORREIA, M.D., 1997. Distribuição espacial dos organismos macrobentônicos no recife de coral da Ponta Verde, Maceió, Alagoas - Brasil. 194f. Tese (Doutorado) - Instituto de Biociências, Universidade de São Paulo, São Paulo.

CosTA, H.R., 1962. Note preliminaire sur les peuplements intercotidaux de substrat dur du littoral de Rio de Janeiro. Rec. Trav. St. Mar. End., bull. 27, fasc. 42, p. 197-207.

Costa Jr, O.S.; Attrill, M.J.; Pedrini, A.G.; De-Paula, J.C., 2002. Spatial and seasonal distribution of seaweeds on coral reefs from southern Bahia, Brazil. Botanica mar., Berlin, v. 45, p. 346-355.

COUTINHO, L.M., 1974. Ecologia vegetal. São Paulo: FUMEST. 21p. (relatório apresentado à FUMEST para o "Plano Geral de Exploração Turística da Ilha Anchieta).

Cunnigham, P.T.M.; Rocha, J.S.; SAUl, A.C., 1996. Contribuição ao conhecimento da ictiofauna da região de Ubatuba, São Paulo, Brasil. IV. Haemulidae. In: SIMPÓSIO SOBRE OCEANOGRAFIA, 3., 1996, São Paulo. Resumos...São Paulo: IOUSP. p. 74.

CunNigham, P.T.M.; RochA, M.L.C.F., 1991. Contribuição ao conhecimento da ictiofauna da região da Ilha Anchieta, Ubatuba, São Paulo, Brasil. In: SIMPÓSIO SOBRE OCEANOGRAFIA, 2., 1991, São Paulo. Resumos...São Paulo: IOUSP. p. 28.

DAYTON, P.K., 1975. Experimental evaluation of ecological dominance in a rock intertidal algal community. Ecol. Monogr., v. 45, p. 137-159.

Dethier, M.N.; Graham, E.S.; Cohen, S.; Tear, L.M., 1993. Visual versus random-point percent cover estimations: 'objective' is not always better. Mar. Ecol. Prog. Ser., Halstenbek, v. 96, p. 93-100.

ECheverría, C.A.; Pires, D.O.; Medeiros, M.S.; Castro, C.B., 1997. Cnidarians of the Atol das Rocas, Brazil. In: INTERNATIONAL CORAL REEF SYMPOSIUM, 8., Cidade do Panamá. Proceedings...Cidade do Panamá: Smithson. Trop. Res. Inst. e Univ. Panamá, 1997, p. 443-446.

Edwards, A.; LubBOck, R., 1983. The ecology of Saint Paul's Rocks (Equatorial Atlantic). J. Zool., London, v. 200, p. 51-69. 
Eston, V.R.; BusSAB, W.O., 1990. An experimental analysis of ecological dominance in a rocky subtidal macroalgal community. J. Exp. Mar. Biol. Ecol., Amsterdam, v. 136, p. 170-195.

Eston, V.R. De; Migotto, A.E.; Oliveira Filho, E.C. De; Rodrigues, S.A.; Freitas, J.C., 1986. Vertical distribution of benthic marine organisms on rocky coasts of the Fernando de Noronha archipelago (Brazil). Bol. Inst. Oceanogr., São Paulo, v. 34, p. 37-54.

Figueiredo, M.A.O.; BARReto, M.B.B.; REIS, R.P., 2004. Caracterização das macroalgas nas comunidades marinhas da Área de Proteção Ambiental de Cairuçú, Parati, RJ - subsídios para futuros monitoramentos. Revista Brasil. Bot., São Paulo, v. 27, n. 1, p. 11-17.

Forneris, L., 1969. Fauna do infralitoral da Ilha Anchieta. Ciênc. Cult., São Paulo, v. 21, n. 02, p. 449-450.

Foster, M.S.; Harrold, C.; Hardin, D.D., 1991. Point vs. Photo quadrat estimates of the cover of sessile marine organisms. J. Exp. Mar. Biol. Ecol., Amsterdam, v. 146, p. 193203.

Furia, R.R.; CunNigham, P.T.M., 1996. Composição das capturas de peixes na Enseada das Palmas - Ilha Anchieta, Ubatuba - SP: variabilidade temporal. In: SIMPÓSIO SOBRE OCEANOGRAFIA, 3., 1996, São Paulo. Resumos...São Paulo: IOUSP. p. 73.

GioRDANO, F., 1986. Ouriços do sublitoral rochoso da região de São Sebastião - São Paulo uma abordagem ecológica. 128f. Dissertação (Mestrado em Ecologia) - Instituto de Biologia, Universidade Estadual de Campinas, São Paulo.

GuERRAZZI, M.C., 1987. Estudos preliminares sobre a estrutura de uma comunidade de costão rochoso, em mesolitoral, num gradiente de salinidade. In: SIMPÓSIO DOS ECOSSISTEMAS DA COSTA SUL E SUDESTE BRASILEIRA: SÍNTESE DOS CONHECIMENTOS, 1., p. 221-232. São Paulo: Academia de Ciências do Estado de São Paulo, 1987. (Publicação ACIESP, 54).

Guillaumon, J.R.; Marcondes, M.A.P.; Negreiros, O.C.; Mota, I.S.; Emmerich, W.; Barbosa, A.F.; Branco, I.H.D.C.; Camara, J.J.C.; Ostini, S.; Pereira, R.T.L.; Scorvo Filho, J.D.; Shimomichi, P.Y.; Silva, D.A.; Melo Neto, J.E., 1989. Plano de manejo do Parque Estadual da Ilha Anchieta. IF - série registros, São Paulo, v. 01, p. 01-103.

Hadel, V.F.; Monteiro, A. M. G.; Ditadi, A. S. F.; Tiago, C. G.; Tommasi, L. R., 1999. Filo Echinodermata. In: Migotto, A E; Tiago, C G. (Eds). Biodiversidade do Estado de São Paulo, Brasil: Síntese do conhecimento ao final do século XX. Invertebrados marinhos. São Paulo: FAPESP, v. 3, cap. 38, p. 261-271. Disponível em: $<$ http://www.biota.org.br/pdf/v3cap38.pdf $>$. Acesso em 10 nov. 2005. 
HaJdu, E.C.M., 1990. Taxonomia de Porifera da Ordem Poecilosclerida Topsent, 1928 de Arraial do Cabo (RJ). 152f. Dissertação (Mestrado em Zoologia) - Instituto de Biociências, Universidade de São Paulo, São Paulo.

Hajdu, E.; Berlinck, R.G.S.; Freitas, J.C., 1999. Filo Porífera. In: Migotto, A E; Tiago, C G. (Eds). Biodiversidade do Estado de São Paulo, Brasil: Síntese do conhecimento ao final do século XX. Invertebrados marinhos. São Paulo: FAPESP, v. 3, cap. 4, p. 19-31. Disponível em: <http://www.biota.org.br/pdf/v3cap04.pdf>. Acesso em 10 nov. 2005. Hartnoll, R.G., 1983. Substratum. In: Earll, R.; Erwin, D.G. (Eds). Sublittoral Ecology the ecology of the shallow sublittoral benthos. Oxford: Claredon Press, p. 97-124.

JOLY, A.B., 1957. Contribuição ao conhecimento da flora ficológica marinha da Baía de Santos e arredores. Bol. Fac. Filos. Cienc. Let. Univ. São Paulo Ser Bot., São Paulo, n. 14 , p. 1-220.

Kelmo, F.; Attrill, M.J., 2001. Cnidarian community structure of coastal reefs from northern Bahia. Bull. Mar. Sci., v. 69, p.547-557.

LAubenfels, M.W., 1956. Preliminary discussion of the sponges of Brazil. Contribuições avulsas do Instituto Oceanográfico (Ocean. Biológica), v. 1, p. 1-4.

LAWRENCE, J.M., 1975. On the relationships between marine plants and sea urchins. Ann. Rev. Oceanogr. Mar. Biol., v. 13, p. 213-286.

LAwsOn, G.W.; JoHn, D.M., 1975. Observation on the marine algal ecology of Gaboon. Bot. Mar., v. 17, n. 4, p. 249-254.

Legendre, L.; Legendre, P., 1984. Écologie numérique. 2 ed. Paris: Masson, v. 2, 335 p. (Collection d'écologie, 13).

LEIGHTON, D.L.; JONES, L.G.; NORTH, W.J., 1966. Ecological relationship between giant Kelp and sea urchins in southern California. In: INTERNATIONAL SEAWEED SYMPOSIUM, 5., New York. Proceedings... New York: Pergamont Press, 1965, p.141153.

LEÃO, Z.M.A.N., 1999. Abrolhos - O complexo recifal mais extenso do Oceano Atlântico Sul. In: Schobbenhaus, C.; Campos, D.A.; Queiroz, E.T.; Winge, M.; Berbert-Born, M. (Eds). Sítios Geológicos e Paleontológicos do Brasil. Disponível em: $<$ http://www.unb.br/ig/sigep/sitio090/sitio090.htm >. Acesso em 10 nov. 2005.

LEÃO, Z.M.A.N.; KIKUCHI, R.K.I.P.; MAIA, M.P.; LAGO, R.A.L., 1997. A catastrophic coral cover decline since 3,000 years B.P., Northern Bahia, Brazil. In: INTERNATIONAL CORAL REEF SYMPOSIUM, 8., Cidade do Panamá. Proceedings...Cidade do Panamá: Smithson. Trop. Res. Inst. e Univ. Panamá, 1997, p. 583-588. 
Lerner, C.B., 2001. Inventariamento da Fauna de Poríferos da Costa do Estado de Santa Catarina, Brasil. 239f. Tese (Doutorado em Zoologia) - Instituto de Biociências, Universidade de São Paulo, São Paulo.

LEWIS, J.R., 1980. Objectives in littoral ecology: a personal viewpoint. In: Price, J.M.; Irvine, D.E.G.; Farnham, W.F. (Eds). The shore environment: proceedings of an international symposium held at the portsmouth polytechnic. London: Academic Press, v. 1, p. 1-18.

Lotufo, T.M.C., 1997. Ecologia das ascídias da Baía de Santos (SP) : período reprodutivo, crescimento e aspectos sucessionais. 113f. Dissertação (Mestrado em Ecologia) Instituto de Biociências, Universidade de São Paulo, São Paulo.

Lotufo, T.M.C., 2002. Ascidiacea (Chordata: Tunicata) do litoral tropical brasileiro. 184f. Tese (Doutorado em Zoologia) - Instituto de Biociências, Universidade de São Paulo, São Paulo.

LUBCHENCO, J., 1978. Plant species diversity in a marine intertidal community: importance of herbivore food preference and algal competitive abilities. Amer. Nat., v. 112, p. 23-39.

LuBCHENCO, J., 1980. Algal zonation in the New England rocky intertidal community: an experimental analysis. Ecology, v. 61, n. 2, p. 333-344.

Maggs, C.A.; Milner, A.A.; Watts, W.; Whittle, M.R., 1979. The Oxford diving expedition to Cabo Frio, Brazil. Bull. Oxford Univ. Explor. Club. New. Serv., Oxford, v. 4, p. 13-40.

MaiA, L.F.; APIFAnio, R.D.; Pinto, A.C., 1998. Steroid composition in Carijoa riisei (Telestacea). Boletin de la Sociedad Chilena de Quimica, v. 43, n. 1, p. 39-43.

MARCUS, E. 1937. Bryozoários marinhos brasileiros, 1. Boletim da Faculdade de Filosofia Ciências e Letras. Universidade de São Paulo, Zoologia, v. 1, p. 5-224.

Marins-Rosa, B.; Amado-Filho, G.; Manso, C. \& Yoneshigue-Valentin, Y. (2005). Estrutura do fitobentos do Sub-litoral das formações recifais da Baía de Todos os Santos (Bahia, Brasil). In: Sociedade Brasileira de Ficologia (Org.). Formação de Ficólogos: um compromisso com a sustentabilidade dos recursos aquáticos. Rio de Janeiro: Museu Nacional, Série Livros 10, p. 255-274.

MASUNARI, S., 1982. Organismos do fital Amphiroa beauvoisii Lamoroux, 1816 (Rhodophyta, Corallinaceae). I. Autoecologia. Bolm. Zool. Univ. S. Paulo, v. 7, p. 57-148.

MCLEAN, B., 1962. Sublittoral ecology of kelp beds of the open coast area near Carmel, California. Biol. Bull., v. 122, p. 95-114.

Mitchell, G.J.P.; SzÉCHY, M.T.M.; SHINDO-MitChell, N., 1986. The algal zonation at Santa Cruz (Espírito Santo State, Brazil). In: INTERNATIONAL SEAWEED SYMPOSIUM, 12., 1986, São Paulo. Resumos... São Paulo: IOUSP. p. 75. 
Mortesen, Th., 1943. A monograph of the Echinoidea. III. Copenhagen: C.A. Reitzel. 446p.

Muñoz, A.O.M.; PereIRA, S.M.B., 1998. Estrutura de comunidades de macroalgas em formações recifais do Estado de Pernambuco, Brasil. In: CONGRESSO LATINOAMERICANO DE FICOlOGIA, 4., 1996, Caxambú. Anais... Caxambú, vol. 2. p. 287297.

MURICY, G., 1989. Sponges as pollution biomonitors at Arraial do Cabo, southeastern Brazil. Rev. Bras. Biol., v. 49, n. 2, p. 347-354.

Muricy, G.; Hadju, E.; Custodio, M.; Klautau, M.; Russo, C.; Peixinho, S., 1991. Sponge distribution at Arraial do Cabo, SE Brazil. In: SYMP. COASTAL OCEAN. MANAG., 7., 1991, Long Beach. Proceedings... Long Beach: ASCE Publs., vol. 2. p. 1183-1196.

Muricy, G.; Meirelles, S., 1988. Análise quantitativa de uma comunidade bentônica de substrato duro em Arraial do Cabo, RJ. Método dos quadrados de freqüência. In: CONGRESSO BRASILEIRO DE ZOOLOGIA, 15., 1988, Curitiba. Resumos... Curitiba: Sociedade Brasileira de Zoologia e Universidade Federal do Paraná, p. 603.

Muricy, G.; Moraes, F.C., 1998. Marine sponges of Pernambuco State, NE Brazil. Rev. Bras. Oceanogr., v. 46, p. 213-217.

Nicoletti, L.; Chimenz Gusso, C., 1995. Bryozoan assemblages and relation with environmental factors: An example from the Latium coast (Italy). Oebalia. v. 21, p. 93 102.

NogueIRA, J.M.M., 2003. Fauna living in colonies of Mussismilia hispida (Verrill) (Cnidaria: Scleractinia) in four South-eastern Brazil islands. Braz. arch. biol. technol., v. 46, n. 3, p. 421-432.

NONATO, E.F., 1974. Ilha Anchieta: relatório preliminar. S.L.p. CONSERVE. 6p. (relatório apresentado à CONSERVE - Contruções e servições de engenharia Ltda, para o "Plano geral de exploração turística da Ilha Anchieta").

NonAto, E.F.; PÈREZ, J.M., 1961. Observation sur quelques peuplements interdidaux de substrat dur dans la region d'Ubatuba. Cah. Biol. Mar., Paris, v. 2, p. 263- 270.

Oigman-Pszczol, S.S.; Fiqueiredo, M.A.O.; C ReED, J.C., 2004. Distribution of benthic communities on the tropical rocky subtidal of Armação dos Búzios, Southeastern Brazil. Marine Ecology, v. 25, n. 03, p. 173-190.

Oliveira, L., 1947. Distribuição geográfica da fauna e flora da Baía da Guanabara. Mem. Inst. Oswaldo Cruz, v. 45, p. 709-735.

OliveirA, L., 1951. Nota prévia sobre a fauna e flora marinha bentônica da Ilha da Trindade. Mem. Inst. Oswaldo Cruz, v. 49, p. 443-456. 
Oliveira, M.M.A., 1983. Moluscos de praia de Ilha Anchieta (Ubatuba - SP). Arq. Biol. Tecnol., Curitiba, v. 26, n. 03, p. 383-390.

Oliveira Filho, E.C. de , 1977. Algas marinhas bentônicas do Brasil. 407f. Tese (Livre Docência) - Instituto de Biociências, Universidade de São Paulo, São Paulo.

Oliveira Filho, E.C. de , 1987. Mesa-redonda: Ecossistemas Costão, Restinga, Duna, Praia Arenosa. In: SIMPÓSIO DOS ECOSSISTEMAS DA COSTA SUL E SUDESTE BRASILEIRA: SÍNTESE DOS CONHECIMENTOS, 1., p. 339-340. São Paulo: Academia de Ciências do Estado de São Paulo, 1987. (Publicação ACIESP, 54).

Oliveira Filho, E.C. de; Berchez, F.A.S., 1978. Algas bentônicas da Baía de Santosalterações da flora no período de 1957-1978. Bol. Bot. Univ. São Paulo, São Paulo, v. 6, p. $49-59$.

OliveIRA FiLHO, E.C. de; MAYAL, E.M., 1976. Seasonal distribution of intertidal organisms at Ubatuba, São Paulo (Brazil). Rev. Bras. Biol., Rio de Janeiro, v. 36, n. 1, p. 305-316.

OliveIRA Filho, E.C. de; PAULA, E.J. de, 1983. Aspectos da distribuição vertical e variação sazonal de comunidades da zona das marés em costões rochosos do litoral norte do Estado de São Paulo. In: ENCONTRO DE MACRÓFITAS MARINHAS, 1., 1983, Arraial do Cabo. Anais... Arraial do Cabo: Instituto de Pesquisas da Marinha. Projeto Cabo Frio (147). p. 44-61.

OsSE, A.C., 1995. Aspectos da estrutura espaço-temporal de uma comunidade intermareal de costão rochoso da Ponta da Fortaleza, Ubatuba, SP. 156 f. Dissertação (Mestrado em Ecologia) - Instituto de Biociências, Universidade de São Paulo, São Paulo.

OsSE, A.C.; Rosso, S., 1989. Estudo qualitativo de comunidade da zona entre-marés de um costão rochoso abrigado da Ponta da Fortaleza - Ubatuba - SP. In: MINI-SIMPÓSIO DE BIOLOGIA MARINHA, 8., 1989, São Sebastião. Resumos... São Sabastião: CEBIMAR - USP. p. 27.

PAINE, R.T.; VADAS, R.L., 1969. The effects of grazong by sea urchins. Strongylocentrotus spp., on benthic algal populations. Limnol. Oceanogr., v. 14, p. 710-719.

PereirA, R.C.; SoAres-Gomes, A., 2002. Biologia Marinha. Rio de Janeiro: Editora Interciência. $382 \mathrm{p}$.

RathBun, R., 1879. A list of the Brazilian Echinoderms, with notes on their distribution. Trans. Can. Acad. Arts Sci., v. 5, p. 139-159.

RAWITSCHER, F.K., 1944. Algumas noções sobre a vegetação do litoral brasileiro. Boletim da Associação dos geógrafos brasileiros ano 4, n. 5, p.13-28. 
RochA, R.M., 1988. Ascídias coloniais do canal de São Sebastião, SP: aspectos ecológicos. 133f. Dissertação (Mestrado em Ecologia) - Instituto de Biologia, Universidade Estadual de Campinas, São Paulo.

RochA, R.M.; D’hondt, J.L., 1999. Filo Bryozoa. In: Migotto, A E; Tiago, C G. (Eds). Biodiversidade do Estado de São Paulo, Brasil: Síntese do conhecimento ao final do século XX. Invertebrados marinhos São Paulo: FAPESP, v. 3, cap. 35, p.243-249. Disponível em: < http://www.biota.org.br/pdf/v3cap35.pdf>. Acesso em 10 nov. 2005.

RochA, R.M.; Monniot, F. 1995. Taxonomic and ecological notes on some Didemnum species (Ascidiacea, Didemnidae) for São Sebastião Channel, South-East Brazil. Revista Brasileira de Biologia, v. 55, n. 04, p. 639-649.

Rodrigues, S. DE A. 1962. Algumas ascídias do litoral sul do Brasil. Bol. Fac. Filos. Cienc.

Let. Univ. São Paulo Ser Zoologia, v. 24, p. 193-216.

Rosso, S.; Plastino, E.M.; Fujit, Mt.; Braga, M.R.A.; Berchez, F.A.S.; Artaza, O.H., 1986. Distribuição vertical dos organismos no costão rochoso da Praia das Cigarras, São Sebastião, SP. In: MINI-SIMPÓSIO DE BIOLOGIA MARINHA, 5., 1986, São Sebastião. Resumos... São Sabastião: CEBIMAR - USP. p. 14.

RutZler, K., 1980. Sponges in coral reefs. In: Stoddart, D.R.; Johannes, R.E. (Eds). Coral reefs: research methods. Monogr. Oceanogr. Methodol.: UNESCO, v. 5, p. 299-313. Sara, M.; Vacelet, J., 1973. Écologie des Demosponges. In: Grassé, P.P. (ed.). Traité de Zoologie, v. 3, n.1: Spongiaires. Paris: Masson et Cie., p. 462-576.

Silva, E.P. da; FERNANDES, F.C., 1990. O bentos de substrato duro das margens da Lagoa de Araruama. In: SIMPÓSIO DOS ECOSSISTEMAS DA COSTA SUL E SUDESTE BRASILEIRA: ESTRUTUTA, FUNÇÃO E MANEJO, 2., v. 4, p. 231-240, 1990. Águas de Lindóia: Academia de Ciências do Estado de São Paulo (Publ. ACIESP, 71).

SILVEIRA, F.L. da, 1986. Aspectos da biologia de Lophogorgia punicea (Milne Edwards \& Haime, 1857) (Gorgonacea, Gorgonidae) do Canal de São Sebastião, Estado de São Paulo. 211f. Tese (Doutorado em Zoologia) - Instituto de Biociências, Universidade de São Paulo, São Paulo.

SteneCK, R.S.; WATLing, L., 1982. Feeding capabilities and limitations of herbivourous molluscs: a functional group approach. Mar. Biol., v. 68, p. 299-319.

TeiXeira, V.L.; Pereira, R.C.; Marques Junior, A.N.; LeITão Filho, C.M.; Silva, C.A.R., 1987. Seasonal variations in infralittoral seaweed communities under a pollution gradient in Baía de Guanabara, Rio de Janeiro (Brazil). Ciência e Cultura, São Paulo, v. 39, n. 4, p. $423-428$. 
Tommasi, L.R., 1966. Lista dos equinóides recentes do Brasil. Contr. Inst. Oceanogr. Univ. S. Paulo (Oceanografia Biológica), São Paulo, v. 11, p. 1-50.

TOMMASI, L.R., 1976. A degradação do meio ambiente. São Paulo: Nobel. 169 p.

TOMmasi, L.R., 1987. Poluição marinha no Brasil: síntese do conhecimento. São Paulo: Instituto Oceanográfico (Pub. Especial do Inst. Oceanográfico, n. 5, p. 1-30).

VANCE, R.R., 1979. Effects of grazing by the sea urchin Centrotephanus coronatus, on prey community composition. Ecology, v. 60, n. 3, p. 537-546.

Vieiralves, T.; Oliveira, I.L.; Silva, C.M.M.; HaJdu, E.C.M.; LÔBo-HaJdu, G., 2004. Estudo taxonômico de Amphimedon viridis -Porifera- da costa brasileira com base em caracteres morfológicos e moleculares. In: CONGRESSO BRASILEIRO DE ZOOLOGIA, 25., 2004, Brasília. Resumos...Brasília: Soc. Bras. de Zoologia, p. 371.

VIEITAS, C.F., 1995. Análise ambiental das Ilhas da região de Ubatuba (SP), e proposta de manejo para a Ilha do Mar Virado. 130 f. Dissertação (Mestrado)- Instituto de Biociências, Universidade de São Paulo, São Paulo.

VILlAÇA, R.C., 1990. Metodologia de amostragem em costões rochosos. Abordagem fitossociológica. In: SIMPÓSIO DOS ECOSSISTEMAS DA COSTA SUL E SUDESTE BRASILEIRA: ESTRUTUTA, FUNÇÃO E MANEJO, 2., p. 1-12. São Paulo: Academia de Ciências do Estado de São Paulo (Publ. ACIESP, 71).

VillaçA, R.C.; Pitombo, F.B., 1997. Benthic communities of shalow-water reefs of Abrolhos, Brazil. Rev. Bras. Oceanogr., v. 45, p. 35-43.

YAOBIN, Q., 1999. Estudos sobre a variação temporal da composição de macroalgas marinhas em uma baía poluída - o caso de Santos, Litoral de São Paulo, Brasil. 139f. Tese (Doutorado em Ecologia) - Instituto de Biociências da Universidade de São Paulo, São Paulo.

Yoneshigue, Y., 1985. Taxonomie et ecologie des algues marines dans la region de Cabo Frio (Rio de Janeiro, Brésil). 466f. Tese (Doutorado em Ciências) - Faculdade de Ciências de Luminy, Universidade de Aix-Marseille II, Marseille.

Yoneshigue-Valentin, Y.; Valentin, J.L., 1992. Macroalgae of the Cabo Frio upwelling region, Brazil: ordination of communities. In: Seeliger, U. (ed.). Coastal plant communities of Latin America. San Diego: Academic Press. cap. 2, p. 31-50. 


\begin{tabular}{|c|c|c|c|c|}
\hline Povoamento & $\begin{array}{c}\text { Latitude } \\
\text { Inicial }\end{array}$ & $\begin{array}{c}\text { Longitude } \\
\text { incial }\end{array}$ & $\begin{array}{c}\text { Latitude } \\
\text { final }\end{array}$ & $\begin{array}{c}\text { Longitude } \\
\text { final }\end{array}$ \\
\hline \multirow[t]{6}{*}{ Banco de Asparagopsis } & $23^{\circ} 32^{\prime} 18.6^{\prime \prime} \mathrm{S}$ & $45^{\circ} 03^{\prime} 51.0^{\prime \prime} \mathrm{W}$ & $23^{\circ} 32^{\prime} 17.75^{\prime \prime} \mathrm{S}$ & $45^{\circ} 03^{\prime} 50.5^{\prime \prime} \mathrm{W}$ \\
\hline & $23^{\circ} 32^{\prime} 17.05^{\prime \prime} \mathrm{S}$ & $45^{\circ} 03^{\prime} 50.1^{\prime \prime} \mathrm{W}$ & $23^{\circ} 32^{\prime} 16.8^{\prime \prime} \mathrm{S}$ & $45^{\circ} 03^{\prime} 49.9^{\prime \prime} \mathrm{W}$ \\
\hline & $23^{\circ} 32^{\prime} 13.2 " \mathrm{~S}$ & $45^{\circ} 03^{\prime} 47.15^{\prime \prime} \mathrm{W}$ & $23^{\circ} 32^{\prime} 12.85^{\prime \prime} \mathrm{S}$ & $45^{\circ} 03^{\prime} 46.8^{\prime} \mathrm{W}$ \\
\hline & $23^{\circ} 32^{\prime} 12.15^{\prime \prime} \mathrm{S}$ & $45^{\circ} 03^{\prime} 46.15^{\prime \prime} \mathrm{W}$ & $23^{\circ} 32^{\prime} 12.05^{\prime \prime} \mathrm{S}$ & $45^{\circ} 03^{\prime} 46.05^{\prime \prime} \mathrm{W}$ \\
\hline & $23^{\circ} 32^{\prime} 11.0^{\prime \prime} \mathrm{S}$ & $45^{\circ} 03^{\prime} 45.6^{\prime \prime} \mathrm{W}$ & $23^{\circ} 32^{\prime} 10.7 ” \mathrm{~S}$ & $45^{\circ} 03^{\prime} 45.3^{\prime \prime} \mathrm{W}$ \\
\hline & $23^{\circ} 32^{\prime} 10.2^{\prime} \mathrm{S}$ & $45^{\circ} 03^{\prime} 44.8^{\prime \prime} \mathrm{W}$ & $23^{\circ} 32^{\prime} 09.4^{\prime \prime} \mathrm{S}$ & $45^{\circ} 03^{\prime} 44.6^{\prime \prime} \mathrm{W}$ \\
\hline \multirow[t]{7}{*}{ Banco de Caulerpa } & $23^{\circ} 32^{\prime} 18.55^{\prime \prime} \mathrm{S}$ & $45^{\circ} 03^{\prime} 50.95^{\prime \prime} \mathrm{W}$ & & \\
\hline & $23^{\circ} 32,17.67 " \mathrm{~S}$ & $\begin{array}{l}45^{\circ} 03^{\prime} 50.4 ” \mathrm{~W} \\
45^{\circ} 03^{\prime}, 5025^{\prime}, \mathrm{W}\end{array}$ & & \\
\hline & $23^{\circ} 32,16.55^{\prime \prime} \mathrm{S}$ & $45^{\circ} 03,49.7^{\prime \prime} \mathrm{W}$ & $23^{\circ} 32^{\prime} 15.65^{\prime \prime} \mathrm{S}$ & $45^{\circ} 03^{\prime} 49.0^{\prime \prime} \mathrm{W}$ \\
\hline & $23^{\circ} 32^{\prime} 13.15^{\prime \prime} \mathrm{S}$ & $45^{\circ} 03^{\prime} 47.1^{\prime \prime} \mathrm{W}$ & & \\
\hline & $23^{\circ} 32^{\prime} 11.2^{\prime \prime} \mathrm{S}$ & $45^{\circ} 03^{\prime} 45.8^{\prime \prime} \mathrm{W}$ & $23^{\circ} 32^{\prime} 11.1 ” \mathrm{~S}$ & $45^{\circ} 03^{\prime} 45.6^{\prime \prime} \mathrm{W}$ \\
\hline & $23^{\circ} 32^{\prime} 10.9^{\prime \prime} \mathrm{S}$ & $45^{\circ} 03^{\prime} 45.5^{\prime \prime} \mathrm{W}$ & $23^{\circ} 32^{\prime} 10.7 ” \mathrm{~S}$ & $45^{\circ} 03^{\prime} 45.3^{\prime \prime} \mathrm{W}$ \\
\hline & $23^{\circ} 32^{\prime} 10.3 ” \mathrm{~S}$ & $45^{\circ} 03^{\prime} 44.9^{\prime \prime} \mathrm{W}$ & $23^{\circ} 32,10.2 \% \mathrm{~S}$ & $45^{\circ} 03^{\prime} 44.8^{\prime \prime} \mathrm{W}$ \\
\hline \multirow[t]{4}{*}{ Banco de Colpomenia } & $23^{\circ} 32^{\prime} 17.9^{\prime \prime} \mathrm{S}$ & $45^{\circ} 03^{\prime} 50.6^{\prime \prime} \mathrm{W}$ & & \\
\hline & $23^{\circ} 32^{\prime} 17.4 ” \mathrm{~S}$ & $45^{\circ} 03^{\prime} 50.35^{\prime \prime} \mathrm{W}$ & $23^{\circ} 32^{\prime} 17.2^{\prime \prime} \mathrm{S}$ & $45^{\circ} 03^{\prime} 50.2^{\prime \prime} \mathrm{W}$ \\
\hline & $23^{\circ} 322^{\prime} 15.05 ” \mathrm{~S}$ & $45^{\circ} 03^{\prime} 48,5^{\prime \prime} \mathrm{W}$ & & \\
\hline & $23^{\circ} 32^{\prime} 12.15^{\prime \prime} \mathrm{S}$ & $45^{\circ} 03^{\prime} 46.15^{\prime \prime} \mathrm{W}$ & & \\
\hline Banco de Dichotomaria & $23^{\circ} 32^{\prime} 18.6^{\prime \prime} \mathrm{S}$ & $45^{\circ} 03^{\prime} 51.0^{\prime \prime} \mathrm{W}$ & $23^{\circ} 32 \times 13.1 ” \mathrm{~S}$ & $45^{\circ} 03^{\prime} 47.05^{\prime \prime} \mathrm{W}$ \\
\hline Banco de Dictyota & $23^{\circ} 32^{\prime} 18.6^{\prime \prime} \mathrm{S}$ & $45^{\circ} 03^{\prime} 51.0^{\prime \prime} \mathrm{W}$ & $23^{\circ} 32^{\prime} 11.5^{\prime \prime} \mathrm{S}$ & $45^{\circ} 03^{\prime} 45.5^{\prime \prime} \mathrm{W}$ \\
\hline \multirow{2}{*}{ Banco de Padina } & $23^{\circ} 32^{\prime} 18.5^{\prime \prime} \mathrm{S}$ & $45^{\circ} 03^{\prime} 50.9^{\prime \prime} \mathrm{W}$ & $23^{\circ} 32^{\prime} 16.45^{\prime \prime} \mathrm{S}$ & $45^{\circ} 03^{\prime} 49.6^{\prime \prime} \mathrm{W}$ \\
\hline & $23^{\circ} 32^{\prime} 15.8^{\prime \prime} \mathrm{S}$ & $45^{\circ} 03^{\prime} 49.1$ 'W & $23^{\circ} 32^{\prime} 12.3^{\prime \prime} \mathrm{S}$ & $45^{\circ} 03^{\prime} 46.25^{\prime \prime} \mathrm{W}$ \\
\hline \multirow[t]{2}{*}{ Banco de Sargassum } & $23^{\circ} 32^{\prime} 18.6^{\prime \prime} \mathrm{S}$ & $45^{\circ} 03^{\prime} 51.0^{\prime \prime} \mathrm{W}$ & $23^{\circ} 32^{\prime} 12.5^{\prime \prime} \mathrm{S}$ & $45^{\circ} 03^{\prime} 46.5^{\prime \prime} \mathrm{W}$ \\
\hline & $23^{\circ} 32^{\prime} 12.3^{\prime \prime} \mathrm{S}$ & $45^{\circ} 03^{\prime} 46.25^{\prime \prime} \mathrm{W}$ & $23^{\circ} 32,10.0 ” \mathrm{~S}$ & $45^{\circ} 03^{\prime} 44.6^{\prime \prime} \mathrm{W}$ \\
\hline \multirow[t]{3}{*}{ Banco de Tropiometra } & $23^{\circ} 32^{\prime} 16.2^{\prime \prime} \mathrm{S}$ & $45^{\circ} 03^{\prime} 49.4^{\prime \prime} \mathrm{W}$ & $23^{\circ} 32^{\prime} 15.55^{\prime \prime} \mathrm{S}$ & $45^{\circ} 03^{\prime} 48.9 ” \mathrm{~W}$ \\
\hline & $23^{\circ} 32^{\prime} 15.05^{\prime \prime} \mathrm{S}$ & $45^{\circ} 03^{\prime} 48.5^{\prime \prime} \mathrm{W}$ & $23^{\circ} 32^{\prime} 13.2^{\prime \prime} \mathrm{S}$ & $45^{\circ} 03^{\prime} 47.15^{\prime \prime} \mathrm{W}$ \\
\hline & $23^{\circ} 32,12.65^{\prime \prime S} \mathrm{~S}$ & $45^{\circ} 03^{\prime} 46.6^{\prime \prime} \mathrm{W}$ & $23^{\circ} 32,11.5^{\prime \prime} \mathrm{S}$ & $45^{\circ} 03^{\prime} 45.5^{\prime \prime} \mathrm{W}$ \\
\hline \multirow[t]{3}{*}{ Colônia de Didemnum } & $23^{\circ} 32^{\prime} 18.6^{\prime \prime} \mathrm{S}$ & $45^{\circ} 03^{\prime} 51.0^{\prime \prime} \mathrm{W}$ & $23^{\circ} 32^{\prime} 17.6^{\prime \prime} \mathrm{S}$ & $45^{\circ} 03^{\prime} 50.45^{\prime \prime} \mathrm{W}$ \\
\hline & $23^{\circ} 32,16.3^{\prime \prime} \mathrm{S}$ & $45^{\circ} 03,49.5 ” \mathrm{~W}$ & $23^{\circ} 32,13.2 \% \mathrm{~S}$ & $45^{\circ} 03^{\prime} 47.15^{\prime \prime} \mathrm{W}$ \\
\hline & $23^{\circ} 32^{\prime} 12.75^{\prime \prime} \mathrm{S}$ & $45^{\circ} 03^{\prime} 46.7^{\prime \prime} \mathrm{W}$ & $23^{\circ} 32^{\prime} 11.5^{\prime \prime} \mathrm{S}$ & $45^{\circ} 03^{\prime} 45.5^{\prime \prime} \mathrm{W}$ \\
\hline \multirow[t]{2}{*}{ Colônia de Mussismilia } & $23^{\circ} 32,14.05^{\prime \prime S ~ S}$ & $45^{\circ} 03^{\prime} 47,28^{\prime \prime} \mathrm{W}$ & & \\
\hline & $23^{\circ} 32^{\prime} 12.65^{\prime \prime} \mathrm{S}$ & $45^{\circ} 03^{\prime} 46.6^{\prime \prime} \mathrm{W}$ & $23^{\circ} 32^{\prime} 12.3^{\prime \prime} \mathrm{S}$ & $45^{\circ} 03^{\prime} 46.25^{\prime \prime} \mathrm{W}$ \\
\hline \multirow[t]{3}{*}{ Colônia de Palythoa } & $23^{\circ} 32^{\prime} 18.35^{\prime \prime} \mathrm{S}$ & $45^{\circ} 03^{\prime} 50.85^{\prime} \mathrm{W}$ & & \\
\hline & $23^{\circ} 32^{\prime} 12.6^{\prime \prime} \mathrm{S}$ & $45^{\circ} 03^{\prime} 46.55^{\prime \prime} \mathrm{W}$ & & \\
\hline & $23^{\circ} 32^{\prime} 12.1^{\prime \prime} \mathrm{S}$ & $45^{\circ} 03^{\prime} 46.1^{\prime \prime} \mathrm{W}$ & & \\
\hline \multirow[t]{6}{*}{ Colônia de Schizoporella } & $23^{\circ} 32^{\prime} 18.55^{\prime \prime} \mathrm{S}$ & $45^{\circ} 03^{\prime} 50.95^{\prime \prime} \mathrm{W}$ & & \\
\hline & $23^{\circ} 32^{\prime} 18.27^{\prime \prime} \mathrm{S}$ & $45^{\circ} 03^{\prime} 50.8^{\prime \prime} \mathrm{W}$ & & \\
\hline & $23^{\circ} 32^{\prime} 17.4 " \mathrm{~S}$ & $45^{\circ} 03^{\prime} 50.35^{\prime \prime} \mathrm{W}$ & & \\
\hline & $23^{\circ} 32^{\prime} 17.2 " \mathrm{~S}$ & $45^{\circ} 03^{\prime} 50.2 ” \mathrm{~W}$ & $23^{\circ} 32^{\prime} 13.2^{\prime} \mathrm{S}$ & $45^{\circ} 03^{\prime} 47.15^{\prime \prime} \mathrm{W}$ \\
\hline & $23^{\circ} 32^{\prime} 12.6^{\prime \prime} \mathrm{S}$ & $45^{\circ} 03^{\prime} 46.55^{\prime \prime} \mathrm{W}$ & & \\
\hline & $23^{\circ} 32^{\prime} 12.4^{\prime \prime} \mathrm{S}$ & $45^{\circ} 03^{\prime} 46.4^{\prime \prime} \mathrm{W}$ & $23^{\circ} 32^{\prime} 12.15^{\prime \prime} \mathrm{S}$ & $45^{\circ} 03^{\prime} 46.15^{\prime \prime} \mathrm{W}$ \\
\hline \multirow[t]{2}{*}{ Colônia de Symplegma } & $23^{\circ} 32,16.45^{\prime \prime} \mathrm{S}$ & $45^{\circ} 03^{\prime} 49.6 ” \mathrm{~W}$ & $23^{\circ} 32^{\prime} 13.6^{\prime \prime} \mathrm{S}$ & $45^{\circ} 03^{\prime} 47.45^{\prime \prime} \mathrm{W}$ \\
\hline & $23^{\circ} 32,12.3 ” \mathrm{~S}$ & $45^{\circ} 03^{\prime} 46.25^{\prime \prime} \mathrm{W}$ & & \\
\hline \multirow[t]{5}{*}{ Crosta de Amphimedon } & $23^{\circ} 32,17.05 ” \mathrm{~S}$ & $45^{\circ} 03^{\prime} 50.1 ” \mathrm{~W}$ & $23^{\circ} 32^{\prime} 15.55^{\prime \prime} \mathrm{S}$ & $45^{\circ} 03^{\prime} 48.9^{\prime \prime} \mathrm{W}$ \\
\hline & $23^{\circ} 32^{\prime} 15.13^{\prime \prime} \mathrm{S}$ & $45^{\circ} 03^{\prime} 48.55^{\prime \prime} \mathrm{W}$ & & \\
\hline & $23^{\circ} 32^{\prime} 14.45^{\prime \prime S} \mathrm{~S}$ & $45^{\circ} 03^{\prime} 48.1 ” \mathrm{~W}$ & $23^{\circ} 32^{\prime} 13.2^{\prime \prime} \mathrm{S}$ & $45^{\circ} 03^{\prime} 47.15^{\prime \prime} \mathrm{W}$ \\
\hline & $23^{\circ} 32^{\prime} 13.05^{\prime \prime} \mathrm{S}$ & $45^{\circ} 03^{\prime} 47.0^{\prime \prime} \mathrm{W}$ & & \\
\hline & $23^{\circ} 32^{\prime} 12.5^{\prime \prime} \mathrm{S}$ & $45^{\circ} 03^{\prime} 46.5^{\prime \prime} \mathrm{W}$ & $23^{\circ} 32^{\prime} 12.15^{\prime \prime} \mathrm{S}$ & $45^{\circ} 03^{\prime} 46.15^{\prime \prime} \mathrm{W}$ \\
\hline Crosta de Corallinaceae & $23^{\circ} 32^{\prime} 18.35^{\prime} \mathrm{S}$ & $45^{\circ} 03^{\prime} 50.85^{\prime \prime} \mathrm{W}$ & $23^{\circ} 32^{\prime} 18.2^{\prime \prime} \mathrm{S}$ & $45^{\circ} 03^{\prime} 50.75^{\prime \prime} \mathrm{W}$ \\
\hline \multirow[t]{6}{*}{ Crosta de Corallinaceae com Echinometra } & $23^{\circ} 32^{\prime} 18.6^{\prime \prime} \mathrm{S}$ & $45^{\circ} 03^{\prime} 51.0^{\prime \prime} \mathrm{W}$ & $23^{\circ} 32^{\prime} 18.35^{\prime \prime} \mathrm{S}$ & $45^{\circ} 03^{\prime} 50.85^{\prime \prime} \mathrm{W}$ \\
\hline & $23^{\circ} 32^{\prime} 16.55^{\prime \prime} \mathrm{S}$ & $45^{\circ} 03^{\prime} 49.7 ” \mathrm{~W}$ & $23^{\circ} 32^{\prime} 16.3^{\prime \prime} \mathrm{S}$ & $45^{\circ} 03^{\prime} 49.5^{\prime \prime} \mathrm{W}$ \\
\hline & $23^{\circ} 32^{\prime} 15.5^{\prime \prime} \mathrm{S}$ & $45^{\circ} 03^{\prime} 48.95^{\prime \prime} \mathrm{W}$ & & \\
\hline & $23^{\circ} 32^{\prime} 15.13^{\prime \prime} \mathrm{S}$ & $45^{\circ} 03^{\prime} 48.55^{\prime \prime} \mathrm{W}$ & & \\
\hline & $23^{\circ} 32^{\prime} 14.45^{\prime \prime} \mathrm{S}$ & $45^{\circ} 03^{\prime} 48.1 ” \mathrm{~W}$ & $23^{\circ} 32^{\prime} 13.2^{\prime \prime} \mathrm{S}$ & $45^{\circ} 03^{\prime} 47.15^{\prime \prime} \mathrm{W}$ \\
\hline & $23^{\circ} 32^{\prime} 13.0^{\prime \prime} \mathrm{S}$ & $45^{\circ} 03^{\prime} 46.95^{\prime \prime} \mathrm{W}$ & $23^{\circ} 32^{\prime} 12.05^{\prime \prime} \mathrm{S}$ & $45^{\circ} 03^{\prime} 46.05^{\prime \prime} \mathrm{W}$ \\
\hline Crosta de Corallinaceae com Polysiphonia & $23^{\circ} 32^{\prime} 18.6^{\prime \prime} \mathrm{S}$ & $45^{\circ} 03^{\prime} 51.0^{\prime \prime} \mathrm{W}$ & $23^{\circ} 32^{\prime} 18.35^{\prime \prime} \mathrm{S}$ & $45^{\circ} 03^{\prime} 50.85^{\prime \prime} \mathrm{W}$ \\
\hline & $23^{\circ} 32^{\prime} 13.0^{\prime \prime} \mathrm{S}$ & $45^{\circ} 03^{\prime} 46.5^{\prime \prime} \mathrm{W}$ & $23^{\circ} 32^{\prime} 12.5^{\prime \prime} \mathrm{S}$ & $45^{\circ} 03^{\prime} 46.05^{\prime \prime} \mathrm{W}$ \\
\hline Crosta de Mycale & $23^{\circ} 32^{\prime} 16.2^{\prime \prime} \mathrm{S}$ & $45^{\circ} 03^{\prime} 49.4^{\prime \prime} \mathrm{W}$ & $23^{\circ} 32^{\prime} 13.2^{\prime} \mathrm{S}$ & $45^{\circ} 03^{\prime} 47.15^{\prime \prime} \mathrm{W}$ \\
\hline & $23^{\circ} 32^{\prime} 12.75^{\prime \prime} \mathrm{S}$ & $45^{\circ} 03^{\prime} 46.7 ” \mathrm{~W}$ & $23^{\circ} 32^{\prime} 12.15^{\prime \prime} \mathrm{S}$ & $45^{\circ} 03,46.15^{\prime \prime} \mathrm{W}$ \\
\hline Crosta de Peyssonnelia & $23^{\circ} 32^{\prime} 17.3^{\prime \prime} \mathrm{S}$ & $45^{\circ} 03^{\prime} 50.3^{\prime \prime} \mathrm{W}$ & & \\
\hline & $23^{\circ} 32^{\prime} 17.05^{\prime \prime} \mathrm{S}$ & $45^{\circ} 03^{\prime} 50.1 ” \mathrm{~W}$ & $23^{\circ} 32^{\prime} 16.9 ” \mathrm{~s}$ & $45^{\circ} 03^{\prime} 50.0^{\prime \prime} \mathrm{W}$ \\
\hline & $23^{\circ} 32^{\prime} 16.45^{\prime \prime} \mathrm{S}$ & $45^{\circ} 03^{\prime} 49.6^{\prime \prime} \mathrm{W}$ & $23^{\circ} 32^{\prime} 16.05^{\prime \prime} \mathrm{S}$ & $45^{\circ} 03^{\prime} 49.3^{\prime \prime} \mathrm{W}$ \\
\hline & $23^{\circ} 32^{\prime} 15.4^{\prime \prime} \mathrm{S}$ & $45^{\circ} 03^{\prime} 48.8^{\prime \prime} \mathrm{W}$ & & \\
\hline & $23^{\circ} 32^{\prime} 14.9^{\prime \prime} \mathrm{S}$ & $45^{\circ} 03^{\prime} 48.4^{\prime \prime} \mathrm{W}$ & $23^{\circ} 32^{\prime} 14.75^{\prime \prime} \mathrm{S}$ & $45^{\circ} 03^{\prime} 48.3^{\prime \prime} \mathrm{W}$ \\
\hline
\end{tabular}


Tabela A2.1 (cont.) - Relação dos povoamentos encontrados na área de estudo e suas respectivas distribuições em termos de latitude e longitude.

\begin{tabular}{|c|c|c|c|c|}
\hline Povoamento & $\begin{array}{c}\text { Latitude } \\
\text { Inicial }\end{array}$ & $\begin{array}{c}\text { Longitude } \\
\text { incial }\end{array}$ & $\begin{array}{c}\text { Latitude } \\
\text { final }\end{array}$ & $\begin{array}{c}\text { Longitude } \\
\text { final }\end{array}$ \\
\hline \multirow[t]{6}{*}{ Crosta de Tedania } & $23^{\circ} 32^{\prime} 18.43^{\prime \prime} \mathrm{S}$ & $45^{\circ} 03^{\prime} 50.87^{\prime \prime} \mathrm{W}$ & & \\
\hline & $23^{\circ} 32^{\prime} 17.67^{\prime} \mathrm{S}$ & $45^{\circ} 03^{\prime} 50.47^{\prime} \mathrm{W}$ & & \\
\hline & $23^{\circ} 32^{\prime} 17.13^{\prime \prime} \mathrm{S}$ & $45^{\circ} 03^{\prime} 50.15^{\prime \prime} \mathrm{W}$ & & \\
\hline & $23^{\circ} 32^{\prime} 16.05^{\prime} \mathrm{S}$ & $45^{\circ} 03 ’ 49.3 ” \mathrm{~W}$ & $23^{\circ} 32^{\prime} 13.9^{\prime \prime} \mathrm{S}$ & $45^{\circ} 03^{\prime} 47.65^{\prime \prime} \mathrm{W}$ \\
\hline & $23^{\circ} 32^{\prime} 13.15^{\prime \prime} \mathrm{S}$ & $45^{\circ} 03^{\prime} 47.1 ” \mathrm{~W}$ & & \\
\hline & $23^{\circ} 32^{\prime} 12.75^{\prime} \mathrm{S}$ & $45^{\circ} 03^{\prime} 46.7^{\prime \prime} \mathrm{W}$ & $23^{\circ} 32^{\prime} 12.15^{\prime} \mathrm{S}$ & $45^{\circ} 03^{\prime} 46.15^{\prime \prime} \mathrm{W}$ \\
\hline Região de Substrato Inconsolidado & $23^{\circ} 32$ ' $18.6^{\prime} \mathrm{S}$ & $45^{\circ} 03^{\prime} 51.0 ” \mathrm{~W}$ & $23^{\circ} 32 ’ 10.0 ” \mathrm{~S}$ & $45^{\circ} 03,44.6 " \mathrm{~W}$ \\
\hline \multirow[t]{2}{*}{ Tapete de Amphiroa e Jania } & $23^{\circ} 32^{\prime} 18.6^{\prime \prime} \mathrm{S}$ & $45^{\circ} 03^{\prime} 51.0 ” \mathrm{~W}$ & $23^{\circ} 32^{\prime} 17.3 ” \mathrm{~S}$ & $45^{\circ} 03^{\prime} 50.3^{\prime \prime} \mathrm{W}$ \\
\hline & $23^{\circ} 32^{\prime} 17.2^{\prime \prime} \mathrm{S}$ & $45^{\circ} 03^{\prime} 50.2^{\prime \prime} \mathrm{W}$ & $23^{\circ} 32^{\prime} 11.5^{\prime \prime} \mathrm{S}$ & $45^{\circ} 03^{\prime} 45.5^{\prime \prime} \mathrm{W}$ \\
\hline \multirow[t]{2}{*}{ Tapete de Amphiroa e Jania com Echinometra } & $23^{\circ} 32^{\prime} 18.5^{\prime \prime} \mathrm{S}$ & $45^{\circ} 03^{\prime} 50.9^{\prime \prime} \mathrm{W}$ & $23^{\circ} 32^{\prime} 18.35^{\prime} \mathrm{S}$ & $45^{\circ} 03^{\prime} 50.85^{\prime \prime} \mathrm{W}$ \\
\hline & $23^{\circ} 32^{\prime} 13.7$ ' S & $45^{\circ} 03^{\prime} 47.5^{\prime \prime} \mathrm{W}$ & & \\
\hline \multirow[t]{4}{*}{ Tapete de Ectoprocta } & $23^{\circ} 32^{\prime} 18.35^{\prime} \mathrm{S}$ & $45^{\circ} 03^{\prime} 50.85^{\prime \prime} \mathrm{W}$ & $23^{\circ} 32^{\prime} 18.05^{\prime \prime} \mathrm{S}$ & $45^{\circ} 03^{\prime} 50.7^{\prime \prime} \mathrm{W}$ \\
\hline & $23^{\circ} 32^{\prime} 17.75^{\prime} \mathrm{S}$ & $45^{\circ} 03^{\prime} 50.5^{\prime \prime} \mathrm{W}$ & $23^{\circ} 32^{\prime} 13.2 ” \mathrm{~S}$ & $45^{\circ} 03^{\prime} 47.15^{\prime \prime} \mathrm{W}$ \\
\hline & $23^{\circ} 32^{\prime} 12.65^{\prime \prime} \mathrm{S}$ & $45^{\circ} 03^{\prime} 46.6^{\prime \prime} \mathrm{W}$ & $23^{\circ} 32^{\prime} 12.05^{\prime} \mathrm{S}$ & $45^{\circ} 03^{\prime} 46.05^{\prime \prime} \mathrm{W}$ \\
\hline & $23^{\circ} 32^{\prime} 10.7$ ' S & $45^{\circ} 03^{\prime} 45.3^{\prime \prime} \mathrm{W}$ & $23^{\circ} 32^{\prime} 10.6 ” \mathrm{~S}$ & $45^{\circ} 03,45.1^{\prime \prime} \mathrm{W}$ \\
\hline \multirow[t]{2}{*}{ Tapete de Ectoprocta com Carijoa } & $23^{\circ} 32^{\prime} 16.55^{\prime \prime} \mathrm{S}$ & $45^{\circ} 03^{\prime} 49.7 ” \mathrm{~W}$ & $23^{\circ} 32^{\prime} 14.6^{\prime \prime} \mathrm{S}$ & $45^{\circ} 03^{\prime} 48.2^{\prime \prime} \mathrm{W}$ \\
\hline & $23^{\circ} 32^{\prime} 13.0 ” \mathrm{~S}$ & $45^{\circ} 03^{\prime} 46.95^{\prime \prime} \mathrm{W}$ & $23^{\circ} 32^{\prime} 12.85^{\prime} \mathrm{S}$ & $45^{\circ} 03^{\prime} 46.8^{\prime \prime} \mathrm{W}$ \\
\hline \multirow[t]{4}{*}{ Tapete de Ectoprocta com Phallusia } & $23^{\circ} 32$ ' 18.6 " S & $45^{\circ} 03^{\prime} 51.0 ” \mathrm{~W}$ & $23^{\circ} 32^{\prime} 18.2 ” \mathrm{~S}$ & $45^{\circ} 03^{\prime} 50.75^{\prime \prime} \mathrm{W}$ \\
\hline & $23^{\circ} 32^{\prime} 17.13^{\prime \prime} \mathrm{S}$ & $45^{\circ} 03^{\prime} 50.15^{\prime \prime} \mathrm{W}$ & & \\
\hline & $23^{\circ} 32^{\prime} 16.55^{\prime} \mathrm{S}$ & $45^{\circ} 03^{\prime} 49.7^{\prime \prime} \mathrm{W}$ & $23^{\circ} 32^{\prime} 13.2^{\prime} \mathrm{S}$ & $45^{\circ} 03^{\prime} 47.15^{\prime \prime} \mathrm{W}$ \\
\hline & $23^{\circ} 32 ' 13.1^{\prime \prime} \mathrm{S}$ & $45^{\circ} 03^{\prime} 47.05^{\prime \prime} \mathrm{W}$ & $23^{\circ} 32^{\prime} 12.15^{\prime \prime} \mathrm{S}$ & $45^{\circ} 03^{\prime} 46.15^{\prime \prime} \mathrm{W}$ \\
\hline \multirow[t]{3}{*}{ Tapete de Ectoprocta com Polysiphonia } & $23^{\circ} 32^{\prime} 18.6^{\prime \prime} \mathrm{S}$ & $45^{\circ} 03,51.0 ” \mathrm{~W}$ & $23^{\circ} 32,17.6 " \mathrm{~S}$ & $45^{\circ} 03^{\prime} 50.45^{\prime \prime} \mathrm{W}$ \\
\hline & $23^{\circ} 32^{\prime} 14.45^{\prime \prime} \mathrm{S}$ & $45^{\circ} 03^{\prime} 48.1 " \mathrm{~W}$ & $23^{\circ} 32^{\prime} 13.6^{\prime \prime} \mathrm{S}$ & $45^{\circ} 03^{\prime} 47.45^{\prime \prime} \mathrm{W}$ \\
\hline & $23^{\circ} 32^{\prime} 13.0^{\prime} \mathrm{S}$ & $45^{\circ} 03^{\prime} 46.95^{\prime \prime} \mathrm{W}$ & $23^{\circ} 32^{\prime} 12.4 ” \mathrm{~S}$ & $45^{\circ} 03^{\prime} 46.4 ” \mathrm{~W}$ \\
\hline \multirow[t]{2}{*}{ Tapete de Ectoprocta com Wrangelia } & $23^{\circ} 32^{\prime} 18.6^{\prime \prime} \mathrm{S}$ & $45^{\circ} 03^{\prime} 51.0 ” \mathrm{~W}$ & $23^{\circ} 32^{\prime} 18.5^{\prime} \mathrm{S}$ & $45^{\circ} 03^{\prime} 50.9^{\prime \prime} \mathrm{W}$ \\
\hline & $23^{\circ} 32^{\prime} 17.2^{\prime \prime} \mathrm{S}$ & $45^{\circ} 03^{\prime} 50.2 ” \mathrm{~W}$ & & \\
\hline \multirow[t]{3}{*}{ Tapete de Falkenbergia } & $23^{\circ} 32^{\prime} 17.1^{\prime \prime} \mathrm{S}$ & $45^{\circ} 03^{\prime} 50.15^{\prime \prime} \mathrm{W}$ & & \\
\hline & $23^{\circ} 32^{\prime} 13.5^{\prime \prime} \mathrm{S}$ & $45^{\circ} 03^{\prime} 47.4 ” \mathrm{~W}$ & & \\
\hline & $23^{\circ} 32^{\prime} 10.7^{\prime} \mathrm{S}$ & $45^{\circ} 03^{\prime} 45.0^{\prime \prime} \mathrm{W}$ & & \\
\hline \multirow[t]{3}{*}{ Tapete de Gelidiopsis e Hypnea } & $23^{\circ} 32^{\prime} 18.6^{\prime \prime} \mathrm{S}$ & $45^{\circ} 03^{\prime} 51.0^{\prime \prime} \mathrm{W}$ & $23^{\circ} 32^{\prime} 17.4$ " S & $45^{\circ} 03^{\prime} 50.35^{\prime \prime} \mathrm{W}$ \\
\hline & $23^{\circ} 32^{\prime} 17.05^{\prime \prime} \mathrm{S}$ & $45^{\circ} 03,50.1 " \mathrm{~W}$ & $23^{\circ} 32,13.2^{\prime \prime} \mathrm{S}$ & $45^{\circ} 03^{\prime} 47.15^{\prime \prime} \mathrm{W}$ \\
\hline & $23^{\circ} 32^{\prime} 13.1 ” \mathrm{~S}$ & $45^{\circ} 03^{\prime} 47.05^{\prime \prime} \mathrm{W}$ & $23^{\circ} 32^{\prime} 12.05^{\prime \prime} \mathrm{S}$ & $45^{\circ} 03^{\prime} 46.05^{\prime \prime} \mathrm{W}$ \\
\hline \multirow[t]{5}{*}{ Tapete de Wrangelia } & $23^{\circ} 32^{\prime} 18.5^{\prime \prime} \mathrm{S}$ & $45^{\circ} 03^{\prime} 50.9 ” \mathrm{~W}$ & & \\
\hline & $23^{\circ} 32^{\prime} 17.6^{\prime \prime} \mathrm{S}$ & $45^{\circ} 03^{\prime} 50.45^{\prime \prime} \mathrm{W}$ & & \\
\hline & $23^{\circ} 32^{\prime} 17.2 ” \mathrm{~S}$ & $45^{\circ} 03^{\prime} 50.2^{\prime \prime} \mathrm{W}$ & & \\
\hline & $23^{\circ} 32^{\prime} 12.57^{\prime \prime} \mathrm{S}$ & $45^{\circ} 03^{\prime} 46.55^{\prime \prime} \mathrm{W}$ & & \\
\hline & $23^{\circ} 32$ ' 11.1" S & $45^{\circ} 03^{\prime} 45.1 ” \mathrm{~W}$ & $23^{\circ} 32^{\prime} 10.8^{\prime \prime} \mathrm{S}$ & $45^{\circ} 03^{\prime} 44.8^{\prime \prime} \mathrm{W}$ \\
\hline
\end{tabular}


Legenda dos povoamentos (Figuras A2.1 e A2.2):

\begin{tabular}{|c|c|}
\hline & Banco de Asparagopsis \\
\hline & Banco de Caulerpa \\
\hline & Banco de Colpomenia \\
\hline & Banco de Dichotomaria \\
\hline & Banco de Dictyota \\
\hline & Banco de Padina \\
\hline & Banco de Sargassum \\
\hline & Banco de Tropiometra \\
\hline & Colônia de Didemnun \\
\hline & Colônia de Mussismilia \\
\hline & Colônia de Palythoa \\
\hline & Colônia de Schizoporella \\
\hline , & Colônia de Symplegma \\
\hline & Crosta de Amphimedon \\
\hline & Crosta de Corallinacea \\
\hline
\end{tabular}

(1) Crosta de Corallinaceae com Echinometra $\Psi$ Crosta de Corallinaceae com Polysiphonia

Crosta de Mycale

$\because$ Crosta de Peyssonnelia

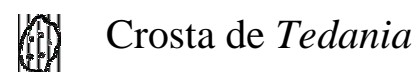

- Fundo arenoso

Y. Tapete de Amphiroa e Jania

Y. Tapete de Amphiroa e Jania com Echinometra

Tapete de Ectoprocta

\$ Tapete de Ectoprocta com Carijoa

Tapete de Ectoprocta com Phallusia

\& Tapete de Ectoprocta com Polysiphonia

Tapete de Ectoprocta com Wrangelia

Tapete de Falkenbergia

fy Tapete de Gelidiopsis e Hypnea

* Tapete de Wrangelia 


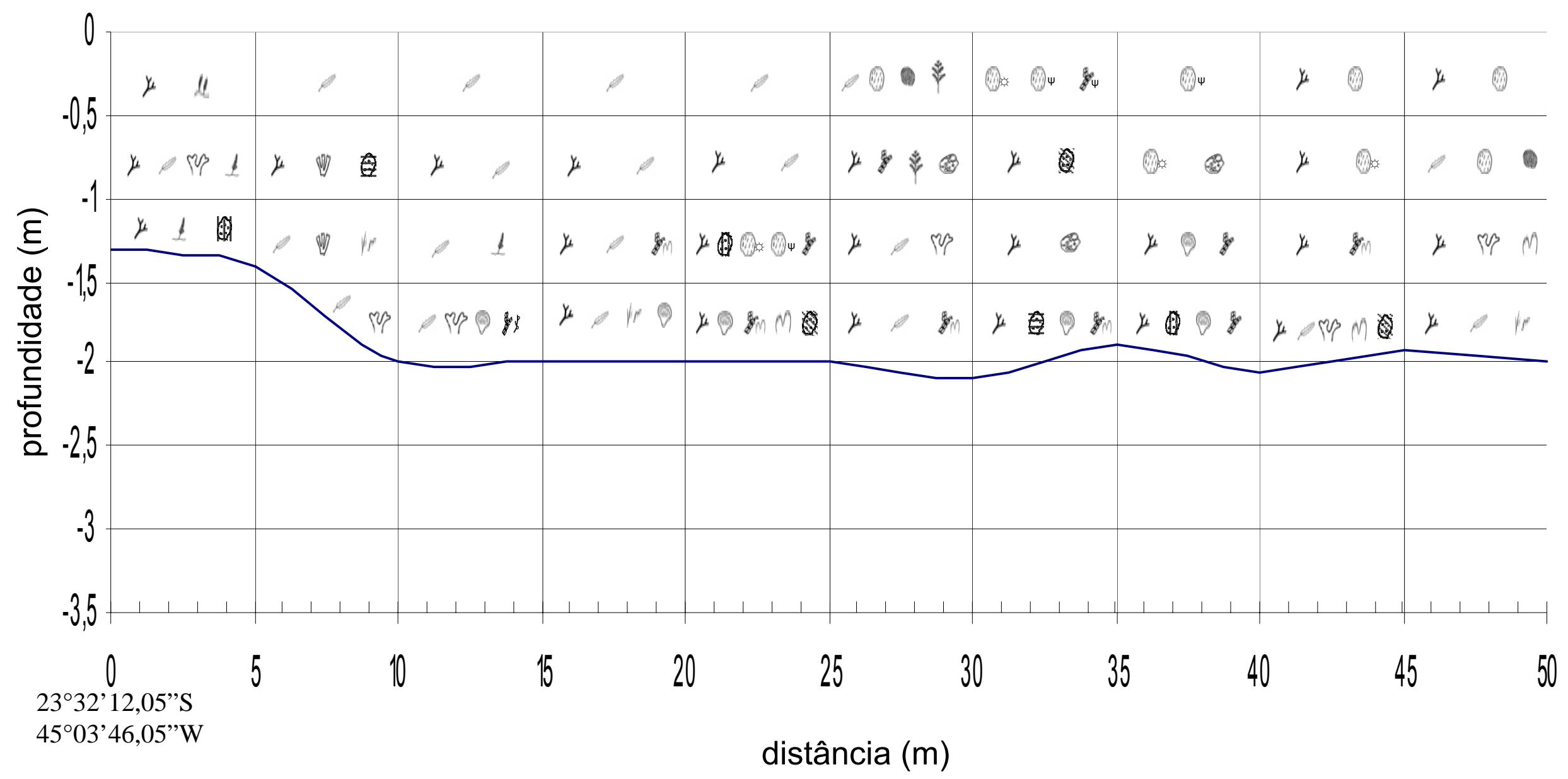

Figura A2.1 - Mapeamento dos povoamentos existentes entre a Praia do Engenho e a Praia do Presídio (PEIA - Ubatuba), trecho com aproximadamente 260 m subdividido de 5 em 5 m, no período de verão. 


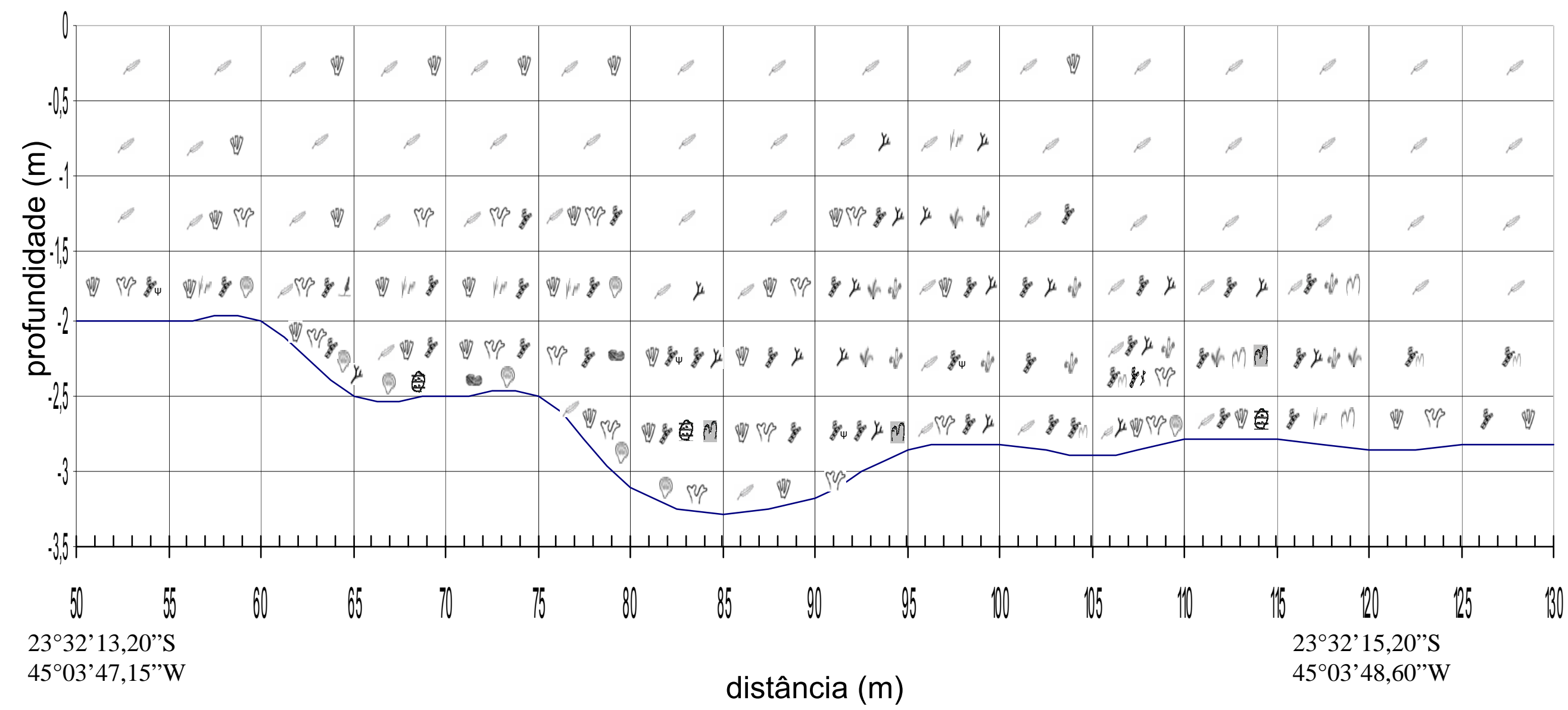

Figura A2.1 cont. 


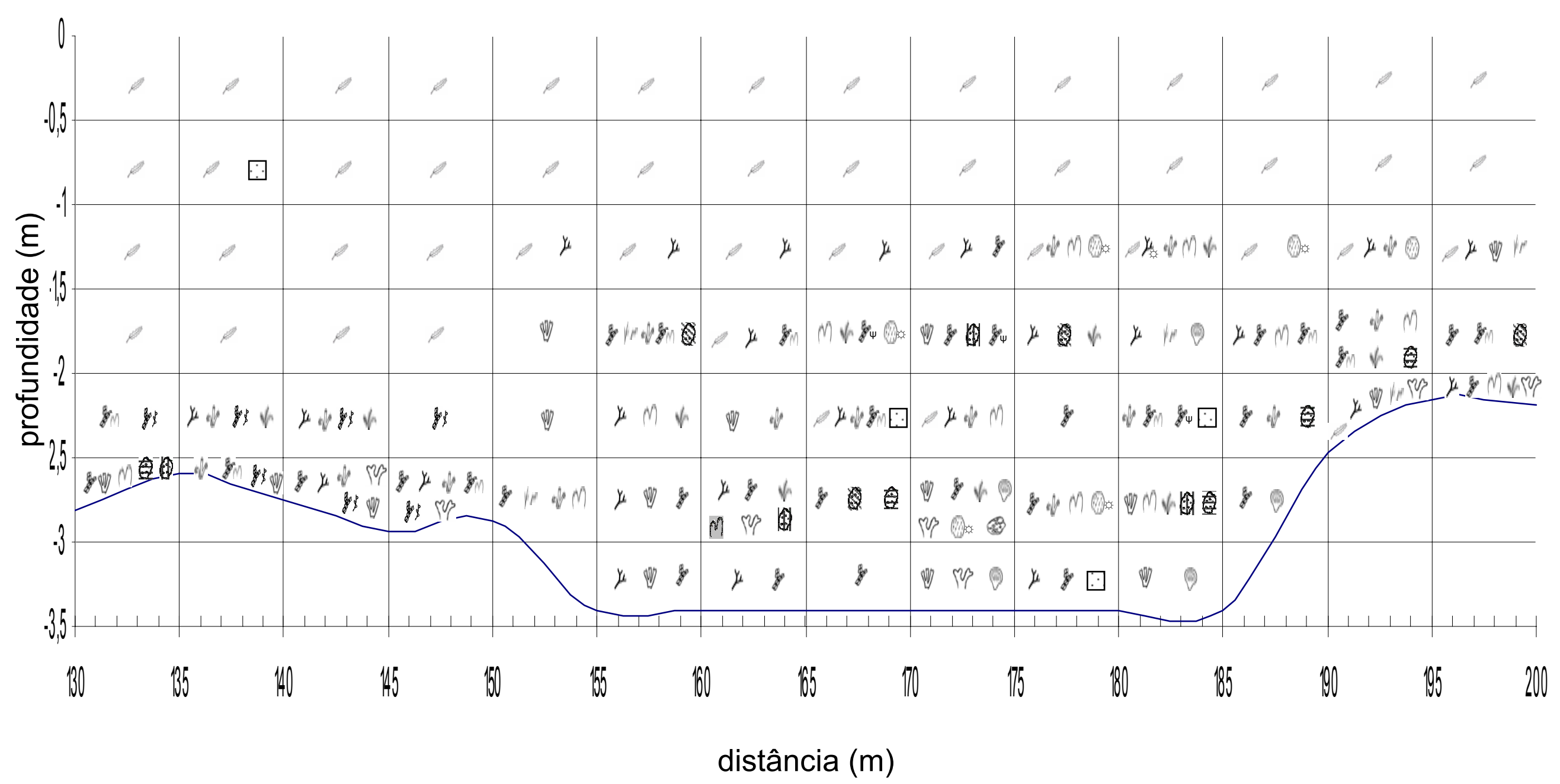

Figura A2.1 cont. 


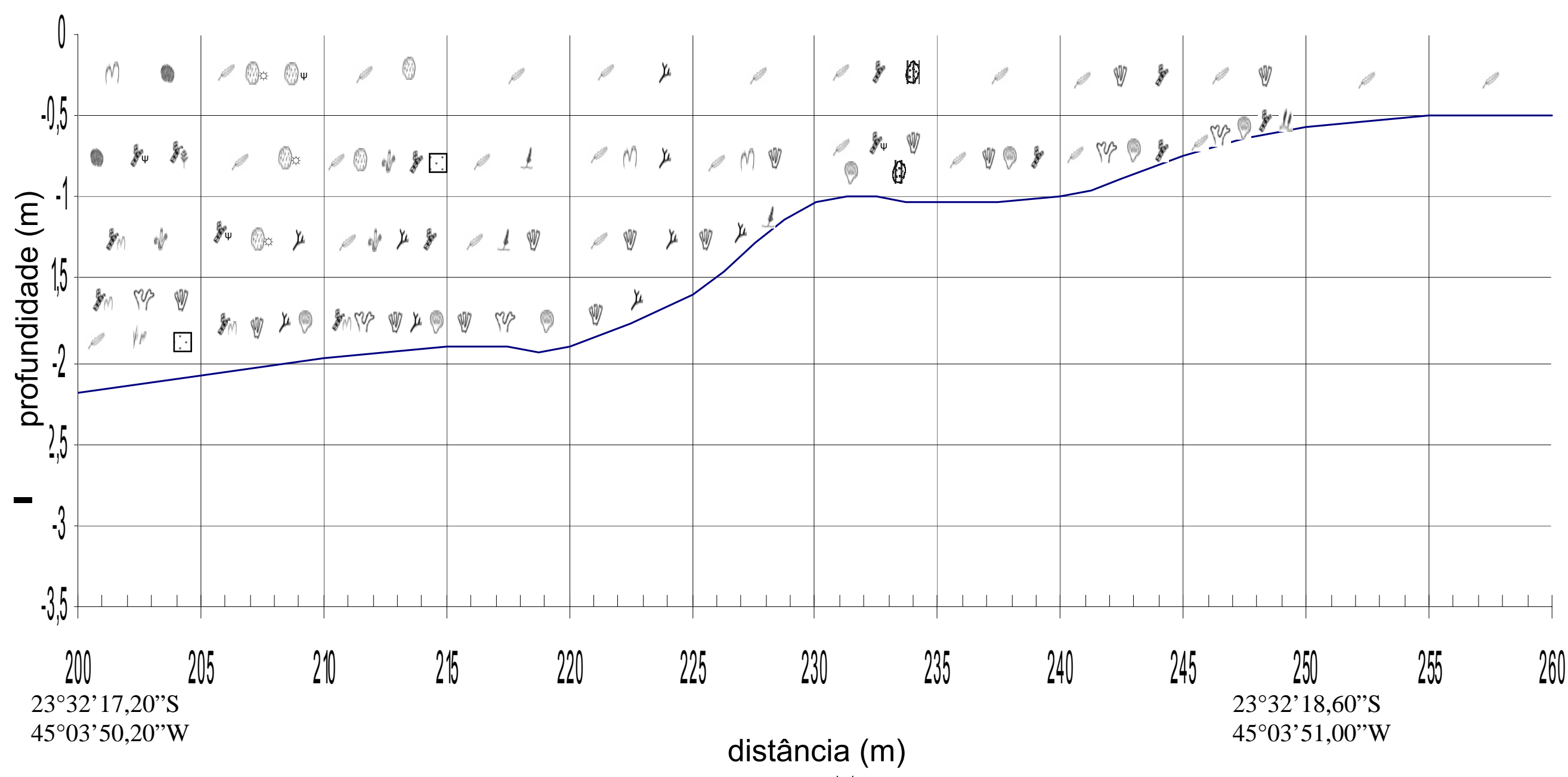

Figura A2.1 cont. 


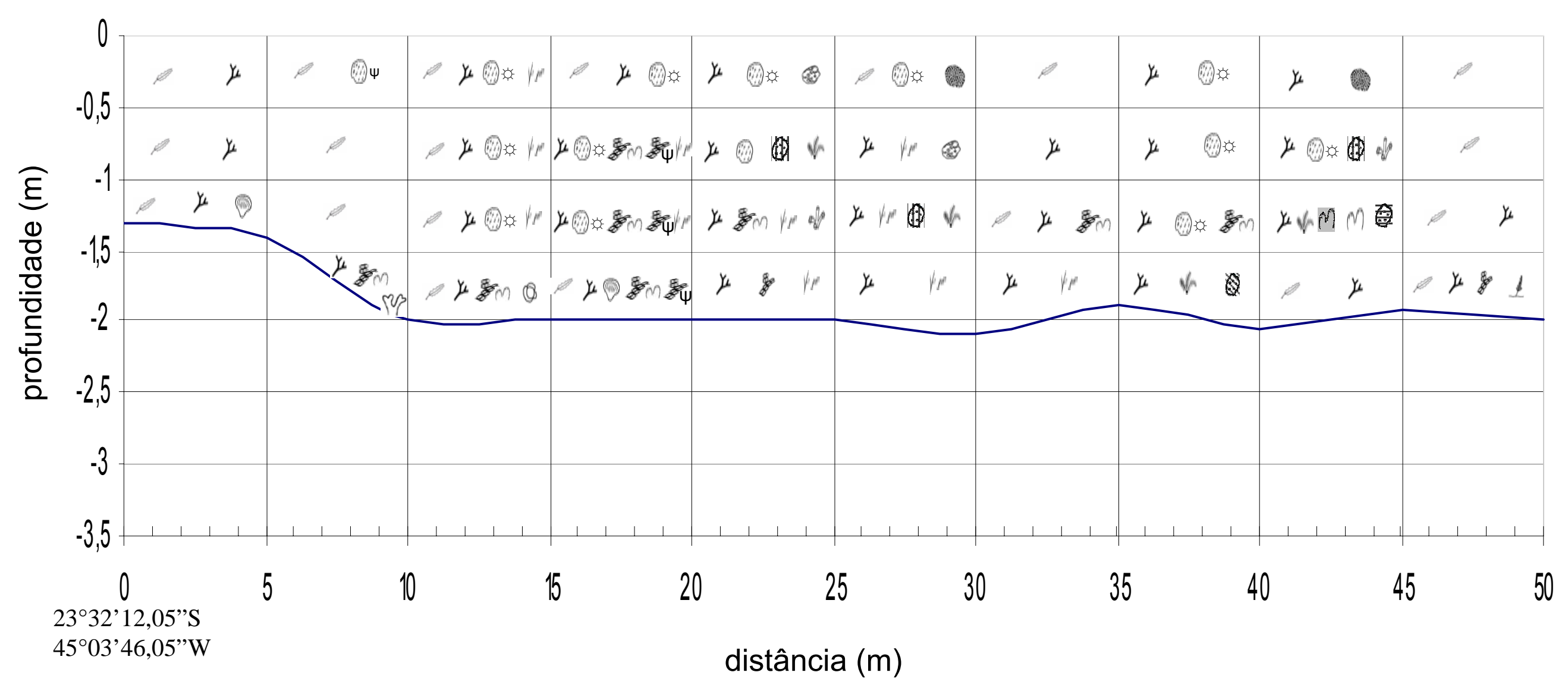

Figura A2.2 - Mapeamento dos povoamentos existentes entre a Praia do Engenho e a Praia do Presídio (PEIA - Ubatuba), trecho com aproximadamente 260 m subdividido de 5 em 5 m, no período do inverno. 


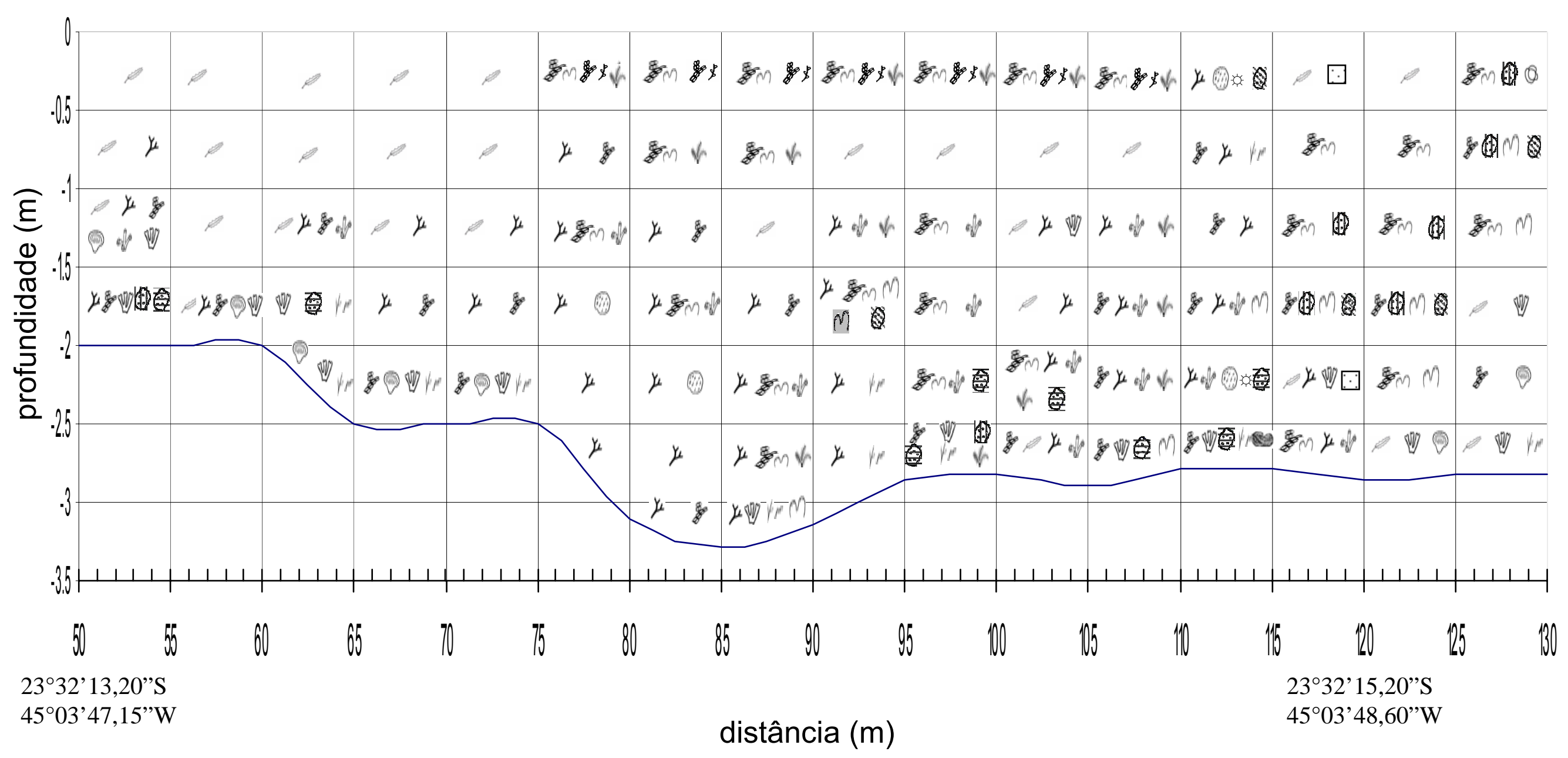

Figura A2.2 cont. 


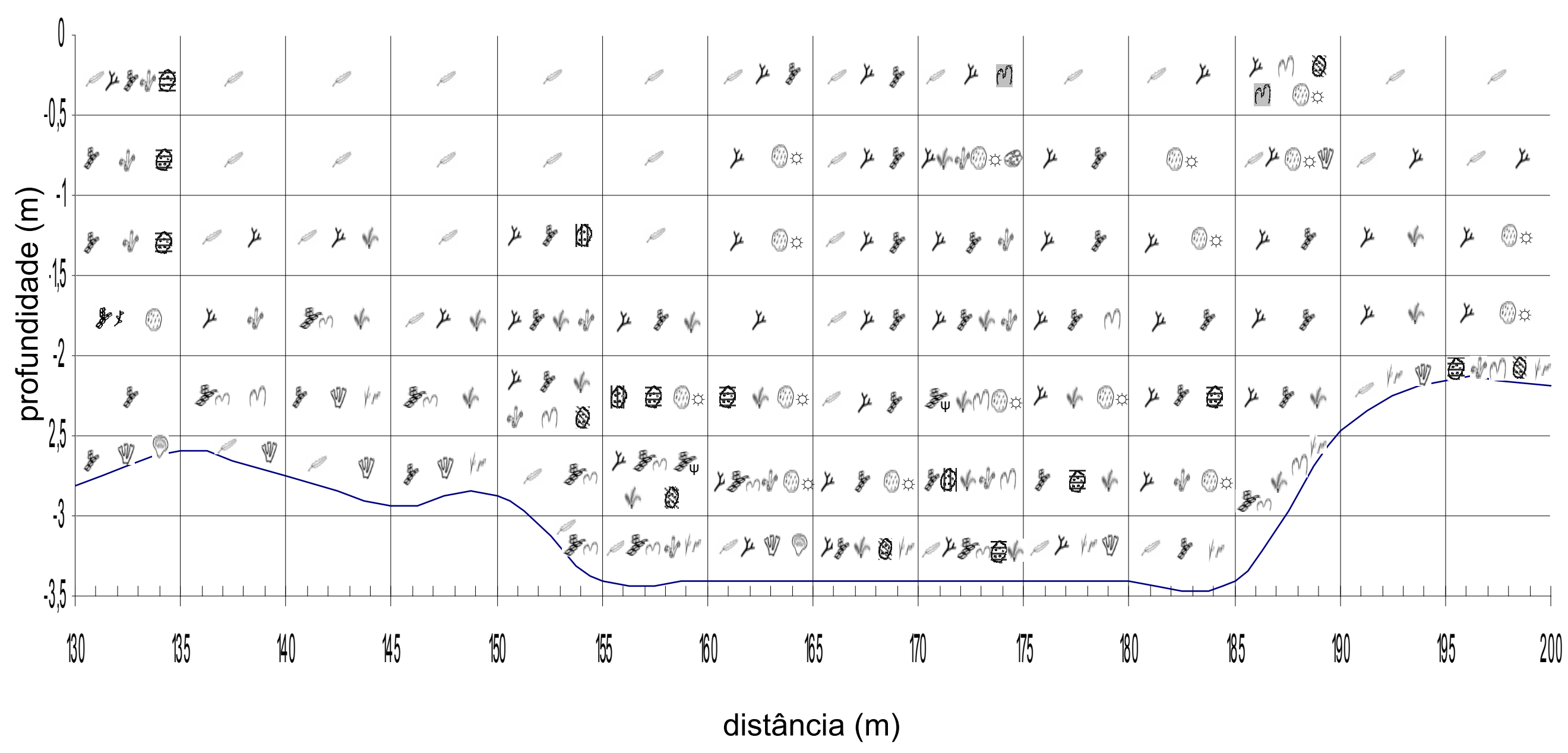

Figura A2.2 cont. 


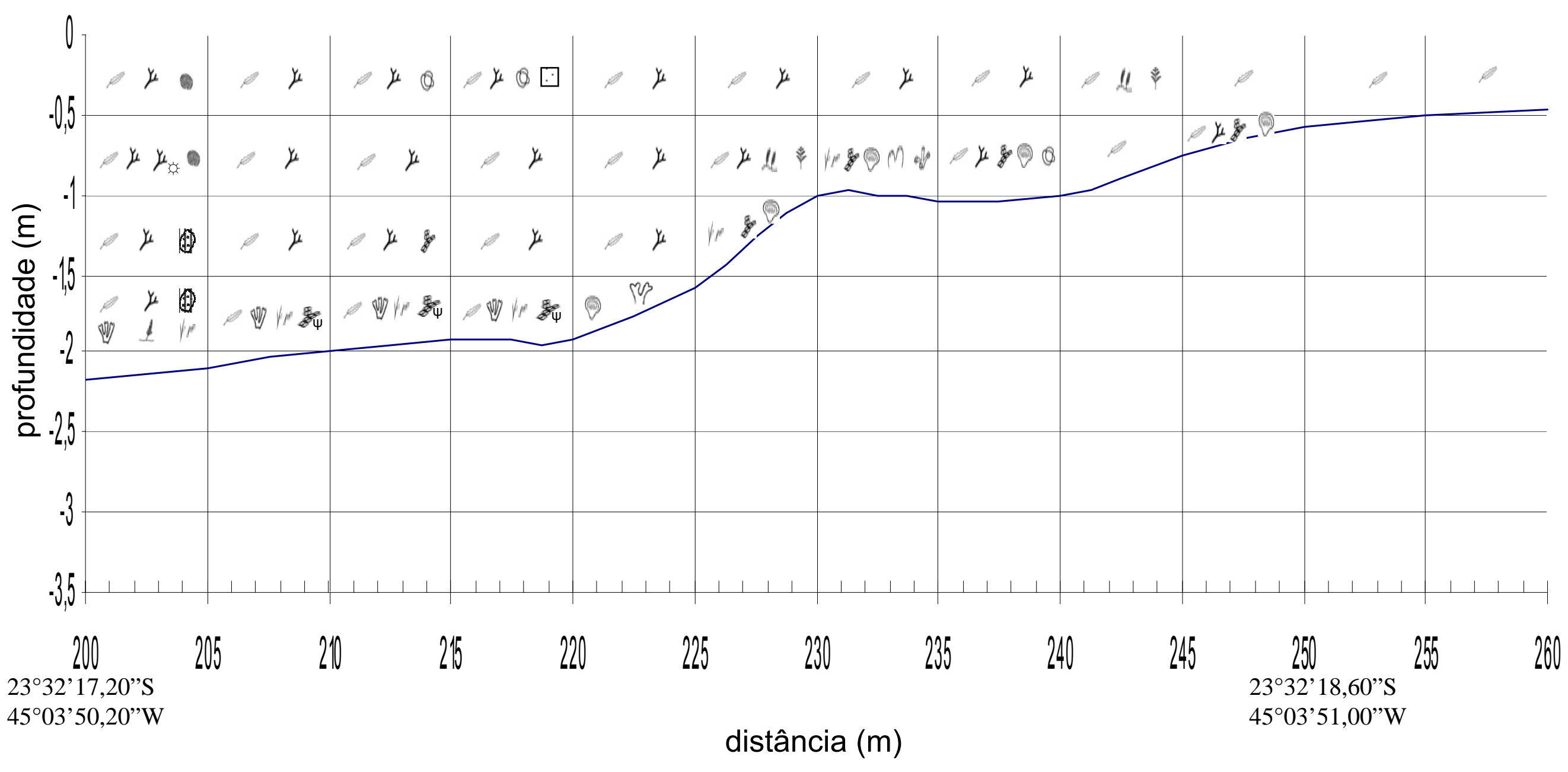

Figura A2.2 cont. 



\section{CAPÍTULO 3}

REPARTIÇÃO ESPACIAL DOS POVOAMENTOS EM TRECHO DO INFRALITORAL CONSOLIDADO DA ENSEADA DAS Palmas (Parque estadual de IlHa Anchieta, Ubatuba, SP) - ANÁlise QUANTITATIVA POR RECOBRIMENTO PERCENTUAL 



\section{Abstract}

The infralittoral communities show some regularity in structural patterns. Their sampling in a representative way is an important step towards the knowledge of the processes which determine these patterns. The "Physiognomic Assessment" method is a tool which allows for the identification of visual patterns, or heterogeneity, of rocky shore benthic communities, using landscape units called physiognomies and settlements. Non-destructive photographic methods allow the afterwards recuperation of data and so are interesting for monitoring purposes. The present study aims at quantitative characterizing the structure of hard bottom benthic communities on an infralittoral stretch between Presídio and Engenho Beaches (Anchieta Island State Park) for the first time, through the percent cover analysis of settlements in digital photographs, randomly obtained, at an area $250 \mathrm{~m}$ large and with variable depth. Cluster analysis in $\mathrm{R}$ and $\mathrm{Q}$ modes and heterogeneity evaluation of the obtained groups were made. Diversity and dominance descriptors, adapted to settlements, were calculated for the sampling units. Sampling units were obtained in numbers of 84 in summer and 100 in winter, from which 26 and 28 settlements could be recognized, respectively. Sargassum Bed showed the highest mean percent cover as much in summer $(26.1 \%)$ as in winter $(32.0 \%)$, followed by Ectoprocta Turf $(19.7 \%$ in summer and $24.2 \%$ in winter), significantly higher than most of the other settlements $(p<0.05)$. Phytobenthic settlements were the most representative in the area $(62.2 \%$ of mean cover in summer and $61.8 \%$ in winter). When settlements categories were considered, phytobenthic beds were the most representative $(31.2 \%$ in summer and $37.0 \%$ in winter). With animals and algae altogether, the category 'turf' was the most represented $(46.3 \%$ in summer and $41.4 \%$ in winter), with great contribution of Amphiroa and Jania Turf and Ectoprocta Turf, indicating a possible sedimentation influence in the area. The cluster analysis in R Mode showed the existence of six groups in summer and five in winter, suggesting settlements with the same ecological exigencies. In Q Mode a highly heterogeneous community could be evidenced, showing a patchy pattern. The settlements Sargassum Bed, Inconsolidate Substrate Region, Amphiroa and Jania Turf, Ectoprocta Turf (and some of its variations) and Gelidiopsis and Hypnea Turf were the responsible for group formation with the use of Morisita-Horn Similarity Index. Mean Settlement Richness were 2.86 and 3.3, mean Shannon's Diversity Index were 0.97 and 1.01, mean Simpson's Dominance Index were 0.70 and 0.65 and mean Pielou's Dominance Index were 0.52 and 0.49 in summer and winter, respectively. There were not any significant differences between the two periods for the analysed descriptors, except mean Settlement Richness, which was higher in winter. This method allowed an initial characterization of local community structure and the data obtained can serve as a basis for more detailed studies in the area and the understanding of the processes which determine this structure. 


\section{RESUMO}

As comunidades de infralitoral apresentam certa regularidade nos padrões estruturais. Amostrar estas comunidades de maneira representativa é um passo importante para o conhecimento dos processos determinantes destes padrões. O método "Levantamento Fisionômico" é uma ferramenta que permite a identificação de padrões visuais, ou heterogeneidade, de comunidades bentônicas de costões rochosos, usando unidades da paisagem chamadas fisionomias e povoamentos. Métodos fotográficos, além de nãodestrutivos, permitem a posterior recuperação dos dados, sendo interessantes para o monitoramento ambiental. O presente estudo objetiva caracterizar quantitativamnete, pela primeira vez, a estrutura da comunidade bentônica de substrato consolidado em trecho do infralitoral entre as Praias do Presídio e do Engenho (PEIA) de forma quantitativa, através da análise de recobrimento percentual de povoamentos a partir de fotografias digitais, obtidas aleatoriamente, em uma área com extensão de $250 \mathrm{~m}$ e profundidade variável. Foram realizadas análises de repartição espacial nos modos $\mathrm{R}$ e $\mathrm{Q}$ e avaliação de heterogeneidade dos agrupamentos formados. Descritores de diversidade e dominância, adaptados para povoamentos, foram usados no âmbito dos elementos amostrais. Foram obtidos 84 elementos amostrais no verão e 100 no inverno, os quais evidenciaram 26 e 28 povoamentos, respectivamente. Banco de Sargassum apresentou maior valor de recobrimento percentual médio tanto no período de verão $(26,1 \%)$ quanto de inverno $(32,0 \%)$, seguido de Tapete de Ectoprocta (19,7\% no verão e $24,2 \%$ no inverno), significativamente maior que a maioria dos demais povoamentos $(\mathrm{p}<0,05)$. Os povoamentos fitobentônicos foram mais representativos na área (62,2\% de recobrimento médio no verão e $61,8 \%$ no inverno). Quando consideradas as categorias de povoamentos, os bancos fitobentônicos foram mais representativos $(31,2 \%$ no verão e $37,0 \%$ no inverno). Se somados animais e algas, a categoria 'tapete' foi a mais representada (46,3\% no verão e $41,4 \%$ no inverno), com grande contribuição dos povoamentos Tapete de Amphiroa e Jania e Tapete de Ectoprocta, indicando uma possível influência da sedimentação na área. A análise de repartição espacial em Modo R evidenciou a existência de seis grupos no verão e cinco no inverno, sugerindo povoamentos com as mesmas exigências ecológicas. Já em Modo Q observou-se que a comunidade da área é bastante heterogênea, apresentando um padrão em manchas, sendo os povoamentos Banco de Sargassum, Região de Substrato Inconsolidado, Tapete de Amphiroa e Jania, Tapete de Ectoprocta (e algumas de suas variações) e Tapete de Gelidiopsis e Hypnea os responsáveis pela formação dos grupos com o Índice de Similaridade de Morisita-Horn. A Riqueza de povoamentos média foi de 2,86 e 3,3, o Índice de Diversidade de Shannon médio foi de 0,97 e 1,01, o Índice de Dominância de Simpson médio foi de 0,70 e 0,65 e o Índice de Dominância de Pielou médio foi de 0,52 e 0,49 para o verão e o inverno, respectivamente. Não houve diferenças significativas entre os dois períodos para os descritores analisados, exceto Riqueza de povoamentos média, que foi maior no inverno. Esse método permitiu uma caracterização inicial da estrutura da comunidade local e os dados obtidos podem servir de base para estudos mais aprofundados na área e para o entendimento dos processos que determinam esta estrutura. 


\section{INTRODUÇÃo}

As comunidades podem ser estudadas sob dois aspectos: estrutural e funcional. Os parâmetros que definem a estrutura de uma comunidade são: sua composição (riqueza e tipos de espécies e suas abundâncias relativas), a natureza e forma das relações entre as espécies componentes (a direção, força relativa e impacto destas relações) e sua dinâmica espacial e temporal (Putman, 1994; Ricklefs \& Miller, 1999).

Existem diversas razões para se analisar padrões na estrutura das comunidades. Primeiro, porque os diferentes padrões observados resultam de diferentes processos, e a documentação desta variabilidade natural é um passo fundamental antes que a explanação de modelos para estes padrões seja proposta (Underwood, 1990; Menconi et al., 1999). Além disso, a síntese dos resultados de estudos experimentais da estrutura local das comunidades naturais facilita o entendimento dos padrões de organização das comunidades em escalas geográficas (Lubchenco \& Menge, 1978).

Os padrões estruturais das comunidades marinhas bentônicas de substrato consolidado do Parque Estadual de Ilha Anchieta ainda são pouco conhecidos e, portanto, estudos neste sentido são necessários, pois podem gerar dados que servirão para futuros monitoramentos e para o entendimento dos processos determinantes destes padrões. Existem para a área apenas uma lista de espécies de algas de mediolitoral elaborada por Coutinho (1974) e um estudo relacionando a diversidade da fauna e flora com o gradiente de profundidade realizado por Nonato (1974), ambos anexados ao Plano de Manejo do Parque (Guillaumon et al., 1989). Para a região do município de Ubatuba, onde se encontra o Parque, existem poucos trabalhos sobre estrutura de comunidades e todos enfocam o mediolitoral (Nonato \& Pérès, 1961; Oliveira Filho \& Mayal, 1976; Oliveira Filho \& Paula, 1983).

O método "Levantamento Fisionômico", proposto por Berchez et al. (2005), é uma alternativa para a caracterização rápida e abrangente das comunidades do local. 
Pelo fato da área ser uma unidade de conservação, é interessante o uso de métodos não-destrutivos, como o fotográfico.

Embora a amostragem a partir de imagens possa não ser adequada para estudos onde se pretenda a identificação de espécies (Dethier et al., 1993; Foster et al., 1991), o que é verdade para a maior parte das comunidades do nosso litoral (Rosso \& Borges, em revisão), ela apresenta resolução suficiente para visualização de organismos dominantes, como foi observado por Correia (1997), onde se utilizou a técnica do vídeo transecto para a determinação da porcentagem de cobertura dos organismos macrobentônicos. O mesmo pode ser esperado para fisionomias e povoamentos.

O método fotográfico é rápido e simples de usar e permite que o investigador obtenha um maior número de amostras por unidade de tempo (Littler \& Littler, 1985), o que é particularmente importante para as comunidades bentônicas de infralitoral, que dependem do tempo de disponibilidade do ar do cilindro de mergulho.

Além disso, como resultado de sua utilização formam-se arquivos históricos permanentes de fotoamostras que descrevem o estado da biota em um dado momento (Littler \& Littler, 1985), permitindo o arquivamento e posterior recuperação dos dados, que podem ser revistos a qualquer momento (Christie, 1983; Foster et al., 1991; Macedo et al., 2006).

Apesar de ainda pouco difundidas no Brasil, metodologias baseadas na análise de fotografias digitais e imagens de vídeo têm sido bastante usadas em estudos de ecologia de comunidades no mundo inteiro (Dayton, 1971, 1975; Littler \& Murray, 1971; Lundälv, 1971; Seapy \& Littler, 1978; Bohnsack, 1979; Souza, 1979; Weinberg, 1981; Christie, 1983; Foster et al., 1991; Whorff \& Griffing, 1991; Meese \& Tomich, 1992; Leonard \& Clark, 1993; Littorin \& Gilek, 1999; Bythel et al., 2001; Kollmann \& Stachowitsch, 2001; Page et al., 2001; Ducrotoy \& Simpson, 2001; Pech et al., 2004; Menge et al., 2005; Moysés, 2005; Tkachenko, 2005; Moysés et al., 2006 e outros). Meese \& Tomich (1992) mostram, entre 
vários métodos testados para análise de cobertura, que o que é feito em computador a partir de fotos digitalizadas apresenta maior precisão e repetitividade.

A confecção de bancos de imagens catalogando os diferentes povoamentos de nosso litoral pode servir de apoio e padronização para outros pesquisadores ou projetos que utilizem o método "Levantamento Fisionômico".

As amostras obtidas com o método fotográfico podem ser usadas para gerar informações quantitativas detalhadas e reproduzíveis, como recobrimento, densidade e freqüência.

O uso do recobrimento percentual como descritor primário em estudos de ecologia de comunidades de substrato consolidado para quantificação de espécies foi recomendado por Goodall (1952) e Bohnsack (1979), uma vez que sua utilização não envolve alterações no ambiente. Pitombo et al. (1988) estudando a diversidade de espécies e padrões de zonação de Cnidaria em Abrolhos (BA), recomendaram a utilização de recobrimento para se evitar erros inerentes ao uso de abundância relativa, devido a diferenças de tamanho entre colônias desses organismos. Os padrões de cobertura são os mais indicados para a classificação das comunidades por serem prontamente observados em campo e mais facilmente quantificados, conforme ressaltam Russel (1980) e Greig-Smith (1983). Além disso, a cobertura por organismos sésseis parece mais interessante para avaliar a estrutura das comunidades, considerando-se que em costões rochosos o espaço disponível é tido como o recurso limitante de maior peso (Connell, 1972). Ballesteros (1986) considerou o recobrimento como um método de quantificação eficiente, entretanto discute sua utilização na quantificação de algas bentônicas devido à sua forma de crescimento, resultando na super ou subestimação de algumas espécies. No caso da amostragem baseada em povoamentos (Berchez et al., 2005) este problema é minimizado, já que é feita a quantificação de associações e não de indivíduos.

No Brasil, muitos dos trabalhos de ecologia de comunidades bentônicas de infralitoral consolidado utilizaram recobrimento percentual como descritor primário (Maggs et al., 1979; 
Teixeira et al., 1987; Figueiredo et al., 2004; Oigman-Pszczol et al., 2004; Eston et al., 1986; Villaça \& Pitombo, 1997; Costa Jr. et al., 2002).

\section{OBJETIVO}

Este estudo objetiva avaliar quantitativamente a repartição espaço-temporal dos povoamentos em um trecho de $250 \mathrm{~m}$ do infralitoral da Enseada das Palmas (Parque Estadual da Ilha Anchieta) através da análise de recobrimento percentual (Abordagem 3 do método "Levantamento Fisionômico").

\section{Materiais E Métodos}

\section{Local}

O estudo foi realizado no costão leste da Praia do Presídio, na Enseada da Palmas, Parque Estadual de Ilha Anchieta, litoral norte do Estado de São Paulo (23 32 ' 18.6”' $45^{\circ}$ 03' 51.0”'W até $\left.23^{\circ} 32^{\prime} 11.5^{\prime} \mathrm{S} 45^{\circ} 03^{\prime} 45.5^{\prime \prime} \mathrm{W}\right)$.

\section{1) Amostragem dos povoamentos}

Como não havia uma estratificação evidente no trecho considerado e como o objetivo do trabalho foi o de evidenciar a repartição espacial de todos os povoamentos, considerou-se como domínio amostral a totalidade da área ao invés do estabelecimento de áreas homogêneas.

Para garantir igual representatividade da amostragem ao longo de todo o domínio amostral, este foi dividido em segmentos horizontais arbitrários de $50 \mathrm{~m}$ cada, nos quais foram situados aleatoriamente 20 elementos amostrais (amostragem aleatória estratificada).

A disposição aleatória dos amostradores foi obtida a partir da subdivisão hipotética de toda a área de amostragem em uma grade com subdivisões correspondentes ao tamanho do elemento amostral. Cada um foi sorteado garantindo-se chances iguais de ocorrência. Na prática, o posicionamento foi operacionalizado com o uso de um sistema de coordenadas no 
qual um cabo lastrado marcado correu paralelamente ao costão em toda a extensão amostrada, com o sorteio de pontos sendo feito previamente ao início da coleta, e de outro cabo, que foi posicionado perpendicularmente ao primeiro no ponto sorteado. O sorteio neste segundo cabo foi feito após a determinação do número de elementos amostrais possíveis no sentido. Caso necessário, um terceiro eixo também foi definido e os elementos amostrais nele contidos foram sorteados.

Os elementos amostrais foram constituídos por imagens retangulares de 35,00 x $26,25 \mathrm{~cm}\left(0,092 \mathrm{~m}^{2}\right)$ com resolução de $640 \times 480$ pixels, obtidas a $90^{\circ}$ do substrato com Câmera Digital Sony Mavica FD-92 acondicionada em caixa estanque Croma PLM. O equipamento foi acoplado a um suporte para que as imagens ficassem a uma distância constante do substrato, de cerca de $40 \mathrm{~cm}$, a qual permitia uma boa visualização dos povoamentos nas fotos mesmo em condições não ideais de visibilidade da água. Esta distância resultou na obtenção do valor de $35,00 \mathrm{~cm}$ de um lado do elemento amostral. Já o valor de $26,25 \mathrm{~cm}$ foi obtido em conseqüência da foto ser retangular.

Considerando-se que o objetivo foi a amostragem de povoamentos, considerou-se apenas um plano mesmo em locais onde as assembléias de espécies eram constituídas de mais de uma camada (recobrimento percentual máximo igual a 100\%).

Para cada elemento amostral, anotou-se em campo quais os povoamentos presentes.

Os organismos que não puderam ser identificados no local foram coletados e acondicionados em frascos plásticos identificados com a data da coleta, profundidade e ponto onde foram coletados.

As algas foram fixadas em formol 4\% diluído em água do mar. Para identificação, foram utilizadas as chaves de Joly $(1957,1965)$ e Taylor (1960). Todas as identificações foram revisadas e atualizadas pelos trabalhos de Wynne (1985) e Silva et al. (1996). As identificações foram submetidas à revisão por especialistas. Posteriormente, as espécies identificadas foram herborizadas segundo os procedimentos de Ramirez (1995). 
Os animais foram preservados segundo os procedimentos de Knudsen (1966). Todos eles foram identificados pelos especialistas do projeto "Levantamento Fisionômico de Comunidades Marinhas Bentônicas de Substrato Consolidado do Litoral do Estado de São Paulo" (Berchez et al., em andamento) ou por outros indicados por estes.

Para detectar possíveis variações na composição das comunidades, a amostragem foi repetida após seis meses. Os estudos foram iniciados no verão, quando ocorrem longos períodos de águas calmas e limpas, ideais para uma amostragem detalhada.

Foram obtidos 84 elementos amostrais no verão $\left(7,73 \mathrm{~m}^{2}\right)$ e 100 no inverno $\left(9,2 \mathrm{~m}^{2}\right)$, extrapolados para uma área de $600 \mathrm{~m}^{2}$.

\section{1) Análise de dados e apresentação dos resultados}

Os dados foram inseridos em uma matriz quantitativa de povoamentos versus elemento amostral. Também foi construída uma matriz na qual os povoamentos foram divididos em fitobentônicos, zoobentônicos e atributos não-biológicos. O descritor analítico primário utilizado foi o recobrimento percentual, apresentado em termos de valores médios das réplicas e respectivos intervalos de confiança (95\%). Este foi determinado indiretamente a partir do número de "pixels" ocupado por cada povoamento (Figura 3.1), definido com o auxílio de uma mesa digitalizadora Genius e dos programas Adobe Photoshop 6.0 e UTHSCSA Image Tool 3.0.

Como a disposição dos elementos amostrais foi aleatória, foi possível a aplicação de teste de hipótese, ou seja, de que os povoamentos eram ou não igualmente representados na área de estudo.

Foi aplicado o teste de Kolmogorov-Smirnov para verificação da normalidade da distribuição dos povoamentos. Como a distribuição encontrada não correspondia à distribuição normal, foi utilizado o teste não paramétrico de Kruskal-Wallis para comparação de lotes referentes a esses resultados e, caso encontradas diferenças significativas, o teste $a$ 
posteriori de comparação de postos (Dunnett), ambos com a utilização do programa SPSS 10.0 para Windows.

Para comparação dos recobrimentos percentuais médios dos povoamentos entre verão e inverno, foi realizado o teste não-paramétrico de Wilcoxon.

a)

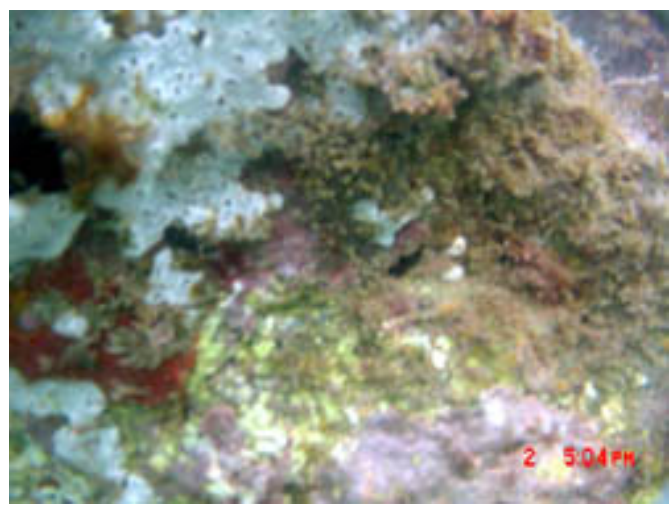

b)

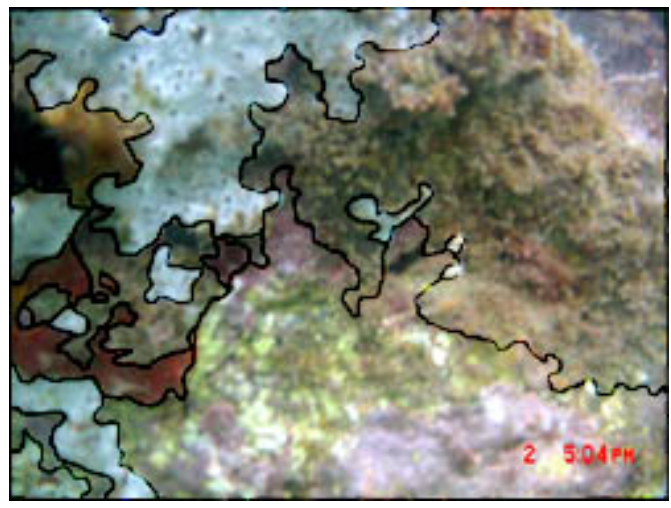

c)

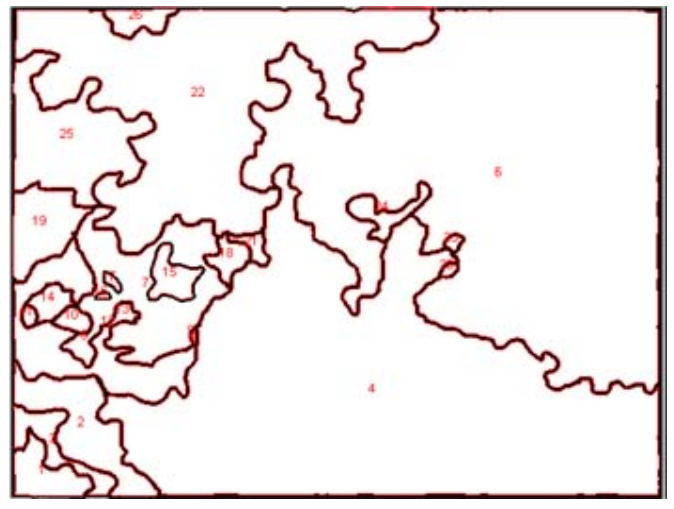

Figura 3.1 - a) Imagem original tratada no programa Adobe Photoshop 6.0; b) Povoamentos contornados (Adobe Photoshop 6.0) e c) Determinação de objetos (numerados em vermelho) correspondentes a cada povoamento, para os quais foi calculada a área (em pixels) ocupada na amostra (Image Tool 3.0). 
Os povoamentos foram hierarquizados com a utilização do descritor sintético Índice de Valor Ecológico (IVE) proposto por Pinder \& Rosso (1998), que leva em consideração a totalidade das espécies representadas nos diversos elementos amostrais, dispensando o estabelecimento arbitrário do grupo principal. O IVE quantifica a importância de cada povoamento em relação àquele, hipotético ou não, que se apresente como dominante em todos os elementos amostrais, sendo sua fórmula a que segue:

$\mathbf{I V E}=\frac{\sum_{j=1}^{N} r k_{i, j}}{\sum_{j=1}^{N} R K_{j}}$ onde,

$\mathrm{N}=$ número total de elementos amostrais

$\mathrm{RK}_{\mathrm{j}}=$ valor do mais alto posto no elemento amostral $\mathrm{j}$

$\mathrm{rk}_{\mathrm{ij}}=$ posto da espécie i no elemento amostral $\mathrm{j}$, correspondendo a $\left[\mathrm{RK}_{\mathrm{j}}-(\mathrm{P}-1)\right]$ sendo que

$\mathrm{P}=$ posição da espécie numa escala decrescente de abundâncias.

O valor de IVE sempre varia de 0 a 1, facilitando a interpretação dos dados (Borges, 1996). O processamento dos valores deste descritor sintético foi realizado no programa DivCalc 1.0 para Windows 98 (Rosso, não publicado).

\section{2) Repartição espacial}

A análise foi feita nos modos Q (entre amostras), nos planos qualitativo e quantitativo, e R (entre povoamentos), no plano qualitativo, segundo Legendre \& Legendre (1984).

\section{1) Repartição espacial em modo $Q$ e seus descritores}

Para o estudo qualitativo foi adotado o Índice de Similaridade de Dice-Sørensen.

$$
\mathrm{S}_{\mathrm{S} \varnothing \mathrm{R}}=\frac{2 c}{a+b+2 c}
$$

Onde: $\mathrm{a}=$ número de elementos exclusivos da amostra a

$\mathrm{b}=$ número de elementos exclusivos da amostra $\mathrm{b}$

$\mathrm{c}=$ número de elementos comuns às duas amostras 
Excluíram-se apenas neste caso os povoamentos que não atingiram valor de IVE de 0,05 em pelo menos um dos períodos estudados, visando reduzir ruído devido à presença de povoamentos pouco importantes e/ou de ocorrência ocasional.

Foram produzidos dendrogramas pela estratégia da média ponderada - WPGMA- que nivela os pesos dos grupos de diferentes tamanhos nas sucessivas fusões e assegura espaçoconservação (Legendre \& Legendre, 1984).

Optou-se pela adoção do cálculo dos níveis significativos de fusão dos elementos. Para determinar a significância dos agrupamentos foram estabelecidos limites de similaridade e dissimilaridade para $p=0,05$. A determinação destes níveis críticos de significância se deu por meio da utilização do aplicativo RANDMAT para Windows XP (Rosso, não publicado), que permitiu a realização de 1000 aleatorizações sucessivas das ocorrências de povoamentos de todos os elementos amostrais. Para cada par de elementos amostrais foram calculados os índices escolhidos nos 1000 possíveis arranjos, após o que se estabeleceram as distribuições de freqüência.

Para o estudo quantitativo, foi utilizado o Índice de Similaridade de Morisita modificado por Horn, que, segundo Wolda (1981), é um índice bastante adequado, pois é pouco influenciado pela riqueza e pelo tamanho das amostras, mas é influenciado por alterações nas abundâncias das espécies (aqui no caso, povoamentos) mais abundantes. Além disso, também foi utilizado o Índice de Distância de Bray-Curtis (Wolda, 1981) que, por sua vez, é influenciado pelo tamanho das amostras e pela alteração nas abundâncias das espécies (também aqui, no caso, povoamentos) intermediárias.

$$
\mathrm{S}_{\mathrm{MOR}-\mathrm{HORN}}=2 \times \sum_{i=1}^{n} \frac{\left(e_{i a} \times e_{i b}\right)}{\left(d_{e i a} \times d_{e i b}\right) E_{a} E_{b}}
$$

Onde: "e $e_{i a}$ " " $e_{i b "}$ " são os efetivos de cada espécie "i" respectivamente nas amostras "a" e "b" " $E_{\mathrm{a}}$ " e " $\mathrm{E}_{\mathrm{b}}$ " são os efetivos totais de todos os povoamentos respectivamente nas amostras "a" e "b" 


$$
\begin{gathered}
d_{e i}=\frac{\sum_{i=1}^{n} e_{i}^{2}}{E_{i}^{2}} \\
\text { S BRAY-CURTIS }=\frac{\sum\left|e_{i a}-e_{i b}\right|}{\sum\left|e_{i a}+e_{i b}\right|}
\end{gathered}
$$

Neste caso todos os povoamentos foram considerados.

No estudo de repartição espacial quantitativo, também foi utilizada a estratégia WPGMA. Da mesma forma que no estudo qualitativo, estabeleceram-se as significâncias para $\mathrm{p}=0,05$.

As planilhas qualitativas e quantitativas foram processadas utilizando o programa MVSP 3.13f (Kovach, 2003) resultando na obtenção de dendrogramas.

Os descritores sintéticos simples da heterogeneidade entre pares de amostras (descritores de $\beta$-diversidade) utilizados nesta etapa permitiram a detecção de grupos qualitativa e quantitativamente homogêneos, os quais serviram de base para as análises do Capítulo 4.

Os valores de IVE dos povoamentos de cada grupo formado com a utilização do Índice de Similaridade Quantitativo de Morisita-Horn foram representados graficamente, permitindo reconhecer os povoamentos mais característicos de cada um deles. Esta hierarquização assume um valor ecologicamente definido, permitindo, por exemplo, referir-se a um dado grupo como "grupo de tal ou tais povoamentos principais", conceito que se aproxima da idéia de Valor Biológico, como um atributo real de sucesso bio/ecológico do povoamento considerado.

\section{2) Repartição em modo $R$ e seus descritores}

A definição de grupos com a utilização de povoamentos como unidade (modo R) possibilitou destacar associações presentes no período de coleta, independentemente das abundâncias envolvidas de cada povoamento. Para isso, a análise em modo $\mathrm{R}$ foi efetuada somente no plano qualitativo e o descritor de heterogeneidade utilizado foi o Índice de 
Similaridade de Dice-Sørensen. Da mesma forma que na análise em modo Q, optou-se pela adoção do cálculo dos níveis significativos de fusão dos elementos através do aplicativo RANDMAT.

Os povoamentos com valor de IVE inferior a 0,05 foram excluídos da análise, para reduzir o ruído na formação dos dendrogramas, e utilizou-se a estratégia de agrupamento Ligação Completa.

\section{3) Avaliação da heterogeneidade}

Para melhor entendimento da repartição espacial de cada um dos grupos formados com a utilização do Índice de Similaridade Quantitativo de Morisita-Horn e para se ter uma noção mais clara da heterogeneidade dos mesmos, analisou-se as distribuições de freqüência deste índice entre elementos amostrais dois a dois dentro de cada grupo. Este tipo de distribuição é uma forma de visualização das similaridades entre réplicas, de forma que o número de modas corresponde ao número de facetas apresentado por aquele grupo.

\section{3) Descritores de diversidade e dominância}

$\mathrm{Na}$ abordagem da diversidade, foram analisadas a Riqueza de povoamentos e a Diversidade de Shannon-Wiener (H') (Wihlm, 1968; Washington, 1984), esta última calculada com base 2. O Índice de Shannon é mais fortemente afetado por espécies com quantidades intermediárias no rank de seqüência das espécies (Whittaker, 1972).

A dominância ecológica foi expressa tanto pelo Índice de Dominância de Simpson $(\lambda)$ (Washington, 1984), que é pouco dependente do tamanho da amostra, mas valoriza as espécies dominantes (Whittaker, 1972), quanto pelo complemento do Índice de Equitatividade de Pielou (1-J'), que quantifica a relação entre a representação desigual da comunidade estudada e uma comunidade hipotética onde todas as espécies são igualmente representadas (Krebs, 1999).

$$
\mathbf{H}^{\prime}=-\sum_{i=1}^{S} p_{i} \log _{2} p_{i}
$$




$$
\begin{aligned}
& \lambda=\sum_{i=1}^{S} p_{i}^{2} \\
& \mathbf{1 - J ^ { \prime }}=\mathbf{1}-\frac{H^{\prime}}{\log _{2} S}
\end{aligned}
$$

Onde: $\mathrm{p}_{\mathrm{i}}=\mathrm{a}$ importância relativa, originalmente a proporção de indivíduos da iésima espécie (aqui no caso povoamento) em relação ao efetivo total da amostra $\mathrm{S}=$ número de espécies (aqui povoamentos)

Em todos os casos, foram usados povoamentos ao invés de espécies para o cálculo dos índices, sendo que os valores encontrados não podem ser comparados com valores padrão normalmente encontrados em casos onde as unidades operacionais são as espécies.

Parece ser de comum acordo entre pesquisadores que as medidas de diversidade devem ser aplicadas sobre ou entre unidades ecológicas (McArthur, 1965; Sanders, 1968; Clifford \& Stephenson, 1975). Os descritores sintéticos simples de dominância e de diversidade podem ser aplicados sobre cada elemento amostral ou sobre grupos homogêneos de elementos amostrais.

Neste estudo, foram determinados índices por elemento amostral, sendo que neste caso a análise se restringiu ao âmbito das amostras sem intenção de extrapolar valores para todo o domínio. Para isso, foi utilizado o programa DivCalc para Windows (Rosso, não publicado). 


\section{Resultados}

\section{1) Avaliação quantitativa da distribuição espaço-temporal dos povoamentos}

\section{1) Descritor primário recobrimento percentual}

$\mathrm{Na}$ avaliação quantitativa, considerou-se o recobrimento percentual médio de cada povoamento nos períodos de verão e inverno.

Observou-se que houve diferenças significativas entre os valores de recobrimento percentual dos povoamentos no período de verão $\left(\chi^{2}=248,540, \mathrm{gl}=18, \mathrm{p}<0,000\right)$.

A Figura 3.2 mostra que no verão o povoamento Banco de Sargassum apresentou o valor de $26,1 \%$ de recobrimento médio, significativamente maior que os demais $(\mathrm{p}<0.05)$, exceto Tapete de Ectoprocta juntamente com seus povoamentos relacionados $(p=1,000)$, com 19,7\%, Tapete de Gelidiopsis e Hypnea $(\mathrm{p}=1,000)$, com 17,5\%, Região de Substrato Inconsolidado ( $\mathrm{p}=0,977$ ), com 14,6\% e Tapete de Amphiroa e Jania ( $\mathrm{p}=0,112)$, com 8,9\%.

Em seguida ficou o povoamento Tapete de Ectoprocta que, juntamente com seus povoamentos relacionados, também não apresentou diferenças significativas com Região de Substrato Inconsolidado $(\mathrm{p}=1,000)$, Tapete de Amphiroa e Jania $(\mathrm{p}=0,945)$ e Tapete de Gelidiopsis e Hypnea $(\mathrm{p}=1,000)$.

Em terceiro lugar ficou o povoamento Tapete de Gelidiopsis e Hypnea que apresentou valor de recobrimento percentual médio significativamente maior que todos os demais povoamentos, exceto os já citados acima, Região de Substrato Inconsolidado $(p=1,000)$ e Tapete de Amphiroa e Jania $(\mathrm{p}=0,998)$.

Em quarto ficou o povoamento Região de Substrato Inconsolidado que apresentou valor de recobrimento percentual médio significativamente maior que todos os demais povoamentos, exceto os já citados acima, Tapete de Amphiroa e Jania $(\mathrm{p}=1,000)$ e Crosta de Corallinaceae $(\mathrm{p}=0,142)$.

Os demais povoamentos não apresentaram diferenças significativas entre si. 
No inverno, também se observaram diferenças significativas entre os valores de recobrimento percentual médio dos povoamentos $\left(\chi^{2}=472.384, \mathrm{gl}=21, \mathrm{p}<0.000\right)$.

A Figura 3.3 mostra que neste período o povoamento Banco de Sargassum apresentou maior recobrimento médio $(32,0 \%)$ da mesma forma que no verão, significativamente maior que os demais povoamentos, exceto novamente o povoamento Tapete de Ectoprocta, juntamente com seus povoamentos relacionados $(\mathrm{p}=1,000)$, o qual apresentou o valor médio de $24,2 \%$, significativamente maior que os demais povoamentos, exceto Tapete de Amphiroa e Jania ( $\mathrm{p}=0,773)$, com 12,7\% e Região de Substrato Inconsolidado ( $\mathrm{p}=0,554)$, com 12,0\%.

Em terceiro lugar ficou, subindo hierarquicamente em relação ao verão, o povoamento Tapete de Amphiroa e Jania, que apresentou valor de recobrimento percentual médio significativamente diferente que os demais povoamentos, exceto os já citados acima, Região de Substrato Inconsolidado $(p=1,000)$, Crosta de Corallinaceae $(p=1,000)$ e Tapete de Gelidiopsis e Hypnea $(\mathrm{p}=0,399)$.

Em quarto, assim como no verão, ficou o povoamento Região de Substrato Inconsolidado, que apresentou valor de recobrimento percentual médio significativamente diferente que os demais povoamentos, exceto os já citados acima, Crosta de Corallinaceae $(\mathrm{p}=1,000)$ e Tapete de Gelidiopsis e Hypnea $(\mathrm{p}=0,533)$.

Em quinto ficou o povoamento Crosta de Corallinaceae, que apresentou valor de recobrimento percentual médio significativamente diferente que os demais povoamentos, exceto os já citados acima e Tapete de Gelidiopsis e Hypnea ( $\mathrm{p}=1,000)$, Banco de Dichotomaria $(\mathrm{p}=0,782)$, Banco de Caulerpa $(\mathrm{p}=0,319)$, Banco de Dictyota $(\mathrm{p}=0,128)$, Crosta de Amphimedon ( $\mathrm{p}=0,119)$, Banco de Padina $(\mathrm{p}=0,107)$, Banco de Asparagopsis $(\mathrm{p}=0,090)$, Tapete de Wrangelia $(\mathrm{p}=0,075)$ e Colônia de Schizoporella $(\mathrm{p}=0,077)$.

Os demais povoamentos não apresentaram diferenças significativas entre si. 


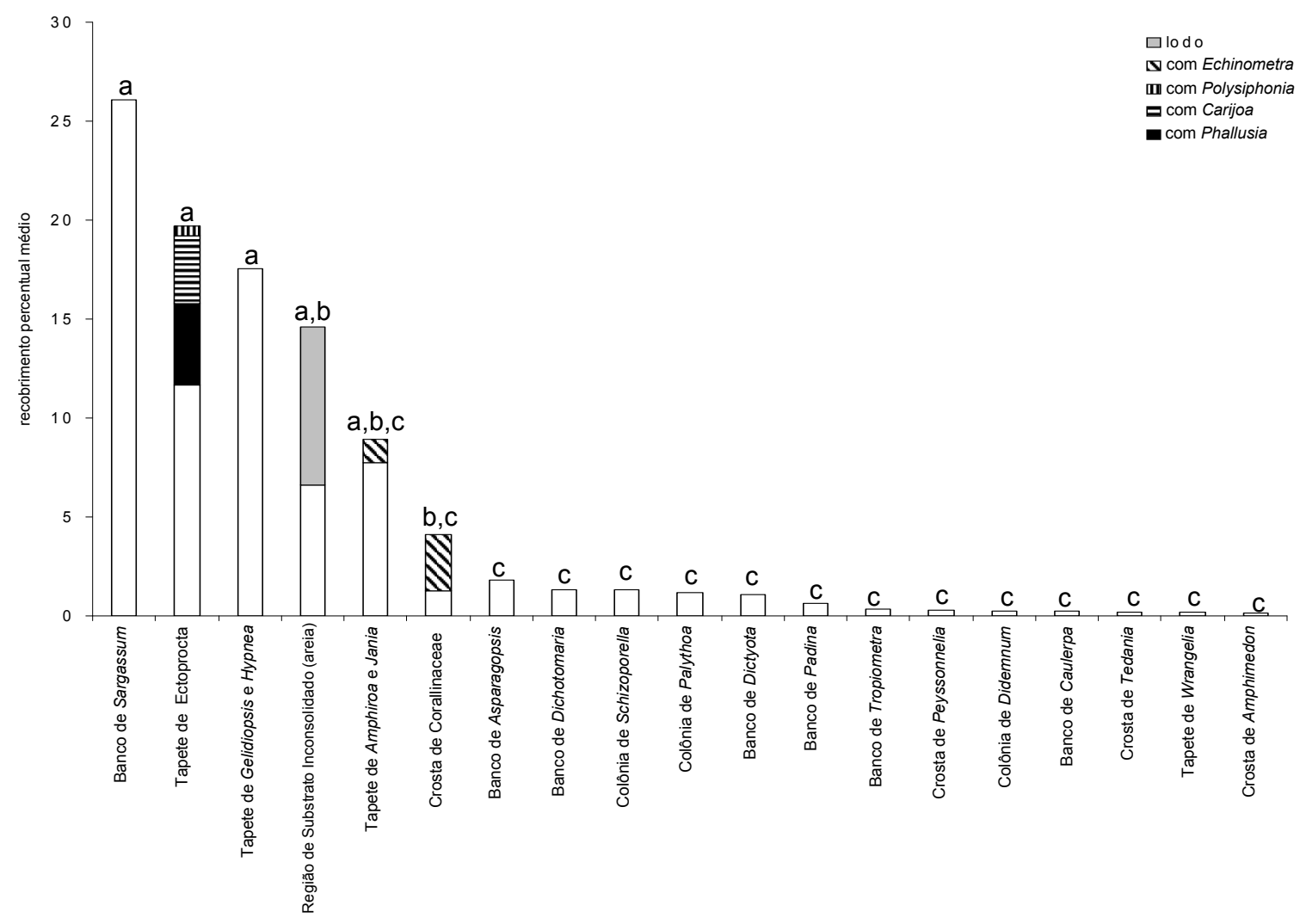

Figura 3.2 - Recobrimento percentual médio dos povoamentos (e povoamentos relacionados) no período de verão. Letras iguais indicam ausência de diferença significativa.

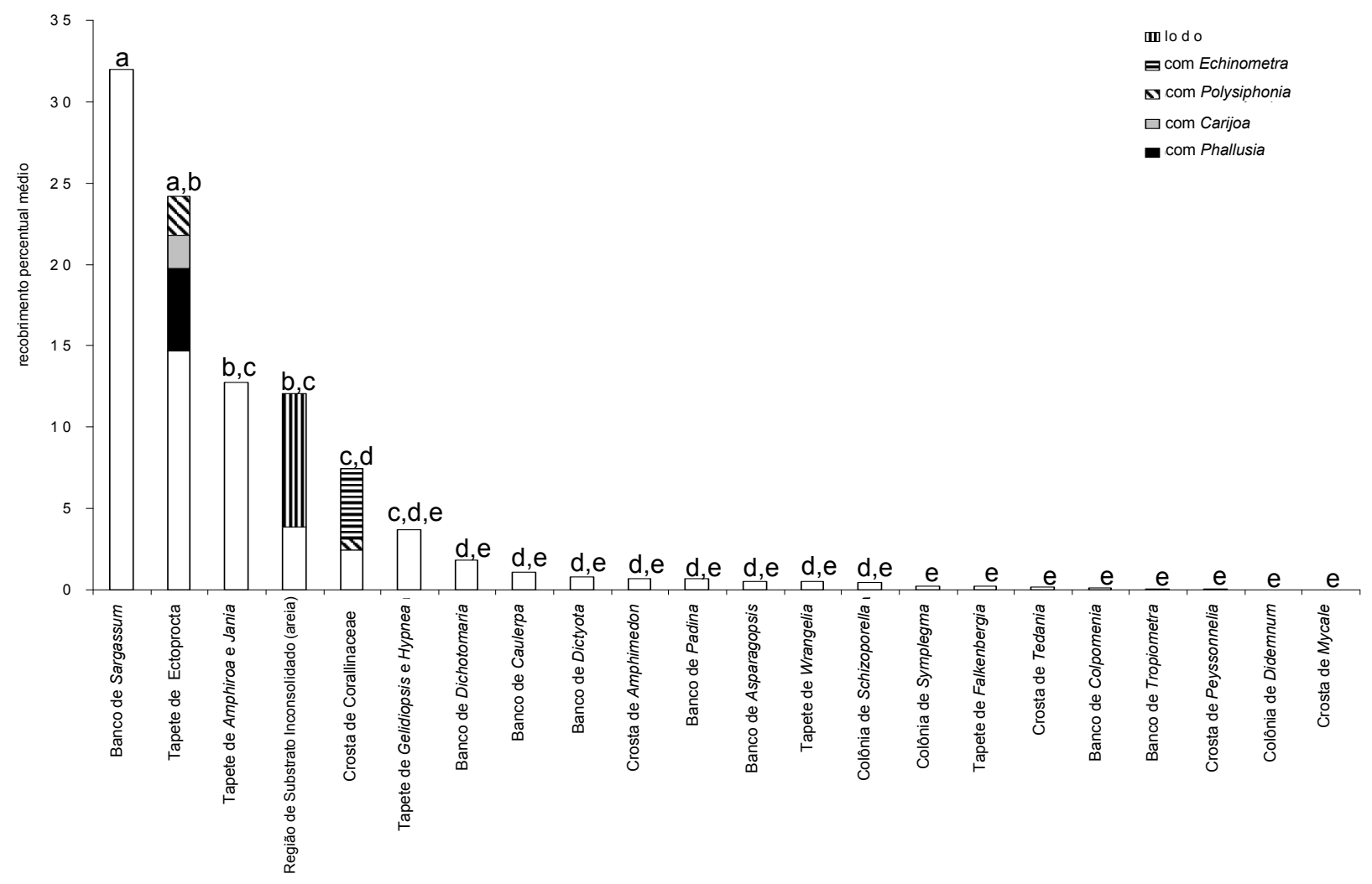

Figura 3.3 - Recobrimento percentual médio dos povoamentos (e povoamentos relacionados) no período de inverno. Letras iguais indicam ausência de diferença significativa. 
Quando comparados verão e inverno, houve diferenças nos povoamentos que foram encontrados, sendo que Colônia de Palythoa só foi encontrada na amostragem de verão e Banco de Colpomenia, Colônia de Symplegma, Crosta de Mycale, Tapete de Falkenbergia só foram encontrados na amostragem de inverno.

Quando os recobrimentos percentuais médios de cada povoamento foram comparados entre verão e inverno, foram observadas diferenças significativas para os povoamentos Banco de Dictyota $(\mathrm{p}=0,040)$, Crosta de Corallinaceae com Polysiphonia $(\mathrm{p}=0,043)$, Tapete de Ectoprocta com Wrangelia $(\mathrm{p}=0,046)$ e Tapete de Gelidiopsis e Hypnea $(\mathrm{p}=0,000)$.

A Figura 3.4 mostra que os povoamentos fitobentônicos apresentaram recobrimentos percentuais médios (62,2\% no verão e $61,8 \%$ no inverno) significativamente maiores que os zoobentônicos (23,1\% no verão e $25,9 \%$ no inverno) e que os atributos não-biológicos da comunidade (14,6\% no verão e $12,0 \%$ no inverno), tanto no verão quanto no inverno $(p=0,000)$. Os povoamentos zoobentônicos e os atributos não-biológicos não apresentaram diferenças significativas entre si no verão $(p=0,254)$. Entretanto os primeiros no inverno apresentaram valores médios significativamente mais altos que os últimos $(p=0,004)$.

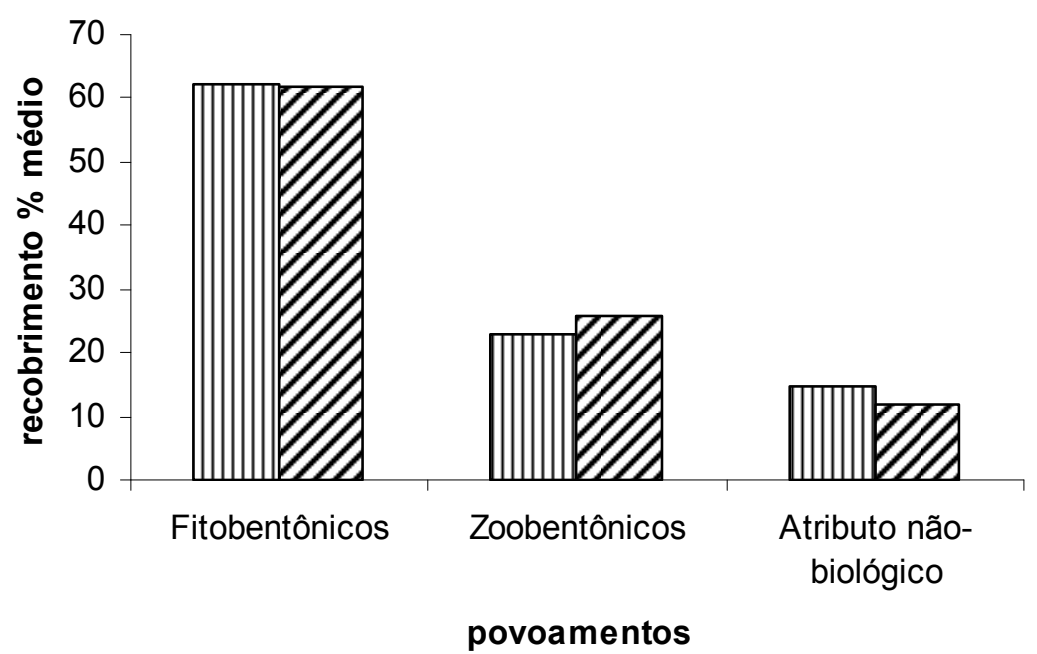

Figura 3.4 - Recobrimento percentual médios dos povoamentos fitobentônicos, zoobentônicos e atributos não-biológicos da comunidade (substrato inconsolidado) no verão (preenchimento com linhas verticais) e inverno (preenchimento com linhas diagonais). 
A Figura 3.5 mostra o recobrimento percentual médio dos povoamentos separados por categoria. Observa-se que os bancos e as crostas foram principalmente formados por algas, que os tapetes foram formados tanto por algas quanto por animais, que as colônias só foram formadas por animais e que as regiões só foram formadas por atributos não-biológicos. Houve uma predominância de bancos fitobentônicos nos dois períodos $(31,2 \%$ e $37,0 \%$ no verão e inverno, respectivamente), seguidos de tapetes fito e zoobentônicos, regiões, crostas fitobentônicas, colônias zoobentônicas, crostas zoobentônicas e bancos zoobentônicos.

No verão, bancos fitobentônicos apresentaram valor de recobrimento percentual médio significativamente mais alto que as demais categorias, exceto tapetes fitobentônicos $(26,6 \%$, $\mathrm{p}=1,000)$ e tapetes zoobentônicos $(19,7 \%, \mathrm{p}=0,738)$. Estes últimos também não apresentaram diferenças significativas das regiões $(14,6 \%, p=0,278$ e $p=1,000$, respectivamente), as quais compreendem apenas atributos não-biológicos da comunidade, e foram significativamente mais altos que as demais categorias. Crostas fitobentônicas apresentaram valor de recobrimento percentual médio $(4,4 \%)$ significativamente diferente das demais categorias, exceto colônias zoobentônicas $(2,75 \%, \mathrm{p}=1,000)$, as quais também apresentaram valor de recobrimento percentual médio significativamente diferente das demais categorias, exceto bancos zoobentônicos $(0,3 \%, p=0,708)$ e crostas zoobentônicas $(0,3 \%, p=0,700)$. Estes dois últimos não apresentaram diferenças significativas entre si $(p=1,000)$.

No inverno, bancos fitobentônicos apresentaram valor de recobrimento percentual médio significativamente mais alto que as demais categorias, exceto apenas tapetes zoobentônicos $(24,2 \%, p=0,322)$, os quais foram significativamente mais altos que as demais categorias, exceto tapetes fitobentônicos $(17,2 \%, p=0,961)$ e regiões $(12,0 \%, p=0,101)$. Tapetes fitobentônicos apresentaram valor de recobrimento percentual médio significativamente diferente das demais categorias, exceto a já citada acima, região $(p=0,992)$ e crostas fitobentônicas $(7,5 \%, p=0,130)$. Crostas fitobentônicas apresentaram valor de recobrimento percentual médio significativamente diferente das demais categorias, exceto as 
já citadas acima e região $(\mathrm{p}=0,982)$. Colônias zoobentônicas $(0,7 \%)$ também apresentaram valor de recobrimento percentual médio significativamente diferente das demais categorias, exceto novamente bancos zoobentônicos $(0,1 \%, p=0,957)$ e crostas zoobentônicas $(0,9 \%$, $\mathrm{p}=1,000)$. Estes dois últimos não apresentaram diferenças significativas entre si $(\mathrm{p}=0,612)$.

Quando comparados verão e inverno, os tapetes fitobentônicos apresentaram queda significativa $(\mathrm{p}=0,004)$. As demais categorias foram igualmente representadas nos dois períodos.

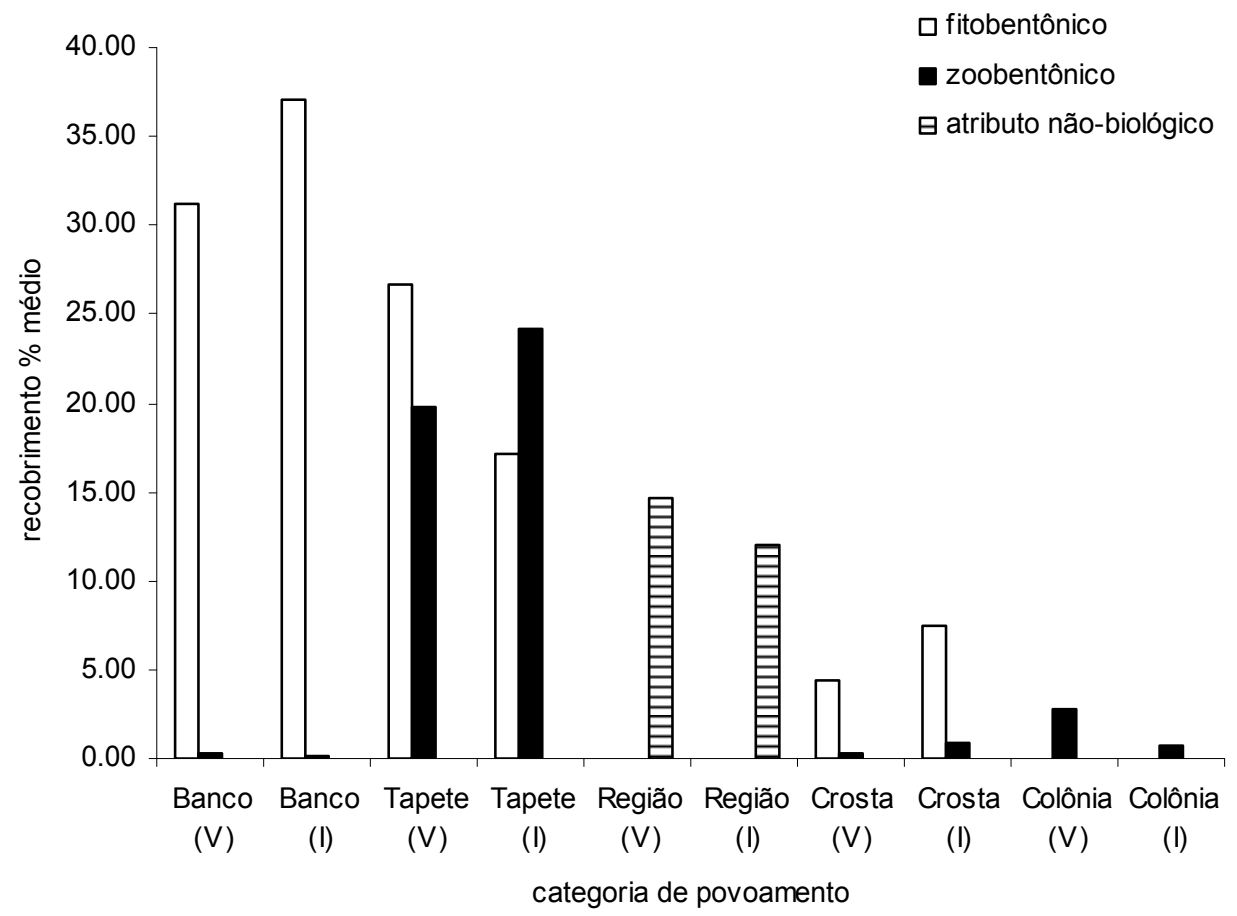

Figura 3.5 - Recobrimento percentual médios dos povoamentos fitobentônicos, zoobentônicos e atributos não-biológicos da comunidade (substrato inconsolidado) separados por categoria. $\mathrm{V}=$ verão e $\mathrm{I}=$ inverno.

\section{2) Repartição espacial}

\section{1) Repartição em modo $Q$ e seus descritores}

A utilização do IVE para a análise no plano qualitativo serviu para eliminar aqueles povoamentos pouco importantes (com valor de IVE abaixo de 0,05) e/ou de ocorrência ocasional, reduzindo desta forma o ruído na formação dos dendrogramas. Foram eles: Banco de Asparagopsis (verão e inverno), Banco de Caulerpa (verão e inverno), Banco de 
Colpomenia (inverno), Banco de Tropiometra (verão e inverno), Colônia de Didemnum (verão e inverno), Colônia de Palythoa (verão), Colônia de Symplegma (inverno), Crosta de Amphimedon (verão e inverno), Crosta de Corallinaceae com Polysiphonia (inverno), Crosta de Mycale (inverno), Crosta de Peyssonnelia (verão e inverno), Crosta de Tedania (verão e inverno), Tapete de Amphiroa e Jania com Echinometra (verão), Tapete de Ectoprocta com Carijoa (verão e inverno), Tapete de Ectoprocta com Polysiphonia (verão e inverno), Tapete de Ectoprocta com Wrangelia (verão), Tapete de Falkenbergia (inverno), Tapete de Wrangelia (verão e inverno) (Tabela 3.1).

Tabela 3.1 - Povoamentos amostrados e seus respectivos valores de IVE para o verão e inverno. Aqueles que não atingiram valor de 0,05 em pelo menos um período estão em negrito.

\begin{tabular}{|c|c|c|}
\hline & Verão & Inverno \\
\hline Banco de Sargassum & 0.363 & 0.464 \\
\hline Tapete de Gelidiopsis e Hypnea & 0.3 & 0.072 \\
\hline Região de Substrato Inconsolidado & 0.245 & 0.166 \\
\hline Tapete de Ectoprocta & 0.219 & 0.373 \\
\hline Tapete de Amphiroa e Jania & 0.181 & 0.283 \\
\hline Substrato Inconsolidado (lodo) & 0.143 & 0.12 \\
\hline Crosta de Corallinaceae com Echinometra & 0.118 & 0.081 \\
\hline Banco de Dichotomaria & 0.097 & 0.072 \\
\hline Crosta de Corallinaceae & 0.089 & 0.139 \\
\hline Colônia de Schizoporella & 0.08 & 0.015 \\
\hline Banco de Padina & 0.059 & 0.093 \\
\hline Tapete de Ectoprocta com Phallusia & 0.055 & 0.078 \\
\hline Banco de Tropiometra & 0.046 & 0.015 \\
\hline Crosta de Peyssonnelia & 0.042 & 0.027 \\
\hline Crosta de Tedania & 0.042 & 0.045 \\
\hline Tapete de Ectoprocta com Wrangelia & 0.042 & - \\
\hline Banco de Dictyota & 0.038 & 0.09 \\
\hline Tapete de Wrangelia & 0.03 & 0.039 \\
\hline Banco de Asparagopsis & 0.025 & 0.042 \\
\hline Tapete de Ectoprocta com Polysiphonia & 0.025 & 0.039 \\
\hline Banco de Caulerpa & 0.021 & $\mathbf{0 . 0 3}$ \\
\hline Colônia de Didemnum & 0.017 & 0.006 \\
\hline Tapete de Ectoprocta com Carijoa & 0.017 & 0.024 \\
\hline Colônia de Palythoa & 0.013 & - \\
\hline Crosta de Amphimedon & 0.013 & $\mathbf{0 . 0 3 9}$ \\
\hline Tapete de Amphiroa e Jania com Echinometra & 0.008 & - \\
\hline Banco de Colpomenia & - & 0.027 \\
\hline Colônia de Symplegma & - & 0.015 \\
\hline Crosta de Corallinaceae com Polysiphonia & - & 0.027 \\
\hline Crosta de Mycale & - & 0.003 \\
\hline Tapete de Falkenbergia & - & $\mathbf{0 . 0 3 3}$ \\
\hline
\end{tabular}


Foram construídos dendrogramas (Figuras 3.6 a 3.8 e Figuras 3.11 a 3.13) a partir dos índices de Dice-Sørensen (similaridade qualitativo), Bray-Curtis (distância quantitativo) e Morisita-Horn (similaridade quantitativo), com estratégia de agrupamento WPGMA.

Para melhor visualização da localização dos elementos amostrais na área de estudo, foram construídos mapas representativos contendo as fotoamostras e suas respectivas localizações e profundidades (Anexo - Figuras A3.1 e A3.2).

Na Figura 3.6 observa-se que os níveis de significância obtidos para o Índice de Similaridade de Dice-Sørensen no verão foram 0,24 e $0,50(p=0,05)$, o que resultou na formação de 14 grupos.

Na Figura 3.7 observa-se que os níveis obtidos para o Índice de Bray-Curtis no verão foram de 0,41 e 1,00 ( $\mathrm{p}=0,05)$, o que resultou na formação de 12 grupos.

Na Figura 3.8 observa-se que os níveis obtidos para o Índice de Morisita-Horn no verão foram de 0,00 e 0,49 ( $p=0,05)$, o que resultou na formação de 9 grupos.

Alguns dos grupos formados com a utilização do Índice de Similaridade Qualitativo de Dice-Sørensen (Figura 3.6) neste período foram reconhecidos como subgrupos daqueles formados com a utilização do Índice de Morisita-Horn (Figura 3.8), enquanto outros continham elementos de dois grupos fundidos.

Os 3 grupos encontrados a mais com o Índice de Bray-Curtis (Figura 3.7) nada mais foram do que subdivisões de grupos encontrados com o Índice de Morisita-Horn. Os elementos amostrais de números 7, 65 e 76 não se agruparam com nenhum outro em nenhum dos dois dendrogramas. Os grupos de número 7, 8 e 9 apareceram em ambos (Figura 3.8).

Tomando como base o IVE dos povoamentos nos elementos amostrais formadores dos grupos no dendrograma com a utilização do Índice de Similaridade Quantitativo de MorisitaHorn neste período (Figura 3.8), verifica-se que os povoamentos mais importantes nos elementos amostrais foram Banco de Sargassum no Grupo 1 (Figura 3.9a), Região de Substrato Inconsolidado no Grupo 2 (Figura 3.9b), Tapete de Gelidiopsis e Hypnea no Grupo 
3 (Figura 3.9c), Região de Substrato Inconsolidado (lodo) no Grupo 4 (Figura 3.9d), Tapete de Ectoprocta no Grupo 5 (Figura 3.9e), Tapete de Amphiroa e Jania no Grupo 6 (Figura 3.9f), Tapete de Ectoprocta com Wrangelia no Grupo 7 (Figura 3.9g), Tapete de Ectoprocta com Phallusia no Grupo 8 (Figura 3.9h) e Tapete de Ectoprocta com Carijoa no Grupo 9 (Figura 3.9i).

Levando-se em conta os níveis críticos de significância encontrados com o software RANDMAT (mínimo de 0,00 e máximo de 0,49) pode-se dizer que neste período, a existência de similaridades entre elementos amostrais menores que 0,5 no Grupo 1 (Figura 3.10a) indica uma heterogeneidade quantitativa interna, porém limitada a proporcionalmente poucos pares de elementos amostrais, sendo que a maior parte das observações ficou acima de 0,6.

O Grupo 2 (Figura 3.10b) mostrou-se bastante heterogêneo, com configuração bimodal e maior número de observações entre os valores de 0,25 e 0,30 de similaridade, além de nenhuma observação em valores acima de 0,55.

O Grupo 3 (Figura 3.10c) apresentou-se bimodal, com uma parcela dos valores abaixo de 0,5 e outra acima de 0,6 .

O Grupo 4 (Figura 3.10d) também se apresentou heterogêneo, com maior número de observações em valores de similaridade entre 0,2 e 0,5 .

O Grupo 5 (Figura 3.10e) apresentou-se heterogêneo, com uma grande quantidade de observações entre 0,3 e 0,5 .

O Grupo 6 (Figura 3.10f) também se apresentou heterogêneo, com as observações se concentrando em valores de similaridade entre 0,4 e 0,5 .

O Grupo 7 apresentou poucos elementos amostrais, o que limita as conclusões que podem ser obtidas.

Já o Grupo 8 (Figura 3.10g) apresentou-se homogêneo, com as observações se concentrando em valores de similaridade entre 0,6 e 0,7 . 


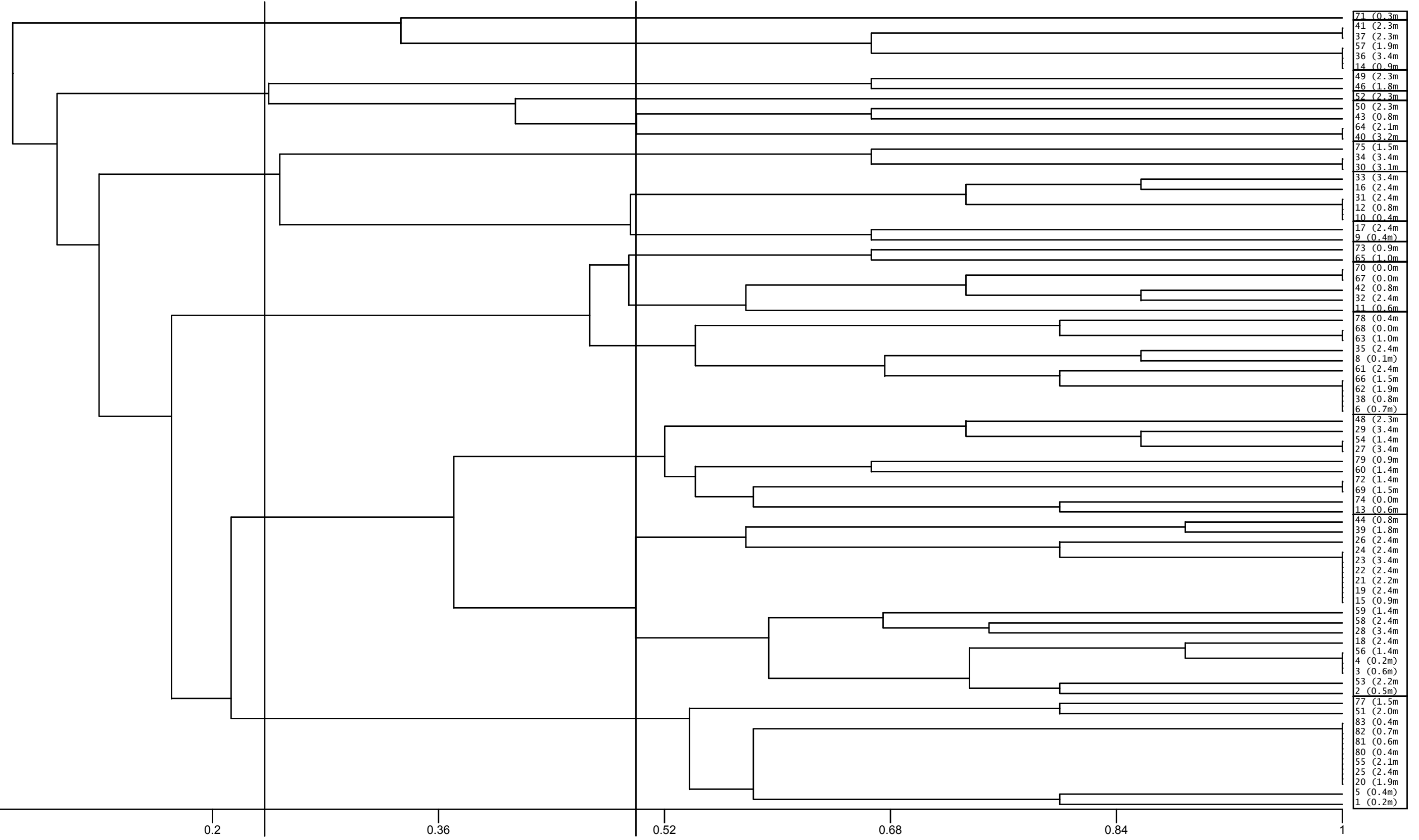

Figura 3.6 - Repartição espacial da comunidade em modo Q para o período de verão. Índice de Similaridade de Dice-Sørensen, estratégia de agrupamento WPGMA. As linhas verticais indicam os limites de significância inferior e superior, entre os quais os grupos podem ser casuais, para uma confiabilidade de $95 \%$. 
Capítulo 3 - Análise quantitativa da repartição espacial de povoamentos do P. Est. Ilha Anchieta

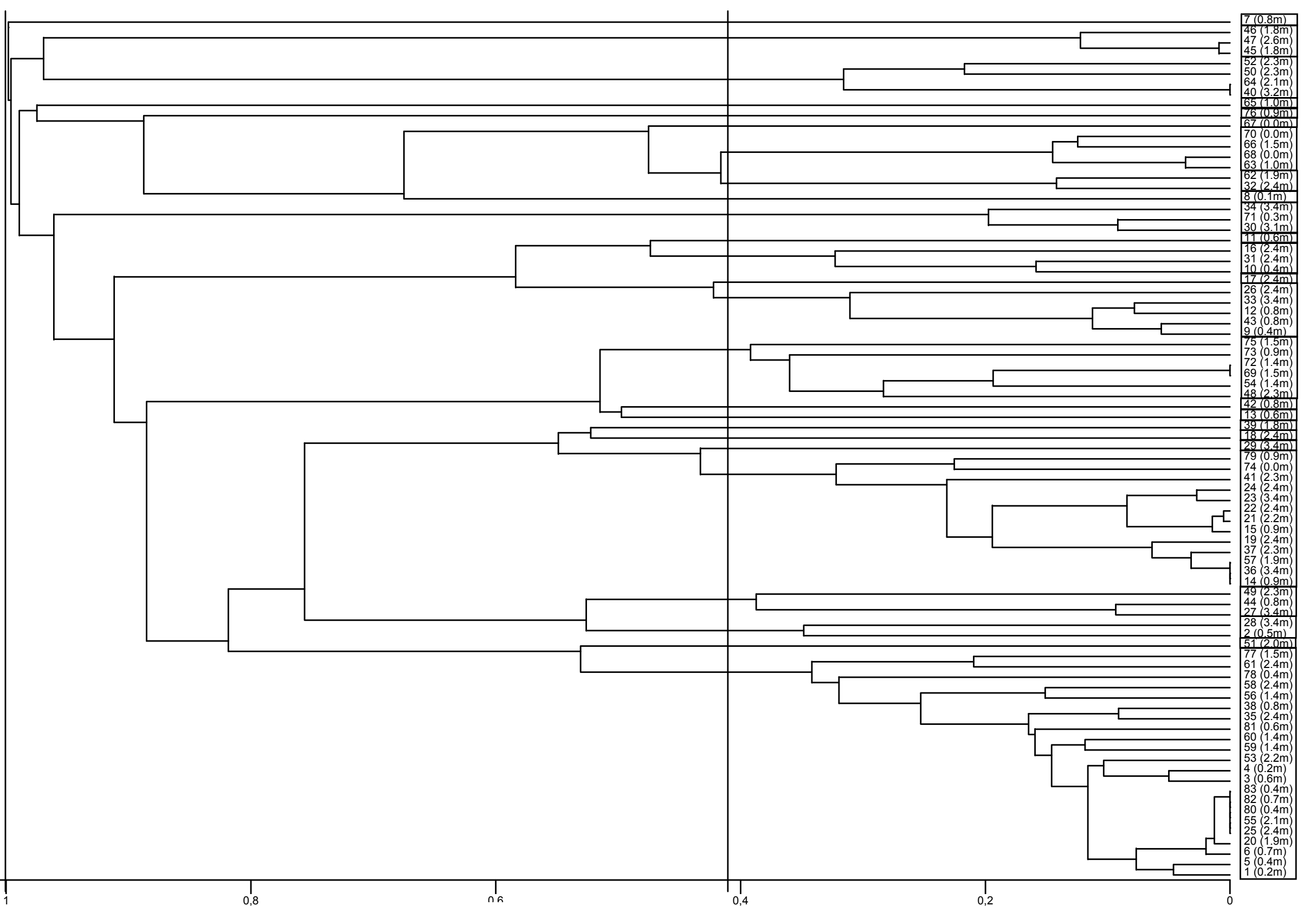

Figura 3.7 - Repartição espacial da comunidade em modo Q para o período de verão. Índice de Distância de Bray-Curtis, estratégia de agrupamento WPGMA. As linhas verticais indicam os limites de significância inferior e superior, entre os quais os grupos podem ser casuais, para uma confiabilidade de $95 \%$. $\overrightarrow{\text { ज }}$ 


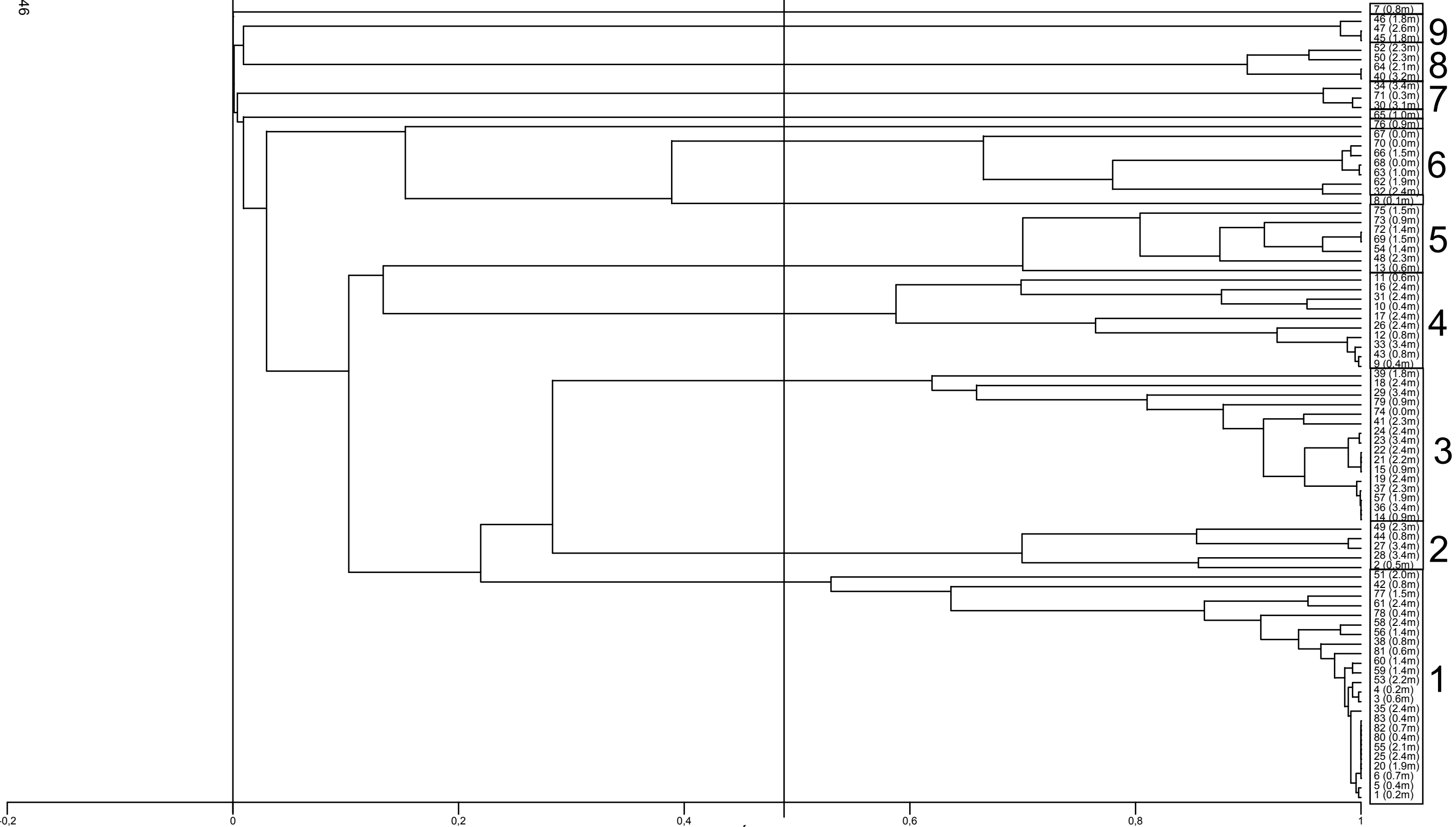

Figura 3.8 - Repartição espacial da comunidade em modo Q para o período de verão. Índice de Similaridade de Morisita-Horn, estratégia de agrupamento WPGMA. As linhas verticais indicam os limites de significância inferior e superior, entre os quais os grupos podem ser casuais, para uma confiabilidade de $95 \%$. Os números dos grupos estão indicados ao lado. 

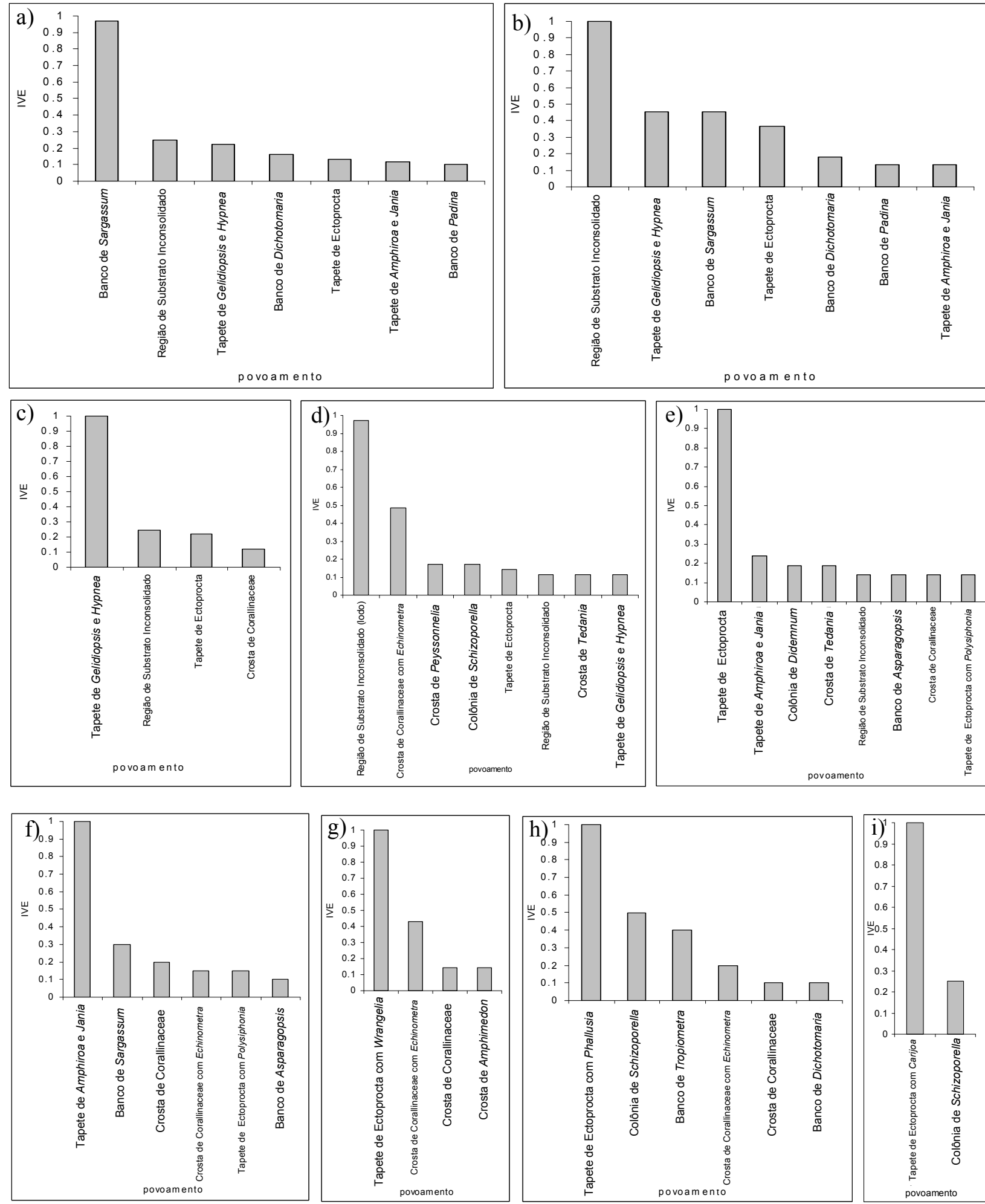

Figura 3.9 - IVE dos povoamentos dos elementos amostrais formadores de grupos significativos com a utilização do índice de similaridade quantitativo de MorisitaHorn no verão. a) Grupo 1; b) Grupo 2; c) Grupo 3; d) Grupo 4; e) Grupo 5; f) Grupo 6; g) Grupo 7; h) Grupo 8; i) Grupo 9. Aqueles com IVE inferior a 0.1 não foram representados. 
Capítulo 3 - Análise quantitativa da repartição espacial de povoamentos do P. Est. Ilha Anchieta

a)

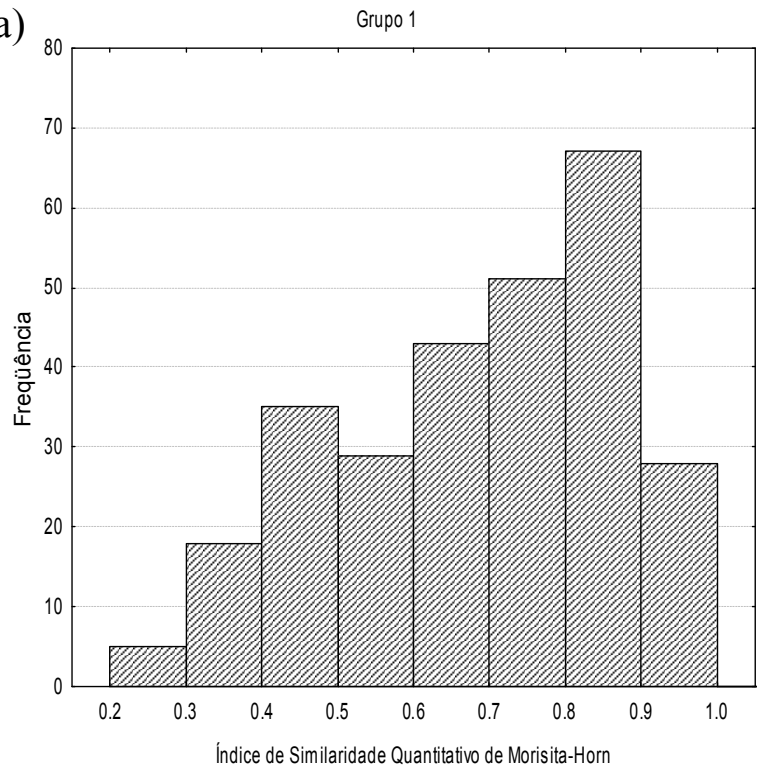

c)

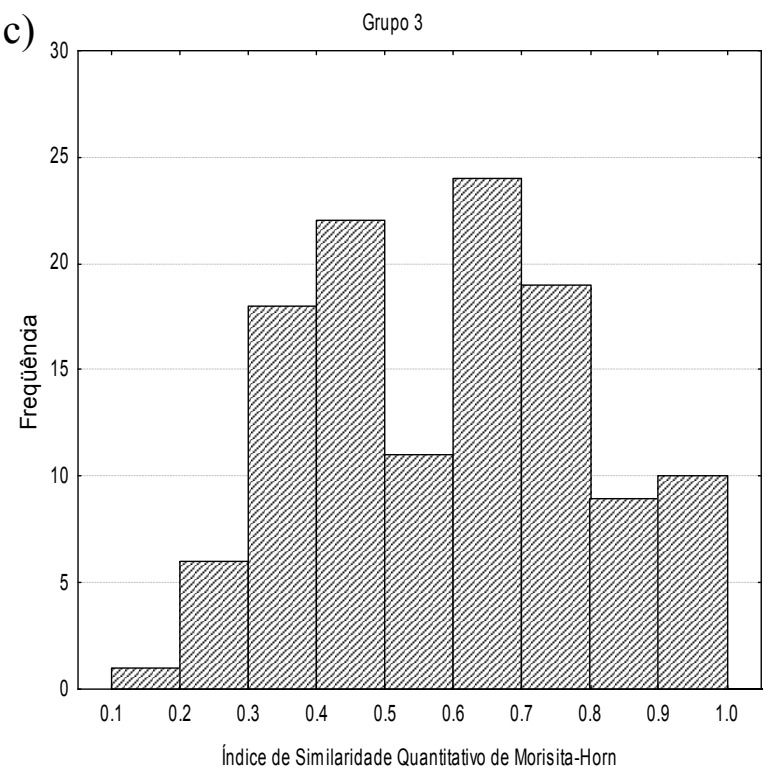

b)

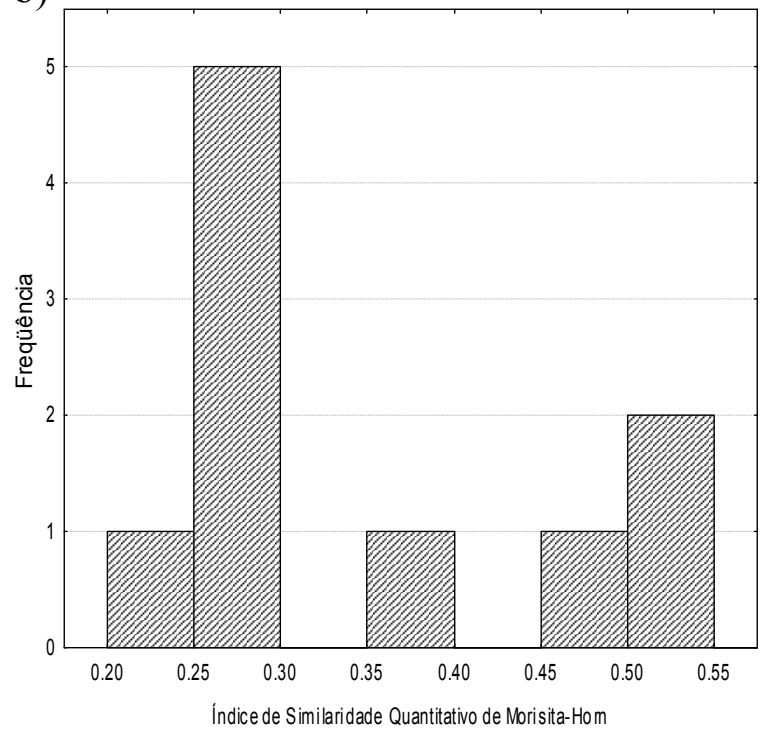

d)

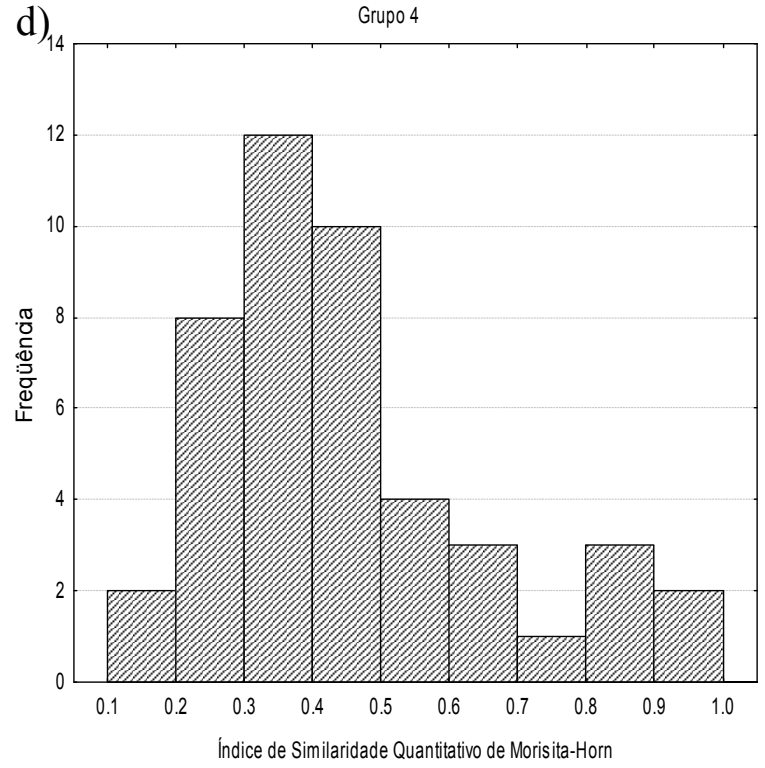

Grupo 6

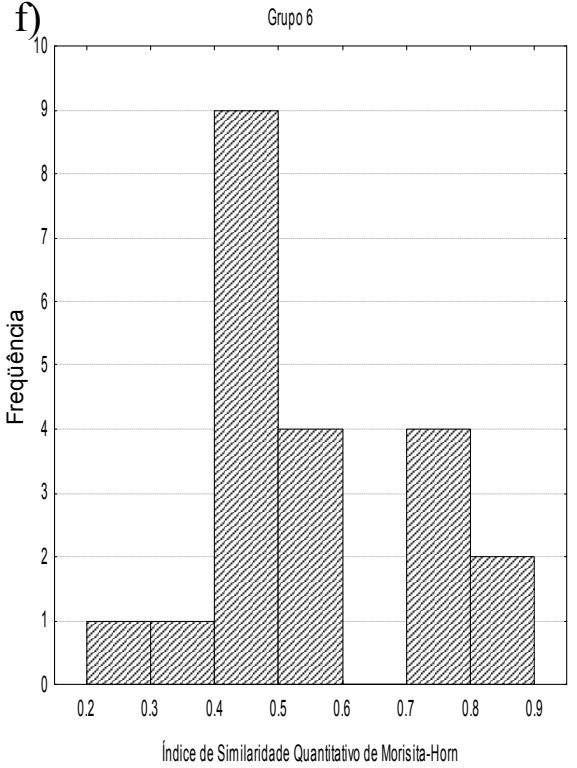

g)

Grupo 8

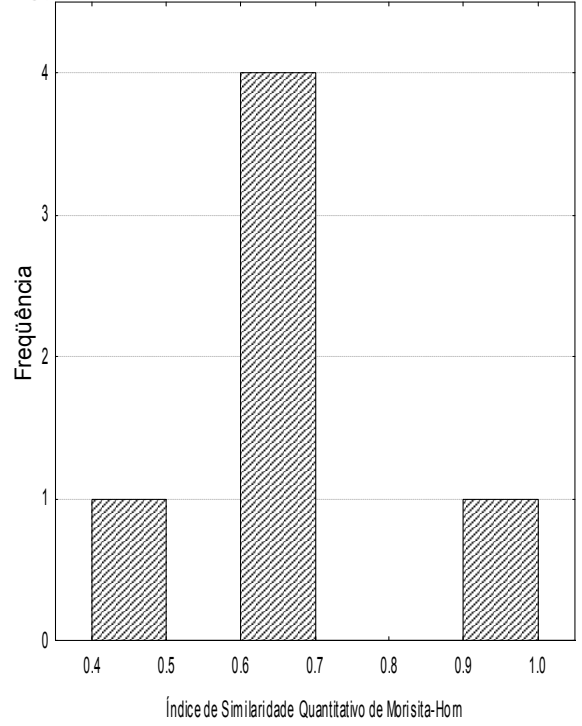

Figura 3.10 - Distribuição de freqüências das similaridades de Morisita-Horn entre os elementos amostrais constituintes dos grupos significativos delimitados no verão, combinados 2 a 2. a) Grupo 1; b) Grupo 2; c) Grupo 3; d) Grupo 4; e) Grupo 5; f) Grupo 6; g) Grupo 8. 
Na Figura 3.11 observa-se que os níveis de significância obtidos para o Índice de Similaridade de Dice-Sørensen no inverno foram 0,24 e 0,50 ( $\mathrm{p}=0,05)$, o que resultou na formação de 15 grupos.

Na Figura 3.12 observa-se que os níveis obtidos para o Índice de Bray-Curtis no inverno foram de 0,57 e 1,00 ( $\mathrm{p}=0,05)$, o que resultou na formação de 11 grupos.

Na Figura 3.13 observa-se que os níveis obtidos para o Índice de Morisita-Horn no inverno foram de 0,00 e 0,43 ( $p=0,05)$, o que resultou na formação de 10 grupos.

Da mesma forma que no verão, alguns dos grupos formados com a utilização do Índice de Similaridade Qualitativo de Dice-Sørensen (Figura 3.11) neste período foram reconhecidos como subgrupos daqueles formados com a utilização do Índice de MorisitaHorn, enquanto outros continham elementos de dois grupos fundidos (Figura 3.13).

Os grupos 1, 7, 9 e 10 formados com o Índice de Morisita-Horn (Figura 3.13) se subdividiram quando da utilização do Índice de Bray-Curtis (Figura 3.12). Os elementos 51 e 59 não se agruparam com nenhum outro em ambos dendrogramas. Já os grupos 2, 3, 4, 5, 6 e 8 se mantiveram.

Tomando como base o IVE dos povoamentos nos elementos amostrais formadores dos grupos no dendrograma com a utilização do Índice de Similaridade Quantitativo de MorisitaHorn neste período (Figura 3.13), nota-se que os povoamentos mais importantes são praticamente os mesmo encontrados para o verão, sendo Banco de Sargassum ou Tapete de Ectoprocta no Grupo 1 (Figura 3.14a), Tapete de Ectoprocta com Polysiphonia no Grupo 2 (Figura 3.14b), Tapete de Gelidiopsis e Hypnea no Grupo 3 (Figura 3.14c), Região de Substrato Inconsolidado (areia) no Grupo 4 (Figura 3.14d), Tapete de Amphiroa e Jania no Grupo 5 (Figura 3.14e), Região de Substrato Inconsolidado (lodo) no Grupo 6 (Figura 3.14f), Tapete de Ectoprocta com Phallusia no Grupo 7 (Figura 3.14g) e Tapete de Ectoprocta com Carijoa no Grupo 8 (Figura 3.14h). 
Também se levando em conta os níveis críticos de significância encontrados com o software RANDMAT (mínimo de 0,00 e máximo de 0,43) neste período, o Grupo 1 (Figura 3.15a) também apresentou pequena heterogeneidade interna, associada a uma pequena quantidade de elementos amostrais, e uma maior quantidade de valores de similaridade entre 0,5 e 1,0, portanto podendo ser considerado homogêneo.

O Grupo 2 (Figura 3.15b) apresentou-se unimodal, com maior número de observações entre valores de 0,5 a 0,9 , da mesma forma podendo ser considerado homogêneo.

Os Grupos 3 e 5 apresentaram poucos elementos amostrais, o que limita as conclusões que podem ser obtidas.

Os Grupos 4 e 6 (Figuras 3.15c e 3.15d) apresentaram maior número de observações em valores de similaridade entre 0,5 e 0,6, portanto relativamente homogêneos.

O Grupo 7 (Figura 3.15e) apresentou-se bimodal, entretanto a pequena quantidade de elementos amostrais neste grupo limita as conclusões a serem obtidas.

O Grupo 8 (Figura 3.15f) apresentou-se homogêneo, com maior número de observações em valores de similaridade entre 0,4 e 0,7 .

O Grupo 9 (Figura 3.15g) apresentou-se heterogêneo, com maior número de observações em valores de similaridade entre 0,3 e 0,4 . 
Capitulo 3 - Análise quantitativa da repartição espacial de povoamentos do P. Est. Ilha Anchieta

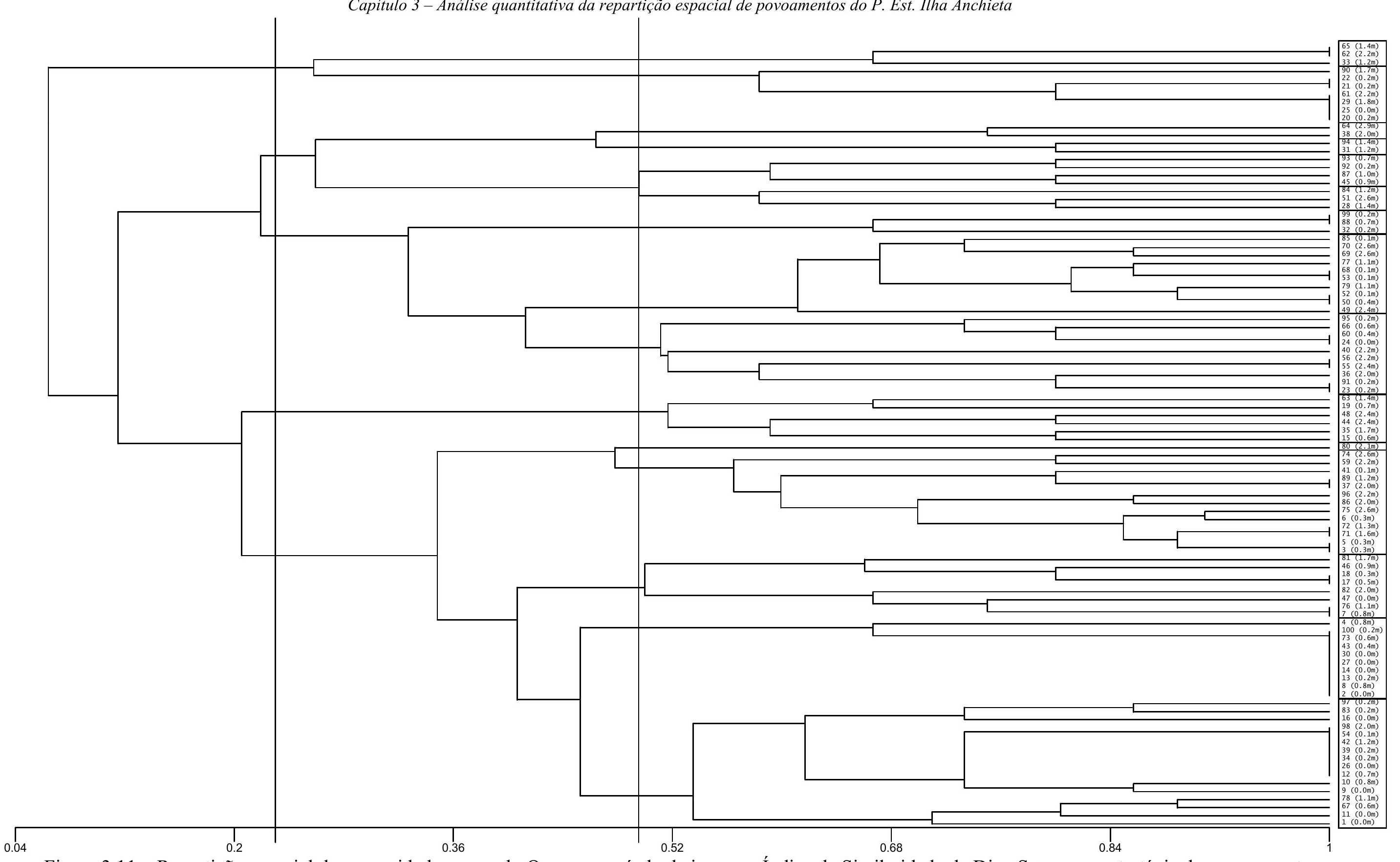

Figura 3.11 - Repartição espacial da comunidade em modo Q para o período de inverno. Índice de Similaridade de Dice-Sørensen, estratégia de agrupamento $\vec{\leftrightarrow} \quad$ WPGMA. As linhas verticais indicam os limites de significância inferior e superior, entre os quais os grupos podem ser casuais, para uma confiabilidade de $95 \%$. 


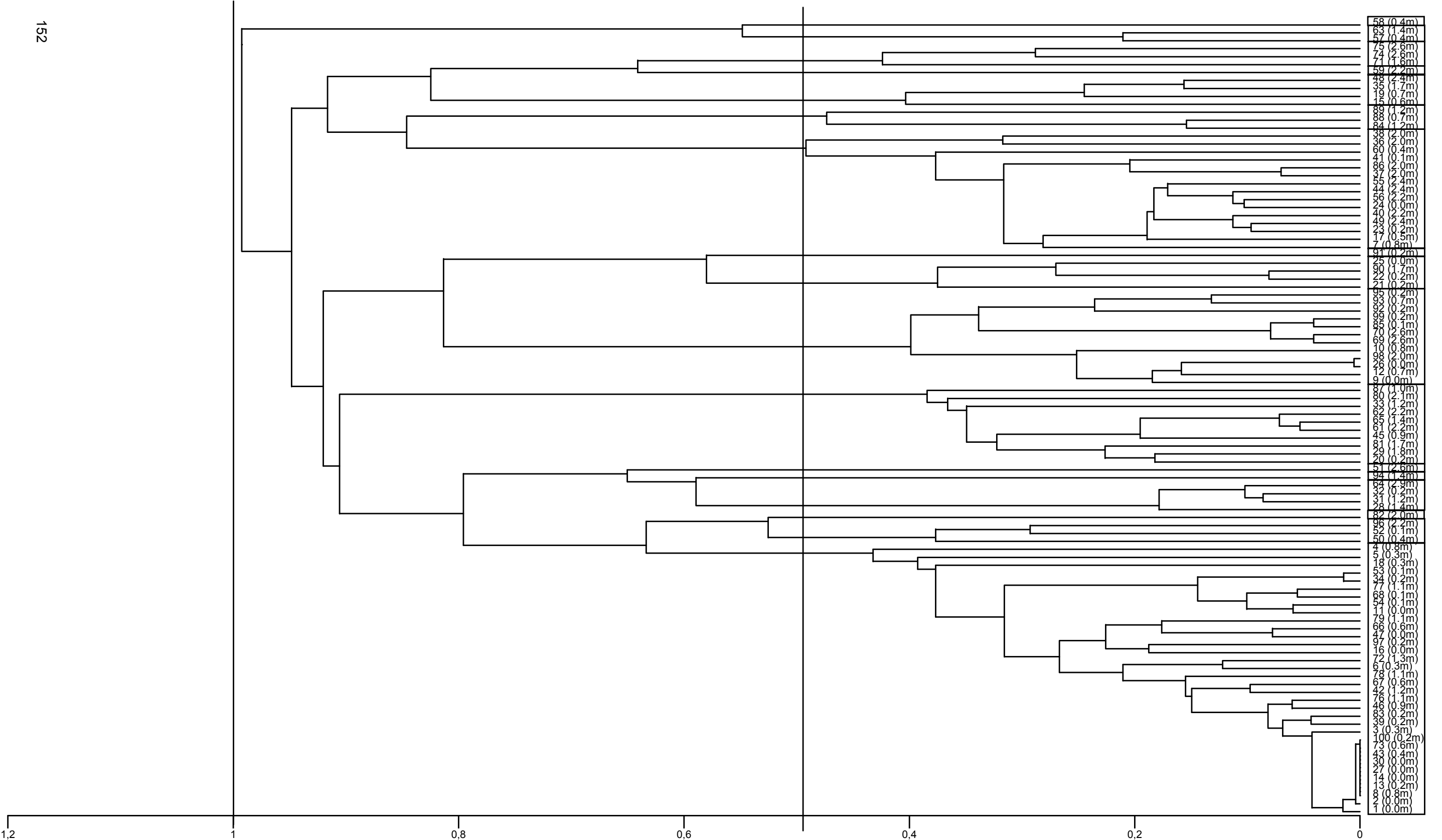

Figura 3.12 - Repartição espacial da comunidade em modo Q para o período de inverno. Índice de Distância de Bray-Curtis, estratégia de agrupamento WPGMA. As linhas verticais indicam os limites de significância inferior e superior, entre os quais os grupos podem ser casuais, para uma confiabilidade de $95 \%$. 


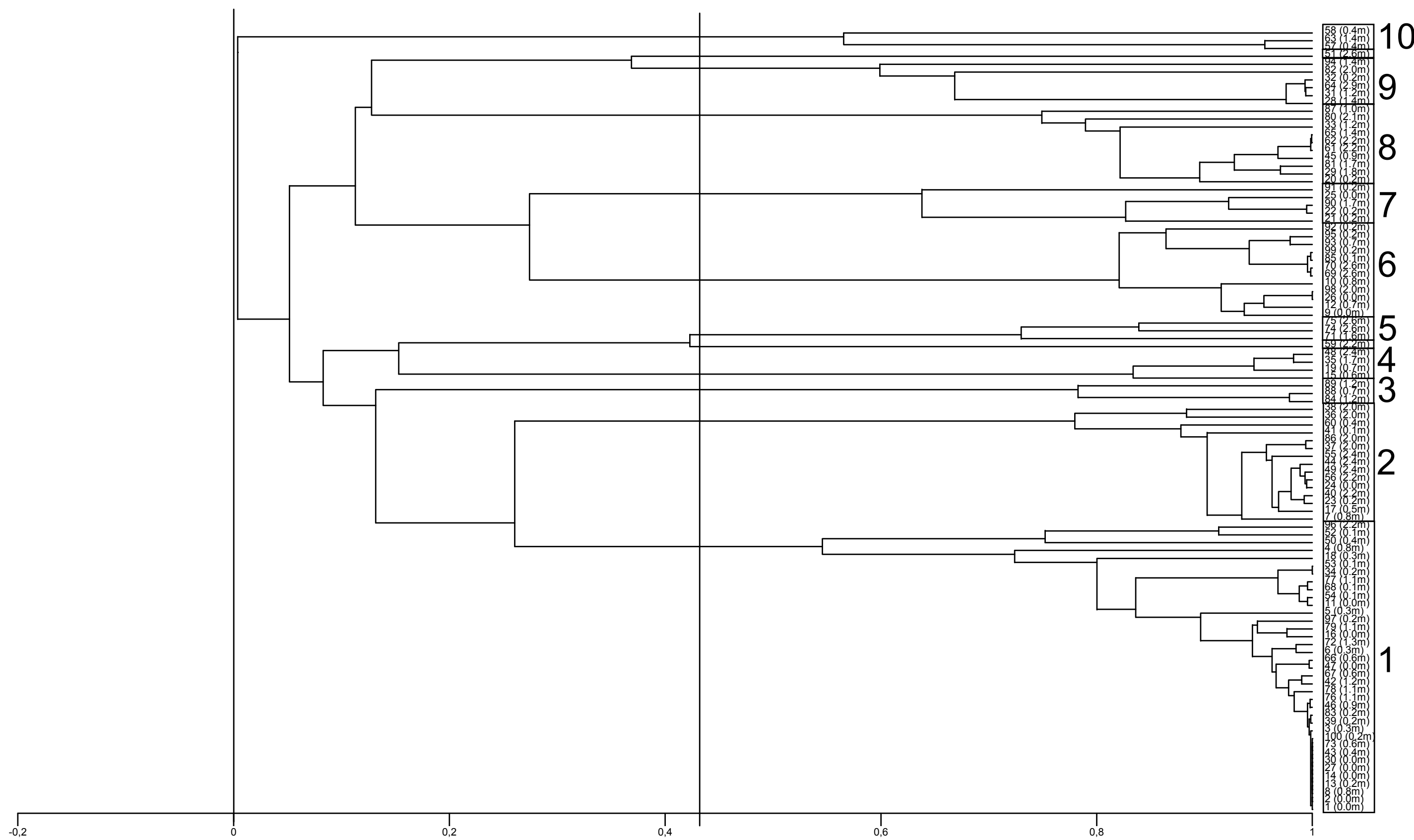

Figura 3.13 - Repartição espacial da comunidade em modo Q para o período de inverno. Índice de Similaridade de Morisita-Horn, estratégia de agrupamento WPGMA. As linhas verticais indicam os limites de significância inferior e superior, entre os quais os grupos podem ser casuais, para uma confiabilidade de $95 \%$. Os números dos 仓े grupos estão indicados ao lado. 

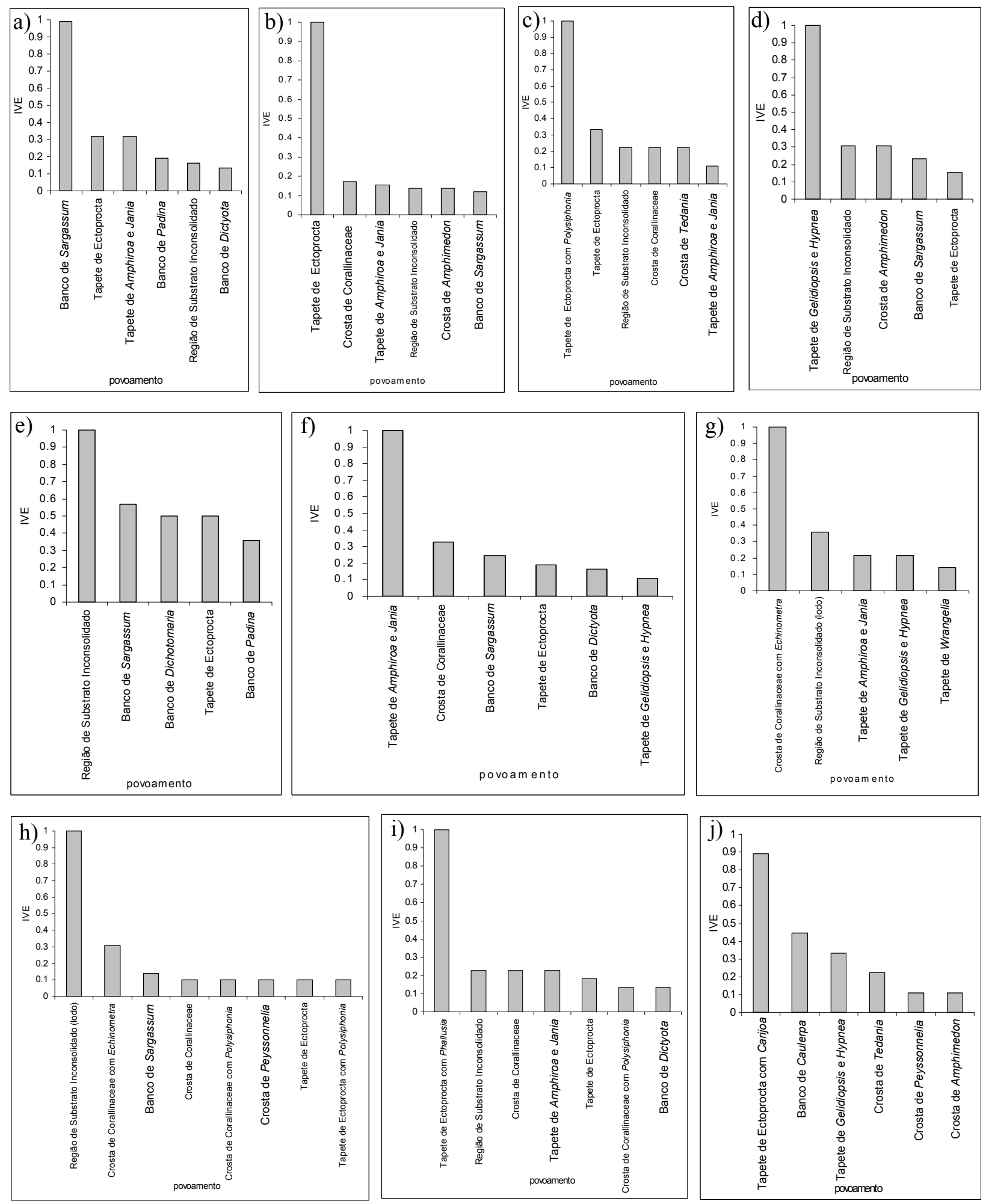

Figura 3.14 - IVE dos povoamentos dos elementos amostrais formadores de grupos significativos com a utilização do índice de similaridade quantitativo de MorisitaHorn no inverno. a) Grupo 1; b) Grupo 2; c) Grupo 3; d) Grupo 4; e) Grupo 5; f) Grupo 6; g) Grupo 7; h) Grupo 8; i) Grupo 9; j) Grupo 10. Aqueles com IVE inferior a 0.1 não foram representados. 
a)

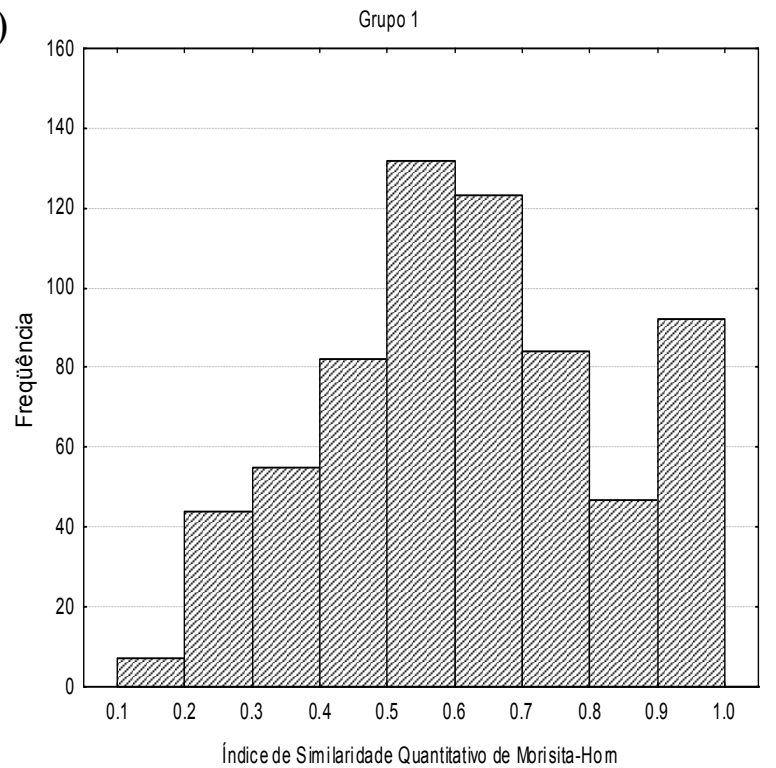

c)

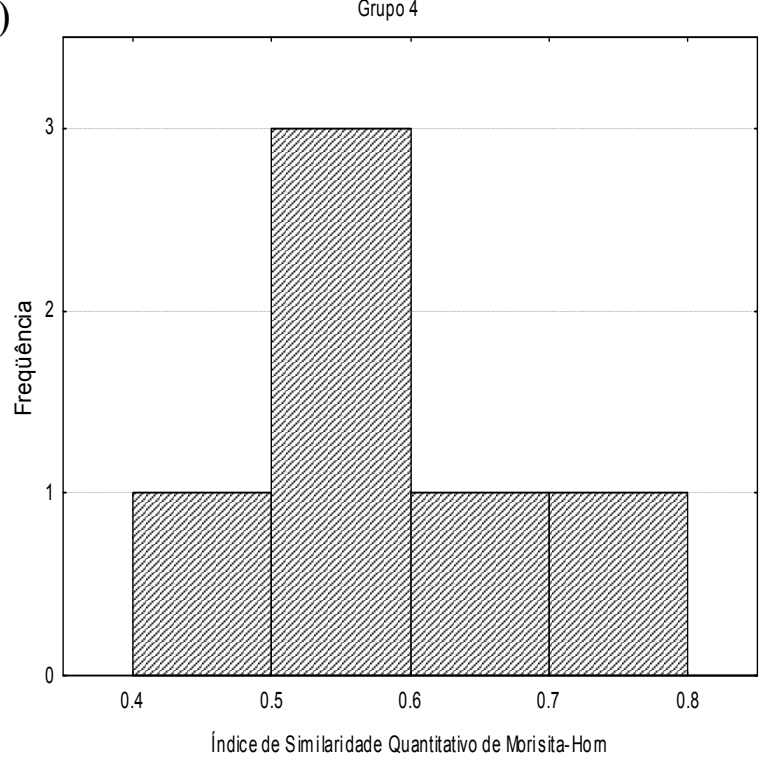

b)

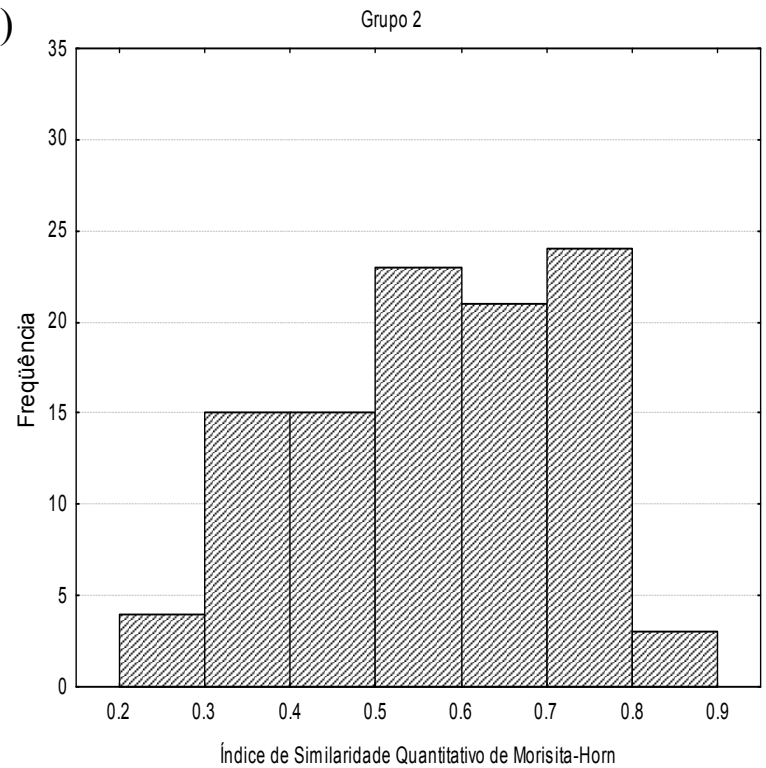

d)

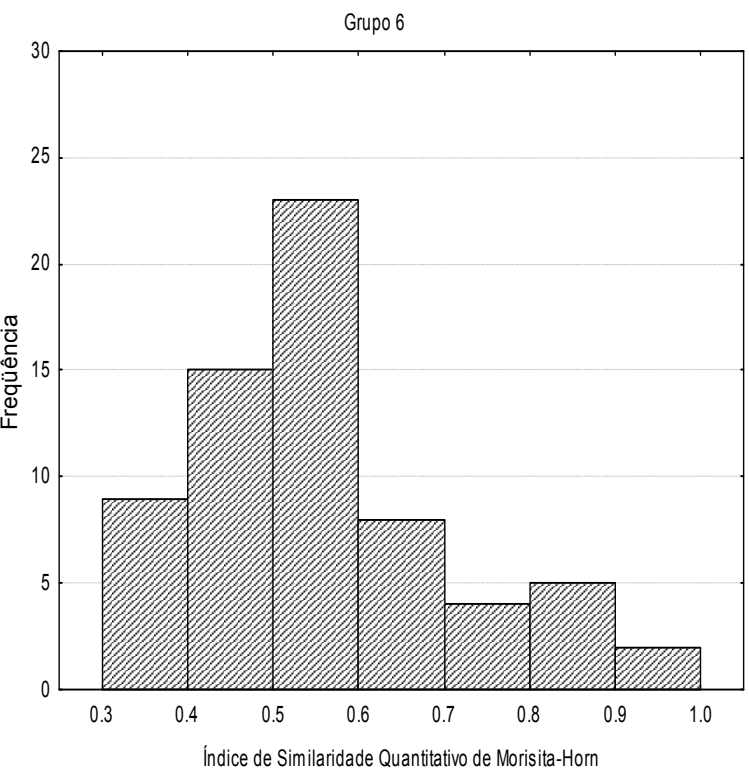

e)

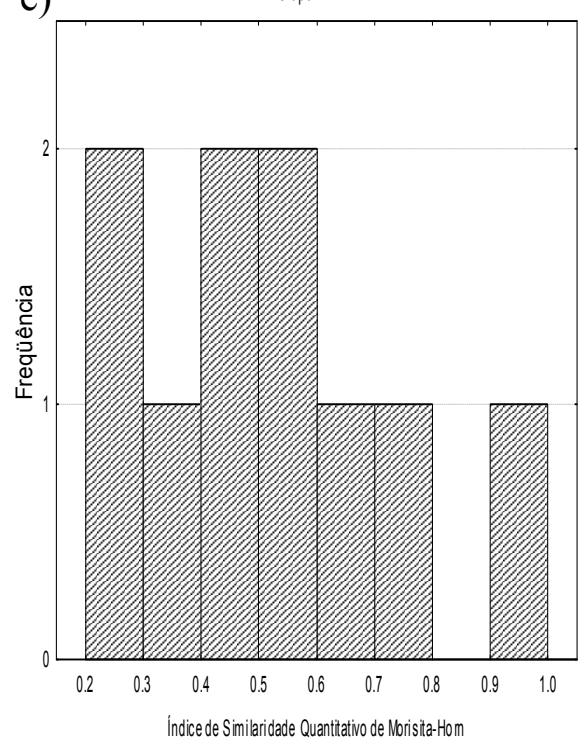

f)

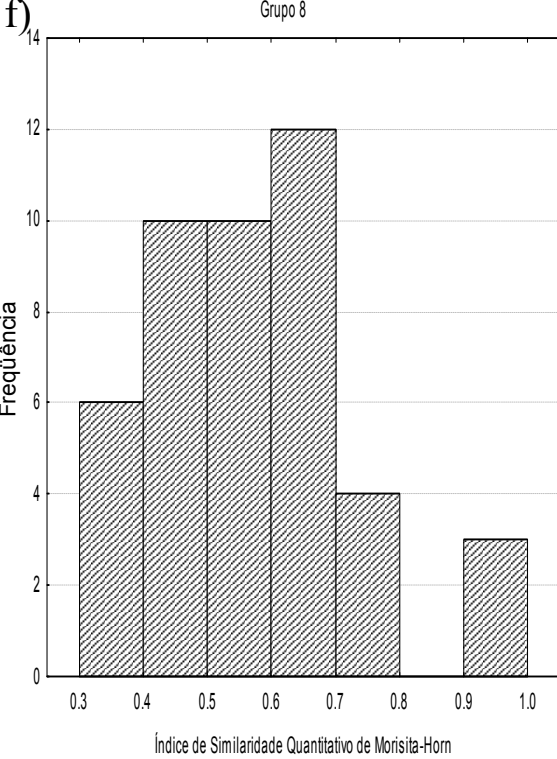

g)

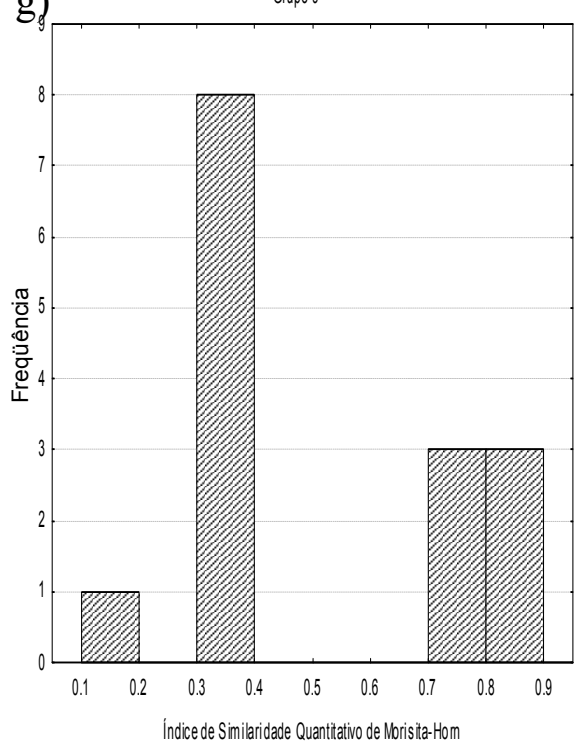

Figura 3.15 - Distribuição de freqüências das similaridades de Morisita-Horn entre os elementos amostrais constituintes dos grupos significativos delimitados no inverno, combinados 2 a 2. a) Grupo 1; b) Grupo 2; c) Grupo 4; d) Grupo 6; e) Grupo 7; f) Grupo 8; g) Grupo 9. 


\section{3) Repartição em modo $R$ e seus descritores}

Foram construídos dendrogramas com a utilização do índice de similaridade de DiceSørensen e a estratégia de agrupamento Ligação Completa. Foram obtidos os níveis de significância (para $\mathrm{p}=0,05$ ) superior de 0,32 e inferior de 0,06 para a amostragem de verão (Figura 3.16) e superior de 0,31 e inferior de 0,05 para a amostragem de inverno (Figura 3.17). Foram encontrados grupos significativamente similares, sendo cinco no verão e três no inverno.

Os povoamentos Crosta de Corallinaceae com Echinometra e Região de Substrato Inconsolidado (lodo); Banco de Dichotomaria e Banco de Padina e Banco de Sargassum e Tapete de Amphiroa e Jania mantiveram-se agrupados tanto no verão quanto no inverno e os demais apresentaram diferenças no agrupamento entre estes dois períodos (Figuras 3.16 e 3.17).

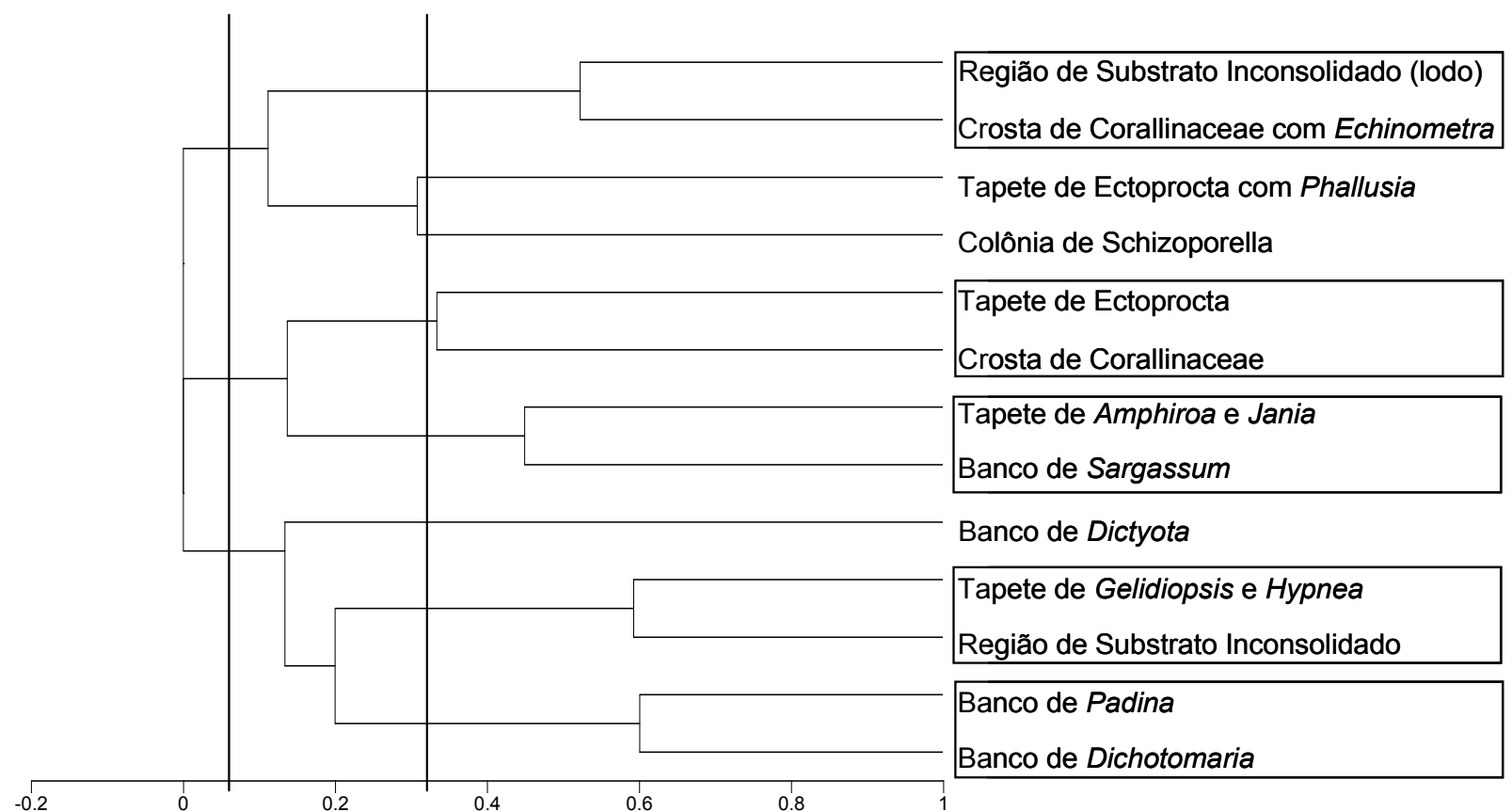

Figura 3.16 - Repartição espaço-temporal da comunidade em modo R para o período de verão. Índice de Similaridade de Dice-Sørensen, estratégia de agrupamento Ligação Completa. As linhas verticais indicam os limites de significância inferior e superior, entre os quais os grupos podem ser casuais, para uma confiabilidade de $95 \%$. 


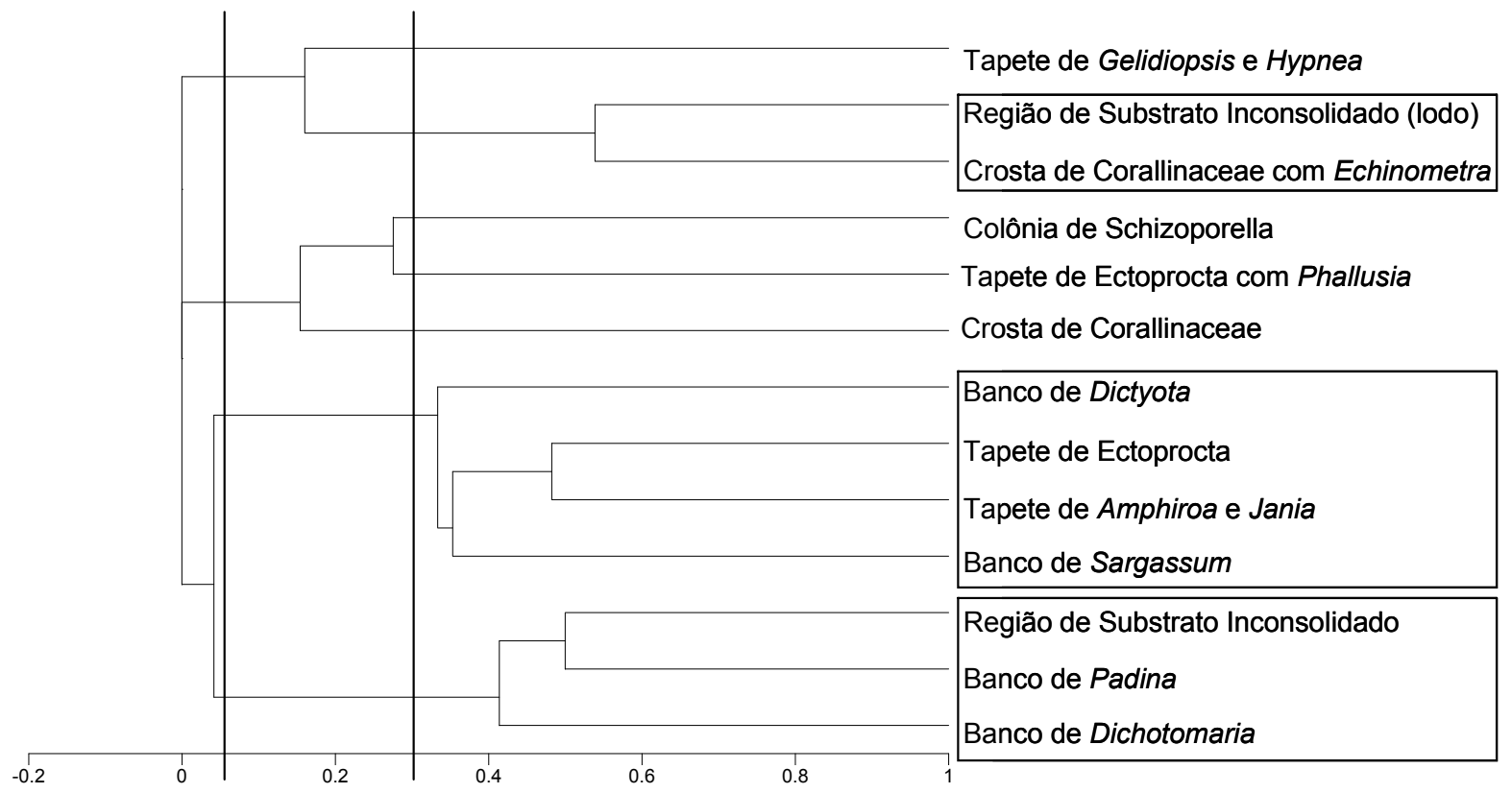

Figura 3.17 - Repartição espaço-temporal da comunidade em modo $\mathrm{R}$ para o período de inverno. Índice de Similaridade de Dice-Sørensen, estratégia de agrupamento Ligação Completa. As linhas verticais indicam os limites de significância inferior e superior, entre os quais os grupos podem ser casuais, para uma confiabilidade de $95 \%$.

\section{3) Dominância e diversidade calculadas no âmbito dos elementos amostrais}

Na Figura 3.18 é possível notar as médias dos valores dos índices nos elementos amostrais. A Riqueza de povoamentos média foi de 2,86 e 3,3, o Índice de Diversidade de Shannon médio foi de 0,97 e 1,01, o Índice de Dominância de Simpson médio foi de 0,70 e 0,65 e o Índice de Dominância de Pielou médio foi de 0,52 e 0,49 para o verão e o inverno, respectivamente.

Comparando-se os dois períodos, observa-se que não há diferença significativa (teste T para amostras dependentes) para os índices de Diversidade de Shannon $(\mathrm{Tc}=1,46 ; \mathrm{p}=0,147)$ Dominância de Simpson $(\mathrm{Tc}=1,35 ; \mathrm{p}=0,181)$ e Dominância de Pielou $(\mathrm{Tc}=1,03 ; \mathrm{p}=0,305)$, entretanto a Riqueza de povoamentos média foi maior no inverno $(\mathrm{Tc}=2,02 ; \mathrm{p}=0,047)$.

Como esperado, observou-se um aumento da Riqueza de povoamentos e Diversidade médias, associado a uma queda da Dominância média.

Deve-se lembrar que os valores aqui obtidos estão adaptados para povoamentos e, portanto, não podem ser comparados com valores padrão conhecidos para espécies. 

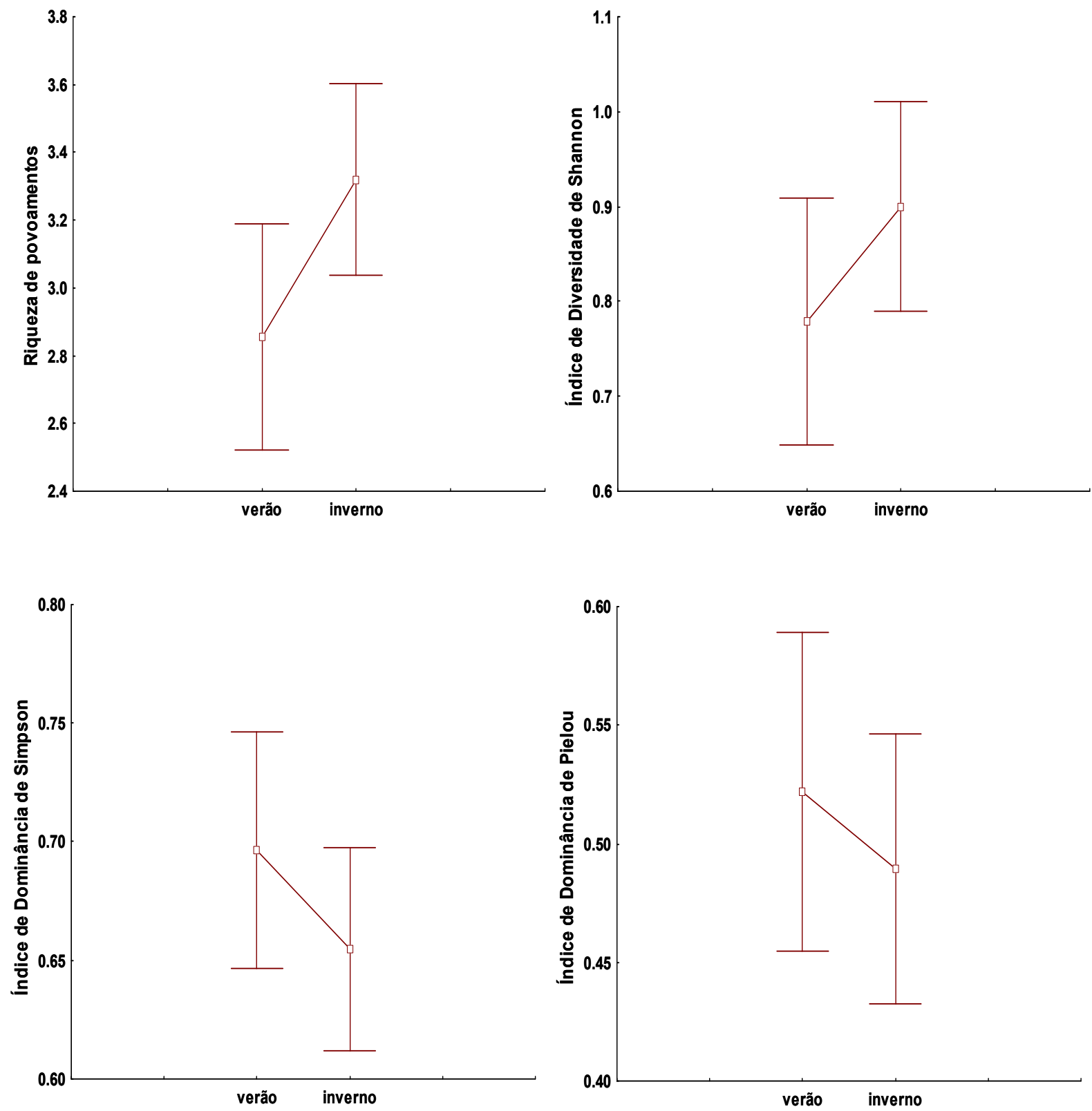

Figura 3.18 - Média dos valores de a) Riqueza de povoamentos e dos índices de b) Diversidade de Shannon, c) Dominância de Simpson e d) Dominância de Pielou. As barras verticais correspondem ao Intervalo de Confiança (95\%). 


\section{DISCUSSÃo}

A amostragem quantitativa realizada na área de estudo fornece uma idéia da estruturação da comunidade local. Alguns dos padrões descritos para comunidades de infralitoral rochoso por Nybakken (1997) puderam ser reconhecidos na área, como a presença de organismos solitários formadores de densos agrupamentos (algas, equinodermos), coloniais (ascídias, cnidários) e incrustantes (esponjas, algas calcárias).

As quantidades de 26 (verão) e 28 (inverno) povoamentos encontradas na área de estudo parecem confirmar a hipótese de que poucas espécies dominantes determinam a estrutura da paisagem dos costões. Outros estudos confirmam esta hipótese, como no infralitoral de um costão em Armação dos Búzios (RJ), onde Oigman-Pszczol et al. (2004), que amostraram espécies em transectos de 14-56 m posicionados até aproximadamente $2 \mathrm{~m}$ de profundidade, encontraram 22 espécies dominantes, número ainda menor.

Entretanto, o costão oeste da Enseada das Palmas (Pereira, em andamento), com 750m de extensão, apresentou um número maior de povoamentos (53). Tal resultado poderia ser explicado pela hipótese de diversidade de hábitat, na qual áreas maiores deveriam conter mais povoamentos, já que em geral possuem uma maior gama de tipos de hábitat (Williams, 1943) ou pela hipótese da amostragem passiva, na qual áreas maiores teriam mais povoamentos por representar "alvos" para a imigração (Coleman et al., 1982).

O povoamento que apresentou maior valor médio de recobrimento percentual no verão e inverno foi Banco de Sargassum, o que confirma a importância desta alga no infralitoral do Brasil (Oliveira Filho \& Paula, 1983; Eston et al., 1986; Paula, 1987; Paula, 1988; Paula \& Eston, 1989; Eston \& Bussab, 1990; Széchy, 1996; Széchy \& Paula, 2000; Costa Jr. et al., 2002; Amado Filho et al., 2003) e de regiões tropicais (Stephenson \& Stephenson, 1972; De Wreede, 1976; Norris \& Fenical, 1982; Eston, 1987; Lüning, 1990; Pereira \& Soares-Gomes, 2002). 
O povoamento que apresentou segundo maior valor médio de recobrimento percentual no verão e inverno foi Tapete de Ectoprocta, o que não era esperado considerando-se outros estudos de infralitoral na região sudeste, onde esponjas e cnidários foram os organismos animais mais importantes em termos de cobertura (Maggs et al.,1979 e Oigman-Pszczol et al., 2004). Gordon (1972) considera que os briozoários marinhos têm sido ignorados nos estudos sobre ecologia faunística, embora desempenhem importante função em ecossistemas de costão, sendo provavelmente a ocupação do espaço o efeito de maior influência em comunidades bentônicas (Sutherland, 1978).

Outra característica importante da comunidade do presente estudo foi o fato de Colônia de Palythoa apresentar apenas 1,16\% de recobrimento no verão e não ter sido sequer incluída na amostragem de inverno, o que não está de acordo com outros estudos de infralitoral do Brasil, nos quais o gênero Palythoa desempenha um importante papel em termos de recobrimento percentual. Edwards \& Lubbock (1983) relataram um zona ocupada por Palythoa caribaeorum entre 3 e $8 \mathrm{~m}$ de profundidade nos Penedos de São Pedro e São Paulo, Villaça \& Pitombo (1997), em estudo realizado no arquipélago de Abrolhos, relataram a presença de $P$. caribaeorum em $50 \%$ das amostras, sendo dominante na Ilha de Santa Bárbara entre 0,8 e $2,5 \mathrm{~m}$ de profundidade, Figueiredo et al. (2004) reportou até $27 \%$ de recobrimento por Palythoa na Ponta do Buraco (RJ) e Oigman-Pszczol et al. (2004) também encontraram altos valores de recobrimento para esta espécie em profundidades até $4 \mathrm{~m}$. Além disso, na própria Enseada das Palmas, no costão situado a oeste, Pereira (em andamento) reportou para Colônia de Palythoa o maior valor médio de recobrimento percentual no verão $(27,7 \%)$ e o segundo maior no inverno $(26,7 \%)$.

No sentido temporal, a amostragem realizada neste estudo foi restrita, englobando apenas duas estações do ano e não foi objetivo deste estudo evidenciar padrões cíclicos de oscilação do descritor utilizado. Entretanto, quando comparados verão e inverno, alguns povoamentos apresentaram diferenças: Banco de Dictyota, Crosta de Corallinaceae com 
Capítulo 3 - Análise quantitativa da repartição espacial de povoamentos do P. Est. Ilha Anchieta

Polysiphonia e Tapete de Gelidiopsis e Hypnea apresentaram queda no recobrimento percentual médio no inverno. Colônia de Palythoa só foi encontrada na amostragem de verão e Banco de Colpomenia, Colônia de Symplegma, Crosta de Mycale, Tapete de Falkenbergia só foram encontrados na amostragem de inverno.

Estes povoamentos não encontrados no período de inverno, assim como aqueles só encontrados neste período, são pouco abundantes, que apesar de não terem sido incluídos na amostragem, foram observados na área de estudo.

Airoldi \& Cinelli (1997), Neto (2000), Diaz-Pulido \& Garzón-Ferreira (2002) e Ateweberhan et al. (2005) relataram comportamento sazonal para espécies de Dictyota e Kaliaperumal \& Rao (1982), para Gelidiopsis variabilis. Wrangelia argus e Polysiphonia sp. são algas pouco competitivas e que sofrem alta pressão de herbivoria, adotando portanto a estratégia de epifitismo, crescimento rápido (Villaça \& Pitombo, 1997) e efemeridade.

Em costões tropicais aparentemente existe maior constância nos padrões ao longo do tempo que em costões temperados. Trabalhos realizados na Baía do Panamá indicaram que a maioria das populações intermareais é mais constante no tempo e espaço que suas equivalentes de ambiente temperado (Garrity \& Levings, 1981; Menge \& Lubchenco, 1981; Garrity, 1984; Levings \& Garrity, 1984; Lubchenco et al., 1984; Menge et al., 1985; Ortega, 1987). Em associações de algas, Underwood \& Chapman (1997) não evidenciaram padrões consistentes estacionais ou mesmo anuais na abundância das espécies dominantes. Estudos mais acurados de dinâmica temporal exigem uma janela de observação bem mais larga que o período das oscilações que se pretende evidenciar (Frontier, 1983). Portanto, são necessários estudos neste sentido para o estabelecimento das oscilações naturais dos povoamentos para que conclusões possam ser obtidas e modelos possam ser propostos.

Em termos composicionais, a comunidade manteve-se estável no período estudado. Foram amostrados 26 povoamentos no verão e 28 no inverno, números bastante próximos ao total de 31 encontrado para a área de estudo por estimativa visual (Capítulo 2). Seguindo os 
conceitos referentes à estabilidade da comunidade apresentados por Putman (1994), podemos dizer que no período estudado a comunidade apresentou-se relativamente constante (sem grandes mudanças no número de povoamentos) e inerte (resistente aos distúrbios aos quais foi submetida neste período). Villaça \& Pitombo (1997) também encontraram uma comunidade estável ao longo do tempo.

A proporção de povoamentos fitobentônicos foi significativamente maior que os zoobentônicos e que os atributos tanto no verão quanto no inverno, sendo que não houve diferenças entre as estações. O mesmo foi observado para o costão oeste da Enseada das Palmas (Pereira, em andamento), sendo que os valores foram bastante semelhantes, de 67,2\% e $67,5 \%$ para os fitobentônicos, $32,2 \%$ e $31,6 \%$ para os zoobentônicos e $0,3 \%$ e $0,9 \%$ para os atributos não-biológicos no verão e inverno, respectivamente. Maggs et al. (1979), Eston et al. (1986), Villaça \& Pitombo (1997), Costa Jr. et al. (2002) e Oigman-Pszczol et al. (2004) também encontraram maior proporção de algas nas áreas estudadas.

Hatcher (1990) lançou a hipótese de que muitos fatores como herbivoria, concentração local de nutrientes, efetividade na defesa de algas, entre outros, afetam a abundância de algas. Littler \& Littler (1984a) disseram que os níveis de nutrientes e a atividade de herbivoria agem como os dois principais fatores controlando a dominância de produtores primários bênticos. A herbivoria é um fator biológico comum na estruturação das comunidades de todo o mundo (revisão em Steneck, 1988).

No presente trabalho nenhum experimento relacionado com herbivoria foi realizado, mas algumas especulações podem ser feitas à luz da abordagem por grupos morfo-funcionais (Littler \& Littler, 1980, 1984b; Littler et al., 1983a e Steneck \& Dethier, 1994), no caso aqui explicitados na forma de 'categorias' de povoamentos. Em relação a estas categorias, os bancos fitobentônicos foram os que apresentaram maior recobrimento tanto no verão quanto no inverno, seguidos dos tapetes fitobentônicos. Destaca-se a contribuição de Banco de Sargassum e de Tapete de Amphiroa e Jania para este resultado. Esta importância dos gêneros 
Sargassum e Amphiroa em comunidades de infralitoral foi reportada em Fernando de Noronha por Eston et al. (1986), para o sul da Bahia por Costa Jr. et al. (2002) e para a Ilha Comprida, Saco da Velha e Praia Vermelha (RJ) por Figueiredo et al. (2004).

Isto parece não ser verdade para comunidades de recifes de coral, as quais são dominadas por algas formadoras de 'tapetes', como foi encontrado, por exemplo, por Villaça \& Pitombo (1997) e Costa Jr. et al. (2002).

Considerando o paradigma de relação de dominância de Littler \& Littler (1984a), a área estudada seria caracterizada por altos níveis de nutrientes e alta pressão de herbivoria, devido à dominância de algas não palatáveis e/ou com defesa física contra herbivoria, como Sargassum e Amphiroa.

Se forem considerados os recobrimentos percentuais médios de organismos, tanto animais quanto algas, formadores de 'tapetes', a soma (46,3\% no verão e $41,4 \%$ no inverno), então, ultrapassa a dos 'bancos' (31,2\% no verão e 37,0\% no inverno). Esta dominância deste tipo de morfologia poderia indicar também a influência de sedimentos na estruturação das comunidades da área (Airoldi \& Cinneli, 1997; Airoldi, 1998, 2000, 2003, 2004; Gorgula \& Connell, 2004), confirmada pelo significativo recobrimento encontrado para Região de Substrato Inconsolidado tanto no verão quanto no inverno.

Algumas espécies são tolerantes à areia ou mesmo parecem prosperar nela, geralmente aquelas com adaptações reprodutivas (propagação vegetativa) ou morfológicas (Airoldi et al., 1995; Stewart, 1983). Em particular, algas formadoras de tapetes, notavelmente as coralináceas, e também briozoários, não só aumentam quando com areia, mas capturam e retém areia e, portanto ajudam a transformar o hábitat posteriormente (Cuffey, 1974; Stewart, 1989; Kendrick, 1991; Airoldi \& Virgilio, 1998). Isto poderia explicar parcialmente a presença relativamente alta de Tapete de Amphiroa e Jania na área estudada, o que tem sido referido por outros autores em condições similares (Littler et al., 1983b; Airoldi \& Cinelli, 1997). O mesmo poderia ser aplicado para Tapete de Ectoprocta, já que as espécies que 
apresentam a forma de crescimento ereto-flexível-articulado-ramificado, geralmente ocorrem em áreas com sedimentação moderada a elevada (Boyer et al., 1986; Amini et al., 2004), como relatado por Nicoletti et al. (1995) para Scrupocellaria delilii.

Num contexto espacial, quanto à detecção de associações em modo $\mathrm{R}$ foi possível a distinção de alguns grupos cujos valores do Índice de Similaridade de Dice-Sørensen foram significativamente similares, sendo o grupo formado por Banco de Padina, Banco de Dichotomaria possivelmente explicado pelo fato das algas formadoras destes povoamentos serem resistentes ao soterramento por areia e sempre recrutarem próximas ao fundo.

A formação do agrupamento Região de Substrato Inconsolidado (lodo) e Crosta de Corallinaceae com Echinometra pode ser explicado pela grande deposição de sedimento que foi observada sobre este povoamento na área. Isto também foi observado para outros povoamentos, porém em menor intensidade.

Banco de Sargassum e Tapete de Amphiroa e Jania foi outro agrupamento consistente. A associação de algas calcárias com Banco de Sargassum já foi reportada por Széchy \& Paula (2000) e parece ser bastante comum para o nosso litoral.

São necessários mais estudos para verificação dos demais agrupamentos formados, já que para o inverno foi observada a formação de grupos diferentes daqueles do verão.

$\mathrm{Na}$ análise em modo Q, a fragmentação dos grupos encontrada nos dendrogramas com a utilização do Índice de Similaridade de Dice-Sørensen era esperada, já que este índice baseia-se em dados qualitativos e não leva em consideração as quantidades relativas entre os diferentes povoamentos existentes nos elementos amostrais considerados.

Os índices quantitativos utilizados foram mais inclusivos, principalmente o de Similaridade de Morisita-Horn, que é influenciado pelos povoamentos dominantes, indicando que existe uma alta dominância de alguns povoamentos nos elementos amostrais considerados, mas que os povoamentos com valores intermediários de recobrimento percentual são variáveis, já que os dendrogramas com a utilização do Índice de Distância de 
Bray-Curtis apresentaram a formação de um maior número de grupos e também pelo fato da análise da distribuição de freqüências ter mostrado certa heterogeneidade interna aos grupos formados pelo Índice de Similaridade de Morisita-Horn. Tanto no verão quanto no inverno a dominância de alguns povoamentos nos grupos formados nos dendrogramas ficou bastante evidente, principalmente de Banco de Sargassum, Região de Substrato Inconsolidado (areia ou lodo), Tapete de Amphiroa e Jania, Tapete de Ectoprocta (e algumas de suas derivações) e Tapete de Gelidiopsis e Hypnea.

O fato dos grupos formados nos dendrogramas não terem apresentado um padrão claro relacionado com a posição no espaço ou profundidade indica que a comunidade é bastante faceteada, apresentando diversas manchas ao invés de faixas bem definidas, pelo menos na resolução da observação adotada neste estudo, já que em uma resolução mais grosseira, levando em consideração apenas a freqüência relativa (Capítulo 2), quatro zonas puderam ser distinguidas.

A zonação é um fato bem conhecido e estabelecido para costões rochosos de todo o mundo (Stephenson \& Stephenson, 1949 e 1972; Lewis, 1961 e 1964; Chapman, 1979; Lubchenco, 1980; Paula, 1987), evidenciado no Brasil não só para o mediolitoral, mas também em estudos realizados no infralitoral, como o de Maggs et al. (1979), Eston et al. (1986), Oigman-Pszczol et al. (2004).

Entretanto, segundo MacArthur (1969), independentemente das quantidades propriamente ditas envolvidas, em locais onde muitas espécies, ou, no caso deste estudo, povoamentos estão presentes as abundâncias tendem a ser mais eqüitativas e com uma repartição espacial mais “em manchas”. Espera-se daí uma relação direta entre riqueza e diversidade, e maior complexidade estrutural, ou heterogeneidade, do sistema estudado, ou seja, maior mosaico. O padrão em manchas, ou mosaico, foi observado em campo para a maioria dos povoamentos encontrados, sendo as manchas formadas por um indivíduo ou grupo de indivíduos agregados, ou seja, com distribuição não aleatória. A heterogeneidade do 
sistema ficou bastante evidenciada não só pela análise da repartição espacial, como também pela análise da distribuição de freqüências.

Isso indica que as espécies dominantes, estruturadoras ou organizadoras do espaço, não se dispersam de modo uniforme ou homogêneo na área, acentuando o mosaico (GreighSmith, 1983; Rosso, 1990). Entretanto, segundo Valiela (1984), os processos biológicos podem, pelo acaso, gerar distribuições não aleatórias e já que a distribuição pode ser de origem estatística ao invés de ter uma origem ecológica direta, a presença de uma distribuição específica deve ser considerada no máximo como uma descrição empírica do que como uma evidência da ação de processos específicos. Além disso, existe uma organização hierárquica de atributos estruturais como diversidade, dominância e heterogeneidade em função da escala da amostragem (Sugihara \& May, 1990; Gee \& Warwick, 1994). Como exemplo deste ponto, cita-se que numa dada escala a distribuição de uma certa espécie pode ser considerada uniforme, enquanto que em uma escala maior já pode se apresentar como agregada. A abordagem das comunidades neste contexto escalar (p. ex. Archambault \& Bourget, 1996; Blanchar \& Bourget, 1999) mostra-se muito promissora dentro do campo da Ecologia descritiva, inclusive com a possibilidade de associação com técnicas desenvolvidas a partir da teoria dos fractais.

Outro fator que poderia estar influenciando a existência de manchas seria, numa visão mais localizada, a ocorrência de perturbações periódicas e estocásticas, heterogêneas no tempo e no espaço e que fazem das comunidades um mosaico de estágios de desenvolvimento (Connell, 1978; Souza, 1979; Machado et al., 1992; Borges, 2002). Desta forma, em um ambiente de costão rochoso, a composição em pequenas áreas está sempre se modificando e o equilíbrio é impedido, sendo que pequenas manchas de substrato são constantemente colocadas à disposição de novos colonizadores, alterando, a partir dos diferentes padrões de sucessão possíveis nestas manchas, a estrutura (repartição horizontal e vertical) e a composição destes mosaicos em diferentes áreas e períodos de tempo. Connel \& Keough 
(1985) concluem que a existência ou não de uma espécie dominante pode definir o caráter determinístico ou estocástico do desenvolvimento da comunidade. Se houver a dominância evidente de uma espécie sobre as demais, a condição de clímax é de certa forma invariável. À medida que observamos uma alta eqüitatividade na comunidade, o caráter estocástico passa a prevalecer.

Devido à ausência de estudos ecológicos na área, o entendimento dos padrões na composição e na repartição espaço-temporal das comunidades foram importantes como um passo inicial de entendimento das mesmas (Begon et al., 1996). A partir deste conhecimento inicial, possíveis diferenças nos padrões observados poderão ser encontradas, resultando de processos variados, e a documentação desta variabilidade natural é um passo fundamental antes que a explanação de modelos para estes padrões seja proposta (Underwood, 1990; Underwood et al., 2000). Como lembrado por Lively et al. (1993), trabalhos experimentais envolvendo predação, impactos, competição e recrutamento em costões rochosos produziram muitas das bases empíricas da moderna ecologia de comunidades. Além disso, somente através de trabalhos de longa duração, também envolvendo tais aspectos funcionais, será possível o entendimento de como os distúrbios espaço-temporais afetam a estrutura das comunidades. 



\section{REFERÊNCIAS}

AIROLDI, L., 1998. Roles of disturbance, sediment stress, and substratum retention on spatial dominance in algal turf. Ecology, v. 79, n. 08, p. 2759-2770.

AIROLDI, L., 2000. Responses of algae with different life histories to temporal and spatial variability of disturbance in subtidal reefs. Mar. Ecol. Prog. Ser.195: 81-92

AIROLDI, L., 2003. The effects of sedimentation on rocky coast assemblages. Oceanography and Marine Biology, v. 41, p.161-236.

AIROLDI, L., 2004. Forecasting the effects of enhanced sediment loads to coastal areas: a plea for long-term monitoring and experiments. Aquatic Conserv: Mar. Freshw. Ecosyst. v. 14, S115-S117.

Airoldi, L.; Cinelli, F., 1997. Effects of sedimentation on subtidal macroalgal assemblages: an experimental study from a Mediterranean rocky shore. Journal of Experimental Marine Biology and Ecology, v. 215, p. 269-288.

Airoldi, L.; Rindi, F.; Cinelli, F., 1995. Structure, seasonal dynamics and reproductive phenology of a filamentous turf assemblage on a sediment influenced, rocky subtidal shore. Botanica mar., v. 38, p. 227-237.

Airoldi, L.; VirgiLIO, M., 1998. Response to turf-formig algae to spatial variations in deposition of sediments. Marine Ecology Progress Series, v. 165, p. 271-282.

Amado Filho, G.M.; Barreto, M.B.B.B.; Marins, B.V.; FeliX, C.; Reis, R.P., 2003. Estrutura das comunidades fitobentônicas do infralitoral da Baía de Sepetiba, RJ, Brasil. Revista Brasil. Bot., v. 26, n. 3, p. 329-342.

AMINI, Z.Z.; AdABI, M.H.; BuRRETT, C.F.; QuILTY, P.G., 2004. Bryozoan distribution and growth form associations as a tool in environmental interpretation, Tasmania, Australia. Sedimentary Geology, v. 167, p. $1-15$.

Archambault, P.; Bourget, E., 1996. Scales of coastal heterogeneity and benthic intertidal species richness, diversity and abundance. Mar. Ecol. Prog. Ser., v. 136, p. 111-121.

Ateweberhan, M.; Bruggemann, J.H.; Breeman, A.M., 2005. Seasonal patterns of biomass, growth and reproduction in Dictyota cervicornis and Stoechospermum polypodioides (Dictyotales, Phaeophyta) on a shallow reef flat in the southern Red Sea (Eritrea). Botanica mar., v. 48, n. 01, p. 8-17.

BALlesteros, E., 1986. Métodos de análisis estructural en comunidades naturales, en particular del fitobentos. Oecologia Aquática, v. 8, p. 117-131.

Begon, M.; HARPer, J.L.; Towsend, C.R., 1996. Ecology: individuals, populations and communities. $3^{\text {rd }}$ ed. Oxford: Blackwell Science Ltda. 1068pp.

Berchez, F.; Rosso, S.; Ghilardi, N.P.; FuJiI, M.T.; Hadel, V., 2005. Characterization of 
hard bottom marine benthic communities: the physiognomic approach as an alternative to traditional methodologies. In: Sociedade Brasileira de Ficologia (Org.). Formação de

Ficólogos: um compromisso com a sustentabilidade dos recursos aquáticos. Rio de Janeiro: Museu Nacional, Série Livros 10, p. 207-220.

Blanchar, D.; Bourget, E., 1999. Scales of coastal heterogeneity: influence on intertidal community structure. Mar. Ecol. Prog. Ser., v. 179, p. 163-173.

BOHNSACK, J.A., 1979. Photographic quantitative sampling of hard bottom benthic communities. Bull. Mar. Sci, v.29, n.2, p.242-252.

BORGES, R.P., 1996. Abordagem temporal da repartição espacial, diversidade e dominância em uma comunidade de costão rochoso intermareal da Praia da Tatuíra, São Sebastião (SP). 97 f. Dissertação (Mestrado em Ecologia) - Instituto de Biociências, Universidade de São Paulo, São Paulo.

BORGES, R. P., 2002. Recrutamento em substrato artificial consolidado no estuário de Santos (Santos-SP): um estudo em médio prazo. 92f. Tese (Doutorado em Ecologia) - Instituto de Biociências, Universidade de São Paulo, São Paulo.

Boyer, M.; Matricardi, G.; PisAno, E., 1986. Variazioni dello spettro zoariale in uma comunità infralitorale di briozoi. Boll. Mus. Ist. Biol. Univ. Genova, v. 52 (suppl.), p. 301-316.

Bythel, J.C.; PAN, P.; LeE, J., 2001. Three-dimensional morphometric measurements of reef corals using underwater photogrammetry techniques. Coral Reefs, v.20, p. 193-199.

Chapman, A.R.O., 1979. Biology of seaweeds: levels of organization. Baltimore: University. Park Press. 134 p.

Christie, H., 1983. Use of video in remote studies of rocky subtidal community interactions. Sarsia, Bergen, v. 68, p.191-194.

Clifford, H.T.; Stephenson, W., 1975. An introduction to numerical classification. New York: Academic Press. 224p.

Coleman, B.D.; Mares, M.A.; Willig, M.R.; Hsieh, Y.-H., 1982. Randomness, area and species richness. Ecology, v. 63, p. 1121-1133.

ConNel, J.H., 1972. Community interactions on marine rocky intertidal shores. A. Rev. Ecol. Syst., v. 03, p. 169-192.

ConNel, J.H., 1978. Diversity in tropical rain forests and coral reefs. Science, New York, n. 199, p. 1302-1310.

Connel, J.H.; KeOugh, M.J., 1985. Disturbance and patch dynamics of subtidal marine animals on hard substrata. In: Pickett, S.T.A.; White, P.S. (eds). The ecology of natural disturbance and patch dynamics. London: Academic Press. P. 125-151. 
CORREIA, M.D., 1997. Distribuição espacial dos organismos macrobentônicos no recife de coral da Ponta Verde, Maceió, Alagoas - Brasil. 194f. Tese (Doutorado) - Instituto de Biociências, Universidade de São Paulo, São Paulo.

Costa Jr, O.S.; Attrill, M.J.; Pedrini, A.G.; De-Paula, J.C., 2002. Spatial and seasonal distribution of seaweeds on coral reefs from southern Bahia, Brazil. Botanica mar., Berlin, v. 45, p. 346-355.

CoutinHO, L.M., 1974. Ecologia vegetal. São Paulo: FUMEST. 21p. (relatório apresentado à FUMEST para o "Plano Geral de Exploração Turística da Ilha Anchieta).

CUfFEY, R.J., 1974. Delineation of bryozoan constructional roles in reefs from comparison of fossil bioherms and living reefs. In: Proceedings of the Second International Symposium on Coral Reefs. v.1.

DAYTON, P.K., 1971. Competition, disturbance and community organization: the provision and subsequent utilization of space in a rocky intertidal community. Ecol. Monogr., v. 41, n. 4, p. 351-389.

DAYTON, P.K., 1975. Experimental evaluation of ecological dominance in a rocky intertidal algal community. Ecol. Monogr., v. 45, p. 137-159.

Dethier, M.N.; Graham, E.S.; Cohen, S.; TeAr, L.M., 1993. Visual versus random-point percent cover estimations: 'objective' is not always better. Mar. Ecol. Prog. Ser., Halstenbek, v. 96, p. 93-100.

DE WREEDE, R.E., 1976. The phenology of three species of Sargassum (Sargassaceae, Phaeophyta) in Hawaii. Phycologia, v. 15, p. 175-183.

Diaz-Pulido, G.; Garzón-Ferreira, J., 2002. Seasonality in Algal Assemblages on Upwelling-influenced Coral Reefs in the Colombian Caribbean. Botanica mar., v. 45, n. 03, p. 284-292.

Ducrotoy, J.;. Simpson, S.D, 2001. Developments in the application of photography toecological monitoring, with reference to algal beds. Aquatic Conserv. Mar. Freshw. Ecosyst., v.11, p.123-135.

Edwards, A.; LubBOck, R., 1983. The ecology of Saint Paul's Rocks (Equatorial Atlantic). J. Zool., London, v. 200, p. 51-69.

ESTON, V.R. de, 1987. Zonação de costões rochosos: infralitoral. In: SIMPÓSIO DOS ECOSSISTEMAS DA COSTA SUL E SUDESTE BRASILEIRA: SÍNTESE DOS CONHECIMENTOS, 1., p. 289-299. São Paulo: Academia de Ciências do Estado de São Paulo (Publicação ACIESP, 54). 
Eston, V.R.; BussaB, W.O., 1990. An experimental analysis of ecological dominance in a rocky subtidal macroalgal community. J. Exp. Mar. Biol. Ecol., Amsterdam, v. 136, p. 170-195.

Eston, V.R. De; Migotto, A.E.; Oliveira Filho, E.C. De; Rodrigues, S.A.; Freitas, J.C., 1986. Vertical distribution of benthic marine organisms on rocky coasts of the Fernando de Noronha archipelago (Brazil). Bol. Inst. Oceanogr., São Paulo, v. 34, p. 37-54.

Figueiredo, M.A.O.; BARReto, M.B.B.; Reis, R.P., 2004. Caracterização das macroalgas nas comunidades marinhas da Área de Proteção Ambiental de Cairuçú, Parati, RJ - subsídios para futuros monitoramentos. Revista Brasil. Bot., São Paulo, v. 27, n. 1, p. 11-17.

Foster, M.S.; Harrold, C.; Hardin, D.D., 1991. Point vs. Photo quadrat estimates of the cover of sessile marine organisms. J. Exp. Mar. Biol. Ecol., Amsterdam, v. 146, p. 193 203.

FrontiER, S., 1983. Choix et constraints de l'echantillonnage écologique. In: Frontier, S. (ed). Stratégies d'echantillonnage en écologie. Paris: Masson. p. 115-162.

GARRITY, S.D., 1984. Some adaptations of gastropods to physical stress on a tropical rocky shore. Ecology, v. 65, p. 559-574.

GARRITY, S.D.; LEVINGS, S.C., 1981. A predator-prey interaction between two physically and biologically constrained tropical rocky shore gastropods: direct, indirect and community effects. Ecological Monographs, v. 51, p. 267-286.

GEE, J.M.; WARWICK, R.M., 1994. Metazoan community structure in relation to the fractal dimensions of marine macroalgae. Mar. Ecol. Prog. Ser., v. 103, p. 141-150.

Goodall, D.W., 1952. Quantitative aspects of plant distribution. Biol. Rev., v. 27, p. 194245.

GORDON, D.P., 1972. Biological relationships of an intertidal Bryozoan population. J. Nat. Hist., v. 6, p.503-514.

GorgulA, S.K.; CONNELL, S.D., 2004. Expansive covers of turf-forming algae on humandominated coast: the relative effects of increasing nutrient and sediment loads. Marine Biology, v. 145, n. 03, p. 613-619.

Greig-Smith, P., 1983. Quantitative Plant Ecology. $3^{\text {rd }}$ ed. Oxford: Blackwell. 359p.

Guillaumon, J.R.; Marcondes, M.A.P.; Negreiros, O.C.; Mota, I.S.; EMmerich, W.; Barbosa, A.F.; Branco, I.H.D.C.; CAMARA, J.J.C.; Ostini, S.; Pereira, R.T.L.; Scorvo Filho, J.D.; Shimomichi, P.Y.; Silva, D.A.; Melo Neto, J.E., 1989. Plano de manejo do Parque Estadual da Ilha Anchieta. IF - série registros, São Paulo, v. 01, p. 01-103.

HATCHER, B.G., 1990. Coral reef productivity: a hierarchy of pattern and process. Trends 
Ecol. Evolution, v. 5, p. 149-155.

JOLY, A.B., 1957. Contribuição ao conhecimento da flora ficológica marinha da Baía de Santos e arredores. Bol. Fac. Filos. Cienc. Let. Univ. São Paulo Ser Bot., São Paulo, n. 14, p. 1-220.

JOLY, A.B., 1965. Flora marinha do litoral norte do Estado de São Paulo e regiões circunvizinhas. Separata de: Bol. Fac. Filos. Cienc. Let. Univ. São Paulo Ser Bot., São Paulo, n. 294, p. 1-393.

JoHn, D.M.; LIEBERMAN, D.; LIEBERMAN, M., 1980. Strategies of data collection and analysis of subtidal vegetation. In: PRICE, J.H.; IRVINE, D.E.G.; FARNHAM, W.F. (Eds). The shore environment: proceedings of an international syposium held at the portsmouth polytechnic. London: Academic Press, v. 1. cap. 10, p. 265-284.

Kaliaperumal, N.; RAO, M.U., 1982. Seasonal growth and reproduction of Gelidiopsis variabilis (Greville) Schmitz. Journal of Experimental Marine Biology and Ecology, v. 61, p. $265-270$.

KENDRICK, G.A., 1991. Recruitment of coralline crusts and filamentous turf algae in the Galapagos Archipelago: effect of simulated sand scour, erosion and accretion. Journal of Experimental Marine Biology and Ecology, v. 147, p. 47-63.

KNUDSEN, J.W., 1966. Biological techniques: collecting, preserving, and illustrating plants and animals. Harper International Edition. New York: Harper \& Row. 525 p.

Kollmann, H.; Stachowitsch, M., 2001. Long-Term Changes in the Benthos of the Northern Adriatic Sea: A Phototransect Approach. Marine Ecology, v. 22, p. 135-154.

Kovach, W.L., 2003. MVSP - A MultiVariate Statistical Package for IBM-PC's, ver. 3.13f. Pentraeth: kovach Computing Services.

KREBS, C.J., 1999. Ecological methodology. $2^{\text {nd }}$ ed. New York: Addison-Welsey Educational Publishers. 620 p.

Legendre, L.; Legendre, P., 1984. Écologie numérique. 2 ed. Paris: Masson, v. 2, 335 p. (Collection d'écologie, 13).

LEONARD, G.H.; ClARK, R.P., 1993. Point quadrat versus video transect estimates of the cover of benthic red algae. Mar. Ecol. Prog. Ser., v. 101, p. 203-208.

LeVIngS, S.C.; Garrity, S.D., 1984. Grazing patterns in Siphonaria gigas (Mollusca, Pulmonata) on the rocky Pacific coast of Panama. Oecologia, v. 64. p. 152-159.

LEWIS, J.R., 1961. The littoral zone on rocky shores - a biological or physical entity ? Oikos, v. 12 , n. 2 , p. $280-301$.

LEWIS, J.R., 1964. The ecology of rocky shores. London:The English University Press. 300p. 
LitTLER, M.M.; LiTTLER, D.S., 1980. The evolution of thallus form and survival strategies in benthic marine macroalgae: field and laboratory tests of a functional form model. The American Naturalist, v. 116, p. 25-44.

LITTLER, M.M.; LiTTLER, D.S., 1984a. Models of tropical reef biogenesis:the contribution of algae. In: Round, F.E.; Chapman, D.J. (Eds.). Progress in phycological research. Amsterdam: Elsevier Biomedical Press. v.3. p.323-364.

LitTler, M.M.; LitTLER, D.S., 1984b. Relationships between macroalgal functional form groups and substrata stability in a subtropical rocky intertidal system. J. Exp. Mar. Biol. Ecol., Amsterdam, v. 74, p. 13-34.

LiTTLER, M.M.; LiTTLER, D.S., 1985. Nondestructive sampling. In: Littler, M.M.; Littler, D.S. (Eds). Handbook of phycological methods. Ecological field methods: macroalgae. Cambridge: Cambridge University Press. cap. 8, p. 161-175.

LitTLER, M.M.; MurRAY, S.N., 1975. Impact of sewage on the distribution, abundance and community structure of rocky intertidal macro-organisms. Marine Biology, v. 30, p. 277-291.

LitTler, M.M.; LitTleR, D.S.; TAYLOR, P.R., 1983a. Evolutionary strategies in a tropical barrier reef system: functional-form groups of marine macroalgae. J. Phycol., v. 19, p. 229-237.

LitTleR, M.M.; MARTZ, D.R.; LiTTLER, D.S., 1983b. Effects of recurrent sand deposition on rocky intertidal organisms: importance of substrate heterogeneity in a fluctuating environment. Marine Ecology Progress Series, v. 11, p. 129-139.

LitToRin, B.; GILEK, M., 1999. A photographic study of the recolonization of cleared patches in a dense population of Mytilus edulis in the northern Baltic proper. Hydrobiologia, v. 393, p. 211-219.

LIVELY, C.M.; RAIMONDI, P.T.; DELPH, L.F., 1993. Intertidal community structure: space-time interactions in the northern Gulf of California. Ecology, v. 74, n. 01, p. 162-173.

LuBCHENCO, J., 1980. Algal zonation in the New England intertidal community: an experimental analysis. Ecology, v. 61, n. 02, p. 333-344.

Lubchenco, J.; Menge, B.A., 1978. Community development and persistence in a low rocky intertidal zone. Ecological Monographs, v. 48, n. 01, p. 67-94.

Lubchenco, J.; Menge, B.A.; Garrity, S.D.; LubChenco, P.J.; AshKenas, L.R.; Gaines, S.D.; Emlet, R.; Lucas, J.; Strauss, S., 1984. Structure, persistence and role of consumers in a tropical rocky intertidal community (Tabouguilla Island, Bay of Panama).

J. Exp. Mar. Biol. Ecol., v. 78, p. 23-73.

LUNDÄLV, T., 1971. Quantitative studies on rocky-bottom biocoenoses by underwater 
photogrammetry. A methodological study. Thalassia Jugoslavica, v. 07, n. 01, p. 201208.

LÜNING, 1990. Seaweeds: their environment, biogeography and ecophysiology. New York: John Wiley. 527p.

MacArthur, R. H., 1969. Patterns of communities in the tropics. Biol. J. Linn. Soc., v. 1, p. 19-30.

MACEDO, I.M.; MAIS, B.P.; ZALMON, I.R., 2006. Comparison of rocky intertidal community sampling methods at the northern coast of Rio de Janeiro state, Brazil. Brazilian Journal of Oceanography, v. 54, n.2/3, p. 147-154.

Machado, K.R.S.S.; Chapman, A.R.O.; CoutinhO, R., 1992. Patch structure in a tropical rocky shore community in Brazil: a mosaic of successional states? Ophelia, Helsingor, v.35, n.3, p.187-195.

Maggs, C.A.; Milner, A.A.; Watts, W.; Whittle, M.R., 1979. The Oxford diving expedition to Cabo Frio, Brazil. Bull. Oxford Univ. Explor. Club. New. Serv., Oxford, v. 4, p. 13-40.

MCARThur, R.H., 1965. Patterns of species diversity. Biol. Rev., v. 40, p. 510-533.

MEESE, R.J.; TOMICH, P.A., 1992. Dots on the rocks: a comparison of percent cover estimation methods. J. Exp. Mar. Biol. Ecol., Amsterdam, v. 165, n. 1, p. 59-73.

Menconi, M.; BenedetTi-CeCCHI, L.; Cinelli, F., 1999. Spatial and temporal variability in the distribution of algae and invertebrates on rocky shores in the northwest Mediterranean. J. Exp. Mar. Biol. Ecol., Amsterdam, v. 233, p. 1-23.

Menge, B.A.; LuBCHENCO, J., 1981. Community organization in temperate and tropical rocky intertidal habitats: prey refuges in relation to consumer pressure gradients. Ecological Monographs, v. 51, n. 04, p. 429-450.

Menge, B.A.; LubChenCO, J.; AshKenAS, L.R., 1985. Diversity, heterogeneity and consumer pressure in a tropical rocky intertidal community. Oecologia, v. 65, n. 3, p.394-405.

Menge, B.A.; Allison, G.W.; Blanchette, C.A.; Farrell, T.M.; Olson, A.M.; Turner, T.A.; VAn TAMElen, P., 2005. Stasis or kinesis? Hidden dynamics of a rocky intertidal macrophyte mosaic revealed by a spatially explicit approach. J. Exp. Mar. Biol. Ecol., Amsterdam, v. 314, p. 3-39.

MOYSÉS, D.N., 2005. Influência da heterogeneidade do substrato no recrutamento de invertebrados bentônicos e sucessão ecológica do mediolitoral do costão rochoso da Ilha do Brandão, Angra dos Reis - RJ. 156f. Dissertação (Mestrado em Ecologia) - Instituto de Biologia, Universidade Federal do Rio de Janeiro, Rio de Janeiro.

MoysÉs, D.N.; Junqueira, A.O.; Lavrado, H.P.; Silva, S.H.G., 2006. Metodologia de 
monitoramento de costões rochosos com inclinação acentuada, por sobreposição temporal de imagens digitais de alta resolução. In: CONGRESSO BRASILEIRO DE BIOLOGIA MARINHA, 1., 2006, Niterói. Resumos... Niterói: Universidade Federal Fluminense, 2006. p. 183.

Neto, A.I., 2000. Observations on the biology and ecology of selected macroalgae from the littoral of Sao Miguel (Azores). Botanica Marina, v. 43, n. 05, p. 483-498.

Nicoletti, L.; Chimenz Gusso, C., 1995. Bryozoan assemblages and relation with environmental factors: An example from the Latium coast (Italy). Oebalia. v. 21, p. 93102.

NonAto, E.F., 1974. Ilha Anchieta: relatório preliminar. S.L.p. CONSERVE. 6p. (relatório apresentado à CONSERVE - Contruções e servições de engenharia Ltda, para o "Plano geral de exploração turística da Ilha Anchieta").

NonAtO, E.F.; PÈreZ, J.M., 1961. Observation sur quelques peuplements interdidaux de substrat dur dans la region d'Ubatuba. Cah. Biol. Mar., Paris, v. 2, p. 263- 270.

NORRIS, J. N.; FenICAL, W., 1982, Chemical defense in tropical marine algae. In: K. Rutzler; Macintyre, I.G. (Eds.). Atlantic barrier reef ecosystem, Carrie Bow Cay, Belize. I. Structure and Communities. Smith. Contr. Mar. Sci., v. 12, p. 417-431.

NYBAKKEN, J.W., 1997. Marine biology: an ecological approach. 4th edition. California: Addison-Wesley Publishing Company. 481p.

Oigman-Pszczol, S.S.; Fiqueiredo,M.A.O.; C REed, J.C., 2004. Distribution of benthic communities on the tropical rocky subtidal of Armação dos Búzios, Southeastern Brazil. Marine Ecology, v. 25, n. 03, p. 173-190.

Oliveira FiLho, E.C. de; MAYAL, E.M., 1976. Seasonal distribution of intertidal organisms at Ubatuba, São Paulo (Brazil). Rev. Bras. Biol., Rio de Janeiro, v. 36, n. 1, p. 305-316.

Oliveira Filho, E.C. de; PAUlA, E.J. de, 1983. Aspectos da distribuição vertical e variação sazonal de comunidades da zona das marés em costões rochosos do litoral norte do Estado de São Paulo. In: ENCONTRO DE MACRÓFITAS MARINHAS, 1., 1983, Arraial do Cabo. Anais... Arraial do Cabo: Instituto de Pesquisas da Marinha. Projeto Cabo Frio (147). p. 44-61.

ORTEGA, S., 1987. Habitat segregation and temporal variation in some tropical intertidal populations. J. Exp. Mar. Biol. Ecol., v. 113, p. 247-265.

Page, C.; Coleman, G.; Ninio, R.; Osborne, K., 2001. Surveys of benthic reef communities using underwater video. Townsville: Australian Institute of Marine Science, Standard Operational Procedure Number 7. 45p. 
PAULA, E.J. de, 1987. Zonação nos costões rochosos: região entremarés. In: SIMPÓSIO DOS ECOSSISTEMAS DA COSTA SUL E SUDESTE BRASILEIRA: SÍNTESE DOS CONHECIMENTOS, 1., p. 266-288. São Paulo: Academia de Ciências do Estado de São Paulo (Publicação ACIESP, 54).

Paula, E.J. de, 1988. O gênero Sargassum C. Ag. (Phaeophyta - Fucales) no litoral do Estado de São Paulo, Brasil. Bol. Bot.Univ. São Paulo, São Paulo, v. 10, p. 65-118.

PAUlA, E.J. de; Eston, V.R., 1989. Secondary sucession on an exposed rocky intertidal algal community of the state of São Paulo (Brazil). Bol. Bot.Univ. São Paulo, v. 11, p. 1-9.

PeCh, D.; Condal, A.R.; Bourget, E.; Ardisson, P.L., 2004. Abundance estimation of rocky shore invertebrates at small spatial scale by high-resolution digital photography and digital image analysis. J. Exp. Mar. Biol. Ecol., Amsterdam, v. 299, p. 185-199.

PereirA, R.C.; SoAres-Gomes, A., 2002. Biologia Marinha. Rio de Janeiro: Editora Interciência. $382 \mathrm{p}$.

PINDER, L.; Rosso, S., 1998. Classification and ordination of plant formations in the Pantanal of Brazil. Plant Ecology, v. 136, n. 2, p. 151-165.

Pitombo, F.B.; RATTO, C.C.; Belem, M.J.C., 1988. Species diversity and zonation pattern of hermatypic corals at two fringing reefs of Abrolhos Archipelago, Brazil. In: INTERNATIONAL CORAL REEF SYMPOSIUM, 6., 1988, Austrália. Proceedings...Austrália. p.02.

Putman, R., 1994. Community ecology. London, New York: Chapman \& Hall. 178p.

RAMIREZ, M.E., 1995. Recolección y colecciones cientificas de macroalgas marinas. In: Alveal, K.; Ferrario, M.E.; Oliveira, E.C.; Sar, E. (Eds). Manual de metodos ficologicos. Concepción: Anibal Pinto. cap.23. p. 417-428.

Ricklefs, R.E.; Miller, G.L., 1999. Ecology. New York: W.H. Freeman and Company. $822 \mathrm{p}$.

Rosso, S., 1990. Estrutura de comunidades intermareais de substrato consolidado das proximidades da Baía de Santos (SP, Brasil): uma abordagem descritiva enfatizando aspectos metodológicos. $217 \mathrm{f}$. Tese (Doutorado em Ecologia) - Instituto de Biociências, Universidade de São Paulo, São Paulo.

Rosso, S.; Borges, R.P. Análise computadorizada de imagens de vídeo como alternativa para o método dos contatos na quantificação dos recobrimentos percentuais de espécies sésseis de povoamentos de costão rochoso. Em revisão.

Russel, G., 1980. Application of simple numerical methods to the analysis of intertidal vegetation. In: Price, J.H.; Irvine, D.E.G.; Farnham, W.F. (eds). The shore environment. v. 1: Methods. London: Academic Press. cap. 6, p.171-192. 
SANDERS, H.L., 1968. Marine benthic diversity: a comparative study. Amer. Nat., v. 102, p. 243-282.

SEAPY, R.R.; LITTLER, M.M., 1978. The distribution, abundance, community structure and primary productivity of macroorganisms from two central California rocky intertidal habitats. Pac. Sci., v. 32, n. 3, p. 293-314.

Silva, P.C.; Basson, P.W.; Moe, R.L., 1996. Catalogue of the Benthic Marine Algae of the Indian Ocean. In: UNIV. OF CALIFORNIA PUBLICATIONS IN BOTANY 79. California: University of California Press. 1259 p.

SouZA, W.P., 1979. Experimental investigations of disturbances and ecological succession in a rocky intertidal algal community. Ecol. Monogr., v. 49, n. 3, p. 227-254.

StENECK, R.S., 1988. Herbivory on coral reefs: a synthesis. Proceedings of the Sixth International Coral Reef Symposium, v.1, p. 37-49.

STENECK, R.S.; DETHIER, M.N., 1994. A functional group approach to the structure of algaldominated communities. Oikos, v. 69, p. 476-498.

StePhenson, T.A.; STEPHEnson, A., 1949. The universal features of zonation between tidemarks on rocky coasts. The Journal of Ecology, v. 37, n. 2, p. 289-305.

StePhenson, T.A.; StePhenson, A., 1972. Life between tide marks on rocky shores. San Francisco: W.H. Freeman and Company. 425p.

STEWART, J. G., 1983. Fluctuations in the quantity of sediments trapped among algal thalli on intertidal rock platforms in Southern California. Journal of Experimental Marine Biology and Ecology, v. 73, p. 205-211.

STEWART, J.G., 1989. Establishment, persistence and dominance of Corallina (Rhodophyta) in algal turf. Journal of Phycology, v. 25, p. 436-446.

Sugihara, G.; MAY, R.M., 1990. Application of fractals in ecology. Trends in Ecology and Evolution, v. 5, p. 79-86.

SutHERLAND, J.P., 1978. Functional roles of Schizoporella and Styela in the fouling community at Beaufort, North Carolina. Ecology, v. 59, n. 2, p. 257-264.

SzÉCHY, M.T.M., 1996. Estrutura de bancos de Sargassum (Phaeophyta, Fucales) do litoral dos estados do Rio de Janeiro e São Paulo. 345f. Tese (Doutorado em Botânica) Insituto de Biociências, Universidade de São Paulo, São Paulo.

SzÉCHY, M. T. \& PAULA, E., 2000. Padrões estruturais quantitativos de bancos de Sargassum (Phaeophyta, Fucales) do litoral dos Estados do Rio de Janeiro e São Paulo, Brasil. Revta. brasil. Bot, v. 23, p. 121-132.

TAYLOR, W.R., 1960. Marine algae of the eastern tropical and subtropical coasts of the Americas. Michigan: University of Michigan Press. 870 p. 
Teixeira, V.L.; Pereira, R.C.; Marques Junior, A.N.; Leitão Filho, C.M.; Silva, C.A.R., 1987. Seasonal variations in infralittoral seaweed communities under a pollution gradient in Baía de Guanabara, Rio de Janeiro (Brazil). Ciência e Cultura, São Paulo, v. 39, n. 4, p. $423-428$.

TKACHENKO, K.S., 2005. An evaluation of the analysis system of video transects used to sample subtidal epibiota. J. Exp. Mar. Biol. Ecol., Amsterdam, v. 318, p. 1-9.

UnDERWOOD, A.J., 1990. Experiments in ecology and management: their logics, functions and interpretations. Australian Journal of Ecology, v. 15, p. 365-389.

Underwood, A.J.; ChAPMAn, M.G., 1997. Variation in algal assemblages on wave-exposed rocky shores. Mar. Fresh. Res., v. 49, p. 241-254.

Underwood, A.J.; Chapman, M.G., Connell, S.D., 2000. Observations in ecology: you can't make progress on processes without understanding the patterns. J. Exp. Mar. Biol. Ecol., v. 250 , p. 97-115.

VALIELA, I., 1984. Marine ecological processes. New York: Springer-Verlag.546p.

VillaçA, R.C.; Pitombo, F.B., 1997. Benthic communities of shallow-water reefs of Abrolhos, Brazil. Rev. Bras. Oceanogr., v. 45, p. 35-43.

WASHINGTON, H.G., 1984. Diversity, biotic and similarity indices: a review with special reference to aquatic ecossystems. Water Res., New York, v. 18, p. 653-694.

WeINBERG, S., 1981. A comparison of coral reef survey methods. Bijdragen tot de Dierkunde, v. 51, n. 2, p. 199-218.

WhitTAKer, R.H., 1972. Evolution and measurement of species diversity. Taxon, v. 21, p. 213-251.

WhORFF, J.S.; GRIFFING, L., 1991. A video recording and analysis system used to sample hard-bottom benthic communities. American Zoologist, v. 31, n. 5, p. A125.

WiHLM, J.L., 1968. Use of biomass emits in Shannon's formula. Ecology, Durham, v. 49, n. 1, p. $153-156$.

Williams, C.B., 1943. Area and number of species. Nature, v. 152, p. 264-267.

WoldA, H., 1981. Similarity indices, sample size and diversity. Oecologia, Berlin, v. 50, p. 57-85.

WynNE, M.J., 1986. A checklist of benthic marine algae of the tropical and subtropical western Atlantic. Can. J. Bot., Ottawa, v. 64, n. 8, p. 2239-2281. 

Capítulo 3 - Análise quantitativa da repartição espacial de povoamentos do P. Est. Ilha Anchieta

\section{ANEXO}
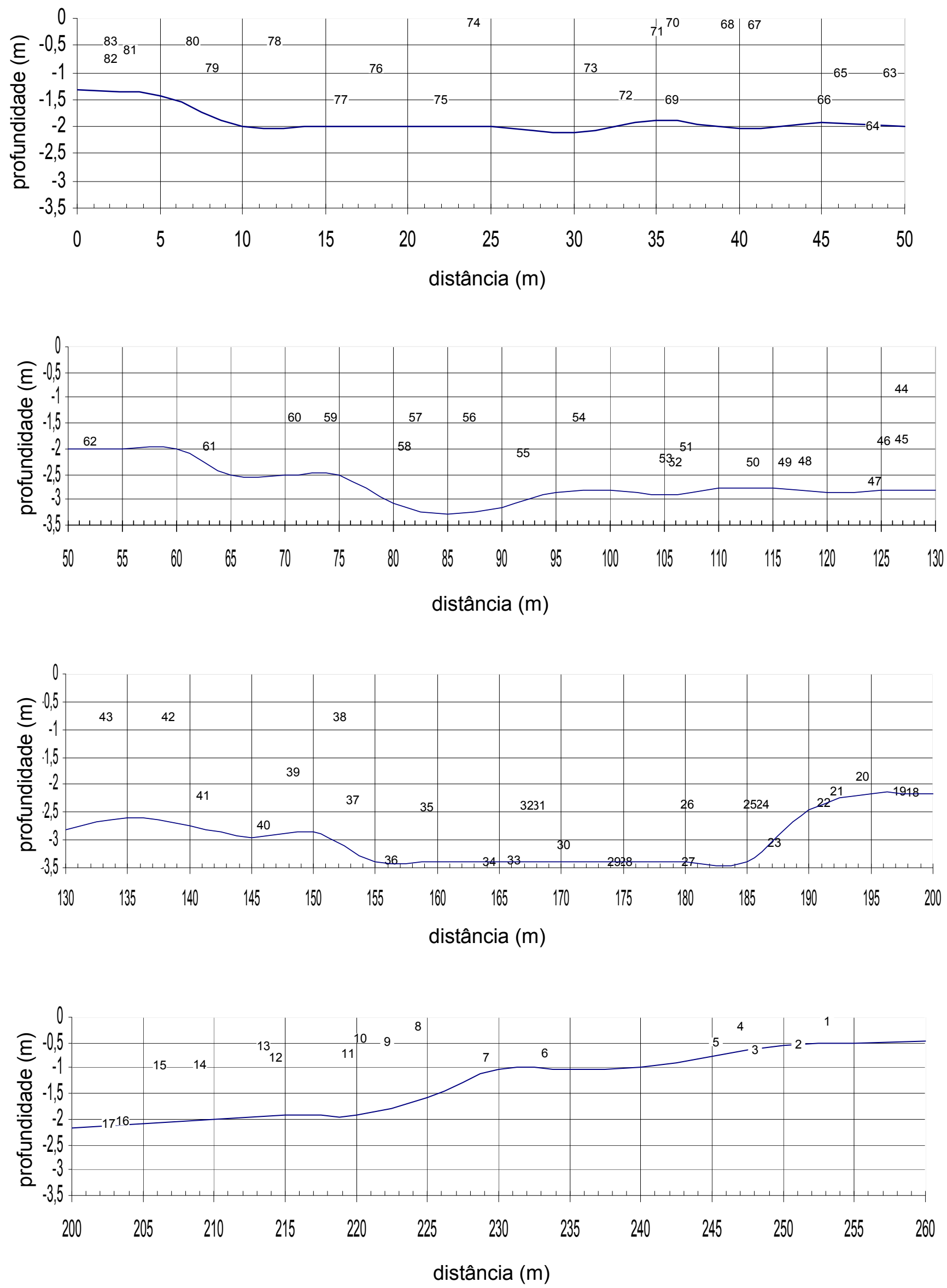

Figura A3.1 - Posicionamento dos elementos amostrais no verão. Os números são equivalentes aos usados nos dendrogramas para a estação. 

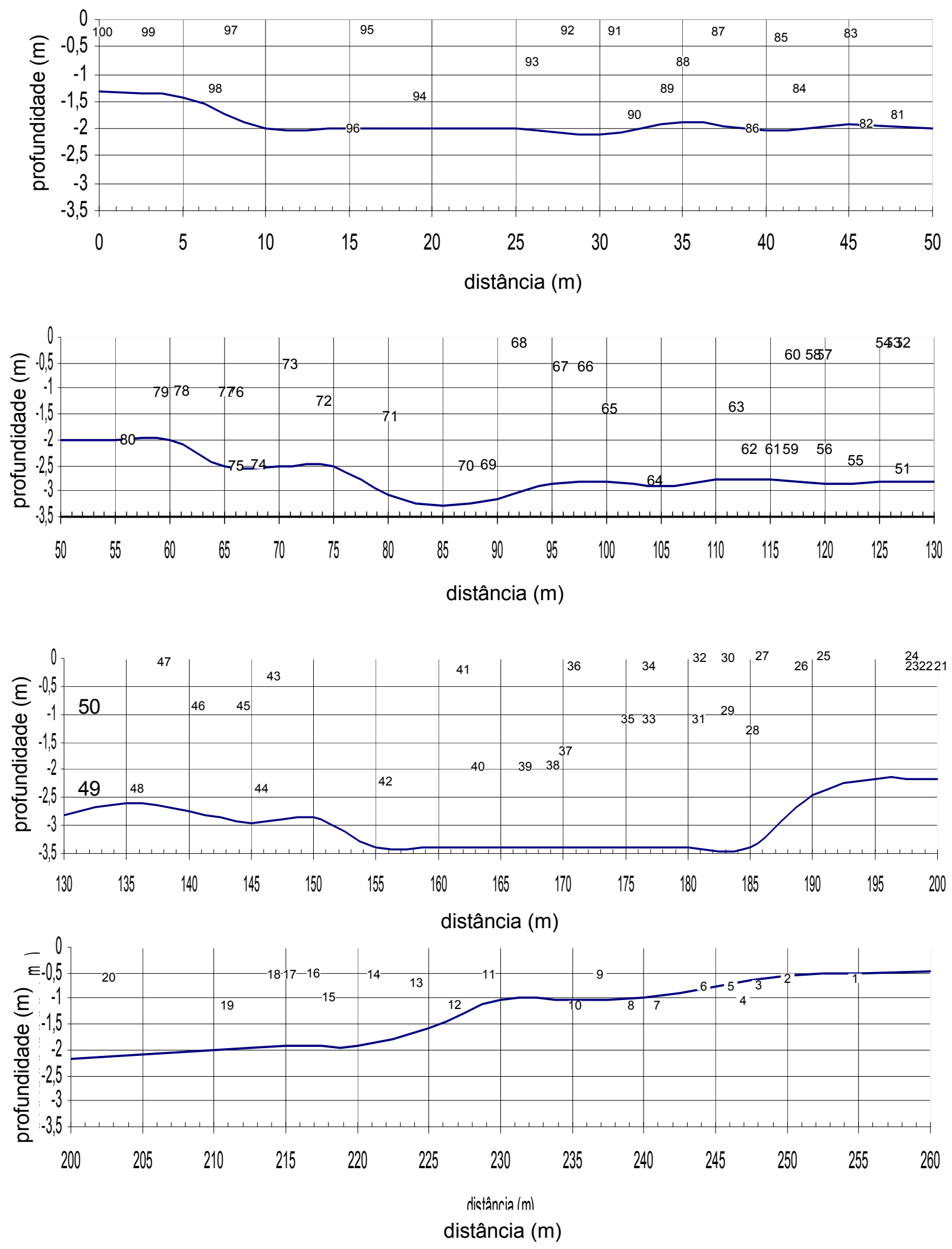

Figura A3.2 - Posicionamento dos elementos amostrais no inverno. Os números são equivalentes aos usados nos dendrogramas para a estação. 
ESTRUTURA E VARIAÇÃO ESPACIAL DOS POVOAMENTOS BANCO DE SARGASSUM, TAPETE DE AMPHIROA E JANIA, TAPETE DE ECTOPROCTA E TAPETE DE GELIDIOPSIS E HYPNEA EM TRECHO DO INFRALITORAL CONSOLIDADO DA ENSEADA DAS Palmas (Parque estadual de IlHa Anchieta, UBATUBA, SP) 



\section{Abstract}

The evaluation of settlements' micro-heterogeneity is important since it allows their defining as consistent ecological units which can be used in structural studies of hard bottom benthic communities. This study was performed on a $250 \mathrm{~m}$ infralittoral stretch at Palmas Bay, Anchieta Island State Park, and aimed at characterizing the specific composition, the spatial micro-repartition, the heterogeneity, the richness and diversity of the settlements Sargassum Bed (SGB), Amphiroa and Jania Turf (AJT), Ectoprocta Turf (ECT) and Gelidiopsis and Hypnea Turf (GHT). Sampling units, of $50 \mathrm{~cm}$ x $50 \mathrm{~cm}$ for SGB and $10 \mathrm{~cm} \mathrm{x}$ $10 \mathrm{~cm}$ for the turfs, were randomly positioned in each settlement. The percent cover was analysed for SGB and Ash Free Dry Weight (AFDW) for the turfs. Data were compared by Kruskall-Wallis non-parametric test and, if necessary, by post hoc test. Species/morphotypes were ranked with Ecological Value Index (EVI). Quantitative cluster analysis in Q mode was performed with the use of Morisita-Horn Similarity Index. Heterogeneity was analysed through Bray-Curtis Distance Index frequency distributions. The descriptors Richness, Shannon's Diversity Index and Simpson Diversity Index behaviour in function of area was analysed and sampling sufficiency was determined by selected Calleja points. Sixty-six species/morphotypes were found and the seaweeds, mainly of Rhodophyta Division, were the most represented as much in the total as in each settlement. Species of the Sargassum genus showed $90.5 \%$ of mean coverage in SGB, confirming the definition of the bed as a settlement. The species of Amphiroa and Jania genera were the most representative and accounted for $360 \mathrm{mg}$ of mean AFDW or $70 \%$ of AJT total biomass. Herdmania momus, which is hidden by other species coverage in field, showed the highest mean AFDW, of $265.2 \mathrm{mg}$ or 44\% of ECT total biomass, whereas Arborescent Ectoprocta, which is the morphotype that defines the turf, presented $97.8 \mathrm{mg}$ or $19 \%$ of total biomass. Gelidiopsis variabilis, Hypnea musciformis and $H$. spinella, species which define GHT, accounted for $151.1 \mathrm{mg}$ of mean AFDW or $44 \%$ of the turf's total biomass. Mean AFDW was between 0.38 and $0.60 \mathrm{~g} / 100 \mathrm{~cm}^{2}$. Settlements were homogeneous, with the formation of two significant clusters in Morisita-Horn Similarity Index-based dendrogram for the turfs, which presented themselves as two facies, and one cluster for SGB. In the case of AJT and ECT, one facie showed H. momus as the most important species and the other showed the defining species/morphotypes of the settlements as the most important. GHT showed G. variabilis as the most important in one facie and $H$. musciformis in the other. The heterogeneity analysis with Bray-Curtis Distance Index showed settlements homogeneity, except for ECT, which showed less homogeneous in spectral Richness analysis as well. Spectral analysis showed sampling sufficiency for all settlements in relation to Calleja points adopted. Richness and diversity spectra were diagonal and rectangular, respectively. Shannon Diversity Index was between 1.6 and 2.2 and Simpson Diversity Index, between 2.6 and 5.7. GHT was the most rich and diverse settlement, suggesting greater diversity of energy flows in it. Settlements can, therefore, be used as consistent ecological units, however more studies are necessary to confirm and extrapolate these results to other localities. 


\section{RESUMO}

A avaliação da micro-heterogeneidade de povoamentos é importante porque permite defini-los como unidades ecológicas consistentes para utilização em estudos de estrutura de comunidades bentônicas de substrato consolidado. Este estudo foi realizado em um trecho de $250 \mathrm{~m}$ de infralitoral da Enseada das Palmas, Parque Estadual de Ilha Anchieta, e objetivou caracterizar a composição específica, a micro-repartição espacial, a heterogeneidade, a riqueza e diversidade dos povoamentos Banco de Sargassum (BSG), Tapete de Amphiroa e Jania (TAJ), Tapete de Ectoprocta (TEC) e Tapete de Gelidiopsis e Hypnea (TGH). Os elementos amostrais, de $50 \mathrm{~cm} \times 50 \mathrm{~cm}$ para BSG e $10 \mathrm{~cm} \times 10 \mathrm{~cm}$ para os tapetes, foram dispostos aleatoriamente dentro de cada povoamento. Foram analisados o recobrimento percentual para BSG e a biomassa seca livre de cinzas (PSLC) para os tapetes. Os lotes de dados foram comparados por análise não-paramétrica de Kruskall-Wallis e, se necessário, por teste a posteriori. As espécies/morfotipos foram hierarquizadas pelo IVE. A análise de repartição espacial em modo $\mathrm{Q}$ foi realizada no plano quantitativo com o Índice de Similaridade de Morisita-Horn. A heterogeneidade foi analisada através da distribuição de freqüências das distâncias de Bray-Curtis. Analisou-se o comportamento dos descritores Riqueza, Índice de Diversidade de Shannon e Índice de Diversidade de Simpson em função da área e a suficiência amostral foi determinada a partir do uso de pontos Calleja. Foram encontradas 66 espécies/morfotipos, sendo as algas, principalmente as da Divisão Rhodophyta, as mais representadas tanto para o total quanto dentro de cada povoamento. As espécies do gênero Sargassum apresentaram 90,5\% de recobrimento médio no BSG, confirmando a definição deste banco como um povoamento. As espécies dos gêneros Amphiroa e Jania foram as mais representativas e somaram $360 \mathrm{mg}$ de biomassa média ou $70 \%$ da biomassa total de TAJ. Herdmania momus, espécie que em campo fica mascarada pela cobertura das demais espécies, apresentou maior valor médio de biomassa, de 265,2 mg ou $44 \%$ da biomassa total de TEC, enquanto Ectoprocta arborescente, morfotipo definidor do tapete, apresentou $97,8 \mathrm{mg}$ ou $19 \%$ da biomassa total. Gelidiopsis variabilis, Hypnea musciformis e $H$. spinella, definidoras de THG, somaram $151,1 \mathrm{mg}$ de biomassa média ou $44 \%$ da biomassa total do tapete. O PSLC médio ficou entre 0,38 e $0,60 \mathrm{~g} / 100 \mathrm{~cm}^{2}$. Os povoamentos se mostraram homogêneos, sendo que houve a formação de dois agrupamentos significativos com a utilização do Índice de Similaridade de Morisita-Horn para os tapetes, que se apresentaram na forma de duas fácies, e de um agrupamento para BSG. No caso de TAJ e TEC, uma fácie apresentou $H$. momus como espécie mais importante e a outra apresentou as espécies/morfotipos definidoras do povoamento como mais importantes. Já THG apresentou G. variabilis como mais importante em uma fácie e H. musciformis na outra. A análise de heterogeneidade com o Índice de Distância de Bray-Curtis mostrou homogeneidade dos povoamentos, exceto de TEC, que na análise espectral de Riqueza também mostrou-se menos homogêneo. A análise espectral evidenciou suficiência amostral para todos os povoamentos em relação aos pontos Calleja adotados. Os espectros de riqueza foram diagonais e os de diversidade foram retangulares. O Índice de Diversidade de Shannon ficou entre 1,6 e 2,2 e o de Diversidade de Simpson, entre 2,6 e 5,7. O povoamento TGH foi o mais rico e o mais diverso, sugerindo maior diversidade de fluxos de energia neste povoamento. Os povoamentos podem, portanto, ser utilizados como unidades ecológicas consistentes, mas mais estudos são necessários para que isso se confirme e possa ser extrapolado para outras localidades. 


\section{INTRODUÇÃO}

O método "Levantamento Fisionômico" é uma alternativa rápida e eficaz de descrição estrutural de comunidades bentônicas de substrato consolidado (ver Capítulos 2 e 3). Uma vez definidas a variedade, importância relativa e repartição espacial dos povoamentos, é necessário verificar se os mesmos podem ou não ser considerados unidades ecológicas (Whittaker, 1965), afinando-se a escala de estudo e investigando-se a variabilidade dentro de cada um deles (micro-heterogeneidade, sensu Forman \& Godron, 1986).

O aumento da disponibilidade de substrato causado pelas espécies estruturadoras ou espécies fundadoras (Dayton, 1972) pode ser substancial, principalmente devido ao aumento na diversidade de hábitats, como os interstícios e a superfície da espécie fundadora (Seed \& Suchanek, 1992). Este aumento de substrato leva a um aumento da diversidade de espécies (Osman \& Whitlatch, 1995), a qual só pode ser estudada através de uma avaliação mais fina dos povoamentos, tendo em vista que a principal desvantagem apresentada pelo método “Levantamento Fisionômico" é a perda de espécies pouco abundantes e a conseqüente subestimação da diversidade. A caracterização de cada um dos povoamentos permitiria a complementação das informações. Esses estudos complementares podem ser realizados tanto em uma abordagem ecológica, semelhante à aleatória estratificada (Krebs, 1999), como em taxonômica.

No Brasil, existem alguns trabalhos abordando variação espaço-temporal de espécies em alguns povoamentos, como bancos de mexilhões (p.ex. Petersen et al., 1986; Jacobi, 1987), Banco de Gracilaria (Silva et al., 1987), bancos de algas calcárias articuladas (Arantes et al., 1995), bancos de Amphiroa e Sargassum (Sabino \& Villaça, 1999), Banco de Ulva (Guimaraens \& Coutinho, 2000), bancos de cracas (Junqueira et al., 2000), Banco de Sargassum (Széchy, 1997; Széchy \& Paula, 2000), Banco de Halodule wrightii (Paula et al., 2003), Banco de Isognomon (Robles, 2003), bancos de rodolitos (Gherardi, 2004). Em relação aos tapetes, apesar de serem abundantes em comunidades marinhas tropicais, poucos estudos 
no mundo tentaram caracterizá-los quantitativamente (Stuercke \& Mcdermid, 2004).

É sabido que os métodos utilizados em abordagens destinadas a quantificar espécies não amostram adequadamente as raras, subestimando ou superestimando-as (Foster et al., 1991; Meese \& Tomich, 1992; Dethier et al., 1993). De qualquer modo, para uma caracterização mais fina dos povoamentos estes métodos são necessários e o protocolo amostral ideal passa a ser operacionalmente viável até mesmo por técnicas destrutivas, admitindo a identificação taxonômica espécie por espécie, inclusive daquelas que são crípticas ou menos conspícuas (Berchez et al., 2005).

A utilização de programas destrutivos de amostragem pode ocorrer em diversos tipos de estudos e para diferentes fins, como por exemplo, no caso de algas, que são colhidas para fornecer dados sobre alocação de recursos, constituintes bioquímicos, dinâmica de populações e associações epifíticas e epifaunais (De Wreede, 1985).

Entretanto, a amostragem destrutiva deve ser realizada com cuidado. Antes de qualquer programa ser escolhido, deve-se considerar com cuidado se a informação pode ser igualmente bem obtida por um programa de amostragem não destrutivo. A amostragem destrutiva acarreta a destruição do hábitat local. Além disso, medidas repetitivas dos estoques naturais na mesma área vão ser alteradas pelos efeitos das amostragens anteriores. Isto é particularmente verdadeiro para espécies com vida longa e pequena capacidade de recrutamento (De Wreede, 1985).

A partir de técnicas destrutivas pode-se obter o descritor primário biomassa. $\mathrm{O}$ uso da biomassa impõe certas dificuldades, pois implica num extenuante e tedioso trabalho de triagem. Muitas vezes a escolha deste descritor torna-se incompatível com os prazos disponíveis para apresentação dos resultados, especialmente em trabalhos de acompanhamento temporal e, além disso, demanda um trabalho adicional considerável no processo de pesagem do material (Boudouresque, 1971; Rosso, 1990). Entretanto, segundo Hulbert (1971), é de comum acordo entre os ecologistas que a importância das espécies deve 
ser preferencialmente baseada em quantidades medidas na forma de biomassa ou de produtividade, desde que possível.

A biomassa, segundo Magurran (1988), é a medida de abundância mais universalmente aplicável e que, deixando de lado o problema de gasto de tempo para obtenção de dados, apresenta inúmeras vantagens, tais como: 1) é medida de mais fácil compreensão e pode ser facilmente extrapolada para diversos grupos de organismos; 2) provê uma comparação mais completa entre diversidades de diferentes grupos; 3) trata-se de uma variável de caráter contínuo. Segundo Santelices (1980) e Mcquaid \& Branch (1984), a partir do uso da biomassa expressam-se melhor os padrões de fluxo energético pela comunidade, os quais estão intimamente relacionados com a complexidade de uma comunidade. Segundo Elton (1958) e Kikkawa (1986), a complexidade de uma comunidade estaria relacionada com o número de espécies nela presente, número de interações entre estas espécies e a força destas interações. Já para Margalef (1995) o grau de complexidade estaria relacionado à quantidade de energia disponível e à eficiência de exploração desta energia, ou seja, quanto mais complexa a comunidade, maior a eficiência na exploração da energia. Esta relação conecta complexidade com diversidade, pois quanto mais diversa e eqüitativa se apresenta a comunidade, maior será a eficiência na exploração da energia e, segundo MacArthur (1955), será menos provável que a densidade de seus constituintes mude em resposta a alguma perturbação.

Portanto, quando o descritor biomassa é utilizado no cálculo da diversidade pode representar a liberdade de escolha da energia por um determinado trajeto através do ecossistema (Frontier, 1983), diferentemente do que acontece quando se utiliza o descritor número de indivíduos ou recobrimento (Wihlm, 1968; Harvey \& Godfray, 1987).

A biomassa expressa na forma de peso seco tem sido muito utilizada tanto em estudos da fauna quanto da flora de regiões marinhas de substrato consolidado (Muñoz \& Pereira, 1998; Yaobin, 1999; Amado Filho et al., 2003; Marins-Rosa et al., 2005, entre outros). 
Por sua vez, o peso seco livre de cinzas (PSLC) é indicado especialmente quando o material apresenta depósitos minerais, de carbonatos ou não, e representa estritamente o conteúdo calórico e de carbono, eliminando-se a água e a presença de eventuais carapaças, esqueletos e/ou detritos sólidos presentes no trato digestivo de alguns organismos (Osse, 1995). Salonen et al. (1976) demonstraram que a biomassa expressa como peso de carbono orgânico pode ser convertida para unidades de energia com razoável acuidade, usando-se o fator de conversão de $46 \mathrm{k}$ Joules/g carb.org., que segundo os autores deve ser válido para a maioria dos invertebrados aquáticos. Para fitoplâncton, o fator de conversão foi de $44,9 \mathrm{k}$ Joules/g carb.org. (Platt \& Irwin, 1973), bem próximo do determinado para os animais.

Segundo Margalef (1995), a expressão da biomassa em termos de carbono orgânico é muito aceitável, porque se compara bem com as medidas de produção que, pelo menos para a produção primária, se pode dar em carbono. Aceita-se que, em média, $1 \mathrm{~g}$ de carbono orgânico equivale a 2,4 g de matéria orgânica sem cinzas.

Para Ballesteros (1986) o PSLC é a quantificação ótima, embora com o inconveniente de exigir muito trabalho na sua determinação. A despeito disso, o PSLC tem sido usado em alguns estudos como expressão da biomassa (p.ex. Rosso, 1990; Osse, 1995; Robles, 2003). Dentre estes, destaca-se o de Rosso (1990), que foi o primeiro trabalho no Brasil integrando fauna e flora numa abordagem quantitativa baseada em biomassa (PSLC), com espécies identificadas a partir de material obtido por amostragem destrutiva e triado finamente em laboratório.

Já a amostragem não-destrutiva deve ser preferida quando for possível realizá-la sem comprometimento das informações a serem obtidas, já que não envolve alterações no ambiente (Goodall, 1952; Bohnsack, 1979). A partir dela, pode ser obtido o descritor primário recobrimento percentual, que segundo Russel (1980) e Greigh-Smith (1983) é mais indicado para a classificação das comunidades por ser prontamente observado em campo e mais facilmente quantificado. Além disso, pelo fato do espaço ser o recurso limitante de maior peso 
nos costões, o uso do recobrimento de organismos sésseis para a avaliação da estrutura das comunidades parece ser mais interessante do que outros descritores (Connell, 1972).

Estimativas de recobrimento podem ser obtidas por diferentes métodos, como estimativa visual, interseção de pontos e métodos de classificação, supervisionados ou não, de imagens digitais (Gounot, 1969; Foster et al., 1991; Whorff \& Griffing, 1992; Meese \& Tomich, 1992; Dethier et al., 1993; Miller \& Ambrose, 2000; Pech et al., 2004). Entretanto, qualquer um destes métodos apresenta erros potenciais para a estimação de propriedades de espécies, como abundância e diversidade, principalmente quando consideradas as espécies menos abundantes ou raras.

No Brasil, muitos dos trabalhos de ecologia de comunidades bentônicas de infralitoral consolidado utilizaram recobrimento percentual como descritor primário (Maggs et al., 1979; Teixeira et al., 1987; Figueiredo et al., 2004; Oigman-Pszczol et al., 2004; Eston et al., 1986; Villaça \& Pitombo, 1997; Costa Jr. et al., 2002).

A caracterização da micro-heterogeneidade de povoamentos do Parque Estadual da Ilha Anchieta através de metodologia tradicional, seja ela a quantificação da biomassa ou do recobrimento percentual de espécies, é importante não só para um conhecimento mais aprofundado das comunidades da Ilha, mas também como um passo inicial para a definição dos povoamentos como comunidades estruturalmente constantes no espaço e que, portanto, podem ser utilizadas como unidades ecológicas em outros estudos.

\section{OBJETIVOS}

Este estudo objetiva avaliar qualitativa e quantitativamente a composição específica dos povoamentos Banco de Sargassum, Tapete de Amphiroa e Jania, Tapete de Ectoprocta e Tapete de Gelidiopsis e Hypnea e verificar sua variação espacial em um trecho de 250m do infralitoral da Enseada das Palmas (Parque Estadual da Ilha Anchieta), através da utilização dos métodos da interseção de pontos ou análise de biomassa, tradicionais no estudo de 
ecologia de comunidades bentônicas de substrato consolidado (Abordagem 4 do Método "Levantamento Fisionômico" de Berchez et al., 2005).

\section{Materiais E Métodos}

\section{Local}

O estudo foi realizado em trecho de $250 \mathrm{~m}$ do costão leste da Praia do Presídio, na Enseada da Palmas, Parque Estadual de Ilha Anchieta, litoral norte do Estado de São Paulo $\left(23^{\circ} 32^{\prime} 18.6^{\prime \prime} \mathrm{S} 45^{\circ} 03^{\prime} 51.0^{\prime \prime} \mathrm{W}\right.$ até $\left.23^{\circ} 32^{\prime} 11.5^{\prime} \mathrm{S} 45^{\circ} 03^{\prime} 45.5^{\prime \prime} \mathrm{W}\right)$.

\section{1) Amostragem dos povoamentos selecionados}

Assim como nas etapas anteriores, os mergulhos foram sempre realizados em duplas. Entretanto, nesta etapa a sua presença foi fundamental para a eficácia da amostragem, devido ao fato de que os materiais que fazem parte desta etapa (sacos de coleta, espátulas, caderno de PVC, quadrats) devem ficar todos amarrados ao corpo do pesquisador e, portanto, com o risco de emaranharem-se, elevando em muito o tempo de coleta. A divisão dos materiais com a dupla minimiza bastante este problema.

A avaliação qualitativa e quantitativa da composição especifica de cada povoamento e de sua constância espacial foi realizada em povoamentos selecionados a partir dos dados obtidos na Abordagem 3 (Capítulo 3).

Foi realizada amostragem aleatória (Krebs, 1999) por povoamento, utilizando o mesmo sistema de coordenadas já descrito no Capítulo 3. Como os povoamentos escolhidos podiam ser encontrados ao longo de toda a área de estudo, realizou-se um sorteio inicial de pontos ao longo da totalidade de sua extensão horizontal. Caso os povoamentos estivessem presentes nos pontos sorteados, entendia-se um segundo cabo e se realizava um segundo sorteio baseando-se na amplitude vertical do povoamento naquele ponto. Entretanto, caso os povoamentos não fossem encontrados nos pontos sorteados, determinava-se o local mais próximo dali onde o povoamento em estudo poderia ser encontrado. Uma vez encontrado o 
povoamento se estabelecia o ponto a ser amostrado através de sorteio, na vertical.

Para viabilizar a amostragem, os elementos amostrais eram posicionados em locais com superfície o mais plana possível que acomodasse o tamanho dos mesmos.

Foram utilizados elementos amostrais de forma quadrada, com $50 \mathrm{~cm}$ de lado no caso do povoamento Banco de Sargassum, e $10 \mathrm{~cm}$ de lado para os povoamentos Tapete de Amphiroa e Jania, Tapete de Ectoprocta e Tapete de Gelidiopsis e Hypnea segundo a metodologia proposta por De Wreede (1985). Foram observadas ainda as recomendações de Villaça (1990), Ballesteros (1986), Magurran (1988) e Rosso (1995) que dão preferência a um grande número de pequenos elementos amostrais em contraposição a um número pequeno de elementos com grande área. Foram analisados pelo menos 20 elementos amostrais por povoamento.

Pringle (1984), baseado nos resultados de um estudo comparativo de eficiência (precisão e tempo gasto) de diversos tamanhos de elementos amostrais para amostragem de organismos bentônicos, sugeriu o uso de unidades amostrais de $50 \mathrm{~cm}$ x $50 \mathrm{~cm}\left(0,25 \mathrm{~m}^{2}\right)$ ou menores para estudos de macrófitas na região sublitorânea. Este tamanho de elemento amostral também foi adotado por outros autores em vários estudos de Banco de Sargassum (Yoshida et al., 1963; Russel, 1972; Paula \& Oliveira Filho, 1980; Critchley, 1981; Oliveira Filho \& Paula, 1983; Ang Jr., 1986; Hara et al., 1986; Paula \& Eston, 1987; Koh et al., 1989; Munda, 1990; Eston \& Bussab, 1990).

Já o tamanho de $10 \mathrm{~cm}$ x $10 \mathrm{~cm}\left(100 \mathrm{~cm}^{2}\right)$ mostrou-se em outros estudos (Petersen et al., 1986; Rosso, 1987, 1990; Osse \& Rosso, 1989) como suficientemente pequeno para identificar padrões internos de repartição e distribuição das espécies presentes e ao mesmo tempo suficientemente grande para viabilizar o trabalho de raspagem no local de estudo (Osse, 1995). Segundo Rosso (1995), este tamanho é muito conveniente quando se deseja evidenciar a escala fina do mosaico dos costões.

Considerando-se o conhecimento empírico sobre Banco de Sargassum, optou-se pelo 
método de intersecção de pontos aleatórios (Gounot, 1969) para estimar o recobrimento percentual, já que este é o método aparentemente mais preciso no caso de comunidades com populações de espécies distribuídas em micro-escala (Foster et al., 1991). Tendo em vista as limitações apontadas para este método por Dethier et al (1993), foi utilizado um grande número (em torno de $50 \%$ ou 60 pontos) de pontos por elemento amostral.

Para tanto, o elemento amostral foi subdividido com fios de nylon, formando um reticulado, de tamanhos iguais, com um total de 121 pontos de contato. O número de pontos desejado foi então sorteado aleatoriamente para cada amostragem e estes foram marcados com tinta colorida, (Coimbra, 1998). Além disso, ao final da contagem foi feita uma amostragem empírica para tentar minimizar a perda de espécies raras. A essas espécies, não detectadas na contagem de pontos, foi atribuído um valor de $0,5 \%$ (Foster et al., 1991).

Neste caso, tendo em vista o objetivo de quantificar o recobrimento percentual por espécies, foram avaliados o recobrimento dos vários estratos, se existentes, podendo o total do recobrimento percentual de cada elemento amostral ultrapassar $100 \%$.

No caso dos povoamentos Tapete de Amphiroa e Jania, Tapete de Ectoprocta e Tapete de Gelidiopsis e Hypnea foi feita a avaliação da biomassa, devido ao fato de ser muito difícil a identificação em campo das espécies componentes destes povoamentos.

Os organismos presentes na área de $100 \mathrm{~cm}^{2}$ foram coletados com auxílio de espátula e acondicionados em sacos de coleta de pano numerados (a numeração dos mesmos era marcada em caderno de PVC de maneira a identificar o ponto sorteado), os quais eram entregues para o mergulhador auxiliar. Após a finalização da coleta, a fixação do material foi feita com o uso de formalina $4 \%$ salina em potes plásticos etiquetados com informações da coleta (povoamento, data, posicionamento horizontal e vertical), os quais foram acondicionados em sacos pretos e em baldes herméticos.

No laboratório, transcorridos pelo menos 30 dias de imersão no fixador, seguindo o exposto por Howmiller (1972) que dá este período como suficiente para a estabilização da 
biomassa dos organismos preservados, os organismos dos potes foram despejados em uma peneira com tela de nylon com malha de aproximadamente $900 \mu \mathrm{m}$ e lavados em água corrente. Esta malha, segundo Nybakken (1982) e Holme \& McIntire (1984) retém a fração macrobêntica marinha que, portanto, foi o objeto deste estudo.

O material retido na peneira foi transferido para uma placa de Petri, mantida constantemente umedecida com água destilada. Desta placa maior eram retiradas pequenas porções, as quais eram transferidas para uma placa menor e triadas ao estereomicroscópio. Só foram considerados para a análise da biomassa os organismos sésseis e semi-sésseis.

As identificações foram feitas até o nível mais próximo de espécie possível, formandose deste modo grupos mono-específicos ou grupos mono-típicos, estes últimos quando a identificação não era possível devido à falta de especialistas ou a dificuldade de identificação sem conseqüente perda de biomassa.

As técnicas utilizadas para obtenção dos dados de biomassa por lote mono-específico ou mono-típico por elemento amostral seguiram basicamente as apresentadas por Niell (1977), Holme \& McIntire (1984), Rosso (1990) e Osse (1995): 1) os lotes foram inicialmente colocados em cadinhos cerâmicos previamente tarados e identificados; 2) estes cadinhos foram encaminhados para estufa e mantidos a $60^{\circ} \mathrm{C}$ por $24 \mathrm{~h}$ para eliminação da água associada aos organismos; 3) após este período, foram transferidos para dessecadores onde permaneciam por mais $24 \mathrm{~h} ; 4)$ após esse período, os cadinhos foram pesados em balança analítica Metler-Toledo, com precisão de 0,00005g; 5) efetuadas as pesagens e, portanto de posse de todos os resultados referentes ao peso seco de cada lote, passava-se a queima destes, visando a eliminação de toda a matéria orgânica presente; 6) os cadinhos eram colocados dentro de uma mufla e aí mantidos por $6 \mathrm{~h}$ a $550^{\circ} \mathrm{C}$; 7) após o desligamento da mufla, esperava-se um período de $12 \mathrm{~h}$ para sua abertura, permitindo a transferência dos cadinhos novamente aos dessecadores; 8) novo processo de pesagem foi realizado para obtenção do peso das cinzas restantes nos cadinhos, correspondentes apenas à porção inorgânica dos 
organismos, como conchas, esqueletos, incrustações, etc.; 9) os valores de PSLC foram obtidos a partir da subtração dos valores obtidos no item 4 dos valores obtidos no item 8.

\section{2) Análise de dados e apresentação dos resultados}

Foram estabelecidas duas frentes principais de análise: o estudo populacional (abundâncias específicas) e a análise da estrutura da comunidade, dividida em dois blocos: heterogeneidade espacial e diversidade (índices).

Os dados foram inseridos em matrizes quantitativas de espécies/morfotipos versus elemento amostral. Os descritores analíticos primários utilizados foram o recobrimento percentual ou a biomassa, apresentados em termos de valores médios das réplicas e respectivos intervalos de confiança (95\%).

Para comparação de lotes referentes a esses resultados, foi realizada análise nãoparamétrica de Kruskall-Wallis e, caso encontradas diferenças significativas, teste a posteriori de comparação de postos, ambos com a utilização do programa SPSS 12.0.

Para se estabelecer com maior clareza a identidade de cada povoamento, as espécies foram hierarquizadas com a utilização do descritor sintético Índice de Valor Ecológico (IVE) proposto por Pinder \& Rosso (1998), que leva em consideração a totalidade das espécies representadas nos diversos elementos amostrais, dispensando o estabelecimento arbitrário do grupo principal. O IVE quantifica a importância de cada espécie em relação àquela, hipotética ou não, que se apresente como dominante em todos os elementos amostrais, sendo sua fórmula a que segue:

$$
\mathbf{I V E}=\frac{\sum_{j=1}^{N} r k_{i, j}}{\sum_{j=1}^{N} R K_{j}} \text { onde, }
$$

$\mathrm{N}=$ número total de elementos amostrais

$\mathrm{RK}_{\mathrm{j}}=$ valor do mais alto posto no elemento amostral $\mathrm{j}$

$\mathrm{rk}_{\mathrm{ij}}=$ posto da espécie i no elemento amostral $\mathrm{j}$, correspondendo a $\left[\mathrm{RK}_{\mathrm{j}}-(\mathrm{P}-1)\right]$ sendo que

$\mathrm{P}=$ posição da espécie numa escala decrescente de abundâncias.

O valor de IVE sempre varia de 0 a 1, facilitando a interpretação dos dados (Borges, 
1996). O processamento dos valores deste descritor sintético foi realizado no programa

DivCalc 1.0 para Windows 98 (Rosso, não publicado).

\section{3) Análise da repartição espacial em modo $Q$}

Esta análise foi realizada apenas no plano quantitativo, com a utilização do Índice de Similaridade de Morisita modificado por Horn, que, segundo Wolda (1981), é um índice bastante adequado, pois é pouco influenciado pela riqueza e pelo tamanho das amostras, mas é influenciado por alterações nas abundâncias das espécies mais abundantes.

$$
\mathrm{S}_{\mathrm{MOR}-\mathrm{HORN}}=2 \times \sum_{i=1}^{n} \frac{\left(e_{i a} \times e_{i b}\right)}{\left(d_{e i a} \times d_{e i b}\right) E_{a} E_{b}}
$$

Onde: "e $\mathrm{i}_{\mathrm{ia}}$ " e " $\mathrm{e}_{\mathrm{ib}}$ " são os efetivos de cada espécie "i" respectivamente nas amostras "a" e "b" "E $E_{a}$ " e "E $E_{b}$ " são os efetivos totais de todos os povoamentos respectivamente nas amostras "a" e "b".

$$
d_{e i}=\frac{\sum_{i=1}^{n} e_{i}^{2}}{E_{i}^{2}}
$$

As planilhas quantitativas foram processadas utilizando o programa MVSP $3.13 \mathrm{f}$ (Kovach, 2003) resultando na obtenção de dendrogramas. Foi utilizada a estratégia da média ponderada - WPGMA- que nivela os pesos dos grupos de diferentes tamanhos nas sucessivas fusões e assegura espaço-conservação (Legendre \& Legendre, 1984).

Optou-se pela adoção do cálculo dos níveis significativos de fusão dos elementos. Para determinar a significância dos agrupamentos foram estabelecidos limites de similaridade e dissimilaridade para $p=0,05$. A determinação destes níveis críticos de significância se deu por meio da utilização do aplicativo RANDMAT para Windows XP (Rosso, não publicado), que permitiu a realização de 1000 aleatorizações sucessivas das ocorrências de espécies de todos os elementos amostrais. Para cada par de elementos amostrais foi calculado o índice escolhido nos 1000 possíveis arranjos, após o que se estabeleceu a distribuição de freqüências.

O descritor sintético simples da heterogeneidade entre pares de amostras (descritor de $\beta$-diversidade) utilizado nesta etapa permitiu a detecção de grupos qualitativa e 
quantitativamente homogêneos.

Os valores de IVE das espécies de cada grupo formado com a utilização do Índice de Similaridade Quantitativo de Morisita-Horn foram representados graficamente, permitindo reconhecer as espécies mais características de cada um deles. Esta hierarquização assume um valor ecologicamente definido permitindo, por exemplo, referir-se a um dado grupo como "grupo de tal ou tais espécies principais", conceito que se aproxima da idéia de Valor Biológico, como um atributo real de sucesso bio/ecológico do povoamento considerado.

\section{1) Avaliação da heterogeneidade}

Para melhor entendimento da repartição espacial dentro de cada um dos povoamentos e para se ter uma noção mais clara da homogeneidade dos mesmos, analisou-se a distribuição de freqüências de distâncias entre os elementos amostrais, utilizando-se o Índice de Distância de Bray-Curtis. Para cada povoamento, as distâncias foram distribuídas entre dez classes arbitrariamente definidas. Esta distribuição é uma forma de visualização das dissimilaridades entre réplicas, de forma que o número de modas corresponde ao número de facetas apresentado por aquele povoamento. Uma distribuição formando um histograma que se configure como unimodal e com maior participação de valores mais baixos indica uma grande homogeneidade interna ao povoamento, já uma distribuição bi ou polimodal das distâncias, e/ou existência de valores altos indica heterogeneidade interna (Boudouresque \& Luck, 1972). Os níveis críticos de significância foram calculados com o software RANDMAT para Windows XP (Rosso, não publicado).

\section{4) Riqueza e diversidade}

$\mathrm{Na}$ abordagem da diversidade foram analisadas: a Riqueza S, a Diversidade de Shannon-Wiener (H') calculada com base 2 (Wihlm, 1968; Washington, 1984) e a Diversidade de Simpson (1/入) (Hill, 1973, Magurran, 1988), sendo:

$$
\mathbf{H}^{\prime}=-\sum_{i=1}^{S} p_{i} \log _{2} p_{i}
$$




$$
\lambda=\sum_{i=1}^{S} p_{i}^{2}
$$

Onde: $p_{i}=a$ importância relativa, originalmente a proporção de indivíduos da iésima espécie em relação ao efetivo total da amostra

O comportamento dos valores em função da área amostral foi determinado utilizando uma técnica bootstrap. Foram amostradas sub-áreas crescentes compostas por números variados de elementos não obrigatoriamente contíguos e selecionados aleatoriamente em cada lote, estabelecendo finalmente as médias e respectivos intervalos de confiança por sub-área (p $=0,05)$. Isso foi realizado com o programa Estimate S Win 7.5.0 (Colwell, 1997).

Com base nos recobrimentos percentuais e nas biomassas, os referidos valores médios dos descritores foram ajustados a uma função que produzia os menores desvios através do programa CAJUS (Santos, 1978).

Além disso, determinaram-se os valores dos índices correspondentes a uma área extrapolada de $4000 \mathrm{~cm}^{2}$ para os povoamentos Tapete de Amphiroa e Jania, Tapete de Ectoprocta e Tapete de Gelidiopsis e Hypnea e de $100000 \mathrm{~cm}^{2}$ para o povoamento Banco de Sargassum (área de 40 elementos amostrais).

Os espectros índice versus área obtidos a partir dessa metodologia foram utilizados então para a avaliação de suficiência amostral, através da determinação de algumas relações custo-benefício expressas por diferentes "Pontos Calleja" (Ballesteros, 1986) (Tabela 4.1).

Tabela 4.1 - Pontos Calleja definidos para os descritores de diversidade adotados. Custo $=$ área adicional $\mathrm{em}^{2} \mathrm{~cm}^{2}$, Benefício $=$ máxima variação aceita no índice, Tapetes $=$ Tapete de Amphiroa e Jania, Tapete de Ectoprocta e Tapete de Gelidiopsis e Hypnea.

\section{Custo}

\section{Benefício}

\begin{tabular}{cccc}
\hline & Banco de Sargassum & Tapetes & \\
\hline Riqueza (S) & 500 & 200 & 1 \\
Diversidade de Shannon & 250 & 100 & 0,005 \\
Diversidade de Simpson & 250 & 100 & 0,05 \\
\hline
\end{tabular}

Segundo Ballesteros (1986), os valores de Pontos Calleja ficam a critério de cada investigador. Rosso (1995) cita diversos autores e as diferentes relações custo-benefício utilizadas por estes. No presente estudo, levou-se em consideração outros estudos de ecologia 
de comunidades realizados no Estado de São Paulo, como os de Osse (1995) e Borges (1996), sendo que os pontos adotados foram mais exigentes do que os usados por estes autores.

Nos espectros de riqueza foram traçadas linhas pontilhadas entre o primeiro e o último ponto ajustado (equivalente a 50 elementos amostrais) e a área obtida entre esta reta e a curva ajustada foi utilizada para evidenciar do grau de estruturação do povoamento em análise, sendo que quanto maior a área maior a estruturação (espectro tendendo mais à forma diagonal).

\section{RESULTADOS}

\section{1) Lista dos táxons}

Foram encontrados 65 UTOs (Tabela 4.2), entre espécies e morfotipos, e 1 atributo não-biológico. Destes, 30 foram encontrados no povoamento Banco de Sargassum, 44 no Tapete de Amphiroa e Jania, 41 no Tapete de Ectoprocta e 47 no Tapete de Gelidiopsis e Hypnea.

Algumas espécies foram unidas em morfotipos na análise quantitativa pela dificuldade envolvida na sua identificação. Isso ocorreu com as espécies do gênero Amphiroa e Jania, pela impossibilidade de identificação em laboratório sem perda de biomassa e conseqüente alteração dos resultados, com as espécies do gênero Sargassum, além de poliquetas e hidrozoários, pela impossibilidade de identificação em laboratório por estarem fragmentados ou em campo, e também com Corallinaceae incrustantes e as espécies de Ectoprocta, pela falta de especialistas nos grupos. 
Tabela 4.2 - Lista das UTOs, organizadas por Filo e posteriormente por Divisão, além de atributos não-biológicos do costão leste da Enseada das Palmas, Parque Estadual da Ilha Anchieta e povoamentos aos quais estavam associados. BSG = Banco de Sargassum, TAJ = Tapete de Amphiroa e Jania, $\mathrm{TEC}=$ Tapete de Ectoprocta e TGH $=$ Tapete de Gelidiopsis e Hypnea .

\begin{tabular}{|c|c|c|c|c|c|c|c|c|}
\hline UTO & Filo & Classe & Ordem & Família & BSG & TAJ & TEC & TGH \\
\hline Nicolea uspiana (Nogueira, 2003) & Annelida & Polychaeta & Terebellida & Terebellidae & $\mathrm{X}$ & $\mathrm{X}$ & $\mathrm{X}$ & $\mathrm{X}$ \\
\hline & Annelida & Polychaeta & Sabellida & Sabellidae & $\mathrm{X}$ & $\mathrm{X}$ & $\mathrm{X}$ & $\mathrm{X}$ \\
\hline & Arthropoda & Maxillopoda & Cirripedia & & & $\mathrm{X}$ & $\mathrm{X}$ & $\mathrm{X}$ \\
\hline Didemnum speciosum (Herdman, 1886) & Chordata (Tunicata) & Ascidiace & Aplousobranchia & Didemnidae & $\mathrm{X}$ & $\mathrm{X}$ & $\mathrm{X}$ & $\mathrm{X}$ \\
\hline Herdmania momus (Savigny, 1816) & Chordata (Tunicata) & Ascidiace & Stolidobranchia & Pyuridae & & $\mathrm{X}$ & $\mathrm{X}$ & $\mathrm{X}$ \\
\hline Phallusia nigra Savigny, 1816 & Chordata (Tunicata) & Ascidiace & Enterogona & Ascidiidae & $\mathrm{X}$ & & & \\
\hline Symplegma rubra Herdman, 1886 & Chordata (Tunicata) & Ascidiace & Stolidobranchia & Styelidae & & & $\mathrm{X}$ & \\
\hline & Cnidaria & Hydrozoa & & & $\mathrm{X}$ & $\mathrm{X}$ & $\mathrm{X}$ & $\mathrm{X}$ \\
\hline Carijoa riisei (Duchassaing and Michelotti, 1860) & Cnidaria & Anthozoa & Alcyonacea & Clavulariidae & & & $\mathrm{X}$ & \\
\hline Echinometra lucunter (Linnaeus, 1758) & Echinodermata & Echinoidea & Echinoida & Echinometridae & $\mathrm{X}$ & & & \\
\hline Lytechinus variegatus (Lamarck, 1816) & Echinodermata & Echinoidea & Temnopleuroida & Toxopneustidae & $\mathrm{X}$ & & & \\
\hline Ectoprocta crostoso & Ectoprocta & & & & & $\mathrm{X}$ & $\mathrm{X}$ & $\mathrm{X}$ \\
\hline Scrupocellaria $\mathrm{sp}$ & Ectoprocta & Gymnolaemata & Cheilostomatida & Candidae & $\mathrm{X}$ & $\mathrm{X}$ & $\mathrm{X}$ & $\mathrm{X}$ \\
\hline $\begin{array}{l}\text { Vittaticella sp. (junto com Scrupocellaria sp. forma o morfotipo } \\
\text { Ectoprocta Arborescente) }\end{array}$ & Ectoprocta & Gymnolaemata & Cheilostomatida & Catenicellidae & $\mathrm{X}$ & $\mathrm{X}$ & $\mathrm{X}$ & $\mathrm{X}$ \\
\hline $\begin{array}{l}\text { Savignyella sp. (junto com Scrupocellaria sp. forma o morfotipo } \\
\text { Ectoprocta Arborescente) }\end{array}$ & Ectoprocta & Gymnolaemata & Cheilostomatida & Savignyellidae & $\mathrm{X}$ & $\mathrm{X}$ & $\mathrm{X}$ & $\mathrm{X}$ \\
\hline Schizoporella unicornis (Johnston, 1847) & Ectoprocta & Gymnolaemata & Cheilostomatida & Schizoporellidae & $\mathrm{X}$ & & & \\
\hline & Porifera & Calcarea & Leucosolenida & & & $\mathrm{X}$ & $\mathrm{X}$ & $\mathrm{X}$ \\
\hline Tedania ignis (Duchassaing \& Michelotti, 1864) & Porifera & Demospongiae & Poecilosclerida & Tedaniidae & $\mathrm{X}$ & $\mathrm{X}$ & $\mathrm{X}$ & $\mathrm{X}$ \\
\hline Amphimedon viridis Duchassaing \& Michelloti, 1864 & Porifera & Demospongiae & Haplosclerida & Niphatidae & $\mathrm{X}$ & & & \\
\hline Caulerpa racemosa (Forsskål) J. Agardh & Chlorophyta & & Bryopsidales & Caulerpaceae & $\mathrm{X}$ & $\mathrm{X}$ & & \\
\hline Caulerpella ambigua (Okamura) Prud'homme \& Lokhorst & Chlorophyta & & Bryopsidales & Caulerpaceae & & $\mathrm{X}$ & $\mathrm{X}$ & $\mathrm{X}$ \\
\hline Cladophora vagabunda (Linnaeus) Hoek & Chlorophyta & & Cladophorales & Cladophoraceae & & & & $\mathrm{X}$ \\
\hline Enteromorpha linza (L.) J. Agardh & Chlorophyta & & Ulvales & Ulvaceae & & $\mathrm{X}$ & & \\
\hline Ulva lactuca Linnaeus & Chlorophyta & & Ulvales & Ulvaceae & $\mathrm{X}$ & & & \\
\hline $\begin{array}{l}\text { Filamentosa } \\
\end{array}$ & Cyanophyta & & & & & & & $\mathrm{X}$ \\
\hline Pseudolithoderma moreirae Yonesh. \& Boudour. & Phaeophyta & & Chordariales & Ralfsiaceae & & $\mathrm{X}$ & & \\
\hline Dictyopteris delicatula J.V. Lamour. & Phaeophyta & & Dictyotales & Dictyotaceae & $\mathrm{X}$ & $\mathrm{X}$ & $\mathrm{X}$ & $\mathrm{X}$ \\
\hline Dictyota menstrualis (Hoyt) Schnetter, Hörnig \& Weber-Peukert & Phaeophyta & & Dictyotales & Dictyotaceae & $\mathrm{X}$ & $\mathrm{X}$ & $\mathrm{X}$ & $\mathrm{X}$ \\
\hline Padina gymnospora (Kütz.) Sond. & Phaeophyta & & Dictyotales & Dictyotaceae & $\mathrm{X}$ & & & $\mathrm{X}$ \\
\hline Feldmania irregularis (Kütz.) Hamel & Phaeophyta & & Ectocarpales & Ectocarpaceae & $\mathrm{X}$ & $\mathrm{X}$ & $\mathrm{X}$ & \\
\hline
\end{tabular}


Tabela 4.2 cont.

\begin{tabular}{|c|c|c|c|c|c|c|c|}
\hline UTO & Divisão & Ordem & Família & BSG & TAJ & TEC & TGH \\
\hline Sargassum filipendula C. Agardh & Phaeophyta & Fucales & Sargassaceae & $\mathrm{X}$ & $\mathrm{X}$ & $\mathrm{X}$ & $\mathrm{X}$ \\
\hline Sargassum vulgare C. Agardh & Phaeophyta & Fucales & Sargassaceae & $\mathrm{X}$ & $\mathrm{X}$ & $\mathrm{X}$ & $\mathrm{X}$ \\
\hline Colpomenia sinuosa (Roth) Derbès \& Solier & Phaeophyta & Scytosiphonales & Scytosiphonaceae & & $\mathrm{X}$ & & $\mathrm{X}$ \\
\hline Sphacelaria $\mathrm{sp}$ & Phaeophyta & Sphacelariales & Sphacelariaceae & & $\mathrm{X}$ & & $\mathrm{X}$ \\
\hline Sphacelaria brachygonia Mont. & Phaeophyta & Sphacelariales & Sphacelariaceae & & & & $\mathrm{X}$ \\
\hline Asparagopsis taxiformis (Delile) Trevis. & Rhodophyta & Bonnemaisoniales & Bonnemaisoniaceae & $\mathrm{X}$ & $\mathrm{X}$ & $\mathrm{X}$ & $\mathrm{X}$ \\
\hline Asparagopsis taxiformis (Delile) Trevis. (fase Falkenbergia) & Rhodophyta & Bonnemaisoniales & Bonnemaisoniaceae & & $\mathrm{X}$ & $\mathrm{X}$ & \\
\hline Centroceras clavulatum (C. Agardh in Kunth) Mont. & Rhodophyta & Ceramiales & Ceramiaceae & & & & $\mathrm{X}$ \\
\hline Wrangelia argus (Mont.) Mont. & Rhodophyta & Ceramiales & Ceramiaceae & & & $\mathrm{X}$ & \\
\hline Chondria sp. & Rhodophyta & Ceramiales & Rhodomelaceae & $\mathrm{X}$ & & & \\
\hline Chondria arcuata Hollenberg & Rhodophyta & Ceramiales & Rhodomelaceae & & & $\mathrm{X}$ & $\mathrm{X}$ \\
\hline Chondria platyramea A.B. Joly \& Ugadim & Rhodophyta & Ceramiales & Rhodomelaceae & & & & $\mathrm{X}$ \\
\hline Chondria dangeardii Dawson & Rhodophyta & Ceramiales & Rhodomelaceae & & & & $\mathrm{X}$ \\
\hline Chondrophycus papillosus (C.Agardh) Garbary \& Harper & Rhodophyta & Ceramiales & Rhodomelaceae & & $X$ & $X$ & $\mathrm{X}$ \\
\hline Corallinaceae incrustante & Rhodophyta & Corallinales & Corallinaceae & $\mathrm{X}$ & $\mathrm{X}$ & $\mathrm{X}$ & $\mathrm{X}$ \\
\hline Amphiroa beauvoisii J.V. Lamour. & Rhodophyta & Corallinales & Corallinaceae & & $\mathrm{X}$ & $\mathrm{X}$ & $\mathrm{X}$ \\
\hline Amphiroa fragilissima (Linnaeus) J.V. Lamour. & Rhodophyta & Corallinales & Corallinaceae & & $\mathrm{X}$ & $\mathrm{X}$ & $\mathrm{X}$ \\
\hline Amphiroa rigida J.V. Lamour. & Rhodophyta & Corallinales & Corallinaceae & & $\mathrm{X}$ & $\mathrm{X}$ & $\mathrm{X}$ \\
\hline Jania adhaerens J.V. Lamour. & Rhodophyta & Corallinales & Corallinaceae & $\mathrm{X}$ & $\mathrm{X}$ & $\mathrm{X}$ & $\mathrm{X}$ \\
\hline Jania ungulata (Yendo) Yendo & Rhodophyta & Corallinales & Corallinaceae & & $\mathrm{X}$ & $\mathrm{X}$ & $\mathrm{X}$ \\
\hline Gelidiella ligulata Dawson & Rhodophyta & Gelidiales & Gelidiellaceae & & & & $\mathrm{X}$ \\
\hline Gelidiella trinitatensis W.R. Taylor & Rhodophyta & Gelidiales & Gelidiellaceae & & $\mathrm{X}$ & $\mathrm{X}$ & \\
\hline Catenella caespitosa (Withering) L.M. Irvine & Rhodophyta & Gigartinales & Caulacanthaceae & & & $\mathrm{X}$ & \\
\hline Chondracanthus acicularis (Roth) Fredericq & Rhodophyta & Gigartinales & Gigartinaceae & & $\mathrm{X}$ & $\mathrm{X}$ & $\mathrm{X}$ \\
\hline Chondracanthus teedei (Mertens ex Roth) Fredericq & Rhodophyta & Gigartinales & Gigartinaceae & & $\mathrm{X}$ & & $\mathrm{X}$ \\
\hline Hypnea musciformis (Wulfen in Jacqu.) J.V. Lamour. & Rhodophyta & Gigartinales & Hypneaceae & & $\mathrm{X}$ & $\mathrm{X}$ & $\mathrm{X}$ \\
\hline Hypnea spinella (C. Agardh) Kützing & Rhodophyta & Gigartinales & Hypneaceae & $\mathrm{X}$ & $\mathrm{X}$ & $\mathrm{X}$ & $\mathrm{X}$ \\
\hline Halymenia $\mathrm{sp}$ & Rhodophyta & Halymeniales & Halymeniaceae & & $\mathrm{X}$ & & \\
\hline Dichotomaria marginata (J. Ellis \& Sol.) Lamarck & Rhodophyta & Nemaniales & Galaxauraceae & $\mathrm{X}$ & $\mathrm{X}$ & $\mathrm{X}$ & $\mathrm{X}$ \\
\hline Champia taironensis Bula-Meyer & Rhodophyta & Rhodymeniales & Champiaceae & & $\mathrm{X}$ & & $\mathrm{X}$ \\
\hline Champia parvula (C. Agardh) Harv. & Rhodophyta & Rhodymeniales & Champiaceae & & $\mathrm{X}$ & $\mathrm{X}$ & $\mathrm{X}$ \\
\hline Champia vieilardii Kützing & Rhodophyta & Rhodymeniales & Champiaceae & & & & $\mathrm{X}$ \\
\hline Gelidiopsis planicaulis (W.R. Taylor) W.R. Taylor & Rhodophyta & Rhodymeniales & Lomentariaceae & $\mathrm{X}$ & $\mathrm{X}$ & $\mathrm{X}$ & $\mathrm{X}$ \\
\hline Gelidiopsis variabilis (Grev. ex J. Agardh) F. Schmitz & Rhodophyta & Rhodymeniales & Lomentariaceae & $\mathrm{X}$ & $\mathrm{X}$ & $\mathrm{X}$ & $\mathrm{X}$ \\
\hline Substrato Inconsolidado & & & & $\mathrm{X}$ & & & \\
\hline
\end{tabular}


A Tabela 4.3 mostra que as algas (45 UTOs) foram mais representadas que os animais (21 UTOs) na totalidade dos povoamentos analisados. A Divisão Rhodophyta foi a mais representada, com 29 UTOs, seguida dentre as algas da Divisão Phaeophyta (10), Chlorophyta (5) e Cyanophyta (1). Dentre os animais, o Filo Ectoprocta (6 UTOs) e o Filo Chordata (4 UTOs) foram os mais representados. O mesmo padrão foi encontrado dentro de cada povoamento, com a Divisão Rhodophyta sempre sendo a mais representada e a Divisão Phaeophyta em segundo lugar.

Tabela 4.3 - Número de UTOs para cada Filo/Divisão encontrado(a) nos povoamentos Banco de Sargassum (BSG), Tapete de Amphiroa e Jania (TAJ), Tapete de Ectoprocta (TEC) e Tapete de Gelidiopsis e Hypnea (TGH).

\begin{tabular}{llllll}
\hline Filo ou Divisão/Povoamento & BSG & TAJ & TEC & TGH & Total \\
\hline Annelida & 2 & 2 & 2 & 2 & 2 \\
Arthropoda & 0 & 1 & 1 & 1 & 1 \\
Chordata (Tunicata) & 2 & 2 & 3 & 2 & 4 \\
Cnidaria & 1 & 1 & 2 & 1 & 2 \\
Echinodermata & 2 & 0 & 0 & 0 & 2 \\
Ectoprocta & 4 & 5 & 5 & 5 & 6 \\
Porífera & 2 & 2 & 2 & 2 & 3 \\
Chlorophyta & 2 & 3 & 1 & 2 & 5 \\
Cyanophyta & 0 & 0 & 0 & 1 & 1 \\
Phaeophyta & 6 & 8 & 5 & 8 & 10 \\
Rhodophyta & 8 & 20 & 20 & 23 & 29 \\
Substrato Inconsolidado & 1 & 0 & 0 & 0 & 1 \\
\hline Total & 30 & 44 & 41 & 47 & 66 \\
\hline
\end{tabular}

\section{2) Recobrimento percentual ou biomassa}

A Figura 4.1 mostra que no povoamento Banco de Sargassum as espécies do gênero Sargassum apresentaram recobrimento percentual médio 90,5\%, acima do limite sugerido para definição das espécies dominantes no método "Levantamento Fisionômico" e significativamente maior que todas as demais espécies/morfotipos $(p=0,000)$. Substrato Inconsolidado e Scrupocellaria sp. apresentaram recobrimento médio significativamente mais alto que todas as demais espécies/morfotipos $(\mathrm{p}=0,000)$, exceto a dominante Sargassum, e não apresentaram diferenças entre si $(\mathrm{p}=0,243)$. Gelidiopsis sp. não apresentou diferenças significativas com Corallinaceae incrustante $(p=1,000)$, Dictyota menstrualis $(p=1,000)$ e 
Tedania ignis $(\mathrm{p}=0,896)$ e apresentou valores médios significativamente maiores do que as demais espécies/morfotipos, exceto as já citadas anteriormente. Corallinaceae incrustante apresentou diferenças significativas de todas as espécies/morfotipos (para mais ou para menos), exceto a já citada Gelidiopsis sp. e Tedania ignis $(\mathrm{p}=1,000)$, Jania $\mathrm{sp} .(\mathrm{p}=0,434)$ e Dichotomaria marginata $(\mathrm{p}=0,131)$. As demais espécies/morfotipos não apresentaram diferenças significativas entre si.

Neste povoamento, os representantes da Divisão Phaeophyta dominaram em termos de recobrimento percentual médio $(97,11 \%)$.

A Figura 4.2 mostra que no povoamento Tapete de Amphiroa e Jania as espécies do gênero Amphiroa apresentaram biomassa média de 309,2 mg, significativamente maior que todas as demais espécies/morfotipos $(\mathrm{p}<0,050)$. As espécies do gênero Jania apresentaram biomassa média de 50,8 $\mathrm{mg}$, significativamente maior que todas as demais espécies/morfotipos, exceto as já citadas e Herdmania momus ( $\mathrm{p}=1,000)$, Gelidiopsis variabilis $(\mathrm{p}=1,000)$, Ectoprocta arborescente $(\mathrm{p}=0,993)$, Chondracanthus acicularis $(\mathrm{p}=0,505)$, Polychaeta tubícola $(\mathrm{p}=0,450)$, Leucosolenida $(\mathrm{p}=0,232)$, Hypnea musciformis $(\mathrm{p}=0,115)$, Didemnum speciosum $(\mathrm{p}=0,064)$ e Champia parvula $(\mathrm{p}=0,055)$. Somadas as biomassas das espécies dos gêneros Amphiroa e Jania, tem-se $70 \%$ do total da biomassa. Ectoprocta arborescente apresentou biomassa média significativamente mais alta que todas as demais espécies/morfotipos, exceto as já citadas acima e Herdmania momus ( $\mathrm{p}=1,000)$, Gelidiopsis variabilis $(\mathrm{p}=1,000)$, Chondracanthus acicularis $(\mathrm{p}=1,000)$, Polychaeta tubícola $(\mathrm{p}=1,000)$, Leucosolenida $(\mathrm{p}=0,867)$ e Hypnea musciformis $(\mathrm{p}=0,171)$. Polychaeta tubícola apresentou biomassa média significativamente mais alta que as 15 espécies com menor biomassa média $(\mathrm{p}<0,050)$. As demais espécies/morfotipos não apresentaram diferenças significativas entre si.

Neste povoamento, os representantes da Divisão Rhodophyta dominaram em termos de biomassa média (420 mg). 


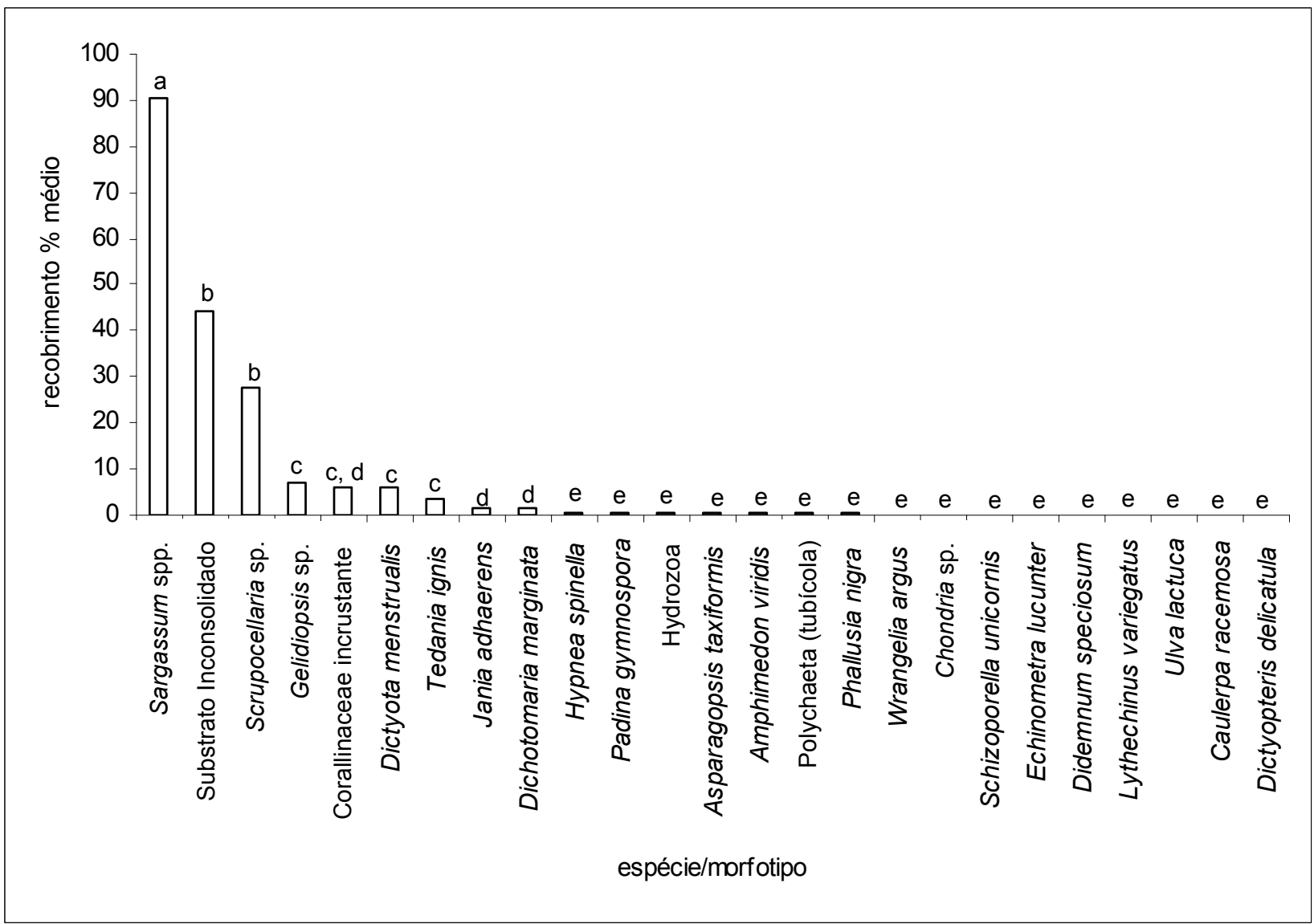

Figura 4.1 - Recobrimento percentual médio das espécies/morfotipos do povoamento Banco de Sargassum. Letras iguais indicam ausência de diferença significativa com o primeiro que apresenta aquela letra, exceto para a última letra da seqüência que indica ausência de diferença significativa entre todos que a apresentam.

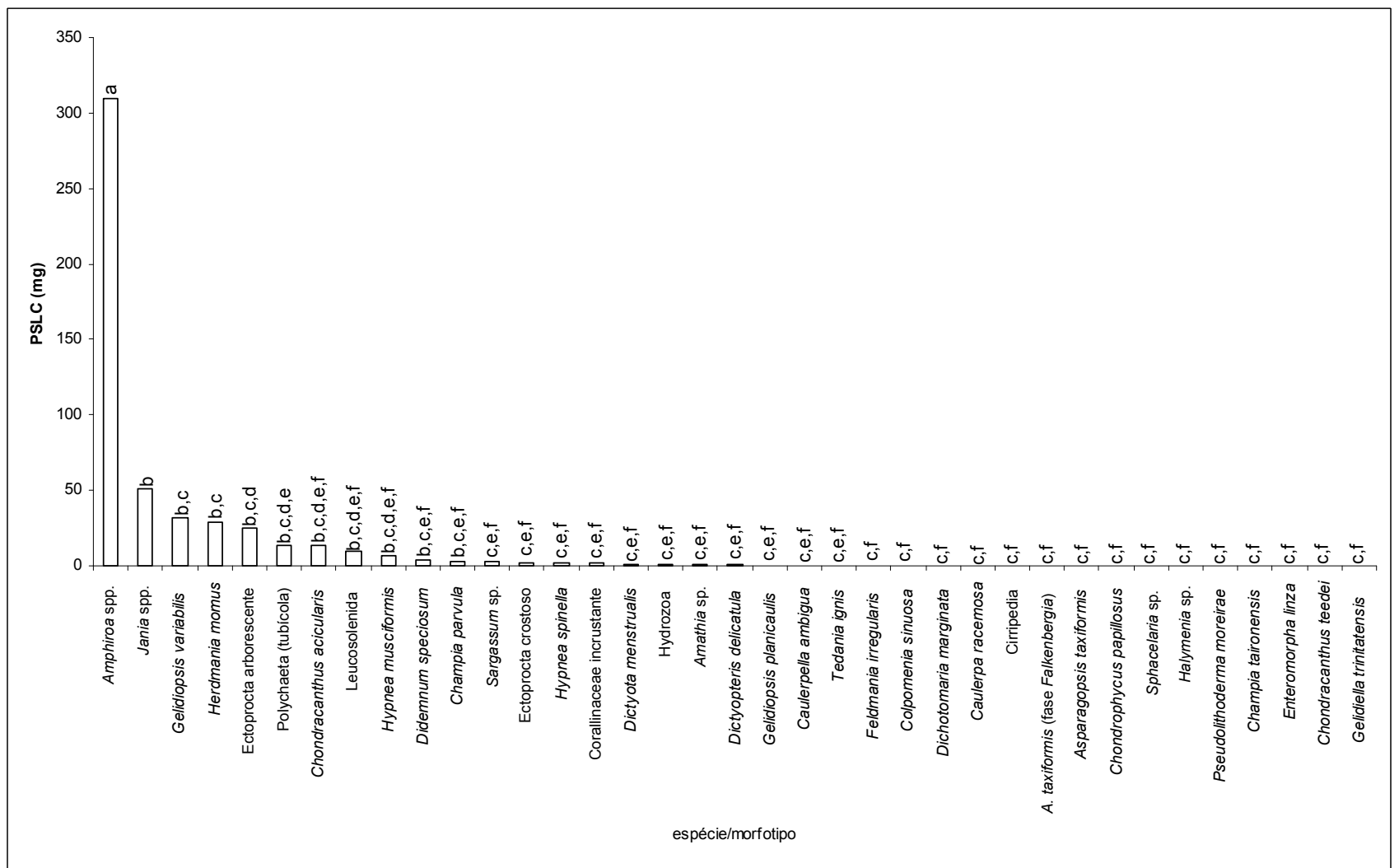

Figura 4.2 - Biomassa seca livre de cinzas $(\mathrm{mg})$ média das espécies/morfotipos do povoamento Tapete de Amphiroa e Jania. Letras iguais indicam ausência de diferença significativa com o primeiro que apresenta aquela letra, exceto para a última letra da seqüência que indica ausência de diferença significativa entre todos que a apresentam. 
A Figura 4.3 mostra que no povoamento Tapete de Ectoprocta, Herdmania momus apresentou a maior biomassa média $(265,2 \mathrm{mg}$ ou $44 \%$ da biomassa total). Entretanto, devido à elevada variabilidade das amostras, ou seja, pelo fato desta espécie estar presente em determinados elementos amostrais com alto valor de biomassa e em outros estar ausente, ela não apresentou diferenças significativas das demais espécies/morfotipos. Ectoprocta arborescente apresentou valor médio de biomassa de 97,8 $\mathrm{mg}$ (19\% da biomassa total), significativamente mais alto que as demais espécies/morfotipos, exceto as espécies do gênero Amphiroa $(\mathrm{p}=0,974)$. As demais espécies/morfotipos não apresentaram diferenças significativas entre si.

Neste povoamento, os representantes do Filo Chordata dominaram em termos de biomassa média (279 mg).

A Figura 4.4 mostra que no povoamento Tapete de Gelidiopsis e Hypnea a espécie Gelidiopsis variabilis apresentou biomassa média de 115,4 mg, significativamente mais alta que todas as demais espécies/morfotipos, exceto as espécies dos gêneros Amphiroa $(\mathrm{p}=1,000)$ e Jania $(\mathrm{p}=0,121)$, Hypnea musciformis $(\mathrm{p}=0,424)$ e Ectoprocta arborescente $(\mathrm{p}=0,093)$. Somadas as biomassas médias de G. variabilis, Hypnea spinella e H. musciformis, tem-se $151,1 \mathrm{mg}$ ou $44 \%$ da biomassa total. As espécies do gênero Amphiroa apresentaram biomassa média significativamente maior que as demais espécies/morfotipos, exceto a já citada $G$. variabilis e as espécies do gênero Jania $(\mathrm{p}=0,444)$, Hypnea musciformis $(\mathrm{p}=0,997)$, Ectoprocta arborescente $(\mathrm{p}=0,297)$ e Chondracanthus acicularis $(\mathrm{p}=0,107)$. As espécies do gênero Jania, Hypnea musciformis, Ectoprocta arborescente e Chondracanthus acicularis não apresentaram diferenças significativas com nenhuma das demais espécies/morfotipos ( $p>0,05)$. As demais espécies/morfotipos não apresentaram diferenças significativas entre si.

Neste povoamento, os representantes da Divisão Rhodophyta dominaram em termos de biomassa média (300 mg). 


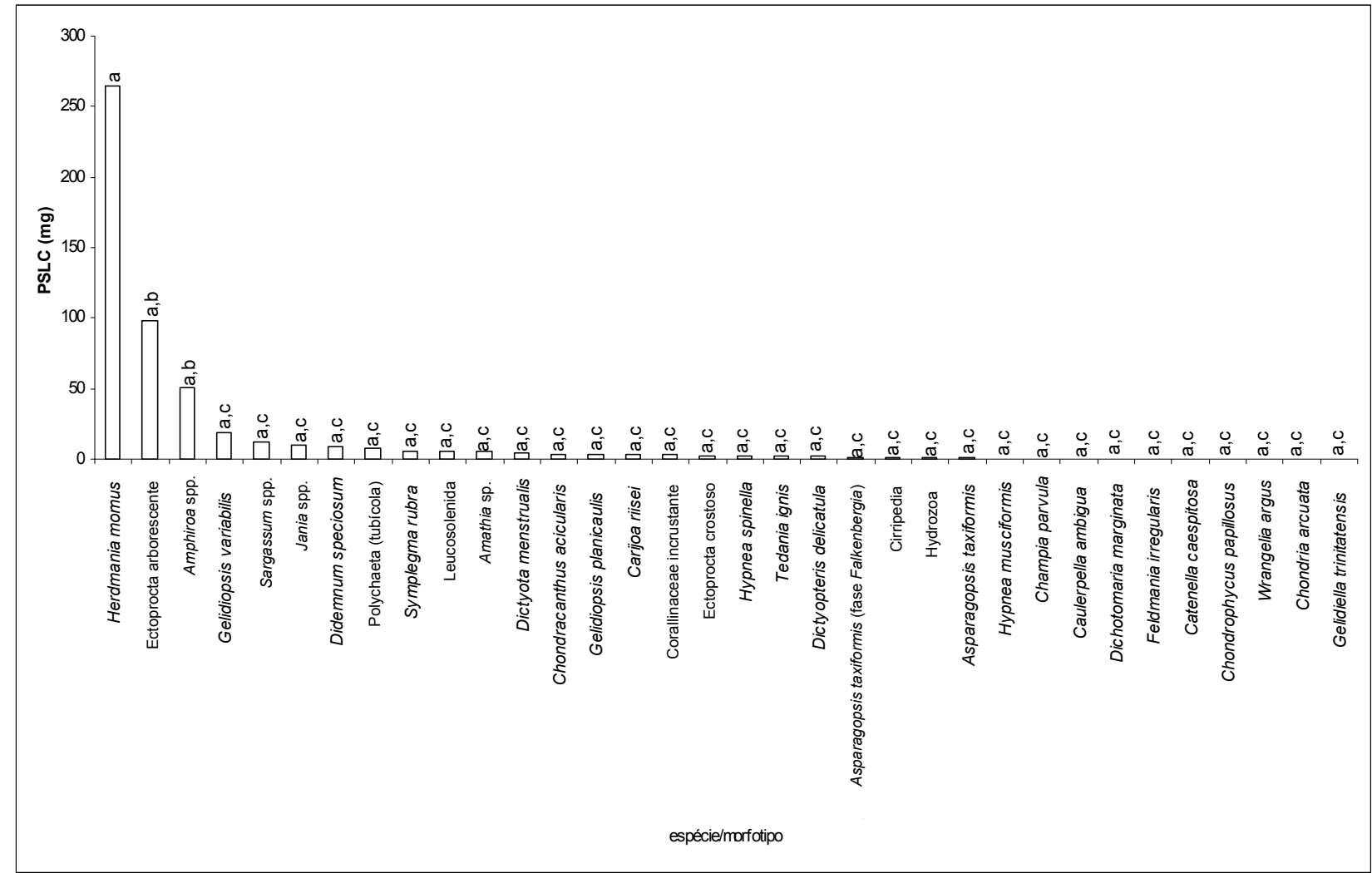

Figura 4.3 - Biomassa seca livre de cinzas $(\mathrm{mg})$ média das espécies/morfotipos do povoamento Tapete de Ectoprocta. Letras iguais indicam ausência de diferença significativa com o primeiro que apresenta aquela letra, exceto para a última letra da seqüência que indica ausência de diferença significativa entre todos que a apresentam.

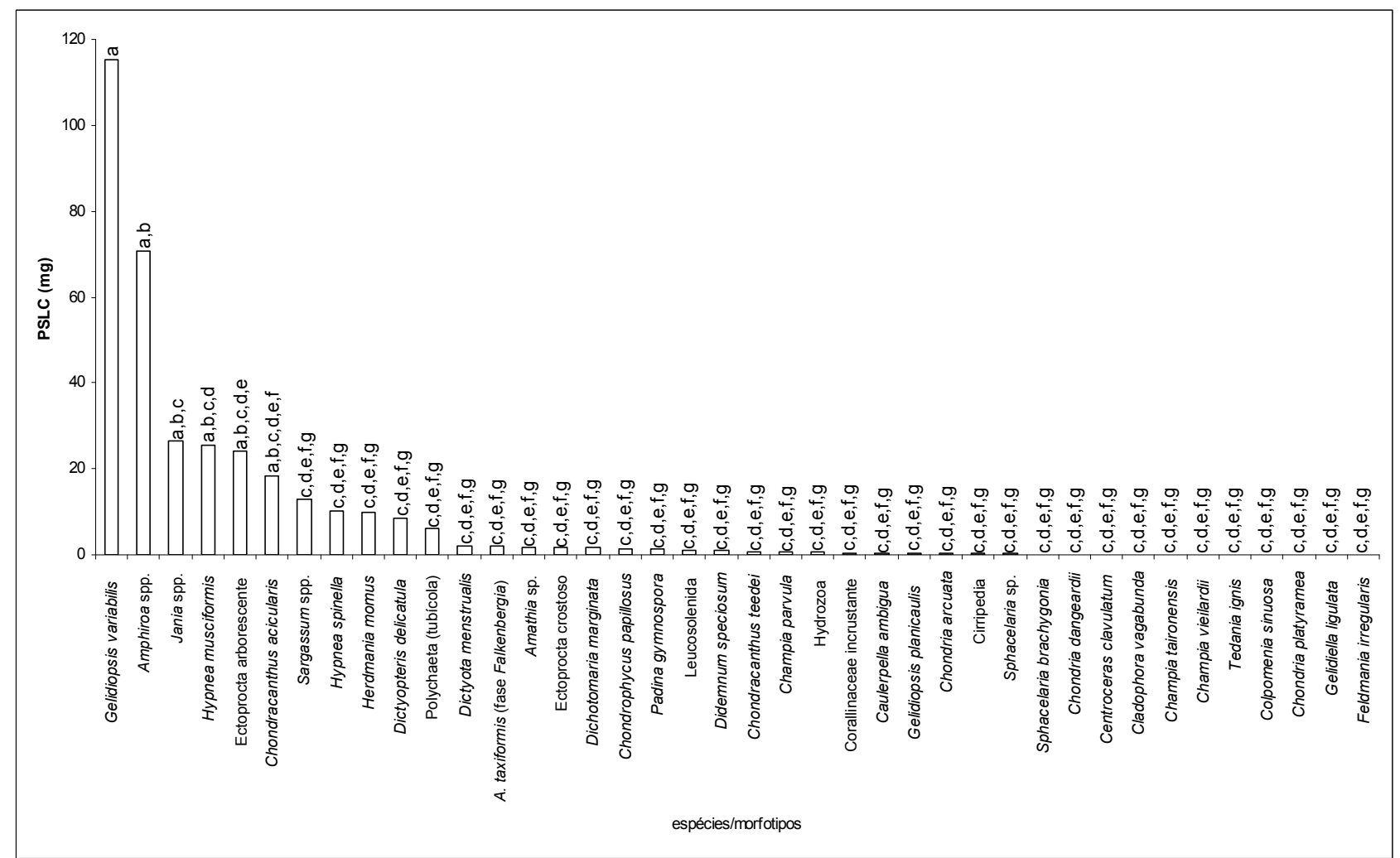

Figura 4.4 - Biomassa seca livre de cinzas (mg) média das espécies/morfotipos do povoamento Tapete de Gelidiopsis e Hypnea. Letras iguais indicam ausência de diferença significativa com o primeiro que apresenta aquela letra, exceto para a última letra da seqüência que indica ausência de diferença significativa entre todos que a apresentam. 
A Tabela 4.4 mostra a biomassa total (biomassa seca e PSLC) dos povoamentos em uma área de $100 \mathrm{~cm}^{2}$ (1 elemento amostral). O povoamento Tapete de Amphiroa e Jania apresentou a maior média $\left(3,62 \mathrm{~g} / 100 \mathrm{~cm}^{2}\right)$ e o maior valor máximo de biomassa seca $\left(9,47 \mathrm{~g} / 100 \mathrm{~cm}^{2}\right)$. Tapete de Ectoprocta apresentou a maior média $\left(0,60 \mathrm{~g} / 100 \mathrm{~cm}^{2}\right)$ e o maior valor máximo de PSLC $\left(2,15 \mathrm{~g} / 100 \mathrm{~cm}^{2}\right)$.

Tabela 4.4 - Biomassa seca e biomassa seca livre de cinzas (PSLC) para os povoamentos Tapete de Amphiroa e Jania, Tapete de Ectoprocta e Tapete de Gelidiopsis e Hypnea para uma área de $100 \mathrm{~cm}^{2}$ no trecho de infralitoral amostrado do Parque Estadual de Ilha Anchieta.

\begin{tabular}{ccccccc}
\hline & \multicolumn{3}{c}{ Biomassa seca $\left.\mathbf{( g / 1 0 0} \mathbf{~ c m}^{\mathbf{2}}\right)$} & \multicolumn{3}{c}{ PSLC $\mathbf{( g / 1 0 0 ~ \mathbf { ~ c m } ^ { \mathbf { 2 } } )}$} \\
\hline & mínima & média & máxima & mínima & média & máxima \\
\hline Tapete de Amphiroa e Jania & 1,23 & 3,62 & 9,47 & 0,18 & 0,59 & 1,24 \\
Tapete de Ectoprocta & 0,55 & 3,17 & 7,75 & 0,11 & 0,60 & 2,15 \\
Tapete de Gelidiopsis e Hypnea & 0,34 & 1,80 & 4,87 & 0,08 & 0,38 & 0,98 \\
\hline
\end{tabular}

\section{3) Heterogeneidade espacial}

\section{1) Repartição espacial em modo $Q$}

Para o povoamento Tapete de Amphiroa e Jania foram obtidos os níveis de significância mínimo 0,14 e máximo de 0,61 para o Índice de Similaridade Quantitativo de Morisita-Horn. A Figura 4.5 mostra que o dendrograma apresentou dois agrupamentos significativos, indicando a existência de duas facetas no povoamento.

As Figuras 4.6 e 4.7 mostram a análise do IVE destes agrupamentos, que evidenciou que no Grupo 1 Herdmania momus foi mais importante $(1,000)$ que as espécies do gênero Amphiroa $(0,931)$. No Grupo 2 as espécies do gênero Amphiroa foram as mais importantes $(0,997)$, seguidas das espécies do gênero Jania $(0,801)$.

Considerando-se os níveis críticos mínimo $(0,24)$ e máximo $(0,75)$ de significância calculados para o Índice de Distância de Bray-Curtis para este povoamento, nota-se que o mesmo pode ser considerado homogêneo, já que houve maior número de observações entre 0,3 e 0,6 e poucas observações entre 0,7 e 0,9 de distância (Figura 4.8). 


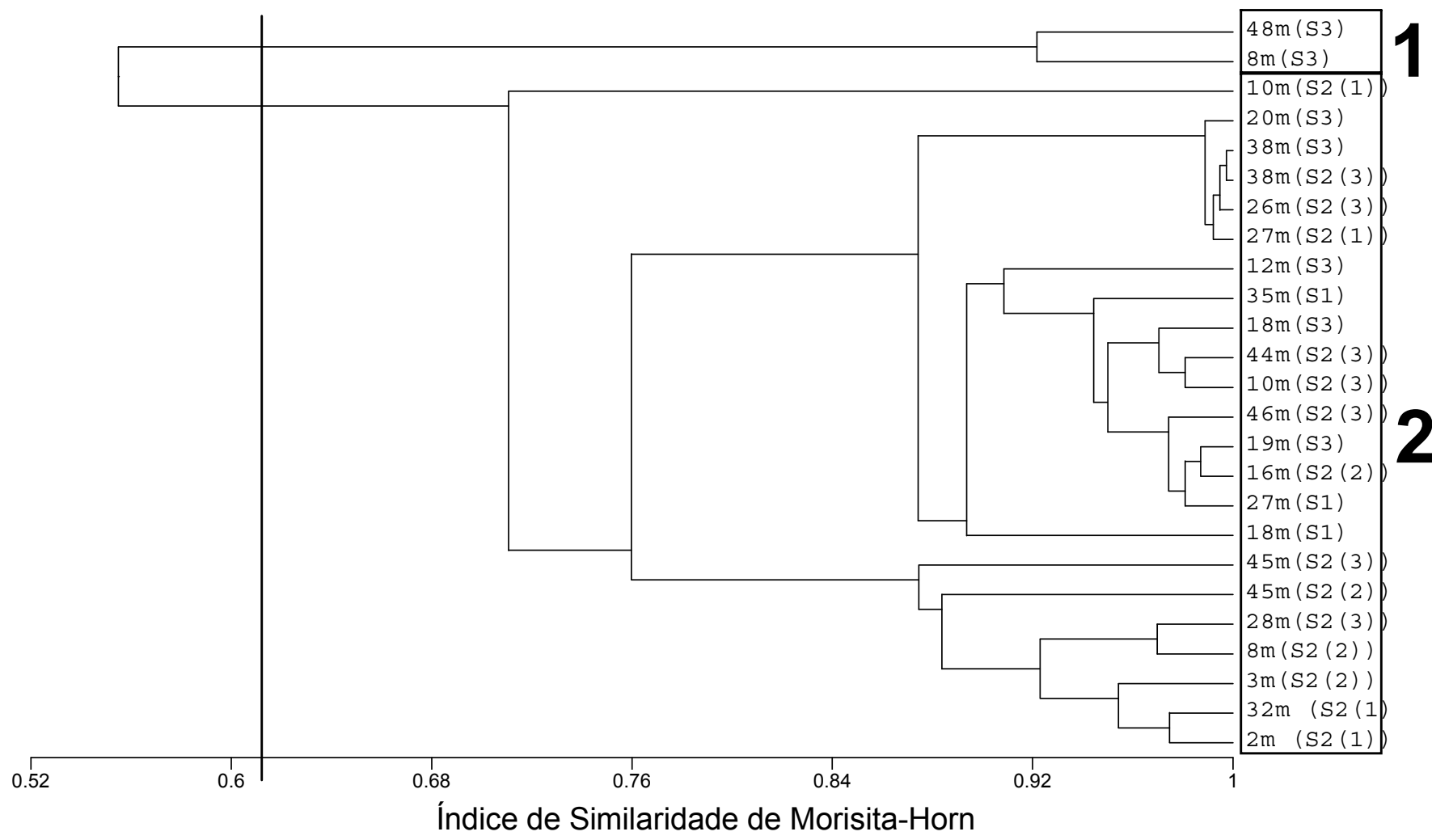

Figura 4.5 -Repartição espacial da comunidade do povoamento Tapete de Amphiroa e Jania em modo Q com uso do Índice de Similaridade de Morisita-Horn e estratégia de agrupamento WPGMA. A linha vertical indica o limite de significância superior, a partir do qual os grupos são considerados significativos, para uma confiabilidade de $95 \%$.

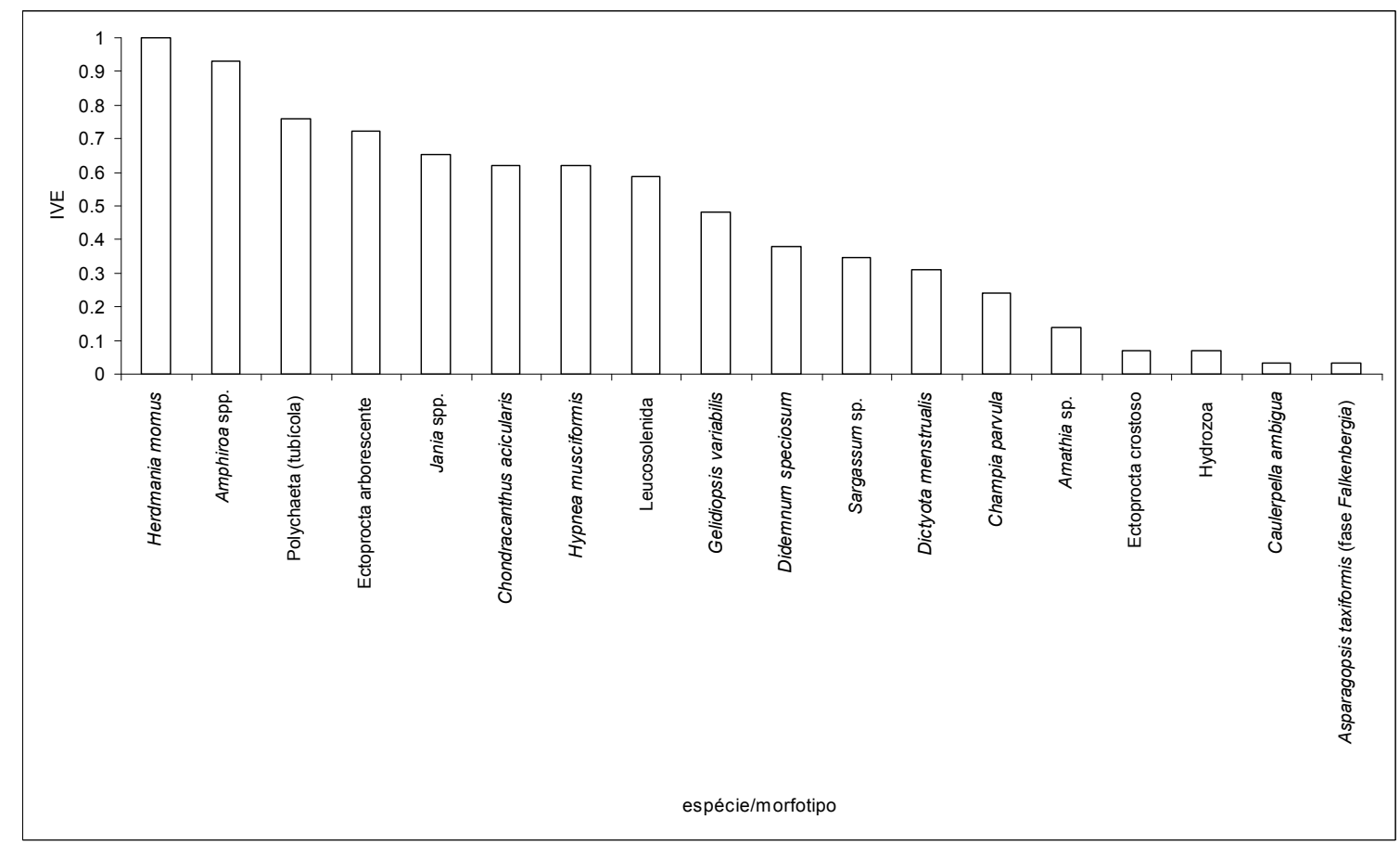

Figura 4.6 - IVE das espécies/morfotipos dos elementos amostrais formadores do Grupo $1 \mathrm{com}$ a utilização do Índice de Similaridade Quantitativo de Morisita-Horn para o povoamento Tapete de Amphiroa e Jania. 


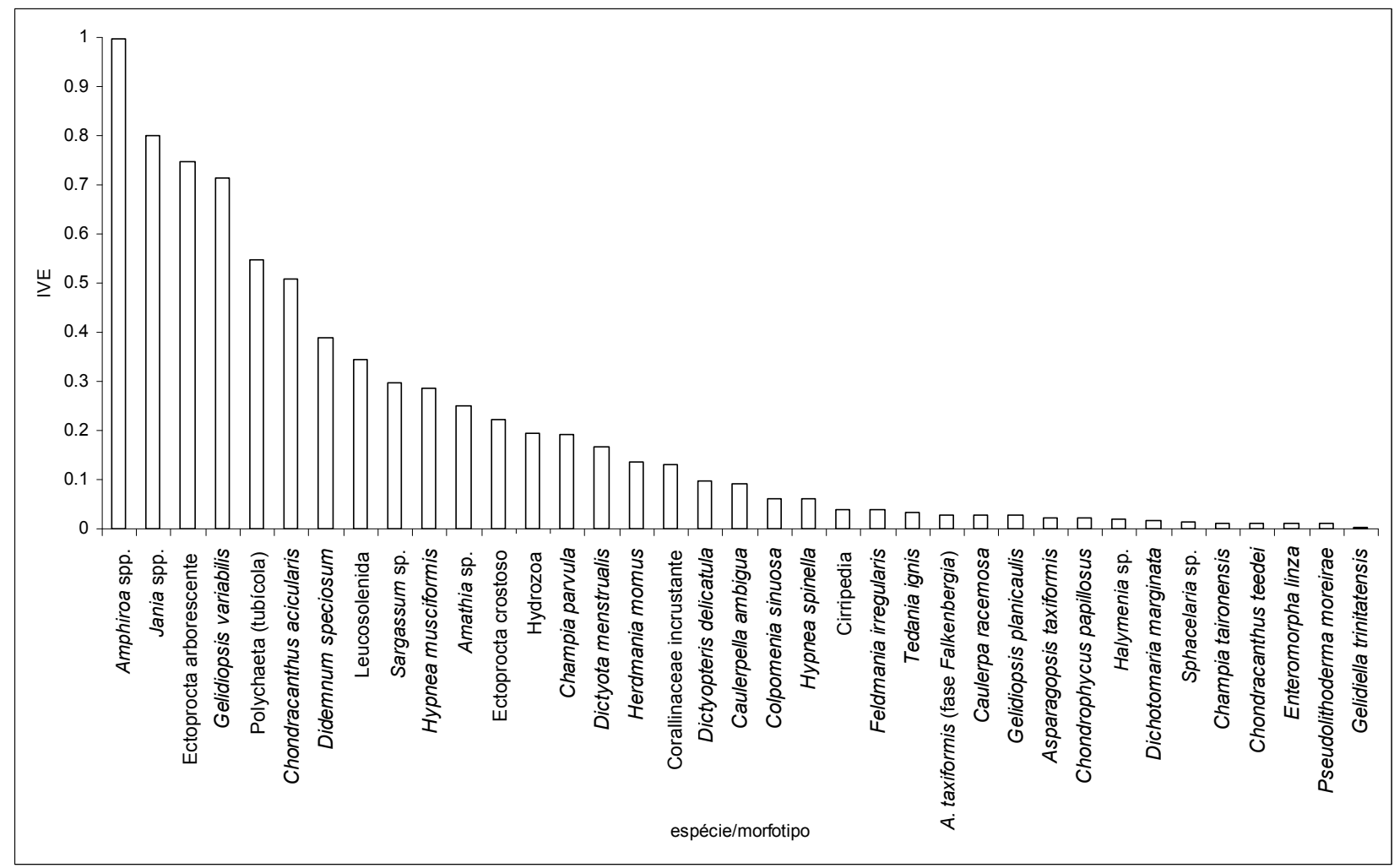

Figura 4.7 - IVE das espécies/morfotipos dos elementos amostrais formadores do Grupo 2 com a utilização do Índice de Similaridade Quantitativo de Morisita-Horn para o povoamento Tapete de Amphiroa e Jania.

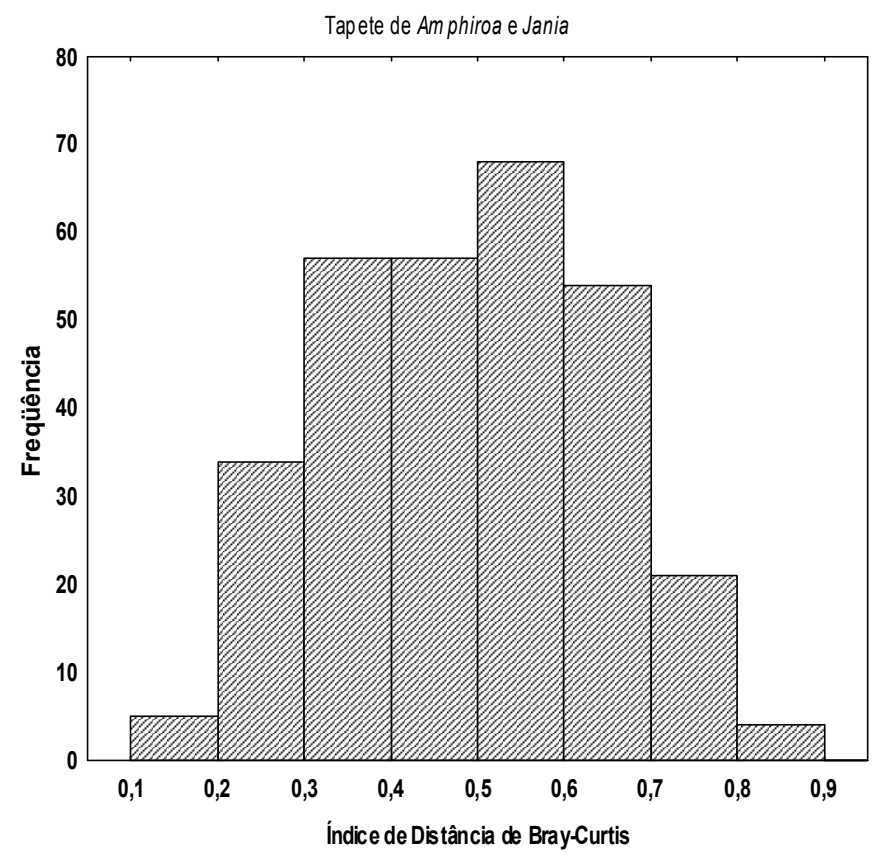

Figura 4.8 - Distribuição de freqüências das distâncias de Bray-Curtis entre os elementos amostrais, combinados 2 a 2, constituintes do povoamento Tapete de Amphiroa e Jania. 
Para o povoamento Tapete de Ectoprocta foram obtidos os níveis de significância mínimo de 0,01 e máximo de 0,42 para o Índice de Similaridade Quantitativo de MorisitaHorn. O dendrograma apresentou dois agrupamentos significativos (Figura 4.9), indicando também a existência de duas facetas no povoamento.

As Figuras 4.10 e 4.11 mostram a análise do IVE destes agrupamentos, que evidenciou que o morfotipo Ectoprocta arborescente foi mais importante $(0,965)$ no Grupo 1 e H. momus no Grupo 2 (0,986), seguido de Ectoprocta arborescente $(0,913)$.

Considerando-se os níveis críticos mínimo $(0,30)$ e máximo $(0,81)$ de significância calculados para o Índice de Distância de Bray-Curtis para este povoamento, nota-se que o mesmo pode ser considerado heterogêneo internamente, pois apesar de ter apresentado maior número de observações entre 0,5 e 0,7 , também apresentou um elevado número de observações entre 0,8 e 1,0 de distância (Figura 4.12).

Para o povoamento Tapete de Gelidiopsis e Hypnea foram obtidos os níveis de significância mínimo de 0,05 e máximo de 0,32 para o Índice de Similaridade Quantitativo de Morisita-Horn. O dendrograma apresentou dois agrupamentos significativos (Figura 4.13), novamente indicando a presença de duas facetas no povoamento.

As Figuras 4.14 e 4.15 mostram a análise do IVE destes agrupamentos, que evidenciou que no Grupo 1 Hypnea musciformis foi mais importante $(0,971)$ e no Grupo 2 Gelidiopsis variabilis foi mais importante $(0,947)$.

Considerando-se os níveis críticos mínimo $(0,32)$ e máximo $(0,81)$ de significância calculados para o Índice de Distância de Bray-Curtis para este povoamento, nota-se que o mesmo pode ser considerado homogêneo, já que apresentou maior número de observações entre 0,5 e 0,6 (Figura 4.16). 


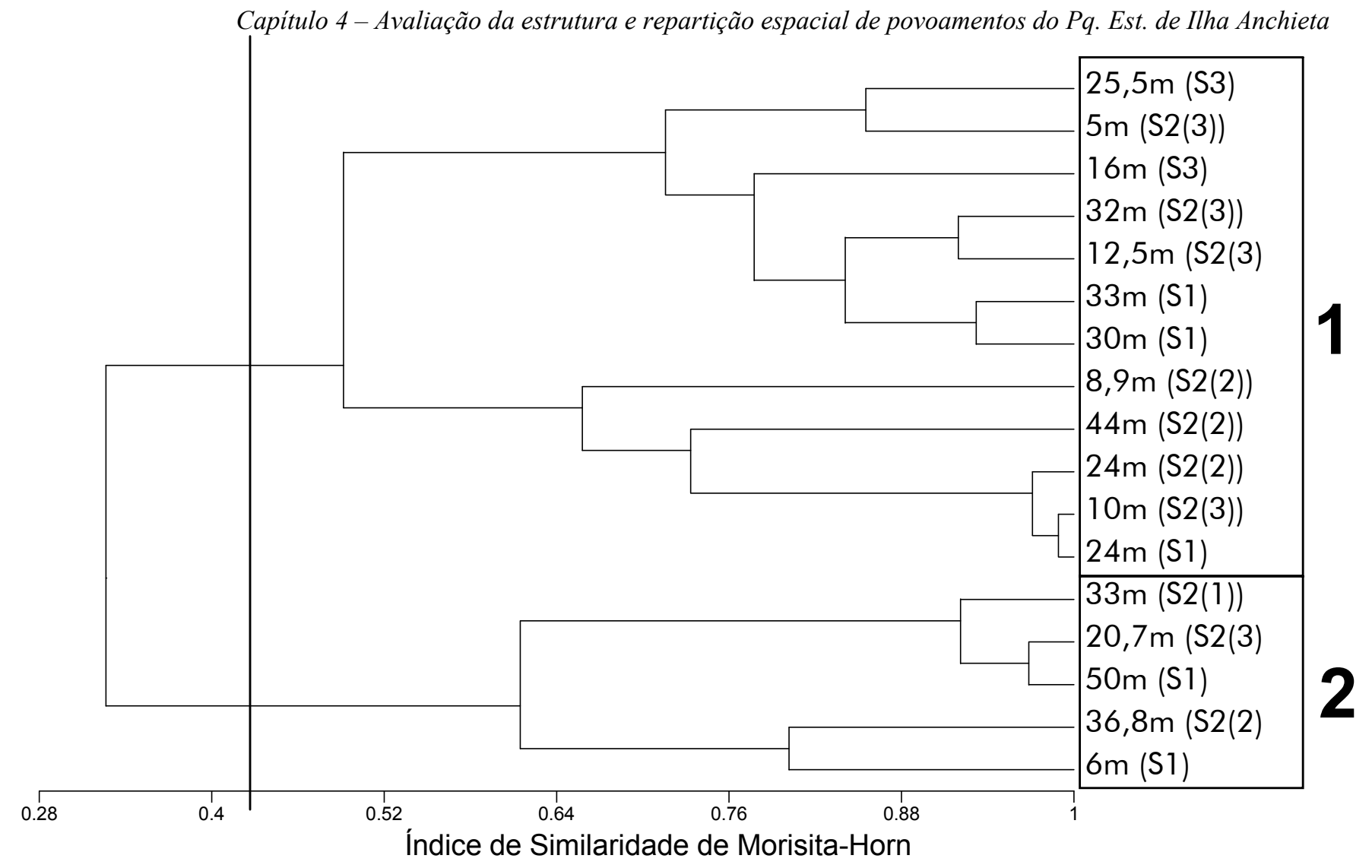

Figura 4.9 -Repartição espacial da comunidade do povoamento Tapete de Ectoprocta em modo Q com uso do Índice de Similaridade de Morisita-Horn e estratégia de agrupamento WPGMA. A linha vertical indica o limite de significância superior, a partir do qual os grupos são considerados significativos, para uma confiabilidade de $95 \%$.

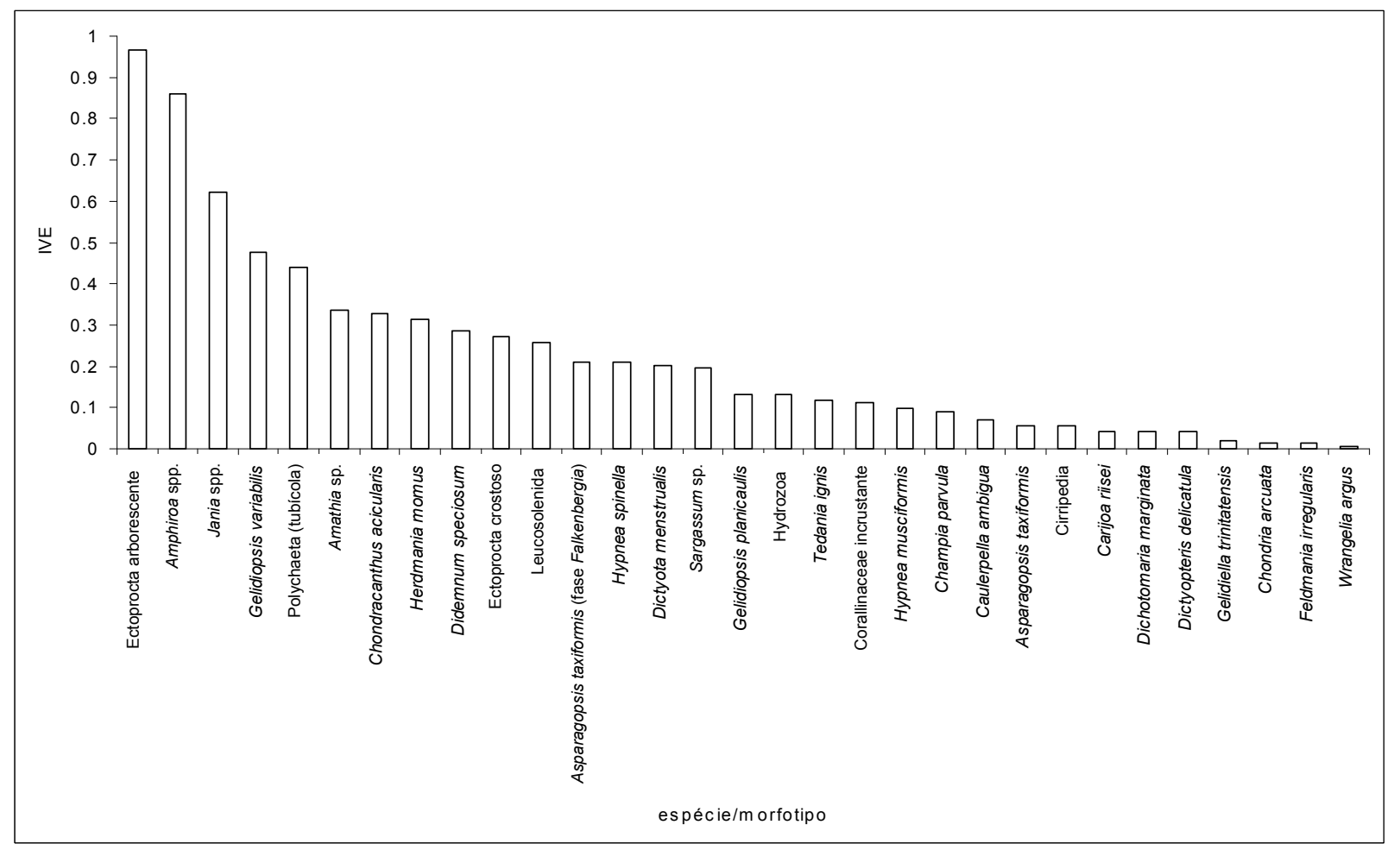

Figura 4.10 - IVE das espécies/morfotipos dos elementos amostrais formadores do Grupo 1 com a utilização do Índice de Similaridade Quantitativo de Morisita-Horn para o povoamento Tapete de Ectoprocta. 


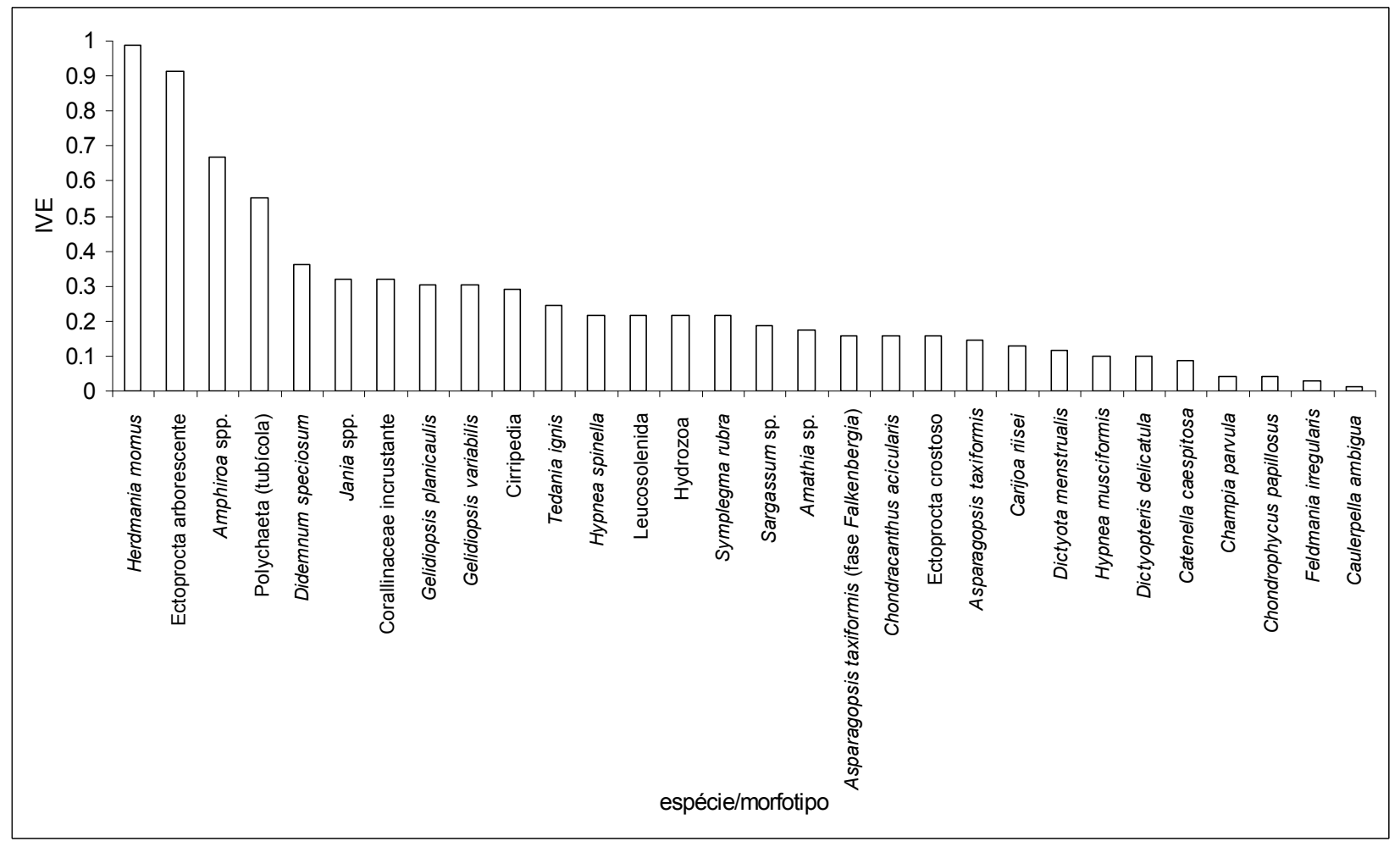

Figura 4.11 - IVE das espécies/morfotipos dos elementos amostrais formadores do Grupo 2 com a utilização do Índice de Similaridade Quantitativo de Morisita-Horn para o povoamento Tapete de Ectoprocta.

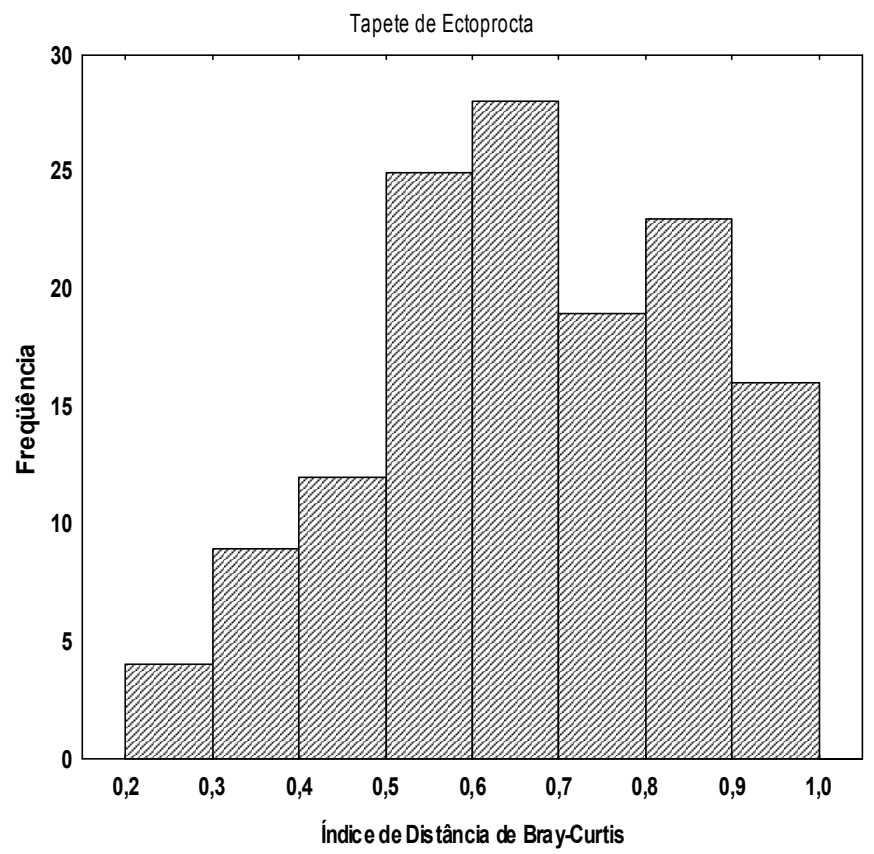

Figura 4.12 - Distribuição de freqüências das distâncias de Bray-Curtis entre os elementos amostrais, combinados 2 a 2, constituintes do povoamento Tapete de Ectoprocta. 


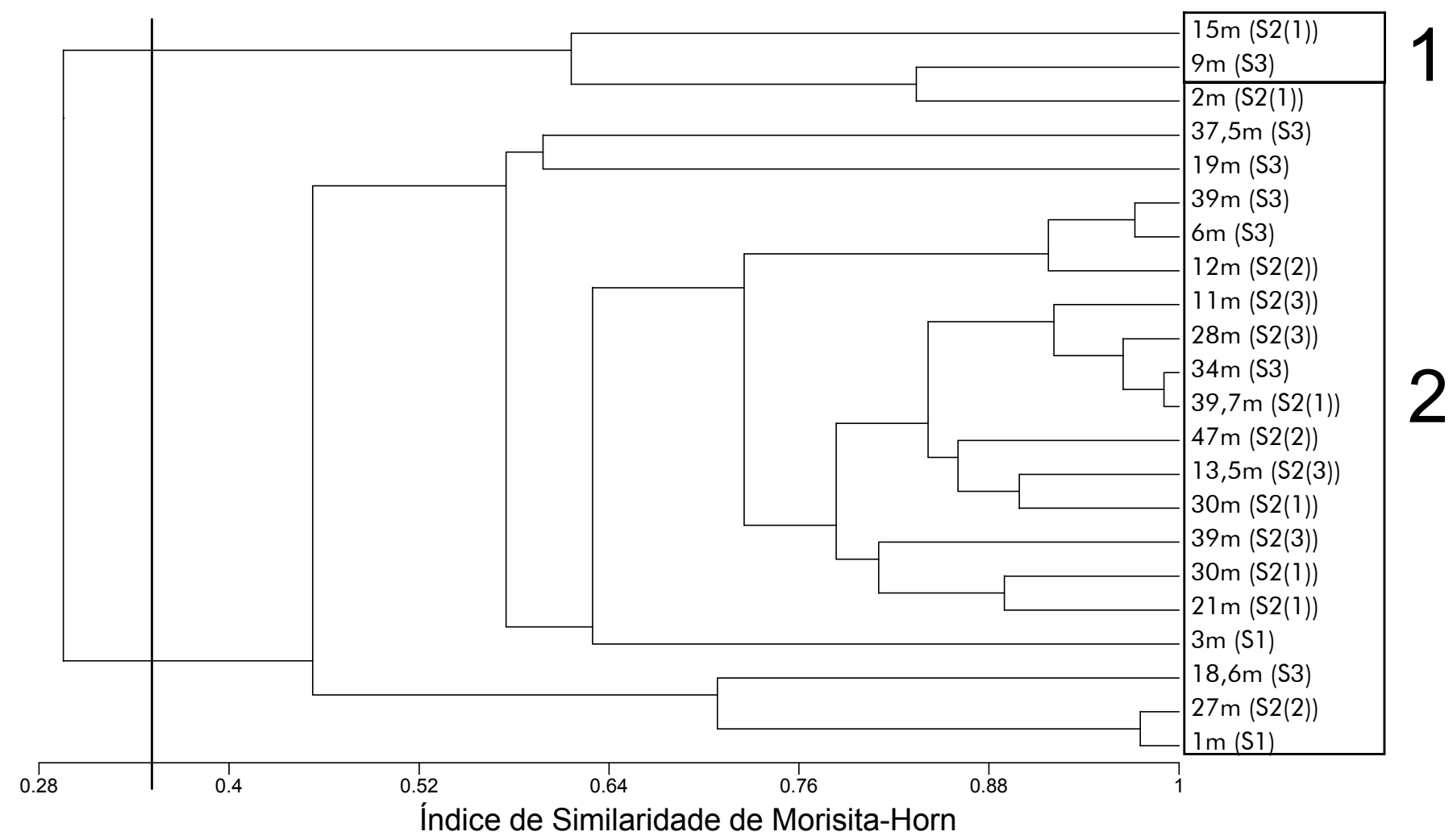

Figura 4.13 - Repartição espacial da comunidade do povoamento Tapete de Gelidiopsis e Hypnea em modo Q com uso do Índice de similaridade de Morisita-Horn e estratégia de agrupamento WPGMA. A linha vertical indica o limite de significância superior, a partir do qual os grupos podem ser considerados significativos, para uma confiabilidade de $95 \%$.

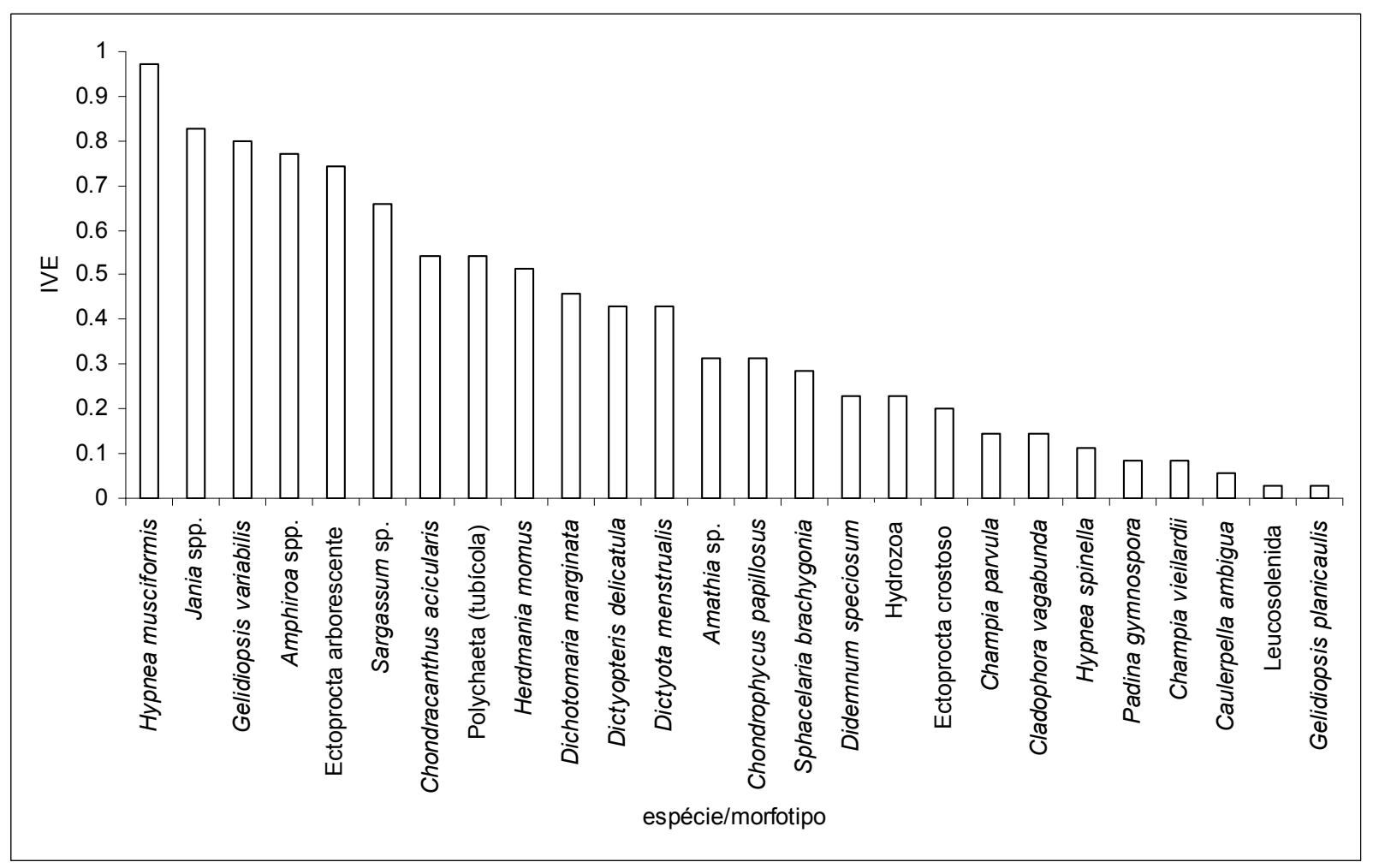

Figura 4.14 - IVE das espécies/morfotipos dos elementos amostrais formadores do Grupo 1 com a utilização do Índice de Similaridade Quantitativo de Morisita-Horn para o povoamento Tapete de Gelidiopsis e Hypnea. 


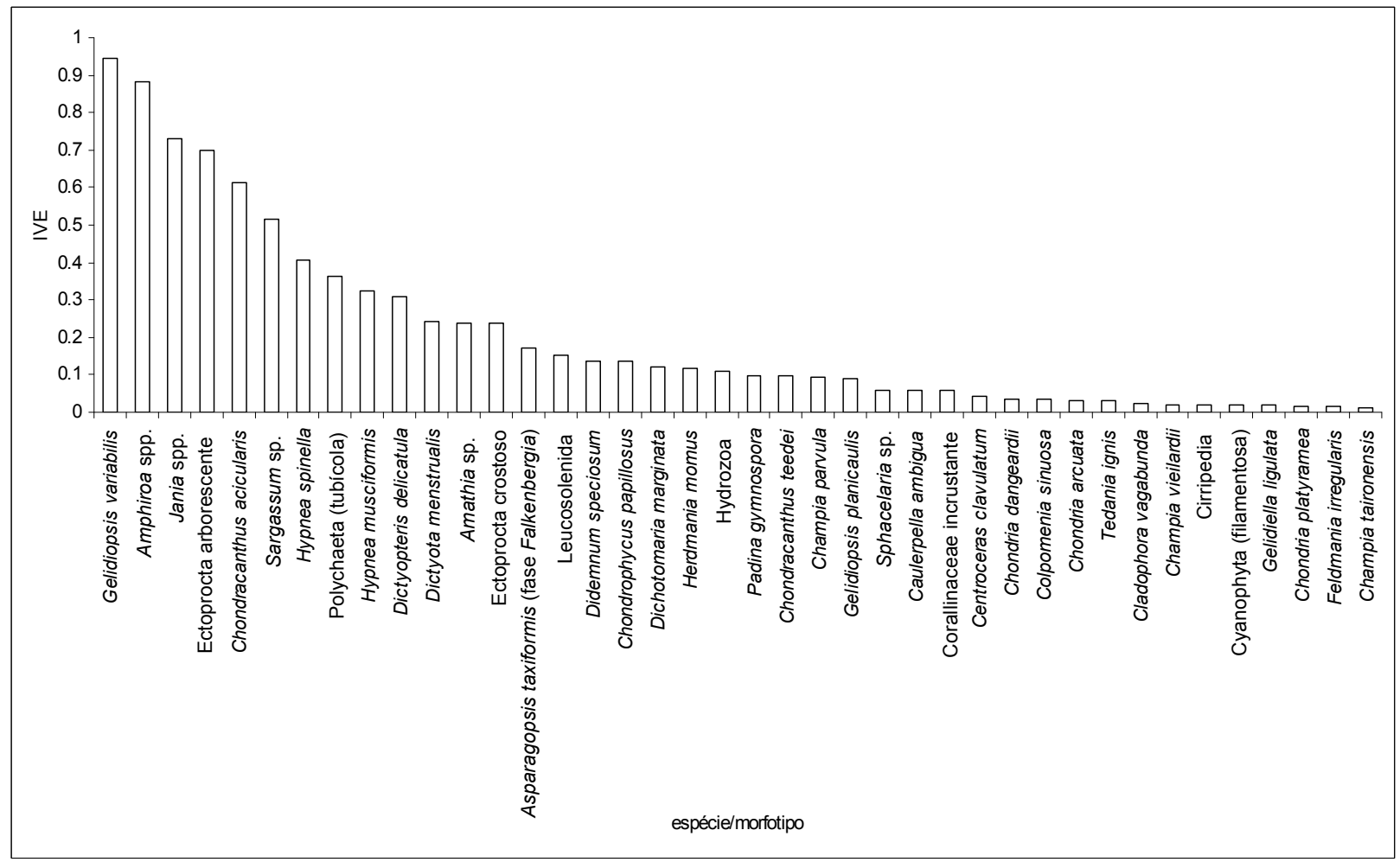

Figura 4.15 - IVE das espécies/morfotipos dos elementos amostrais formadores do Grupo 2 com a utilização do Índice de Similaridade Quantitativo de Morisita-Horn para o povoamento Tapete de Gelidiopsis e Hypnea.

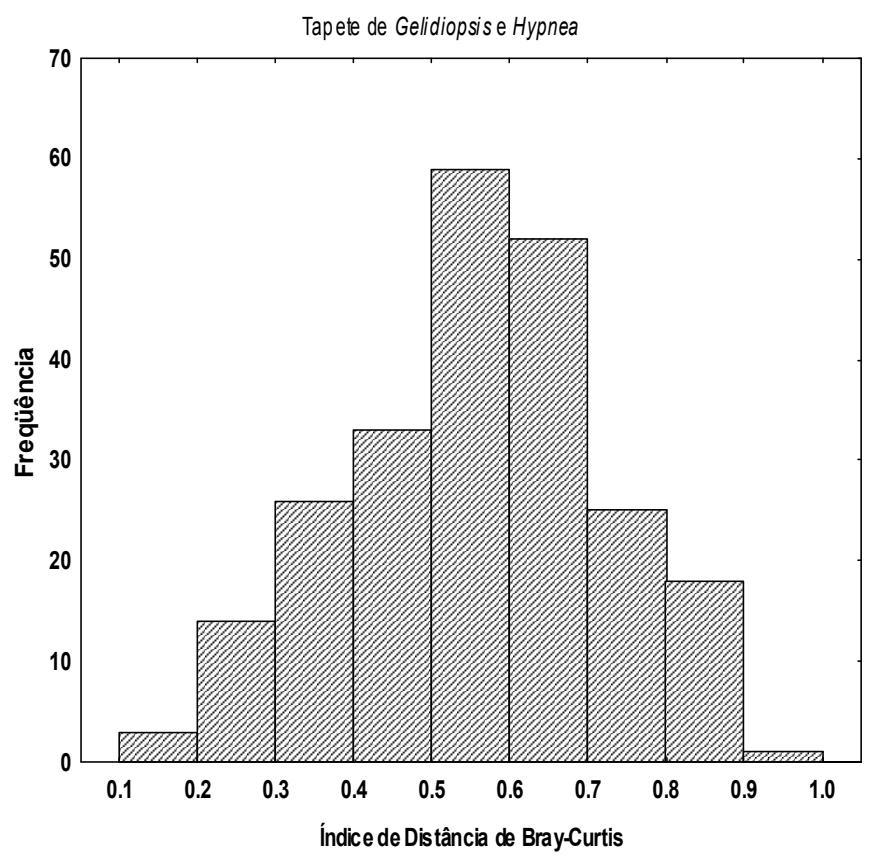

Figura 4.16 - Distribuição de freqüências das distâncias de Bray-Curtis entre os elementos amostrais, combinados 2 a 2, constituintes do povoamento Tapete de Gelidiopsis e Hypnea. 
Já para o povoamento Banco de Sargassum foram obtidos os níveis de significância mínimo de 0,24 e máximo de 0,39 para o Índice de Similaridade Quantitativo de MorisitaHorn. O dendrograma apresentou a formação de apenas um agrupamento significativo (Figura 4.17), sendo que o valor de similaridade ficou acima de $82 \%$.

O IVE das espécies/morfotipos para este povoamento mostrou a grande importância das espécies do gênero Sargassum $(0,995)$ e de Substrato Inconsolidado $(0,745)$ e Scrupocellaria sp. $(0,646)$ (Figura 4.18).

Considerando-se os níveis críticos mínimo $(0,12)$ e máximo $(0,39)$ de significância calculados para o Índice de Distância de Bray-Curtis para este povoamento, nota-se que o mesmo pode ser considerado homogêneo, já que apresentou maior número de observações entre 0,1 e 0,2 de distância (Figura 4.19).

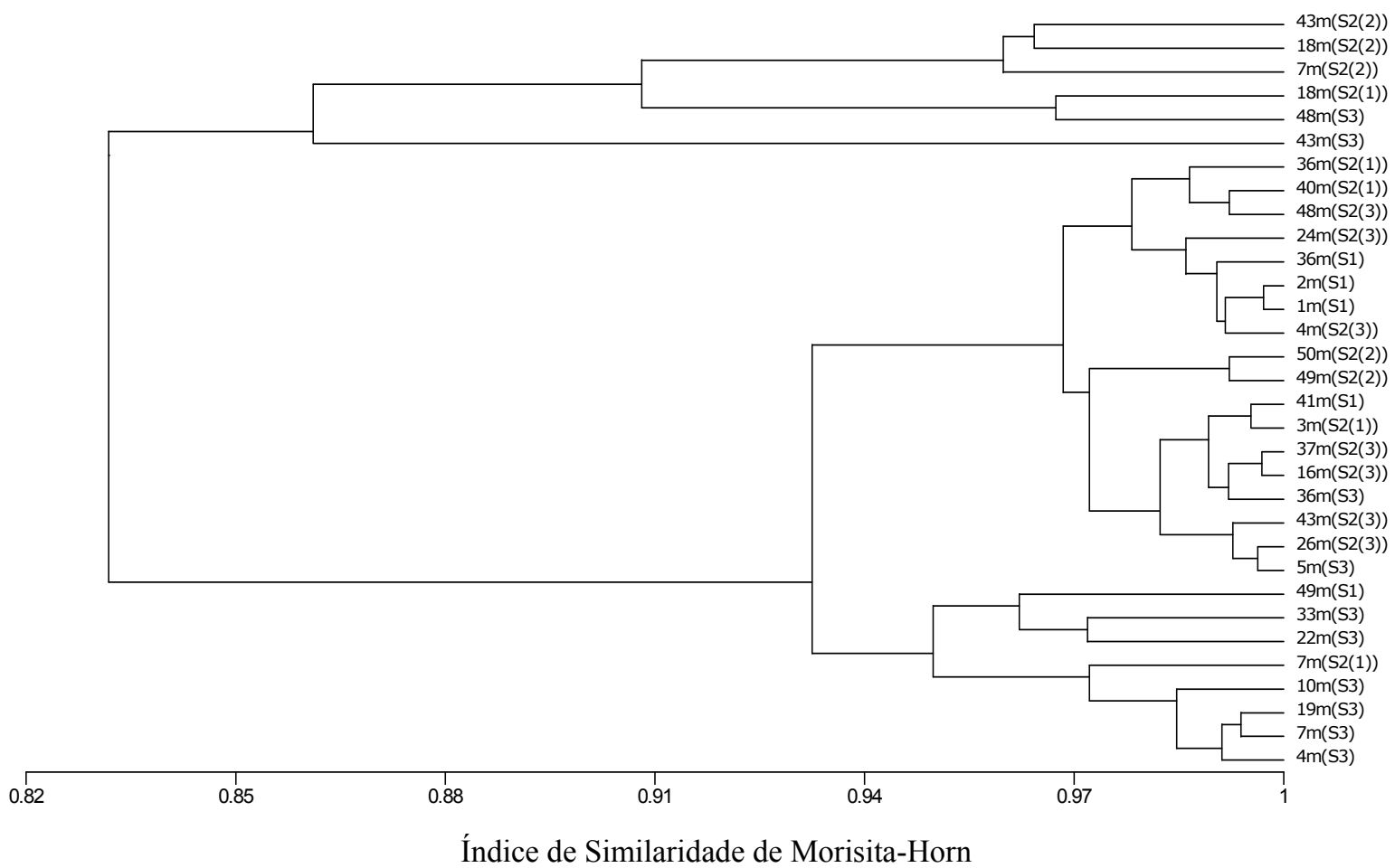

Figura 4.17 - Repartição espacial da comunidade do povoamento Banco de Sargassum em modo Q com uso do Índice de Similaridade de Morisita-Horn e estratégia de agrupamento WPGMA. 


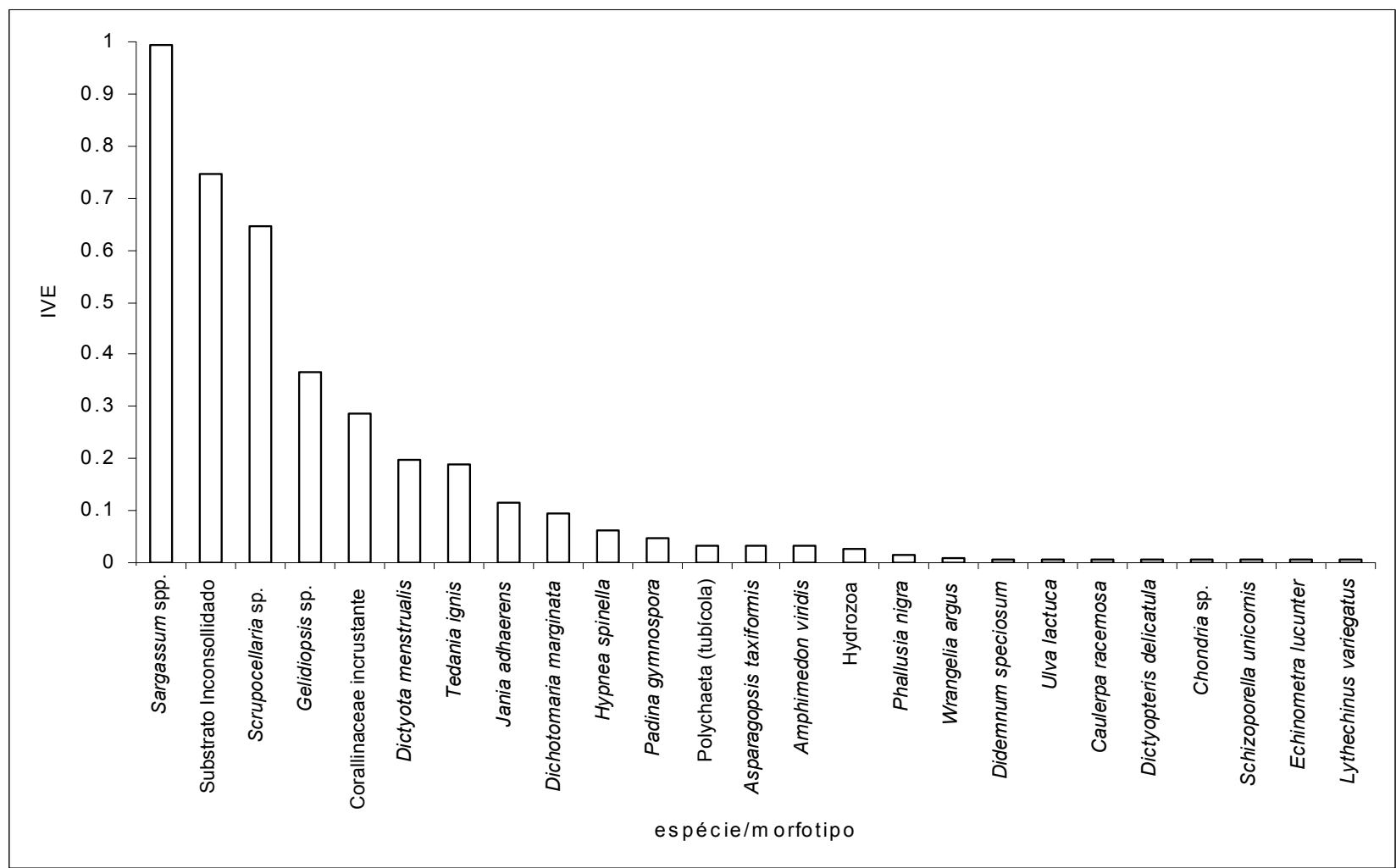

Figura 4.18 - IVE das espécies/morfotipos dos elementos amostrais formadores do grupo com a utilização do Índice de Similaridade Quantitativo de Morisita-Horn para o povoamento Banco de Sargassum.

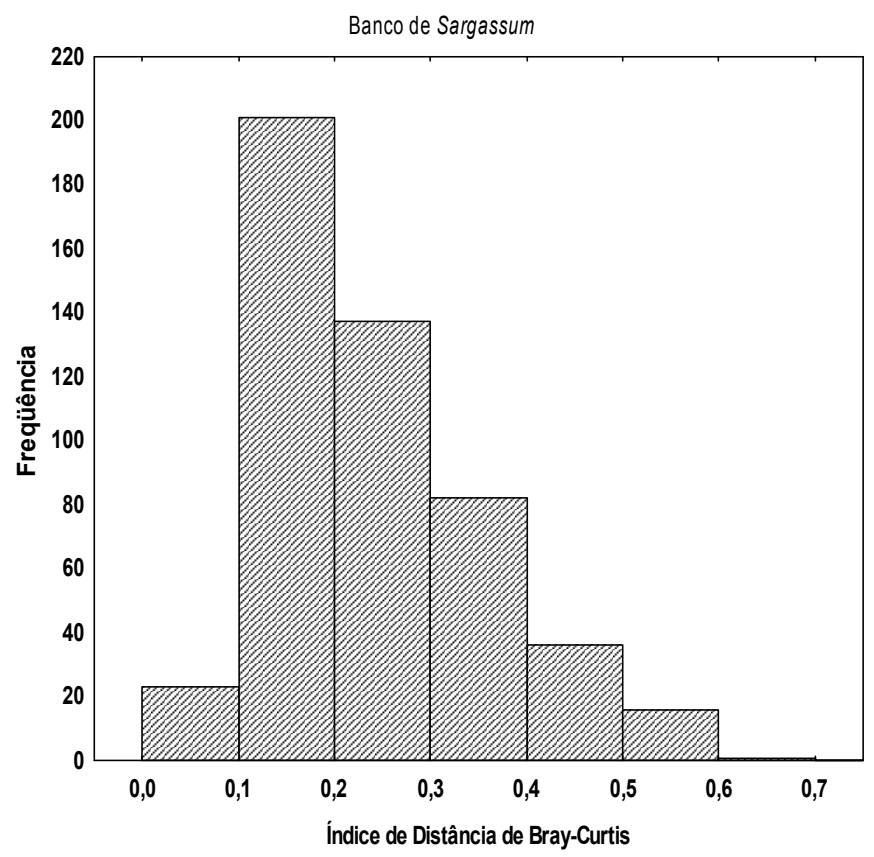

Figura 4.19 - Distribuição de freqüências das distâncias de Bray-Curtis entre os elementos amostrais, combinados 2 a 2, constituintes do povoamento Banco de Sargassum. 


\section{4) Estrutura dos domínios em termos de riqueza e diversidade}

As Figuras 4.20 a 4.22 evidenciam as análises espectrais dos descritores Riqueza, Diversidade de Shannon e Diversidade de Simpson para os quatro povoamentos.

A Figura 4.20 mostra que a suficiência amostral para estimativa de Riqueza foi obtida para todos os povoamentos, sendo que o número de elementos amostrais que satisfazem as condições impostas pelas notações dos pontos Calleja foram bastante semelhantes, sendo de 14 para Banco de Sargassum, 17 para Tapete de Amphiroa e Jania, 12 para Tapete de Ectoprocta e 14 para Tapete de Gelidiopsis e Hypnea.

A Figura 4.21 mostra que a suficiência amostral para estimativa do Índice de Diversidade de Shannon foi obtida para todos os povoamentos, sendo que o número de elementos amostrais necessários para satisfazer as condições impostas pelas notações dos pontos Calleja aumentou de Banco de Sargassum (8) para Tapete de Amphiroa e Jania (10) para Tapete de Ectoprocta (11) e finalmente para Tapete de Gelidiopsis e Hypnea (14).

A Figura 4.22 mostra que a suficiência amostral para estimativa do Índice de Diversidade de Simpson foi obtida para todos os povoamentos, sendo que o número de elementos amostrais necessários para satisfazer as condições impostas pelas notações dos pontos Calleja foi maior para Tapete de Gelidiopsis e Hypnea. 


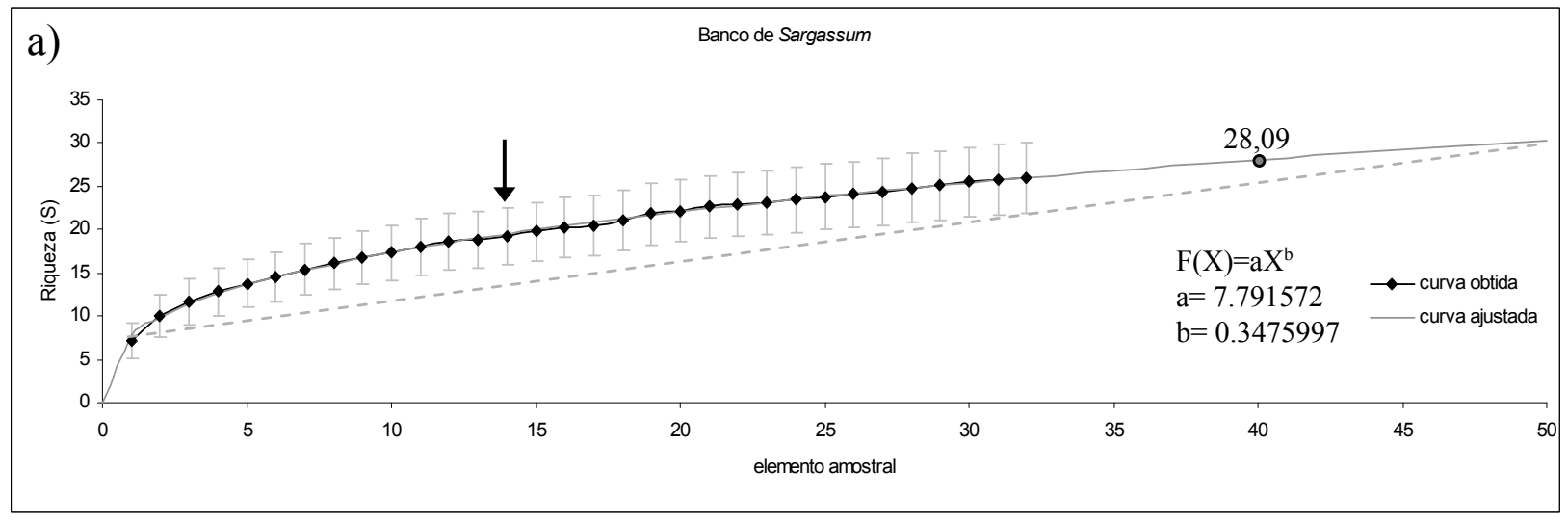

b) Tapete de Amphiroa e Jania
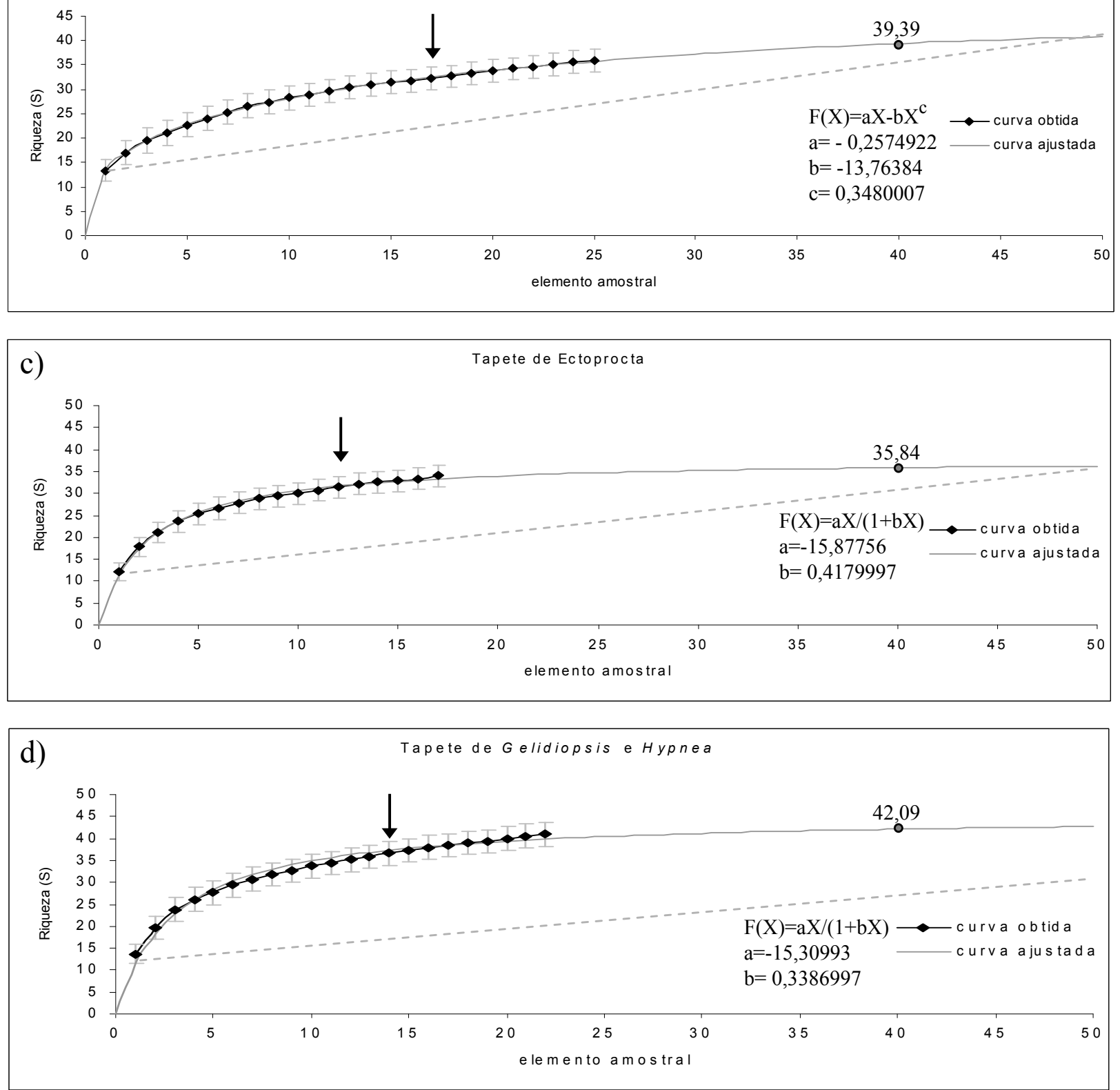

Figura 4.20 - Espectros da Riqueza (obtido e ajustado) para os povoamentos a) Banco de Sargassum, b) Tapete de Amphiroa e Jania, c) Tapete de Ectoprocta e d) Tapete de Gelidiopsis e Hypnea. A função de ajustamento está indicada no gráfico, assim como o valor do índice para uma área equivalente a 40 elementos amostrais. As setas indicam o ponto de estabilização segundo o ponto Calleja definido. As barras verticais representam o desvio padrão. 

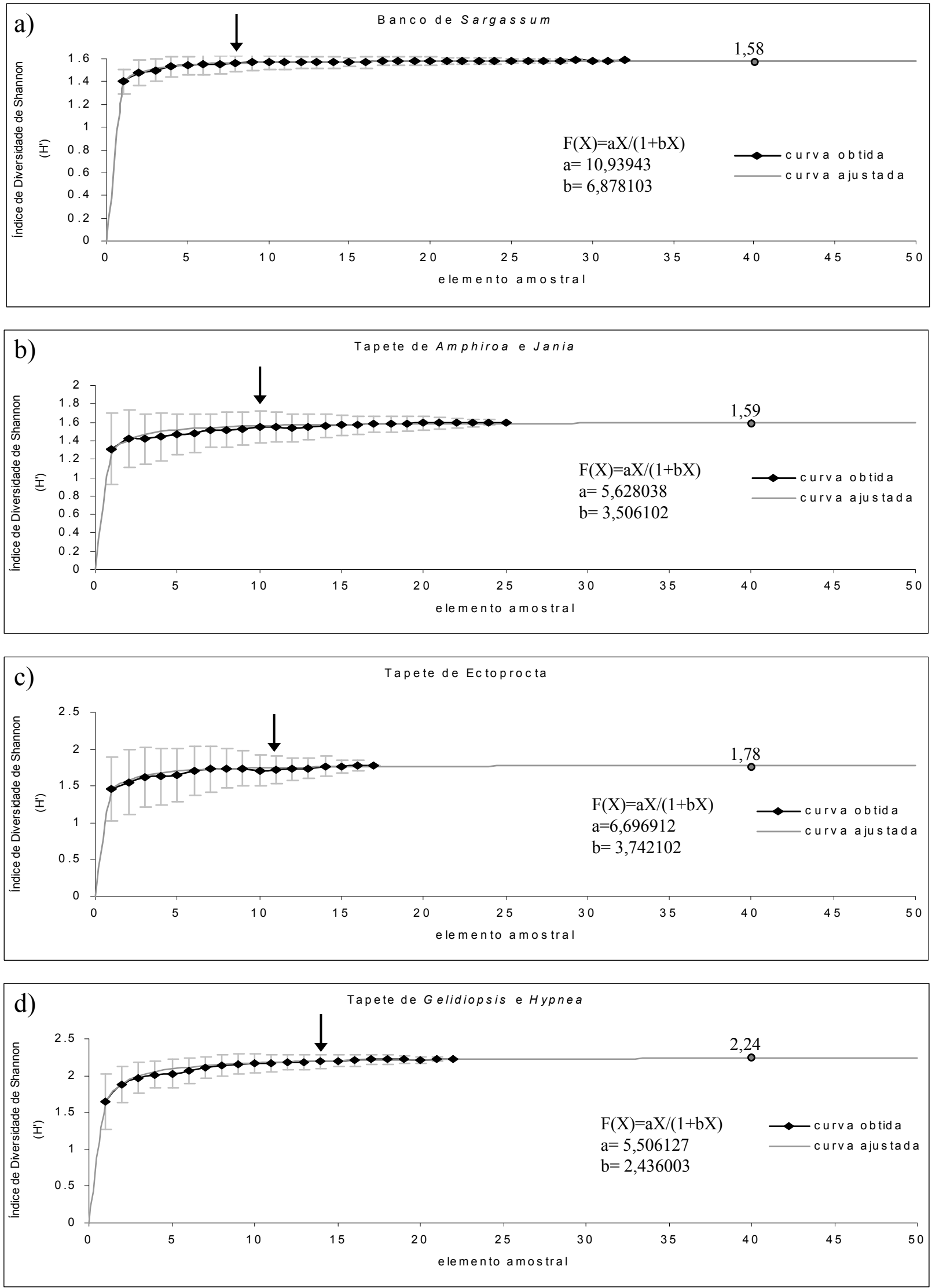

Figura 4.21 - Espectros da Diversidade de Shannon (obtido e ajustado) para os povoamentos a) Banco de Sargassum, b) Tapete de Amphiroa e Jania, c) Tapete de Ectoprocta e d) Tapete de Gelidiopsis e Hypnea. A função de ajustamento está indicada no gráfico, assim como o valor do índice para uma área equivalente a 40 elementos amostrais. As setas indicam o ponto de estabilização segundo o ponto Calleja definido. As barras verticais representam o desvio padrão. 

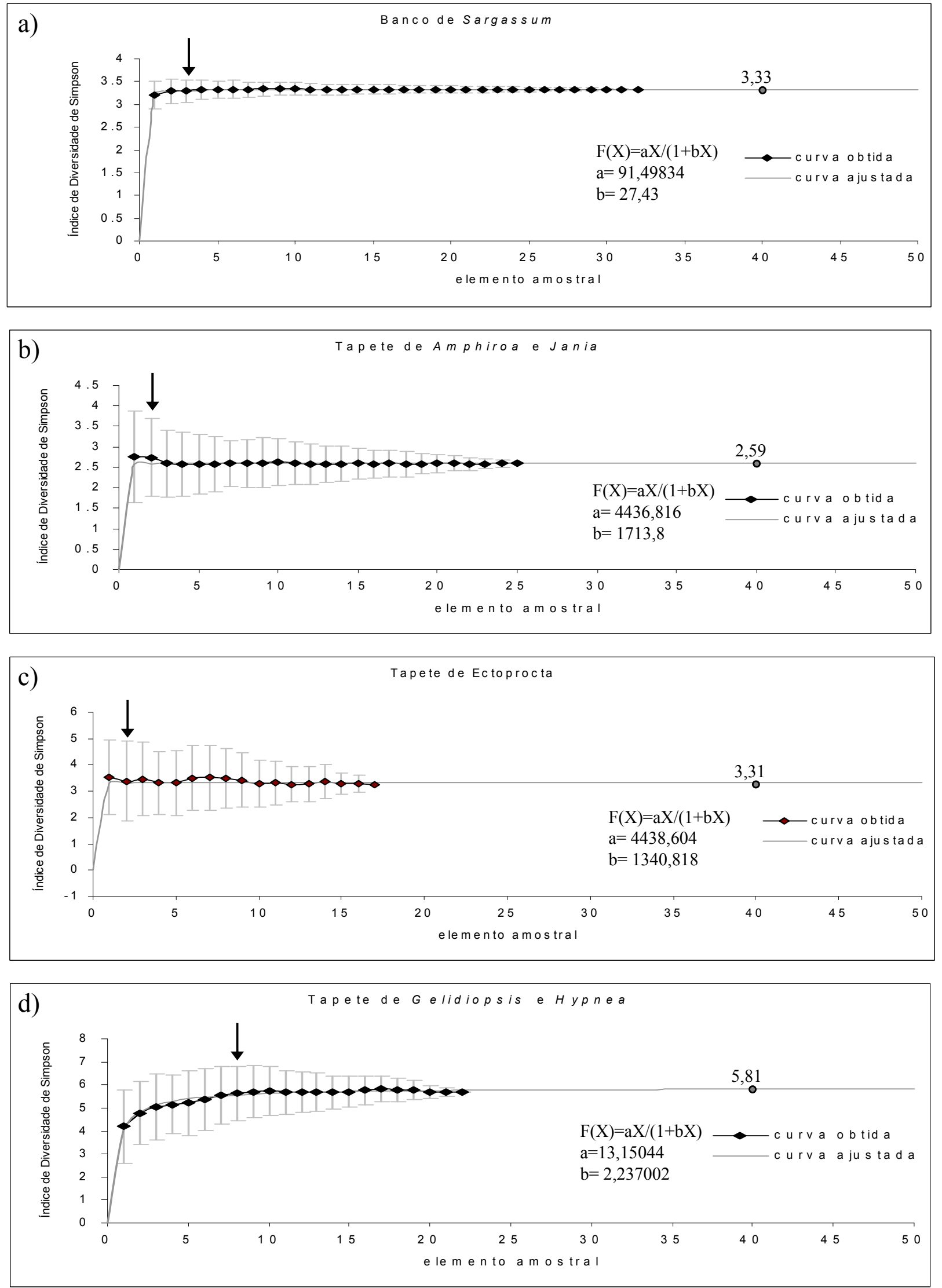

Figura 4.22 - Espectros da Diversidade de Simpson (obtido e ajustado) para os povoamentos a) Banco de Sargassum, b) Tapete de Amphiroa e Jania, c) Tapete de Ectoprocta e d) Tapete de Gelidiopsis e Hypnea. A função de ajustamento está indicada no gráfico, assim como o valor do índice para uma área equivalente a 40 elementos amostrais. As setas indicam o ponto de estabilização segundo o ponto Calleja definido. As barras verticais representam o desvio padrão. 


\section{DISCUSSÃo}

Os resultados aqui mostrados evidenciaram a estruturação de quatro povoamentos.

O número de espécies encontradas nestes povoamentos na Abordagem 1 do método "Levantamento Fisionômico" (6 espécies dominantes, ou seja, com 80\% ou mais do recobrimento do povoamento) representa $10 \%$ do número encontrado na Abordagem 4. Isso era esperado, dado o esforço despendido na amostragem e análise dos dados da Abordagem 4, evidenciando que as diferentes técnicas devem ser usadas com propósitos distintos, sendo a primeira para uma caracterização inicial rápida e abrangente da repartição-espacial dos povoamentos e a última para a verificação de sua variação espacial e/ou temporal.

A maior representatividade das rodofíceas, em termos de número de espécies/morfotipos, está de acordo com o esperado para a região (Taylor, 1960; Joly, 1965; Yoneshigue-Braga, 1971, 1972a, 1972b; Ugadim, 1973, 1974, 1975, 1976; Oliveira Filho, 1977; Pedrini, 1980; Yoneshigue, 1985; Wynne, 1986; Lüning, 1990; Mitchell et al., 1990; Stuercke \& Mcdermid, 2004).

Em geral as macroalgas foram dominantes nos povoamentos, exceto em Tapete de Ectoprocta, no qual ficaram em segundo lugar. Yaobin (1999) encontrou biomassa sempre maior para os animais em seus pontos de coleta. Entretanto, o autor utilizou peso seco nas suas análises e as partes calcárias podem ter influenciado neste resultado.

No caso de Banco de Sargassum, o padrão de recobrimento das macroalgas (97,3\%) e do próprio gênero Sargassum $(90,5 \%)$ encontrado foi semelhante ao relatado por Széchy (1996), sendo que a autora encontrou valores de recobrimento de macroalgas entre $64,7 \%$ a $100 \%$ e de Sargassum de até $98,9 \%$. Isso permite considerar este banco como um povoamento segundo a definição do método "Levantamento Fisionômico", já que a(s) espécie(s) dominante(s) ocupam mais de $80 \%$ da área do mesmo.

O padrão do banco encontrado na Ilha Anchieta é análogo ao referido por Ang Jr. (1986) como tendo cobertura máxima de Sargassum e foi referido por Széchy (1996) como 
padrão de cobertura 3a e por Széchy \& Paula (2000) como padrão B1. Neste padrão, outras algas eretas também são importantes, como Dictyopteris delicatula, Hypnea spp., Dichotomaria spp., assim como poríferos, todos encontrados no presente estudo. Além disso, Gelidiopsis spp., Asparagopsis taxiformis e animais sésseis, como briozoários e hidrozoários, também são presentes neste padrão, apresentando seus maiores valores de cobertura, apesar de pouco expressivos, o que corrobora em parte o que foi encontrado no presente estudo, já que Gelidiopsis sp. e Scrupocellaria sp. foram mais representativos do que outras espécies.

Este padrão parece ser típico de locais protegidos a moderados, que formam bancos densos e homogêneos quanto à físionomia, com algas calcárias articuladas e crostosas presentes, mas não abundantes, o que se verificou no presente estudo. Jania adhaerens e crostas calcárias têm sido referidas junto a populações de Sargassum por outros autores, como Kimura et al. (1987), que confirmaram a importância da família Corallinaceae em bancos de Sargassum okamurae Yoshida et T. Konno, na Baía de Tosa, Japão e Van den Hoek (1969) que as citou como as mais freqüentes em três tipos de bancos de Sargassum do litoral de Curaçao. Este último autor citou também a presença pouco expressiva de Dictyopteris delicatula, o que também ocorreu no presente estudo.

Vale ressaltar ainda a presença de Padina gymnospora e de Phallusia nigra associadas a este banco na área de estudo. Espécies de Padina foram encontradas junto a populações de Sargassum por muitos autores que trabalharam no litoral brasileiro (Joly, 1951; Costa, 1962; Paula \& Oliveira Filho, 1980; Oliveira Filho \& Paula, 1983; Eston et al., 1986; Yoneshigue \& Valentin, 1988; Figueiredo, 1989). Trono Jr. \& Lluisma (1990) incluíram Padina spp. dentre as espécies de macroalgas mais abundantes em bancos de Sargassum de Bolinao, Filipinas. No presente estudo, entretanto, a espécie não apresentou cobertura significativa (cerca de $2 \%$ ). Esse gênero de crescimento rápido também foi encontrado durante a recolonização em comunidades de Sargassum de locais protegidos do litoral do Estado de São Paulo (Paula, 1978; Paula \& Eston, 1987; Eston \& Bussab, 1990). 
Já os ascidiáceos foram reconhecidos como representantes importantes de bancos de Sargassum do litoral brasileiro (Nonato \& Péres; Oliveira Filho \& Mayal, 1976; Maggs et al., 1979; Eston \& Bussab, 1990) e da Austrália (Underwood et al., 1991). No presente estudo apresentaram cobertura baixa, em torno de $1 \%$.

De forma geral, o povoamento Banco de Sargassum amostrado no Parque Estadual da Ilha Anchieta foi condizente com o descrito para outras áreas do sudeste brasileiro. $\mathrm{O}$ povoamento foi bastante homogêneo ao longo da área de estudo, como pode ser verificado pelo dendrograma utilizando o Índice de Similaridade Quantitativo de Morisita-Horn, no qual foi encontrado apenas um agrupamento significativo envolvendo todos os elementos amostrais, e também pela distribuição de freqüências do Índice de Distância Quantitativo de Bray-Curtis, que apresentou maior número de observações entre 0,1 e 0,2 . Esta homogeneidade foi verificada para o litoral dos estados de São Paulo e Rio de Janeiro (Széchy \& Paula, 2000), sendo que algumas espécies são descritas como características para o banco por ocorrerem em mais de 70\% das amostragens. Estas espécies são: Dictyopteris delicatula, Hypnea musciformis (as espécies mais freqüentes), Amphiroa brasiliana, Jania adhaerens, Pneophyllum fragile, Gelidiopsis planicaulis, G. variabilis, Asparagopsis taxiformis - fase tetrasporofítica, Hypnea spinella, Dictyota cervicornis, Ulva fasciata, Chondracanthus teedei e Padina gymnospora e a maior parte delas foi encontrada na Ilha Anchieta.

No caso do povoamento Tapete de Amphiroa e Jania, o fato das espécies da Divisão Rhodophyta serem as mais representadas em número corrobora o encontrado por Arantes et al. (1995) para o Estado do Espírito Santo, no único estudo realizado com bancos de algas calcárias articuladas no Brasil. Das 27 espécies de algas encontradas no presente estudo, 48\% foram encontradas por estes autores em bancos de algas calcárias do estado.

As espécies dominantes formadoras deste povoamento representaram $70 \%$ da biomassa total, valor inferior aos $80 \%$ que define um povoamento. Entretanto, deve-se levar 
em consideração que o descritor primário utilizado foi a biomassa e não o recobrimento percentual o qual, em campo, mostrou satisfazer esta condição.

O valor do Índice de Diversidade de Shannon $(1,78)$ ficou dentro do intervalo de valores (entre 0,64 e 3,02) encontrado por Arantes et al. (1995) para manchas de Amphiroa brasiliana. Já os valores médios de biomassa seca foram bem maiores para o Espírito Santo, sendo de $14,32 \mathrm{~g} / 100 \mathrm{~cm}^{2}$ contra apenas $3,62 \mathrm{~g} / 100 \mathrm{~cm}^{2}$ para o costão amostrado no presente estudo.

Este povoamento apresentou-se homogêneo com a utilização do índice de MorisitaHorn, com a formação de apenas dois agrupamentos significativos, sendo um contendo apenas dois elementos amostrais (Grupo 1) e o outro os demais (Grupo 2). Nos dois agrupamentos, as espécies do gênero Amphiroa foram bastante importantes, entretanto no Grupo 1 Herdmania momus foi a espécie mais importante. Esta espécie permanecia sempre mascarada pela cobertura das calcárias articuladas, muitas vezes servindo como substrato para o mesmo e, por isso, decidiu-se considerar estes dois agrupamentos como fácies de um mesmo povoamento ao invés de dividí-lo em mais de um, já que o método "Levantamento Fisionômico" é baseado no reconhecimento visual de manchas em campo e certamente a presença de $H$. momus só é percebida quando a amostragem destrutiva é realizada.

Esta razoável homogeneidade também pode ser observada pela grande quantidade de valores entre 0,3 e 0,6 e uma pequena entre 0,7 e 0,9 encontradas para este povoamento na distribuição de freqüências do Índice de Distância de Bray-Curtis, corroborando a existência de um grande número de elementos amostrais semelhantes entre si e um pequeno número, possivelmente aqueles formadores do Grupo 1, pouco semelhante com o restante.

No povoamento Tapete de Gelidiopsis e Hypnea, as espécies dominantes somaram apenas $44 \%$ da biomassa total, mas, da mesma forma que no Tapete de Amphiroa e Jania, deve-se levar em consideração o recobrimento percentual destas espécies em campo. 
Este povoamento apresentou dois agrupamentos significativos, um contendo dois elementos amostrais (Grupo 1) e o outro contendo os demais (Grupo 2). No Grupo 1 Hypnea musciformis foi a mais importante e no Grupo 2, Gelidiopsis variabilis. Estas duas espécies são consideradas como as definidoras deste povoamento e, portanto, esta alternância da dominância entre elas novamente mostra um povoamento que se apresenta como duas fácies na área de estudo. O alto número de observações entre 0,5 e 0,6 na distribuição de freqüências do Índice de Distância de Bray-Curtis demonstra que é um povoamento que pode ser considerado homogêneo, com uma certa variação nas abundâncias relativas das espécies/morfotipos intermediárias, o que é esperado em comunidades naturais.

Existe uma carência de estudos ecológicos estruturais relacionados com este povoamento. Apesar de H. musciformis apresentar uma distribuição mundial, os dados ecológicos são principalmente relacionados com variação sazonal da biomassa ou estudos de populações (Faccini \& Berchez, 2000). Tanto espécies de Hypnea quanto de Gelidiopsis apresentaram altos valores de biomassa em comunidades de infralitoral da Baía de Sepetiba, no Estado do Rio de Janeiro (Amado Filho et al., 2003), mas sua importância para a estruturação de outras comunidades do país ainda é pouco conhecida.

Finalmente, no povoamento Tapete de Ectoprocta, a espécie H. momus foi dominante em termos de biomassa em diversos elementos amostrais e representou $44 \%$ da biomassa total, enquanto Ectoprocta Arborescente representou apenas 19\%. Da mesma forma que em Tapete de Amphiroa e Jania, H. momus permanecia mascarada pela cobertura dos Ectoprocta e apesar desta importância em termos de biomassa, sua presença provavelmente não seria notada através da avaliação visual realizada na Etapa 1 do método "Levantamento Fisionômico" e, portanto, julgou-se mais prudente considerar todos os elementos amostrais como parte de um só povoamento, o qual se apresenta na forma de duas fácies na área de estudo. 
Estas duas fácies ficaram evidentes pela formação de dois agrupamentos significativos no dendrograma quantitativo com a utilização do Índice de Similaridade de Morisita-Horn.

A análise de distribuição de freqüências do Índice de Distância Quantitativo de BrayCurtis evidenciou uma heterogeneidade interna neste povoamento, com razoável número de observações entre 0,8 e 1,0. Isso pode ser explicado não só pela diferença da espécie mais importante entre os dois grupos do dendrograma, mas também pela alteração da importância de algumas espécies/morfotipos intermediários, como pode ser observado pela análise de IVE para Polychaeta (tubícola), espécies do gênero Amphiroa e Gelidiopsis variabilis.

Esta heterogeneidade também ficou evidente no espectro de riqueza do povoamento, que foi mais diagonal do que os demais, sugerindo maior grau de estruturação deste povoamento.

Um maior detalhamento deste povoamento não foi possível principalmente devido à falta de especialistas neste grupo atuantes no país, o que dificultou a identificação das espécies e a sua separação em um maior número de UTOs. Entretanto, por não haver nenhum estudo no Brasil com este enfoque para este povoamento, os dados aqui obtidos já são de extrema importância para o estabelecimento de um conhecimento de base a respeito do mesmo.

As análises espectrais mostraram que houve suficiência amostral, referente aos pontos Calleja adotados, para todos os descritores utilizados e que, portanto, as considerações relativas aos povoamentos podem ser consideradas como representativas do que realmente ocorre na área de estudo.

Em contraste com os espectros de Riqueza que se mostraram diagonais, os espectros da Diversidade de Shannon para os quatro povoamentos se mostraram bastante retangulares, demonstrando que quantitativamente e sob uma condição de menor participação de espécies menos importantes os povoamentos são mais homogêneos. 
Os espectros da Diversidade de Simpson também se apresentaram bastante retangulares, exceto no caso de Tapete de Gelidiopsis e Hypnea, que também apresentou-se mais diverso.

Os povoamentos com maior Riqueza foram Tapete de Ectoprocta (34) e Tapete de Gelidiopsis e Hypnea (41). Entretanto, a falta de estudos existente para estes povoamentos impede que conclusões mais aprofundadas sejam feitas em relação a ambos. A menor riqueza encontrada para Banco de Sargassum era de certa forma esperada, já que o método utilizado para descrição deste povoamento foi o da interseção de pontos e a identificação dos organismos foi realizada em campo, dificultando a observação de organismos menores e mais raros.

O Índice de Diversidade de Shannon para os quatro povoamentos ficou entre 1,6 e 2,2. Os povoamentos mais diversos também foram Tapete de Ectoprocta $(1,78)$ e Tapete de Gelidiopsis e Hypnea (2,22). Segundo Margalef (1972) e May (1975) é de se esperar que os valores calculados do Índice de Shannon sempre se encontrem em um intervalo entre 1,5 e 3,5 podendo muito eventualmente atingir até 4,5. No presente estudo, no caso dos tapetes foram usadas unidades de biomassa para o cálculo do índice e, portanto, os valores encontrados sugerem como é uso de energia por estes tapetes no ambiente (Wolda, 1968), sendo maior para Tapete de Gelidiopsis e Hypnea.

As maiores Riqueza, Diversidade de Shannon e Diversidade de Simpson encontradas para o Tapete de Gelidiopsis e Hypnea podem indicar que este povoamento é mais complexo que os demais, apresentando uma maior diversidade de fluxos de energia entre seus organismos componentes, já que os dados usados para o cálculo dos dois índices de diversidade foram baseados na biomassa orgânica.

A relativa constância espacial dos povoamentos na área de estudo indica que a mesma apresenta uma uniformidade espacial relacionada com os fatores bióticos e abióticos nela atuantes (Menge et al., 1985). Entretanto, como os elementos amostrais foram coletados em 
porções do substrato diferenciadas em termos de inclinação, profundidade e hidrodinamismo, provavelmente os fatores abióticos apresentaram alguma variação e, portanto, fatores bióticos, como por exemplo a falta de um predador para controlar a alta densidade do competidor dominante, e características biológicas das espécies dominantes, como a alta capacidade reprodutiva, podem ter determinado esta constância (Lubchenco, 1978). Em costões temperados existem padrões relativamente regulares de recrutamento das espécies e também predadores de topo específicos e vorazes (Underwood \& Denley, 1984), o que muitas vezes, não se aplica a costões tropicais e isso pode explicar a variação encontrada nas abundâncias relativas das espécies componentes de alguns povoamentos, resultando na ocorrência de fácies.

Em síntese, os povoamentos aqui analisados podem ser considerados unidades ecológicas, já que foram homogêneos ou apresentaram-se na forma de fácies ao longo da área de estudo. Mais estudos são necessários para verificar se a estrutura encontrada no Parque Estadual da Ilha Anchieta se repete em outras áreas, principalmente em relação aos povoamentos Tapete de Ectoprocta e Tapete de Gelidiopsis e Hypnea, que carecem de estudos ecológicos.

A comunidade foi descrita estruturalmente, revelando a sua diversidade e como as espécies se organizam no espaço, fornecendo informações e dados para estudos experimentais que visem determinar os processos responsáveis pela determinação desta estrutura como, por exemplo, o padrão de mosaico em pequena escala (patches), que pode ser explicado por diversos fatores, como por exemplo, diferentes níveis de recrutamento e mortalidade das espécies caracterizadas como importantes (Hartnoll \& Hawkins, 1985); ocorrência simultânea de diferentes estágios sucessionais (Davis \& Wilce, 1987; Machado et al., 1992; BenedettiCechi et al., 1994) e variabilidade espacial na disponibilidade de larvas (Gaines \& Roughgarden, 1985). 



\section{REFERÊNCIAS}

Amado Filho, G.M.; Barreto, M.B.B.B.; Marins, B.V.; Felix, C.; Reis, R.P., 2003. Estrutura das comunidades fitobentônicas do infralitoral da Baía de Sepetiba, RJ, Brasil. Revista Brasil. Bot., v. 26, n. 3, p. 329-342.

ANG JR., P.O., 1986. Analysis of the vegetation structure of a Sargassum community in the Philippines. Mar. Ecol. Prog. Ser., v. 28, p. 9-19.

Arantes, P.V.S.; NASSAR, C.A.G.; Gestinari, L.M.S., 1995. Comunidades de algas calcárias articuladas na Baía do Espírito Santo. Nerítica, v. 9, n. 1-2, p. 33-48.

BAllesteros, E., 1986. Métodos de análisis estructural en comunidades naturales, en particular del fitobentos. Oecologia aquática, v. 8, p.117-131.

Benedetti-Cecchi, L.; Bulleri, F.; Cineli, F., 1994. Recovery of patches in an assemblage of geniculate coralline algae: variability at different successional stages. Mar. Ecol. Prog. Ser., v. 110, p. 9-18.

Berchez, F.; Rosso, S.; GhILARdI, N.P.; FuJII, M.T.; HAdEL, V., 2005. Characterization of hard bottom marine benthic communities: the physiognomic approach as an alternative to traditional methodologies. In: Sociedade Brasileira de Ficologia (Org.). Formação de Ficólogos: um compromisso com a sustentabilidade dos recursos aquáticos. Rio de Janeiro: Museu Nacional, Série Livros 10, p. 207-220.

BOHNSACK, J.A., 1979. Photographic quantitative sampling of hard bottom benthic communities. Bull. Mar. Sci, v.29, n.2, p.242-252.

BORGES, R.P., 1996. Abordagem temporal da repartição espacial, diversidade e dominância em uma comunidade de costão rochoso intermareal da Praia da Tatuíra, São Sebastião (SP). 97 f. Dissertação (Mestrado em Ecologia) - Instituto de Biociências, Universidade de São Paulo, São Paulo.

Boudouresque, C., 1971. Méthodes d'étude qualitative et quantitative du benthos (em particulier du phytobenthos). Tethys, v.3, n.1, p.79-104.

Boudouresque, C.; LuCK, H.B., 1972. Recherches de bionomie structurale au niveau d'un peuplement benthic sciaphile. J. Exp. Mar. Biol. Ecol., v. 8, n. 2, p. 133-144.

COIMBRA, C.S., 1998. Caracterização ecológica das comunidades bentônicas da região entremarés no costão sul da Praia do Itaguá, Ubatuba, SP. 136f. Dissertação (Mestrado) Instituto de Biociências, Universidade de São Paulo, São Paulo.

COLWELL, R. K., 1997. EstimateS: statistical estimation of species richness and shared species from samples. Version 7.50. User's Guide and Application. Disponível em: http://viceroy.eeb.uconn.edu/EstimateS . Acesso em: 10 mar. 2005. 
Connel, J.H., 1972. Community interactions on marine rocky intertidal shores. A. Rev. Ecol. Syst., v. 03, p. 169-192.

CostA, H.R., 1962. Note preliminaire sur les peuplements intercotidaux de substrat dur du littoral de Rio de Janeiro. Rec. Trav. St. Mar. End., bull. 27, fasc. 42, p. 197-207.

Costa Jr, O.S.; Attrill, M.J.; Pedrini, A.G.; De-Paula, J.C., 2002. Spatial and seasonal distribution of seaweeds on coral reefs from southern Bahia, Brazil. Botanica mar., Berlin, v. 45, p. 346-355.

Critchley, A.T., 1981. Ecological studies on Sargassum muticum (Yendo) Fensholt. 529f. Tese (Doutorado em Filosofia) - Porstmouth Polytechnic, Portsmouth.

DAVIS, A.N.; WILCE, R.T., 1987. Algal diversity in relation to physical disturbance: a mosaic of successional stages in a subtidal cobble habitat. Mar. Ecol. Prog. Ser., v. 37, p. 229237.

DAYTON, P.K., 1972. Toward an understanding of community resilience and the potential effects of enrichment to the benthos at McMurdo Sound, Antarctica. In: Baker, C. (ed). Proceedings of the colloquium on conservation problems in Antarctica. Kansas: Allen Press. p. 81-95.

Dethier, M.N.; Graham, E.S.; Cohen, S.; Tear, L.M., 1993. Visual versus random-point percent cover estimations: 'objective' is not always better. Mar. Ecol. Prog. Ser., Halstenbek, v. 96, p. 93-100.

De WeEdRE, R.E., 1985. Destructive (harvest) sampling. In: Littler, M.M.; Littler, D.S.(Eds).

Handbook of phycological methods. Ecological field methods: macroalgae. Cambridge: Cambridge University Press. cap. 7, p. 147-160.

Elton, C.S., 1958. The ecology of invasions by animals and plants. London: Methuen. $181 \mathrm{p}$.

ESTON, V.R.; BusSAB, W.O., 1990. An experimental analysis of ecological dominance in a rocky subtidal macroalgal community. J. Exp. Mar. Biol. Ecol., Amsterdam, v. 136, p. 170-195.

Eston, V.R. De; Migotto, A.E.; Oliveira Filho, E.C. De; Rodrigues, S.A.; Freitas, J.C., 1986. Vertical distribution of benthic marine organisms on rocky coasts of the Fernando de Noronha archipelago (Brazil). Bol. Inst. Oceanogr., São Paulo, v. 34, p. 37-54.

FACCINI, A.L.; BERCHEZ, F., 2000. Management of natural beds and standing stock evaluation of Hypnea musciformis (Gigartinales, Rhodophyta) in south-eastern Brazil. Journal of Applied Phycology, v. 12, p. 101-103.

Figueiredo, M.A.O., 1989. Ficoflora marinha bentônica do município de Paraty, Rio de Janeiro. 241f. Dissertação (Mestrado) - Museu Nacional, Universidade Federal do Rio 
de Janeiro, Rio de Janeiro.

Figueiredo, M.A.O.; BARReto, M.B.B.; ReIS, R.P., 2004. Caracterização das macroalgas nas comunidades marinhas da Área de Proteção Ambiental de Cairuçú, Parati, RJ - subsídios para futuros monitoramentos. Revista Brasil. Bot., São Paulo, v. 27, n. 1, p. 11-17.

Forman, R.T.T.; GODRON, M., 1986. Landscape ecology. New York: Wiley. 619 p., il.

Foster, M.S.; Harrold, C.; Hardin, D.D., 1991. Point vs. Photo quadrat estimates of the cover of sessile marine organisms. J. Exp. Mar. Biol. Ecol., Amsterdam, v. 146, p. 193 203.

FrontiER, S., 1983. L'echantillonnage de la diversité specifique. In: Frontier, S. (ed). Stratégies d'echantillonnage en écologie. Paris: Masson. p. 416-436.

Gaines, S.D.; Roughgarder, J., 1985. Larval settlement rate: a leading determinant of structure in an ecological community of the marine intertidal zone. Proc. Nat. Acad. Sci. USA, v. 82, p. 3707-3711.

GHERARDI, D.F.M., 2004. Community structure and carbonate production of a temperate rhodolith bank from Arvoredo Island, southern Brazil. Brazilian Journal of Oceanography, v. 52, n. 03/04, p. 207-224.

GoODALl, D.W., 1952. Quantitative aspects of plant distribution. Biol. Rev., v. 27, p. 194245.

Gounot, M., 1969. Méthodes d'étude quantitative de la végétation. Paris: Masson. 314 p.

Greig-Smith, P., 1983. Quantitative Plant Ecology. $3^{\text {rd }}$ ed. Oxford: Blackwell. 359p.

Guimaraens, M.A.; Coutinho, R., 2000. Temporal and spatial variation of Ulva sp. and water properties in the Cabo Frio upwelling regions of Brazil. Aquat. Bot., v. 66, n. 2, p. 101-114.

HARA, T.; KoIKe, F.; MATSUI, K., 1986. Crowding effect in marine macrophytic populations. Bot. Mag., v. 99, p. 319-321.

Harvey, P.H.; Goodfray, H.C.J., 1987. How species divide resources. Amer. Nat., v. 129, p. 318-320.

Hartnoll, R.G.; Hawkins, S.J., 1985. Patchiness and fluctuations on a moderately exposed rocky shore. Ophelia, v. 24, p. 53-63.

HILl, M. O., 1973. Diversity and evenness: A unifying notation and its consequences. Ecology, v. 54, n. 2, p. 427-432.

Holme, N.A.; Mcintyre, A.D., 1984. Methods for the study of Marine Benthos. $2^{\text {nd }}$ ed. Oxford: Blackwell. 387p.

HOWMILLER, R.P., 1972. Effects of preservatives on weights of some common macrobenthic invertebrates. Trans. Am. Fish. Soc., v. 101, n. 4, p. 743-746. 
HulBerT, S.H., 1971. The non-concept of species diversity: a critique and alternative parameters. Ecology, v. 52, p. 577-582.

JACOBI, C.M., 1987. Habitat heterogeneity in rocky shores. A case study: mussel beds. In: SIMPÓSIO DOS ECOSSISTEMAS DA COSTA SUL E SUDESTE BRASILEIRA: SÍNTESE DOS CONHECIMENTOS, 1., p. 254-265. São Paulo: Academia de Ciências do Estado de São Paulo (Publicação ACIESP, 54).

JOLY, A.B., 1951. Contribuição ao conhecimento da flora algológica marinha do estado do Paraná. I - Zonação e distribuição segundo hábitats. Bolm. Inst. Oceanogr. S. Paulo, v. 02, n. 01, p. 125-138.

JoLY, A.B., 1965. Flora marinha do litoral norte do Estado de São Paulo e regiões circunvizinhas. Separata de: Bol. Fac. Filos. Cienc. Let. Univ. São Paulo Ser Bot., São Paulo, n. 294, p. 1-393.

Junqueira, A.O.R.; FAlCÃO, A.P.C.; Mayer-Pinto, M.; Viana, M.S.; Silva, S.H.G., 2000.

Spatial and temporal variations on intertidal barnacle abundance in a tropical bay. Nauplius, v. 8, n. 2, p. 195-204.

KIKKawA, J., 1996. Complexity, diversity and stability. In: Kikkawa, J.; Anderson, D.J. (Eds.). Community ecology: pattern and process. Melbourne: Blackwell Scientific. $432 \mathrm{p}$.

Kimura, T.; Orosco, C.A.; OHNO, M., 1987. Ecological study of Sargassum okamurae Yoshida et T. Konno in Tosa Bay, Japan. Rep. Usa mar. biol. Inst. Kochi Univ., v. 9, p. 149-167.

KoH, C.H.; OH, S.H.; Sung, N.; AHN, I.; KANG, Y.C., 1989. Algal zonation and seasonality in subtidal area of a wave-exposed coast at Ohori, east coast of Korea. Korean J. Phycol., v. 04, n. 02, p. 171-182.

Kovach, W.L., 2003. MVSP - A MultiVariate Statistical Package for IBM-PC's, ver. 3.13f. Pentraeth: kovach Computing Services.

KREBS, C.J., 1999. Ecological methodology. $2^{\text {nd }}$ ed. New York: Addison-Welsey Educational Publishers. 620 p.

LegendRe, L.; LegendRe, P., 1984. Écologie numérique. 2 ed. Paris: Masson, v. 2, 335 p. (Collection d'écologie, 13).

LUBCHENCO, J., 1978. Plant species diversity in a marine intertidal community: importance of herbivore food preference and algal competitive abilities. Amer. Nat., v. 112, p. 23-39.

LÜNING, 1990. Seaweeds: their environment, biogeography and ecophysiology. New York: John Wiley. 527p. 
MACARTHUR, R.H., 1955. Fluctuations of animal populations and a measure of community stability. Ecology,.v. 36, p. 533-536.

Machado, K.R.S.S.; Chapman, A.R.O.; Coutinho, R., 1992. Patch structure in a tropical rocky shore community in Brazil: a mosaic of successional states? Ophelia, Helsingor, v.35, n.3, p.187-195.

Maggs, C.A.; Milner, A.A.; Watts, W.; Whittle, M.R., 1979. The Oxford diving expedition to Cabo Frio, Brazil. Bull. Oxford Univ. Explor. Club. New. Serv., Oxford, v. 4 , p. $13-40$.

MagurRan, A.E., 1988. Ecological diversity and its measurement. London: Croom-Helm. $179 \mathrm{p}$.

Margalef, R., 1972. Homage to evelyn hutchinson, or why is there no upper limit to diversity. Trans. Connect. Acd. Arts. Sci., v. 44,p. 211-235.

Margalef, R., 1995. Ecología. Barcelona:Ediciones Omega S.A. 951p.

Marins-Rosa, B.; Amado-Filho, G.; Manso, C. \& Yoneshigue-Valentin, Y. (2005). Estrutura do fitobentos do Sub-litoral das formações recifais da Baía de Todos os Santos (Bahia, Brasil). In: Sociedade Brasileira de Ficologia (Org.). Formação de Ficólogos: um compromisso com a sustentabilidade dos recursos aquáticos. Rio de Janeiro: Museu Nacional, Série Livros 10, p. 255-274.

MAY, R.M., 1975. Patterns of Species Abundance and Diversity, p. 81-120. In: Cody, M.L.; Diamond, J.M. (Eds.). Ecology and Evolution of Communities. Cambridge: Belknapp Press. 543p.

MCQUAID, C.D.; BRANCH, G.M., 1984. Influence of sea temperature, substratum and wave exposure on rocky intertidal communities: an analysis of faunal and floral biomass. Mar. Ecol., v. 19, p. 145-151.

Menge, B.A.; LubChenco, J.; AshKenAs, L.R., 1985. Diversity, heterogeneity and consumer pressure in a tropical rocky intertidal community. Oecologia, v. 65, n. 3, p.394-405.

MeESE, R.J.; TOMICH, P.A., 1992. Dots on the rocks: a comparison of percent cover estimation methods. J. Exp. Mar. Biol. Ecol., Amsterdam, v. 165, n. 1, p. 59-73.

Miller, A.W.; AmBrose, R.F., 2000. Sampling patchy distributions: comparison of sampling designs in rocky intertidal habitats. Mar. Ecol. Prog. Ser., v. 196, p. 1-14.

Mitchell, G.J.P.; NASSAR, C.A.G.; MAURAT, M.C.S.; FAlCÃO, C., 1990. Tipos de vegetação marinha da Baía do Espírito Santo sob a influência da poluição - Espírito Santo (Brasil). In: SIMPÓSIO DOS ECOSSISTEMAS DA COSTA SUL E SUDESTE BRASILEIRA: ESTRUTUTA, FUNÇÃO E MANEJO, 2., p. 202-214. São Paulo: Academia de Ciências do Estado de São Paulo (Publicação ACIESP, 71). 
MundA, I.M., 1990. Resources and possibilities for exloitation of north Adriatic seaweeds. Hydrobiologia, v. 204/205, p. 309-315.

MuÑoz, A.O.M.; PereirA, S.M.B., 1998. Estrutura de comunidades de macroalgas em formações recifais do Estado de Pernambuco, Brasil. In: CONGRESSO LATINOAMERICANO DE FICOLOGIA, 4., 1996, Caxambú. Anais... Caxambú, vol. 2. p. 287297.

NiELL, F.X., 1977. Método de recolección y área mínima de muestreo en estudios estructurales del macrofitobentos rocoso intermareal de la Ría de Vigo. Invest. Pesq., v. 41, n. 2, p. 509-521.

NonAtO, E.F.; PÈreZ, J.M., 1961. Observation sur quelques peuplements interdidaux de substrat dur dans la region d'Ubatuba. Cah. Biol. Mar., Paris, v. 2, p. 263 - 270.

NyBAKKen, J., 1982. Marine biology: an ecological approach. New York: Harper \& Row. $446 \mathrm{p}$.

Oigman-Pszczol, S.S.; Fiqueiredo, M.A.O.; C REeD , J.C., 2004. Distribution of benthic communities on the tropical rocky subtidal of Armação dos Búzios, Southeastern Brazil. Marine Ecology, v. 25, n. 03, p. 173-190.

OliveIRA Filho, E.C. de , 1977. Algas marinhas bentônicas do Brasil. 407f. Tese (Livre Docência) - Instituto de Biociências, Universidade de São Paulo, São Paulo.

OliveIRA FiLhO, E.C. de; MAYAL, E.M., 1976. Seasonal distribution of intertidal organisms at Ubatuba, São Paulo (Brazil). Rev. Bras. Biol., Rio de Janeiro, v. 36, n. 1, p. 305-316.

Oliveira Filho, E.C. de; PAUlA, E.J. de, 1983. Aspectos da distribuição vertical e variação sazonal de comunidades da zona das marés em costões rochosos do litoral norte do Estado de São Paulo. In: ENCONTRO DE MACRÓFITAS MARINHAS, 1., 1983, Arraial do Cabo. Anais... Arraial do Cabo: Instituto de Pesquisas da Marinha. Projeto Cabo Frio (147). p. 44-61.

Osman, R.W.; Whitlatch, R.B., 1995. The influence of resident adults on recruitment: a comparison to settlement. J. Exp. Mar. Biol. Ecol., v. 190, p. 169-198.

OSSE, A.C., 1995.Aspectos da estrutura espaço-temporal de uma comunidade intermareal de costão rochoso da Ponta da Fortaleza, Ubatuba, SP. 156 f. Dissertação (Mestrado em Ecologia)- Instituto de Biociências, Universidade de São Paulo, São Paulo.

Osse, A.C.; Rosso, S., 1989. Estudo qualitativo de comunidade da sona entre-marés de um costão rochoso abrigado da Ponta da Fortaleza - Ubatuba - SP. In: MINI-SIMPÓSIO DE BIOLOGIA MARINHA, 8., São Sebastião. Resumos... São Sabastião: CEBIMAR USP, 1989. p.27. 
Paula, E.J. DE, 1978. Taxonomia, aspectos biológicos e ecológicos do gênero Sargassum (Phaeophyta - Fucales) no litoral do Estado de São Paulo. 190f. Dissertação (Mestrado) Instituto de Biociências, Universidade de São Paulo, São Paulo.

PAula, E.J. DE; Eston, V.R., 1987. Are there other Sargassum species potentially as invasive as $S$. muticum? Botanica mar., v. 30, n. 05, p. 405-410.

Paula, E.J. De; Oliveira Filho, E.C. DE, 1980. Phenology of two populations of Sargassum cymosum (Phaeophyta, Fucales). Phycologia, v. 21, n. 02, p. 145-153.

Paula, A.F. De; Figueiredo, M.A.O.; Creed, J.C., 2003. Structure of the Macroalgal Community Associated with the Seagrass Halodule wrightii Ascherson in the Abrolhos Marine National Park, Brazil. Botanica Marina, v. 46, p. 413-424.

Pech, D.; Condal, A.R.; Bourget, E.; Ardisson, P.L., 2004. Abundance estimation of rocky shore invertebrates at small spatial scale by high-resolution digital photography and digital image analysis. J. Exp. Mar. Biol. Ecol., Amsterdam, v. 299, p. 185-199.

PedrinI, A.G., 1980. Algas marinhas da Baía de Sepetiba e arredores (Rio de Janeiro). 397f. Dissertação (Mestrado) - Instituto de Biologia, Universidade Federal do Rio de Janeiro, Rio de Janeiro.

Petersen, J.A.; Sutherland, J.P.; ORTEGA, S., 1986. Patch dynamics of mussel beds near São Sebastião (São Paulo), Brazil. Marine Biology, v. 93, p. 389-393.

PINDER, L.; Rosso, S., 1998. Classification and ordination of plant formations in the Pantanal of Brazil. Plant Ecology, v. 136, n. 2, p. 151-165.

Platt, T.; IRWIN, B., 1973. Caloric content of phytoplankton. Limnol. Oceanogr., v. 18, p. 306-310.

PRINGLE, J.D., 1984. Efficiency estimates for various quadrat sizes used in benthic sampling. Can. J. Fish. Aquat. Sci., v. 41, n. 10, p. 1485-1489.

RoBLES, F.R., 2003. O banco de Isognomon bicolour Adams 1845: estrutura da comunidade e processo sucessional inicial. 148f. Tese (Doutorado em Ecologia) - Instituto de Biociências, Universidade de São Paulo, São Paulo.

Rosso, S., 1987. Comunidade de organismos sésseis e semi-sésseis intermareais de um costão rochoso da Praia das Cigarras, São Sebastião, SP - uma abordagem metodológica. . In: MINI-SIMPÓSIO DE BIOLOGIA MARINHA, 6., 1987, São Sebastião. Resumos... São Sabastião: CEBIMAR - USP. p.17.

Rosso, S., 1990. Estrutura de comunidades intermareais de substrato consolidado das proximidades da Baía de Santos (SP, Brasil): uma abordagem descritiva enfatizando aspectos metodológicos. 217 f. Tese (Doutorado em Ecologia) - Instituto de Biociências, Universidade de São Paulo, São Paulo. 
Rosso, S., 1995. Dimensionamento amostral em estudos descritivos de comunidades de organismos bênticos sésseis e semi-sésseis. In: SIMPÓSIO SOBRE ESTRUTURA, FUNCIONAMENTO E MANEJO DE ECOSSISTEMAS. OECOLOGIA BRASILIENSIS, 1., 1995, Rio de Janeiro. Anais... Rio de Janeiro: Instituto de Biologia. Universidade Federal do Rio de Janeiro. p. 193-223.

Russel, G., 1972. Phytossociological studies on a two-zone shore. I - Basic pattern. J. Ecol., v. 65, p. $485-495$.

RUSSEL, G., 1980. Application of simple numerical methods to the analysis of intertidal vegetation. In: Price, J.H.; Irvine, D.E.G.; Farnham, W.F. (eds). The shore environment. v. 1: Methods. London: Academic Press. cap. 6, p.171-192.

SABINO, C.M.; VillaÇA, R., 1999. Estudo comparativo de métodos de amostragem de comunidades de costão. Rev. Brasil. Biol., v. 59, n. 3, p. 407-419.

SAlonen, K.; SarVala, J.; HaKala, I.; VilJanen, M., 1976. Two relationships of energy and organic carbon in aquatic invertebrates. Limnol. Oceanogr., v. 21, n. 5, p. 724-730.

SANTELICES, B., 1980. Muestreo cuantitativo de comunidades intermareales de Chile Central. Arch. Biol. Med. Exp., v. 13, p. 413-424.

SANTOS, E.P., 1978. Dinâmica de populações aplicada à pesca e psicultura. São Paulo: HUCITEC/EDUSP. 129p.

SeED, R.; SuchaneK, T.H., 1992. Population and community ecology of Mytilus. In: Gosling, E.M. (Ed). The mussel Mytilus: ecology, physiology, genetics and culture. Amsterdam: Elsevier Press. p. 87-157.

Silva, R. L.; Pereira, S. M. B.; Oliveira Fo. E. C. de; Eston, V. R., 1987. Structure of a Bed of Gracilaria spp. (Rhodophyta) in Northeastern Brazil. Botanica mar., v. 30, p. 517523.

StUERCKe, B.; MCDERMID, K.J., 2004. Variation in algal turf species composition and abundance on two Hawaiian shallow subtidal reefs. Cryptogamie Algologie, v. 25, n. 04, p. 353-365.

SzÉCHY, M.T.M., 1996. Estrutura de bancos de Sargassum (Phaeophyta, Fucales) do litoral dos estados do Rio de Janeiro e São Paulo. 345f. Tese (Doutorado em Botânica) Insituto de Biociências, Universidade de São Paulo, São Paulo.

SzÉCHY, M. T. \& PAULA, E., 2000. Padrões estruturais quantitativos de bancos de Sargassum (Phaeophyta, Fucales) do litoral dos Estados do Rio de Janeiro e São Paulo, Brasil. Revta. brasil. Bot, v. 23, p. 121-132.

TAYLOR, W.R., 1960. Marine algae of the eastern tropical and subtropical coasts of the Americas. Michigan: University of Michigan Press. 870 p. 
Teixeira, V.L.; Pereira, R.C.; Marques Junior, A.N.; Leitão Filho, C.M.; Silva, C.A.R.,

1987. Seasonal variations in infralittoral seaweed communities under a pollution gradient in Baía de Guanabara, Rio de Janeiro (Brazil). Ciência e Cultura, São Paulo, v. 39, n. 4, p. $423-428$.

Trono JR., G.C., Lluisma, A.O., 1990. Seasonality of standing crop of a Sargassum (Fucales, Phaeophyta) bed in Bolinao, Pangasinan, Philippines. Hydrobiologia, v. 204/205, p. 331-338.

Ugadim, Y., 1973. Algas marinhas bentônicas do litoral sul do Estado de São Paulo e do litoral do Estado do Paraná. III. Divisão Rhodophyta (3) Ceramium (Ceramiaceae, Ceramiales). Bolm. Zool. Biol. Mar. N.S., v. 30, p. 691-712.

UgAdim, Y., 1974. Algas marinhas bentônicas do litoral sul do Estado de São Paulo e do litoral do Estado do Paraná. III. Divisão Rhodophyta (1) Goniothricales, Bangiales, Nemalionales e Gelidiales. Bolm. Bot. Univ. São Paulo, v. 02, p. 93-137.

Ugadim, Y., 1975. Algas marinhas bentônicas do litoral sul do Estado de São Paulo e do litoral do Estado do Paraná. III. Divisão Rhodophyta (2) Cryptonemiales, Gigartinales e Rhodymeniales. Bolm. Bot. Univ. São Paulo, v. 03, p. 115-163.

Ugadim, Y., 1976. Ceramiales (Rhodophyta) do litoral sul do Estado de São Paulo e do litoral do Estado do Paraná. Bolm. Bot. Univ. São Paulo, v. 04, p. 133-173.

Underwood, A.J.; Denley, E.J., 1984. Paradigms, explanations, and generalizations in models for the structure of intertidal communitites on rocky shores. In: Strong Jr., D.R.; Simberloff, D.; Abele, L.G.; Thistle, A.B. (Eds). Ecological communities. Conceptual issues and the evidence. New Jersey: Princeton University Press. cap. 11, p.151-180.

Underwood, A.J.; Kingsford, M.J.; Andrew, N.L., 1991. Patterns in shallow subtidal marine assemblages along the coast of New South Wales. Aust. J. Ecol., v. 06, p. 231249.

VAN DEN HoEK, C., 1969. Algal vegetation-types along the open coasts of Curaçao, Netherlands Antilles, I. Proc. K. ned. Akad. Wet., ser. C, v. 72, n. 05, p. 537-558.

VILLAÇA, R.C., 1990. Metodologia de amostragem em costões rochosos. Abordagem fitossociológica. In: SIMPÓSIO DOS ECOSSISTEMAS DA COSTA SUL E SUDESTE BRASILEIRA: ESTRUTUTA, FUNÇÃO E MANEJO, 2., p. 1-12. São Paulo: Academia de Ciências do Estado de São Paulo (Publicação ACIESP, 71).

VillaçA, R.C.; Pitombo, F.B., 1997. Benthic communities of shallow-water reefs of Abrolhos, Brazil. Rev. Bras. Oceanogr., v. 45, p. 35-43.

Washington, H.G., 1984. Diversity, biotic and similarity indices: a review with special reference to aquatic ecossystems. Water Res., New York, v. 18, p. 653-694. 
WhitTAKer, R.H., 1965. Dominance and diversity in land plant communities. Science, v. 147, p. $250-260$.

WhORFF, J.S.; GRIFFING, L., 1991. A video recording and analysis system used to sample hard-bottom benthic communities. American Zoologist, v. 31, n. 5, p. A125.

WiHLM, J.L., 1968. Use of biomass units in Shannon's formula. Ecology, Durham, v. 49, n. 1, p. 153-156.

Wolda, H., 1981. Similarity indices, sample size and diversity. Oecologia, Berlin, v. 50, p. $57-85$.

WynNe, M.J., 1986. A checklist of benthic marine algae of the tropical and subtropical western Atlantic. Can. J. Bot., Ottawa, v. 64, n. 8, p. 2239-2281.

YAOBIN, Q., 1999. Estudos sobre a variação temporal da composição de macroalgas marinhas em uma baía poluída - o caso de Santos, Litoral de São Paulo, Brasil. 139f. Tese (Doutorado em Ecologia) - Instituto de Biociências da Universidade de São Paulo, São Paulo.

Yoneshigue, Y., 1985. Taxonomie et ecologie des algues marines dans la region de Cabo Frio (Rio de Janeiro, Brésil). 466f. Tese (Doutorado em Ciências) - Faculdade de Ciências de Luminy, Universidade de Aix-Marseille II, Marseille.

Yoneshigue, Y.; Valentin, J.L., 1988. Comunidades algais fotófilas de infralitoral de Cabo Frio, Rio de Janeiro, Brasil. Gayana, v. 45, p. 61-75.

Yoneshigue-BragA, Y., 1971. Flora marinha bentônica da Baía de Guanabara e cercanias III. Rhodophyta. 1. Goniothricales, Bangiales, Compsognales, Nemalionales, Gelidiales. Inst. Pesq. Marinha, v. 35, p. 1-36.

Yoneshigue-Braga, Y., 1972a. Flora marinha bentônica da Baía de Guanabara e cercanias III. Rhodophyta. 2. Cryptonemiales, Gigartinales e Rhodymeniales. Inst. Pesq. Marinha, v. 62, p. 1-39.

Yoneshigue-BragA, Y., 1972b. Flora marinha bentônica da Baía de Guanabara e cercanias III. Rhodophyta. 3. Ceramiales. Inst. Pesq. Marinha, v. 61, p. 1-49.

YoshidA, T.; SAwAdA, T.; HigAKI, M., 1963. Sargassum vegetation growing in the sea around Tsuyasaki, North Kyushu, Japan. Pacif. Sci., v. 17., b. 02, p. 135-144. 
CAPÍTULO 5

CONSIDERAÇõES FINAIS 

Como pôde ser visto neste estudo, poucos trabalhos sobre ecologia de comunidades bentônicas de substrato consolidado foram realizados no Brasil, o que é um problema grave já que este ambiente vem sofrendo alterações, possivelmente substanciais, decorrentes do impacto antrópico local e também das mudanças globais, como alteração da temperatura média da água dos oceanos, da salinidade, do pH e do nível do mar (Fields et al., 1992; Ray et al., 1992; Bernal, 1993; Daniels et al., 1993; Levitus et al., 2000; Liu, 2000; Fitt et al., 2001; IPCC, 2001; Harvell et al., 2002).

A caracterização destas comunidades torna-se imprescindível para que se estabeleça um conhecimento a partir do qual estas alterações possam ser devidamente quantificadas e avaliadas.

Os métodos atualmente usados neste ambiente apresentam inconvenientes relacionados com o tempo de amostragem, que geralmente é elevado devido à necessidade de identificação de um grande número de espécies e à abrangência das mesmas, já que geralmente são baseadas em transecções, as quais não permitem a extrapolação dos dados para áreas maiores do que aquelas efetivamente amostradas (Berchez et al., 2005).

Algumas alternativas foram propostas para minimizar o problema do tempo de amostragem, reduzindo a necessidade de identificação de espécies em campo, como os grupos morfo-funcionais e a identificação apenas das espécies dominantes ou grandes grupos taxonômicos (Correia, 1997; Villaça \& Pitombo, 1997; Gherardi \& Bosense, 2001; Costa Jr. et al., 2002; Figueiredo et al., 2004; Oigman--Pszczol et al., 2004).

A proposta realizada neste estudo é a do uso de uma metodologia que não só não apresente os inconvenientes das metodologias tradicionalmente utilizadas em estudos de costão rochoso, mas também que seja rápida e extrapolável para grandes áreas, visando justamente sanar esta lacuna de conhecimento e contribuir para a caracterização de nosso litoral.

Para isso, sugeriu-se aqui o uso do método "Levantamento Fisionômico", baseado em 
unidades de heterogeneidade da paisagem, denominados fisionomias e povoamentos. No presente estudo, apenas o enfoque de povoamentos foi utilizado.

Por se tratar de metodologia inédita, a definição dos povoamentos do trecho de costão avaliado foi se aprimorando com o decorrer do estudo, já que não só diferentes Famílias foram abordadas, mas diferentes Filos e Divisões. Além disso, o grau de variação existente no comportamento ecológico (em relação ao recobrimento percentual) de cada grupo taxonômico tornou esta tarefa ainda mais complexa. Por exemplo, certas algas formam extensos tapetes e algumas cracas formam faixas bem definidas, entretanto, a maior parte das esponjas e ascídias forma pequenas crostas não tão representativas em termos de recobrimento percentual, mas bastante chamativas e facilmente reconhecidas macroscopicamente. Decidiu-se, portanto, considerar estes dois últimos casos também como "povoamentos".

Vale ressaltar que o mais importante nessa nova abordagem é sua possível utilização futura para a constituição de bancos de dados e também para o monitoramento ambiental e a possível adequação da escala e resolução em função dos objetivos a serem alcançados pelos diferentes estudos que forem utilizá-la (Kolasa \& Pickett, 1991; Metzger, 2001). Um fator importante para isso é o desligamento dos pesquisadores do paradigma específico e a concentração dos esforços na identificação de padrões ecológicos, muito mais interessantes do ponto de vista de monitoramento ambiental. A precisão na caracterização de cada povoamento vai depender principalmente da especialização do pesquisador que estiver utilizando o método e dos objetivos de cada estudo.

Alguns povoamentos muito semelhantes foram diferenciados neste estudo e considerados como "povoamentos relacionados". Isso ocorreu pelo fato de que estas pequenas diferenças entre eles poderiam estar relacionadas com alguma condição ambiental específica e, portanto, seria interessante manter esta diferenciação com propósitos de monitoramento ambiental.

Foram identificados e descritos 30 povoamentos e 1 atributo não-biológico, incluídos 
nas categorias 'banco', 'crosta', 'colônia', 'tapete' e 'região'. Todos foram caracterizados por uma ou no máximo duas espécies dominantes. A categoria Tapete foi a mais representada na área, com dez povoamentos. Todos os povoamentos descritos são característicos da região sudeste do Brasil e do Estado de São Paulo, e podem ser encontrados em outros trabalhos sobre ecologia de comunidades realizados no país.

Em relação ao mapeamento, pôde-se notar que foi bastante eficiente para uma caracterização rápida e abrangente da área de estudo, tendo sido realizados apenas 6 mergulhos no verão e 6 no inverno para sua finalização.

A maioria dos povoamentos ocorreu pontualmente, sendo que o número e a repartição horizontal dos mesmos praticamente não se alteraram entre verão e inverno. Banco de Sargassum apresentou maior freqüência relativa no verão $(25,3 \%)$ e Tapete de Amphiroa e Jania, no inverno $(21,3 \%)$.

Quanto à repartição vertical, foram delimitadas quatro principais zonas baseadas na freqüência relativa: uma mais rasa definida por Banco de Sargassum, outra intermediária superior definida por Tapete de Amphiroa e Jania, outra intermediária inferior definida por Tapete de Ectoprocta e uma mais funda definida por povoamentos variáveis com a estação do ano.

Os dados resultantes desta abordagem mostram uma constância e consistência das categorias de povoamentos e seus padrões de repartição espacial ao longo da área estudada. Em outros locais no Estado de São Paulo, uma proporção significativa dos povoamentos aqui descritos re-ocorre (Berchez et al., vários estudos em andamento). A Ilha do Francês, uma estação cerca de $1000 \mathrm{~km}$ ao norte, no Estado do Espírito Santo, compartilha 47\% de seus povoamentos (incluindo os de infra, medio e supralitoral) com a Ilha Anchieta (G. Pereira Filho e F. Berchez, em andamento). Isto demonstra que a presença destes componentes e seus posicionamentos espaciais e temporais não são ao acaso, mas uma conseqüência direta dos fatores atuantes nas comunidades, e que os povoamentos podem ser usados como unidades 
definidas para a descrição destas, podendo levar a uma idéia mais clara e precisa do todo e evitando a vagarosidade e desvios relacionados com o uso de espécies como unidade operacional.

Já na abordagem quantitativa do método "Levantamento Fisionômico" encontra-se mais uma vantagem da utilização de unidades visuais de heterogeneidade, que é o fato das mesmas serem facilmente reconhecidas em fotografias. $\mathrm{O}$ uso de imagens digitais como elementos amostrais apresenta uma série de vantagens, como por exemplo ser mais um fator de minimização do tempo de amostragem em campo e por permitir a confecção de bancos permanentes de imagens, que fornecem o panorama da paisagem naquele instante e podem ser revistas a qualquer momento, o que também é muito interessante para o monitoramento das comunidades (Christie, 1983; Littler \& Littler, 1985; Foster et al., 1991; Macedo et al., 2006).

$\mathrm{Na}$ análise quantitativa realizada neste estudo foram obtidos 84 elementos amostrais no verão e 100 no inverno, os quais, pelo fato de terem sido posicionados aleatoriamente na área de estudo, puderam ser extrapolados para o restante da área, com cerca de $600 \mathrm{~m}^{2}$.

Banco de Sargassum foi o povoamento mais representativo, ou seja, com maior valor de recobrimento percentual médio, tanto no período de verão $(26,1 \%)$ quanto de inverno (32,0\%). Isto confirma a importância desta alga no infralitoral do Brasil (Oliveira Filho \& Paula, 1983; Eston et al., 1986; Paula, 1987; Paula, 1988; Paula \& Eston, 1989; Eston \& Bussab, 1990; Széchy, 1996; Széchy \& Paula, 2000; Costa Jr. et al., 2002; Amado Filho et al., 2003).

O povoamento com segundo recobrimento percentual médio foi Tapete de Ectoprocta ( $19,7 \%$ no verão e $24,2 \%$ no inverno), significativamente maior que a maioria dos demais povoamentos $(\mathrm{p}<0,05)$, o que não era esperado considerando-se outros estudos de infralitoral na região sudeste, onde esponjas e cnidários foram os organismos animais mais importantes em termos de cobertura (Maggs et al.,1979 e Oigman-Pszczol et al., 2004).

Os povoamentos fitobentônicos foram mais representativos na área $(62,2 \%$ de 
recobrimento médio no verão e $61,8 \%$ no inverno), o que foi encontrado em outros estudos (Maggs et al., 1979; Eston et al., 1986; Villaça \& Pitombo, 1997; Costa Jr. et al., 2002; Oigman-Pszczol et al., 2004).

Em termos de recobrimento percentual médio, quando consideradas as categorias de povoamentos, os bancos fitobentônicos foram mais representativos $(31,2 \%$ no verão e $37,0 \%$ no inverno). Se somados animais e algas, a categoria 'tapete' foi a mais representada $(46,3 \%$ no verão e 41,4\% no inverno), com grande contribuição dos povoamentos Tapete de Amphiroa e Jania e Tapete de Ectoprocta, indicando uma possível influência da sedimentação na estruturação da comunidade da área (Airoldi \& Cinneli, 1997; Airoldi, 1998, 2000, 2003, 2004; Gorgula \& Connell, 2004), confirmada pelo significativo recobrimento encontrado para Região de Substrato Inconsolidado tanto no verão quanto no inverno.

A análise de repartição espacial em Modo Q evidenciou que a comunidade da área é bastante heterogênea, apresentando um padrão em manchas, sendo os povoamentos Banco de Sargassum, Região de Substrato Inconsolidado, Tapete de Amphiroa e Jania, Tapete de Ectoprocta (e algumas de suas variações) e Tapete de Gelidiopsis e Hypnea os responsáveis pela formação dos grupos com o Índice de Similaridade de Morisita-Horn. Estes povoamentos foram então escolhidos para uma análise mais detalhada no Capítulo 4.

Se compararmos os dados obtidos a partir da abordagem por freqüência relativa realizada no Capítulo 2 com a abordagem quantitativa realizada no Capítulo 3, podemos notar que os resultados foram bastante semelhantes e evidenciaram que os povoamentos mais importantes para a estruturação da área estudada são Banco de Sargassum, Tapete de Amphiroa e Jania e Tapete de Ectoprocta, os quais se encontram de forma contínua ou em grandes manchas. A importância de Tapete de Amphiroa e Jania foi um pouco superestimada no Capítulo 2, já que ficou em segundo lugar em termos de freqüência relativa no verão e em primeiro no inverno, enquanto que na abordagem por recobrimento percentual ficou em quinto lugar no verão e terceiro no inverno. Isto pode ter ocorrido pelo fato deste povoamento 
apresentar-se na forma de manchas um pouco mais descontínuas e/ou menores que Banco de Sargassum e Tapete de Ectoprocta, porém abrangendo toda a área assim como eles.

Já Tapete de Gelidiopsis e Hypnea teve sua importância bastante subestimada na abordagem por freqüência relativa, provavelmente pelo fato de ocorrer como manchas bastante descontínuas e mais restritas a áreas próximas ao fundo arenoso. Já na abordagem quantitativa apresentou-se em terceiro lugar no verão e sexto no inverno.

O principal problema encontrado na abordagem quantitativa foi a dependência do método em relação à transparência da água, a qual foi considerada boa apenas em curtos períodos de tempo, provavelmente devido à composição granulométrica das áreas de entorno, como a Enseada do Flamengo, que é constituída de 70\% de areais fina a muito fina e o Canal do Boqueirão com uma deposição de fundo silte-argilosa (Magliocca \& Kutner, 1965), o que poderia estar influenciando a Enseada das Palmas na Ilha Anchieta através de correntes na região. Além disso, o método também foi mais demorado em áreas de maior profundidade, mas ainda assim foi muito mais rápido que as abordagens tradicionais. Em casos em que não é possível a espera por condições melhores de visibilidade da água, sugere-se a minimização deste problema com a construção de aparatos de acrílico cheios de água limpa para serem acoplados na frente da câmera, permitindo a visualização da área a ser fotografada.

Finalmente, a Abordagem 4 mostrou que os povoamentos analisados até então (Banco de Sargassum, Tapete de Amphiroa e Jania, Tapete de Ectoprocta e Tapete de Gelidiopsis e Hypnea) podem ser considerados unidades ecológicas, já que foram homogêneos ou no máximo apresentaram alguma variação nas proporções das espécies componentes (fácies). A presença da espécie Herdmania momus como definidora de uma das fácies dos povoamentos Tapete de Amphiroa e Jania, Tapete de Ectoprocta não foi suficiente para a divisão destes povoamentos em dois, já que a mesma em campo é dificilmente visualizada, sendo recoberta pelas outras espécies componentes destes povoamentos. Mais estudos envolvendo estes e outros povoamentos são necessários para que esta homogeneidade se confirme e que a 
metodologia receba subsídios consistentes para que possa ser utilizada.

Concluiu-se, portanto, que o método "Levantamento Fisionômico" é vantajoso, pois permite a caracterização estrutural das comunidades de áreas relativamente extensas, se comparadas com estudos tradicionais de ecologia de comunidades marinhas bentônicas de substrato consolidado, e de maneira rápida. Além disso, a associação deste método com a amostragem aleatória e o uso de imagens digitais como elementos amostrais permite uma análise mais apurada dos dados, que ficam permanentemente armazenados e disponíveis para futuras novas análises. A associação deste método com técnicas de sensoriamento remoto ou com a teoria dos fractais se mostra muito promissora para o levantamento e monitoramento dos recursos naturais de nossa costa e mais esforço nesta direção deve ser despendido. 



\section{REFERÊNCIAS}

AIROLDI, L., 1998. Roles of disturbance, sediment stress, and substratum retention on spatial dominance in algal turf. Ecology, v. 79, n. 08, p. 2759-2770.

AIROLDI, L., 2000. Responses of algae with different life histories to temporal and spatial variability of disturbance in subtidal reefs. Mar. Ecol. Prog. Ser.195: 81-92

AIROLDI, L., 2003. The effects of sedimentation on rocky coast assemblages. Oceanography and Marine Biology, v. 41, p.161-236.

AIROLDI, L., 2004. Forecasting the effects of enhanced sediment loads to coastal areas: a plea for long-term monitoring and experiments. Aquatic Conserv: Mar. Freshw. Ecosyst. v. 14, S115-S117.

Airoldi, L.; Cinelli, F., 1997. Effects of sedimentation on subtidal macroalgal assemblages: an experimental study from a Mediterranean rocky shore. Journal of Experimental Marine Biology and Ecology, v. 215, p. 269-288.

Amado Filho, G.M.; Barreto, M.B.B.B.; Marins, B.V.; Felix, C.; Reis, R.P., 2003. Estrutura das comunidades fitobentônicas do infralitoral da Baía de Sepetiba, RJ, Brasil. Revista Brasil. Bot., v. 26, n. 3, p. 329-342.

Berchez, F.; Rosso, S.; Ghilardi, N.P.; FuJiI, M.T.; Hadel, V., 2005. Characterization of hard bottom marine benthic communities: the physiognomic approach as an alternative to traditional methodologies. In: Sociedade Brasileira de Ficologia (Org.). Formação de Ficólogos: um compromisso com a sustentabilidade dos recursos aquáticos. Rio de Janeiro: Museu Nacional, Série Livros 10, p. 207-220.

BERnAL, P.A., 1993. Global climate change in the oceans: a review. In: Mooney, H.A., Fuentes, E.R., Kronberg, B.I. (eds.). Earth System Responses to Global Change: Contrast between North and South America. San Diego: Academic Press, p. 1-15.

CHRISTIE, H., 1983. Use of video in remote studies of rocky subtidal community interactions. Sarsia, Bergen, v. 68, p.191-194.

CORREIA, M.D., 1997. Distribuição espacial dos organismos macrobentônicos no recife de coral da Ponta Verde, Maceió, Alagoas - Brasil. 194f. Tese (Doutorado) - Instituto de Biociências, Universidade de São Paulo, São Paulo.

Costa Jr, O.S.; Attrill, M.J.; Pedrini, A.G.; De-Paula, J.C., 2002. Spatial and seasonal distribution of seaweeds on coral reefs from southern Bahia, Brazil. Botanica mar., Berlin, v. 45, p. 346-355.

DANiEls, R.C.; White, T.W.; CHAPMAN, K.K., 1993. Sea-level rise: destruction of threatened and endangered species habitat in South Carolina. Environ. Manage., v. 17, p. 373-385. 
Eston, V.R.; BusSAB, W.O., 1990. An experimental analysis of ecological dominance in a rocky subtidal macroalgal community. J. Exp. Mar. Biol. Ecol., Amsterdam, v. 136, p. 170-195.

Eston, V.R. De; Migotto, A.E.; Oliveira Filho, E.C. De; Rodrigues, S.A.; Freitas, J.C., 1986. Vertical distribution of benthic marine organisms on rocky coasts of the Fernando de Noronha archipelago (Brazil). Bol. Inst. Oceanogr., São Paulo, v. 34, p. 37-54.

Fields, P.A.; Graham, J.B.; Rosenblatt, R.H.; Somero, G.N., 1993. Effects of expected global climate change on marine faunas. Trends in Ecology \& Evolution, v. 8, p. 361367.

Figueiredo, M.A.O.; BARRETO, M.B.B.; REIS, R.P., 2004. Caracterização das macroalgas nas comunidades marinhas da Área de Proteção Ambiental de Cairuçú, Parati, RJ - subsídios para futuros monitoramentos. Revista Brasil. Bot., São Paulo, v. 27, n. 1, p.11-17.

FITT, W.K.; BROWN, B.E.; WARNER, M.E.; DUNNE, R.P., 2001. Coral bleaching: Interpretation of thermal tolerance limits and thermal thresholds in tropical corals. Coral Reefs, v. 20, p. 51-65.

Foster, M.S.; Harrold, C.; Hardin, D.D., 1991. Point vs. Photo quadrat estimates of the cover of sessile marine organisms. J. Exp. Mar. Biol. Ecol., Amsterdam, v. 146, p. $193-$ 203.

Gherardi, D.F.M.; BosenCE, D.W.J., 2001. Composition and community structure of the coralline algal reefs from Atol das Rocas, South Atlantic, Brazil. Coral reefs, Berlin, v. 19 , p. 205-219.

Gorgula, S.K.; CONNELL, S.D., 2004. Expansive covers of turf-forming algae on humandominated coast: the relative effects of increasing nutrient and sediment loads. Marine Biology, v. 145, n. 03, p. 613-619.

Harvell, C.D.; Mitchell, C.E.; Ward, J.R.; Altizer, S.; Dobson, A.P.; OstFeld, R.S.; SAMUEL, M.D., 2002. Climate warming and disease risks for terrestrial and marine biota. Science. v. 296, p. 2158-2162.

IPCC (Intergovernmental Panel on Climate Change), 2001. Coastal zones and marine ecosystems. In: McCarthy, J.J.; Canziani, O.F.; Leary, N.A.; Dokken, D.J.; White, K.S. (eds.). Climate Change 2001: Impacts, Adaptation, and Vulnerability. Cambridge: Cambridge University Press, p. 1032.

KolaSA, J.; PicketT, S.T.A., 1991. Ecological heterogeneity. New York : Springer-Verlag. $332 \mathrm{p}$.

Levitus, S.; Antonov, J.I.; Boyer, T.P.; StePhens, C., 2000. Warming of the world ocean. Science, v. 287, p. 2225-2229. 
LitTLER, M.M.; LiTTLER, D.S., 1985. Nondestructive sampling. In: Littler, M.M.; Littler, D.S. (Eds). Handbook of phycological methods. Ecological field methods: macroalgae. Cambridge: Cambridge University Press. cap. 8, p. 161-175.

LIU, S., 2000. Effects of climate change and sea level on coastal systems. In: Sheppard, C. (ed.). Global Issues and Processes, III. Amsterdam: Pergamon, p. 187-196.

MACEDO, I.M.; MAIS, B.P.; ZALMON, I.R., 2006. Comparison of rocky intertidal community sampling methods at the northern coast of Rio de Janeiro state, Brazil. Brazilian Journal of Oceanography, v. 54, n.2/3, p. 147-154.

Maggs, C.A.; Milner, A.A.; Watts, W.; Whittle, M.R., 1979. The Oxford diving expedition to Cabo Frio, Brazil. Bull. Oxford Univ. Explor. Club. New. Serv., Oxford, v. 4, p. 13-40.

Magliocca, A.; Kutner, A.S., 1965. Sedimentos de fundo da Enseada do Flamengo Ubatuba. Contribuições Avulsas do Instituto Oceanográfico, série Oceanografia Física, n. 8, p. 1-14.

Metzger, J.P., 2001. O que é ecologia da paisagem? Biota Neotropica, Campinas, v. 1, n. 1/2, dez. 2001. Disponível em: http://www.biotaneotropica.org.br Acesso em: 10 mar. 2004.

Oigman-Pszczol, S.S.; Fiqueiredo, M.A.O.; C ReEd, J.C., 2004. Distribution of benthic communities on the tropical rocky subtidal of Armação dos Búzios, Southeastern Brazil. Marine Ecology, v. 25, n. 03, p. 173-190.

Oliveira Filho, E.C. de; Paula, E.J. de, 1983. Aspectos da distribuição vertical e variação sazonal de comunidades da zona das marés em costões rochosos do litoral norte do Estado de São Paulo. In: ENCONTRO DE MACRÓFITAS MARINHAS, 1., 1983, Arraial do Cabo. Anais... Arraial do Cabo: Instituto de Pesquisas da Marinha. Projeto Cabo Frio (147). p. 44-61.

PAULA, E.J. de, 1987. Zonação nos costões rochosos: região entremarés. In: SIMPÓSIO DOS ECOSSISTEMAS DA COSTA SUL E SUDESTE BRASILEIRA: SÍNTESE DOS CONHECIMENTOS, 1., p. 266-288. São Paulo: Academia de Ciências do Estado de São Paulo (Publicação ACIESP, 54).

Paula, E.J. de, 1988. O gênero Sargassum C. Ag. (Phaeophyta - Fucales) no litoral do Estado de São Paulo, Brasil. Bol. Bot.Univ. São Paulo, São Paulo, v. 10, p. 65-118.

PAULA, E.J. de; ESTON, V.R., 1989. Secondary sucession on an exposed rocky intertidal algal community of the state of São Paulo (Brazil). Bol. Bot.Univ. São Paulo, São Paulo, v. 11 , p. $1-9$. 
RAY, G.C.; HAYDEn, B.P.; Bulger, A.J. JR.; MCCORMICK-RAY, M.G., 1992. Effects of global warming on the biodiversity of coastal-marine zones. In: Peters, R.L.; Lovejoy, T.E. (eds.). Global Warming and Biological Diversity. New Haven: Yale University Press, p. 91-104.

SzÉCHY, M.T.M., 1996. Estrutura de bancos de Sargassum (Phaeophyta, Fucales) do litoral dos estados do Rio de Janeiro e São Paulo. 345f. Tese (Doutorado em Botânica) Insituto de Biociências, Universidade de São Paulo, São Paulo.

SzÉCHY, M. T. \& PAUlA, E., 2000. Padrões estruturais quantitativos de bancos de Sargassum (Phaeophyta, Fucales) do litoral dos Estados do Rio de Janeiro e São Paulo, Brasil. Revta. brasil. Bot, v. 23, p. 121-132.

VillaçA, R.C.; Pitombo, F.B., 1997. Benthic communities of shalow-water reefs of Abrolhos, Brazil. Rev. Bras. Oceanogr., v. 45, p. 35-43. 